Chapman University

Chapman University Digital Commons

Education (PhD) Dissertations

Dissertations and Theses

Summer 8-2020

\title{
The Labyrinth of Autism: Heuristic Journeys of Fathers Who Have a Child on the Autism Spectrum
}

\author{
Lisa Boskovich \\ Chapman University, bosko103@mail.chapman.edu
}

Follow this and additional works at: https://digitalcommons.chapman.edu/education_dissertations

Part of the Education Commons

\section{Recommended Citation}

Boskovich, L. (2020). The labyrinth of autism: Heuristic journeys of fathers who have a child on the autism spectrum [Doctoral dissertation, Chapman University]. Chapman University Digital Commons.

https://doi.org/ 10.36837/chapman.000186

This Dissertation is brought to you for free and open access by the Dissertations and Theses at Chapman University Digital Commons. It has been accepted for inclusion in Education (PhD) Dissertations by an authorized administrator of Chapman University Digital Commons. For more information, please contact laughtin@chapman.edu. 


\title{
The Labyrinth of Autism:
}

\section{Heuristic Journeys of Fathers Who Have a Child on the Autism Spectrum}

\author{
A Dissertation by \\ Lisa Boskovich
}

\author{
Chapman University \\ Orange, CA
}

Attallah College of Educational Studies

Submitted in partial fulfillment of the requirements for the degree of

Doctor of Philosophy in Education

\author{
August 2020 \\ Committee in charge: \\ Dawn Hunter, Ph.D., Chair \\ Whitney McIntyre Miller, Ph.D. \\ Margie Sauceda Curwen, Ph.D. \\ Richard Rosenberg, Ph.D.
}


The dissertation of Lisa Boskovich is approved.
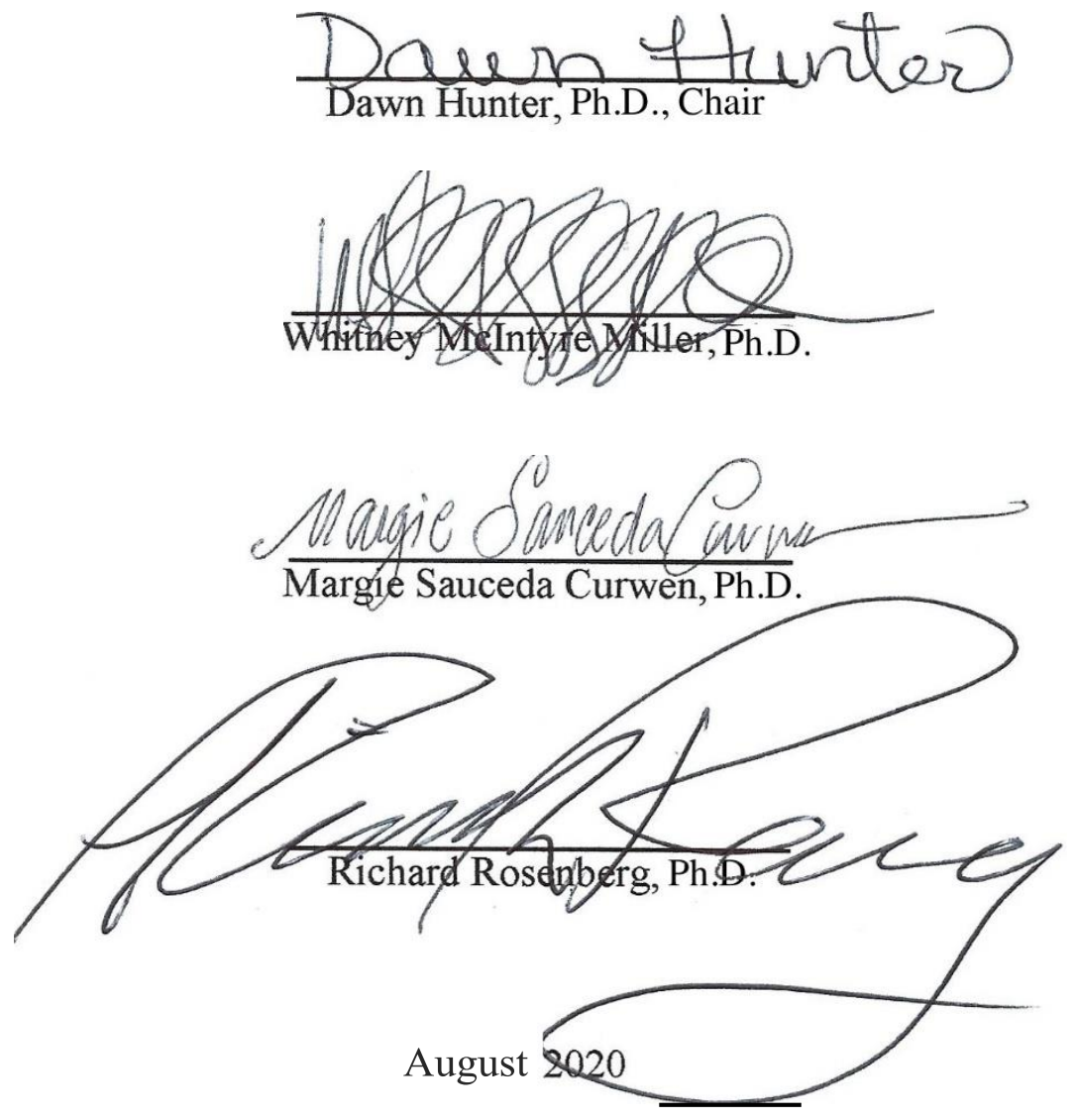
The Labyrinth of Autism:

Heuristic Journeys of Fathers Who Have a Child on the Autism Spectrum Copyright (C) 2020

by Lisa Boskovich 


\section{DEDICATION}

To the voices and words of the fathers in my study who are no longer in silence. 


\section{ACKNOWLEDGEMENTS}

I am who I was always meant to become because of my journey at Chapman University. I did not arrive at this juncture by myself, it was the hands of each of you who held me. To write on a subject so close to my heart required my best self. I first thank the fathers in my study. Your presence and your individual journeys and courage made my study possible.

I am thankful to all the faculty who have been a part of my journey at the Donna Ford Attallah College of Educational Studies. Each teacher provided support and wisdom along my path. I want to thank Leslie Fierro for all your help and support.

I am deeply grateful to Dr. Dawn Hunter, my dissertation chair and mentor. Where or how do I even begin to thank you. With your ever-guiding hand and presence, I couldn't have completed this journey without you? Through the past 8 years you have either heard or read every poem or narrative I have written. Through hundreds of pages, my soul and mind have and continue to grow. If it wasn't for one question you had the courage to ask, I never would have realized the truths about myself on this wide and beautiful spectrum called autism. As the years passed sitting across from you, it only took one raised eyebrow and I knew your expectation. Thank you for stepping back and not telling me what I needed to know. You trusted I would arrive at learnings destination and when I did, you would sit back and smile. To trust another is a gift. To learn from each other a gift I continue to treasure.

I am very grateful to Dr. Whitney McIntyre Miller. Thank you for listening to me and encouraging me to sit in liminal spaces. One of the best decisions I made was taking Leading From Within and Grounded Theory from you, and the trip Peru it was so much more than an academic journey. You pushed me through your leadership and convinced me that conducting a pilot study was within my reach. You provided light along the path, not just metaphorically, but 
physically when during my dissertation proposal defense, Chapman lost all power. Your continuing work regarding peace inspires me to reach higher.

I am very grateful to Dr. Margie Curwen; I have learned so much from you over the past 8 years since I first took EDUC 500/501 as a master's student. I remember the first day in class, you talked about a study you were conducting. All I could think about, I want to do a study and I did. I'll never forget when we took that extra hike at Machu Picchu, and I asked you, "would this be the part where my dissertation would begin?" You paused, "No this is the place of your proposal.” I did not understand that then, I understand now.” Margie, you told me long ago, “a writer I did become." Thank you for always pushing me to be my best and produce my very best work through many a draft and revision. I will always be a lifelong learner. Even though you were not with me physically while I wrote my dissertation, I felt your presence each time I sat down to write. I was never alone.

My appreciation to Dr. Richard Rosenberg my outsider person and committee member. Thank you for the text messages when I had asked the universe for a sign it was there.

I am grateful for Dr. Don Cardinal for his support and for always reminding me to have not just one back up plan, but backup plans, 2, 3, and 4.

I am thankful for the support and understanding from my parents Larry and Carol Boskovich.

Carol Lepel, thank you for believing in me and thank you for all your patience.

Rev Nancy Brink, to sit with another through their journey of spiritual healing is a most sacred space. You who understand the inherent power found in the healing of ritual and its importance in my life. The hours spent talking with you through the years continue to transform my life. To understand another is a gift beyond words. Thank you for hearing me, for learning 
how Asperger's impacts one's life and for helping me accept all the parts of the rainbow I call self.

Rev Cisa Payuyo, thank you for the moments in your office when I'd stop by. Your listening ear, kind heart, and supportive soul always reminded me, I could and would finish. My feet would find their way into your office, at the Fish Center. My home, my safe place of deepest soul healing. Thank you for Wednesday night worship and communion, where through community I healed my soul.

Dr. Scott De Long from our theory class where my love of theory met your pragmatism, to a night in Grounded Theory where ideas connected as our feet swung back and forth as we talked, while the rest of the class and Whitney waited smiling, to a long conversation while we waited for our plane to take off to Cusco and while the train that swayed back and forth in Peru. I have enjoyed our conversations and mutual support given. Thank you.

Dr. Greg Barraza, I thank you for listening to my thoughts as they took shape through the years and then turned into my dissertation though all the classes we had together. You always listened, as if it was the first time, when I was talking about my ideas and dreams.

Tom Curwen- I am grateful for your support and encouragement during this journey. To be a writer is to create from a world of words, crafted through interviews the narrative develops. Our work touches upon sacred ground as those who open their hearts and souls in their sharing trust us to tell their stories. Thank you for our conversations in Peru and our emails helped shape my thoughts regarding writing.

Kristen Tarantino, my editor who read my poems along with the running narrative I wrote throughout my dissertation. I thank you for your editing and support while I wrote my dissertation. 
Mark Allen Physical Therapist extraordinaire without your help and generosity all the hours spent at an computer as I revised my dissertation, typing wouldn't have been possible. Thank you for listening and for your support.

Randy Lewis, I thank you for our conversations and gifts found inside the spoken word. Flynn, to my four-legged supporter, thank you for your presence beneath my feet, and for looking at me barking, because you knew I should be at my desk writing. 


\begin{abstract}
The Labyrinth of Autism:

Heuristic Journeys of Fathers Who Have a Child on the Autism Spectrum

by Lisa Boskovich
\end{abstract}

The relationship between a father and his child on the autism spectrum (AS) is a life changing and powerful experience. However, there is a paucity in the literature about fathers and their experiences with raising a child on the AS. This research study explored the phenomenological experiences of fathers who have a child on the autism spectrum through the use of heuristic inquiry. In this study, I conducted interviews with 10 fathers whose children had an official AS diagnosis. By using Seidman's three separate, semistructured interview method, this study highlighted fathers' experiences and provided greater understanding into their lives. Seidman's interview method provided opportunities for the fathers to reveal the truth in their lived experiences. They revealed their joys, sorrows, and moments that have shaped their lives. The study gathered data in key areas and are organized by the findings that emerged. These findings are organized by subquestions and include: (a) fathers' reactions before and after receiving a diagnosis, (b) the new reality the fathers experienced, (c) the roles played by fathers in their children's lives, (d) fathers' views on disability, (e) the impact of the fathers' beliefs on their views of their child and autism, (f) the experiences of fathers with two children on the AS, and (g) fathers' experiences of personal growth. The findings in this study are significant and show the continuing commitment that fathers who have a child on the AS have regarding their children. As autism prevalence rates continue to rise, this study illustrates the need for further research on fathers who have a child on the AS. 


\section{TABLE OF CONTENTS}

$\underline{\text { Page }}$

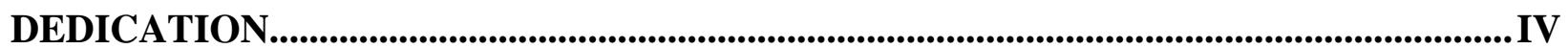

ACKNOWLEDGEMENTS _.................................................................................................. V

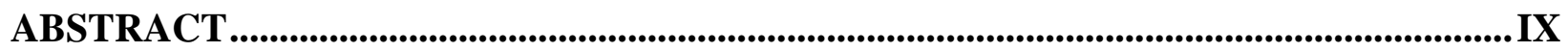

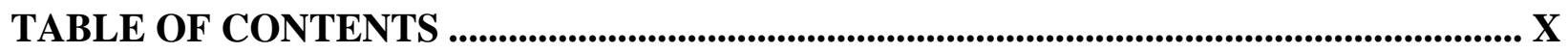

LIST OF TABLES ................................................................................................................................XV

CHAPTER 1-INTRODUCTION......................................................................................................... 1

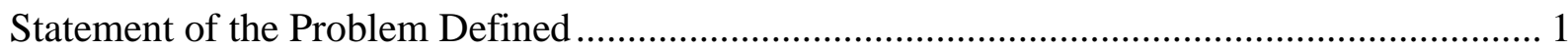

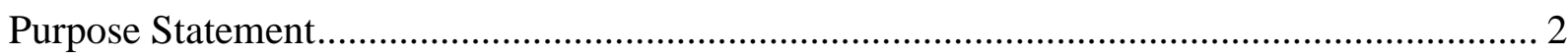

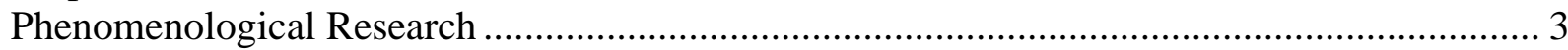

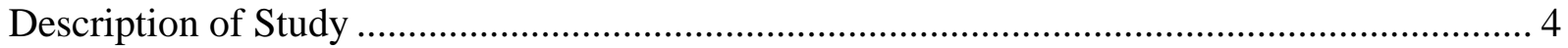

Research Questions ................................................................................................. 4

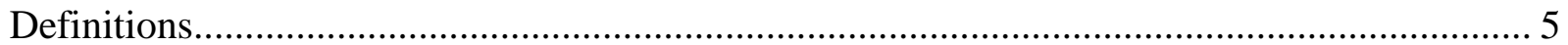

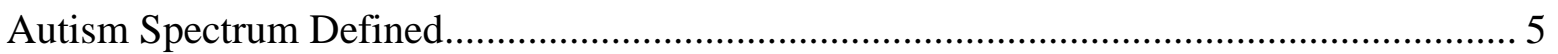

Severe Autism Defined .............................................................................................. 6

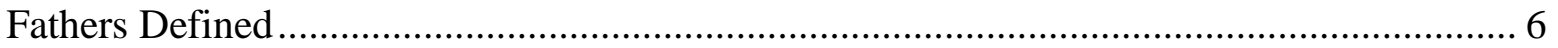

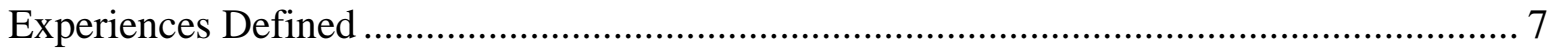

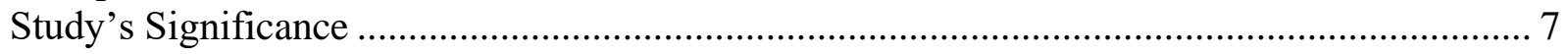

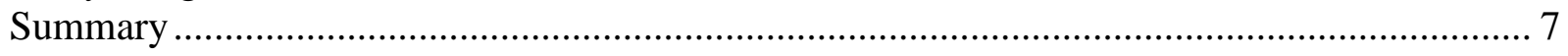

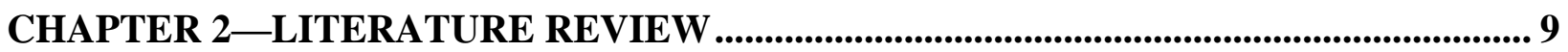

Concise History of Autism................................................................................................ 9

Grunia Sukhareva: An Overlooked Researcher ............................................................ 10

Early Autism Researchers ........................................................................................... 10

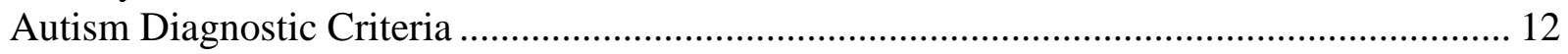

History of Autism Diagnostic Criteria ........................................................................ 12

Concise History of Autism's Diagnostic Changes............................................................... 13

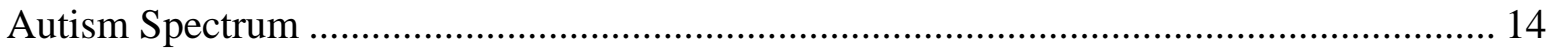

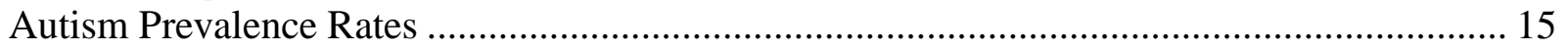

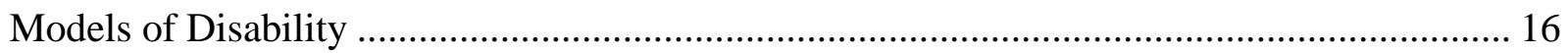

The Medical Model of Disability ................................................................................. 17

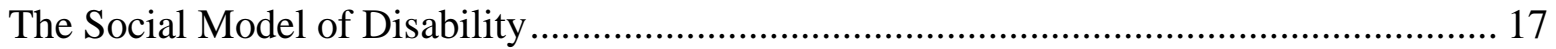

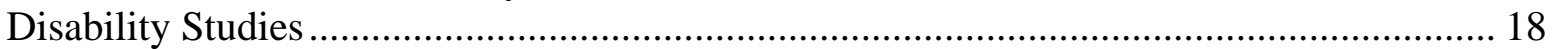

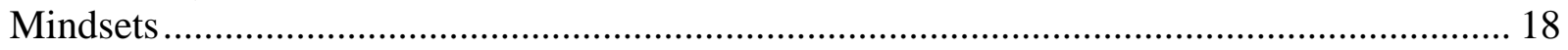

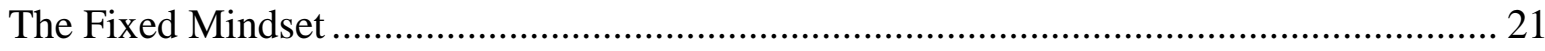

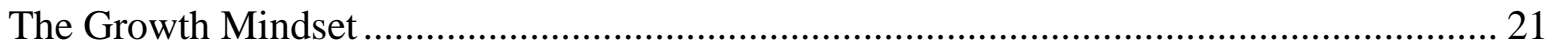

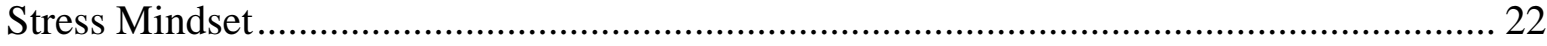

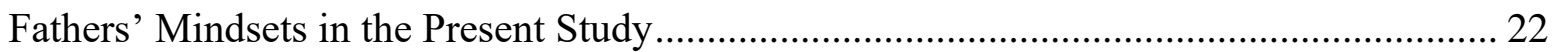

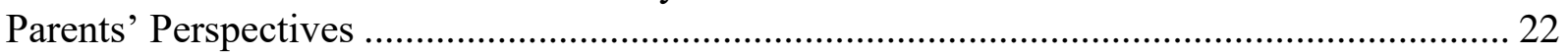


Stigma

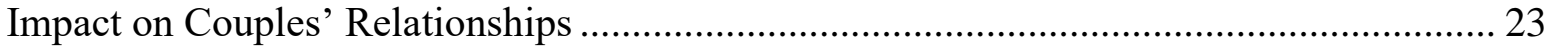

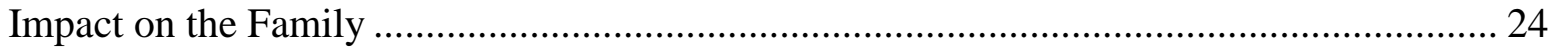

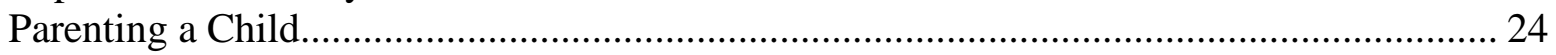

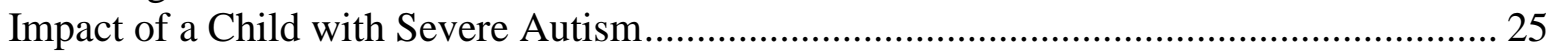

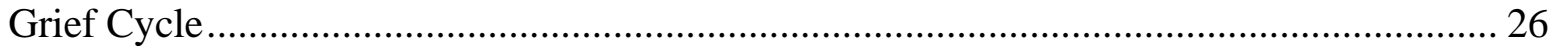

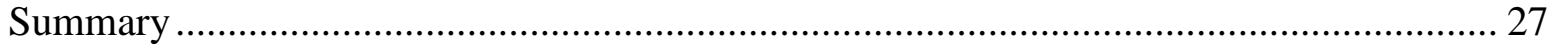

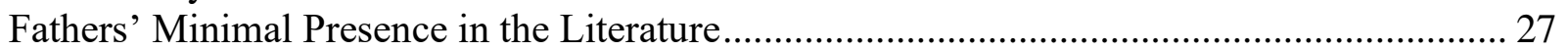

Fathers and Children with a Disability The 1940s, 1950s, and 1960s............................... 28

Fathers and Children with a Disability in the 1970s and Beyond......................................... 29

Literature on Fathers' Experiences of Their Children and Autism........................................... 30

Fathers' Awareness of their Child's Difference Prediagnosis of AS ................................... 31

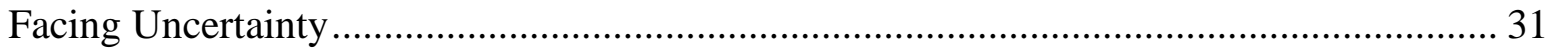

Fathers' Feelings Post-Autism Spectrum Diagnosis.................................................... 32

Behavioral Issues as Perceived by Other Family Members and Friends .............................. 33

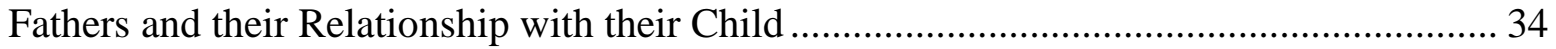

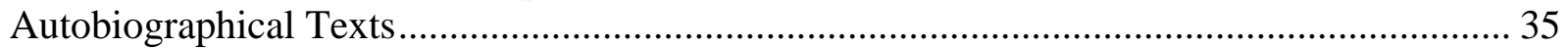

Mismatch Between Initial Themes and Current Study's Research Findings ........................ 38

Review of Phenomenological Studies in the Literature......................................................... 43

United States Studies ................................................................................................... 44

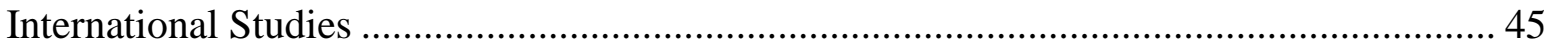

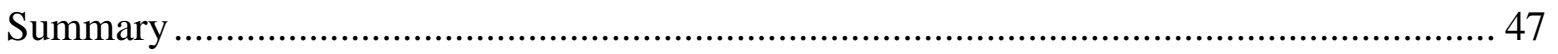

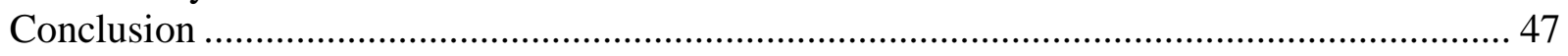

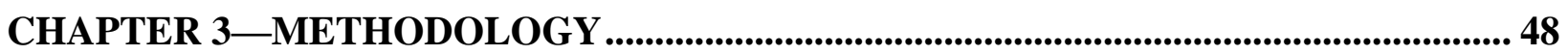

Introduction: Heuristic Phenomenology ……………….................................................. 48

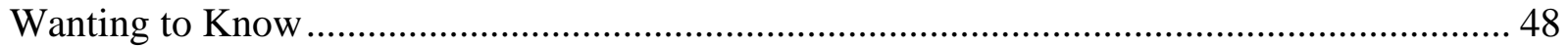

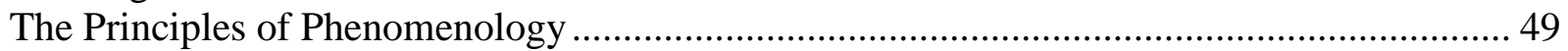

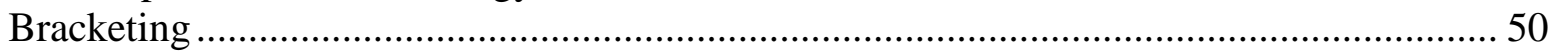

Brentano and Psychological Phenomenology .................................................................. 51

Husserl and Transcendental Phenomenology …………………………………………... 51

Tenets of Transcendental Phenomenology ………….......................................................... 53

Transcendental Phenomenology vs. Phenomenology ............................................................. 54

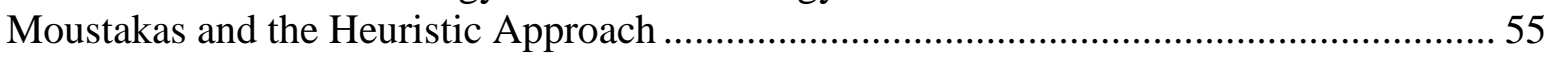

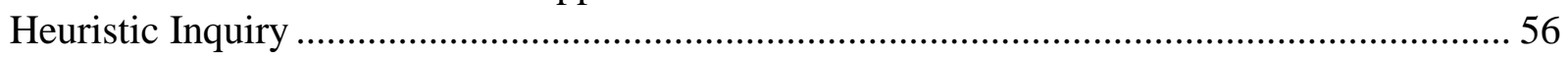

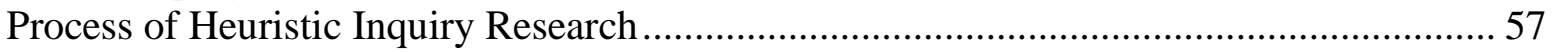

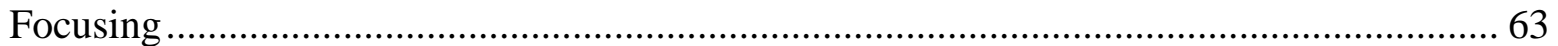

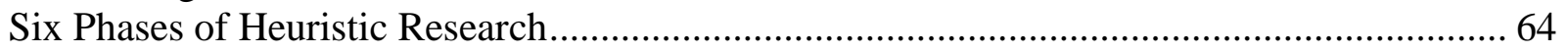

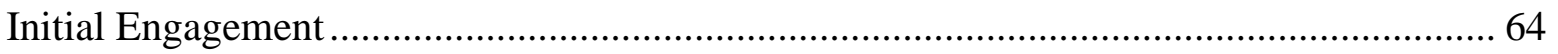

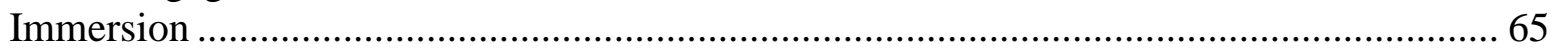

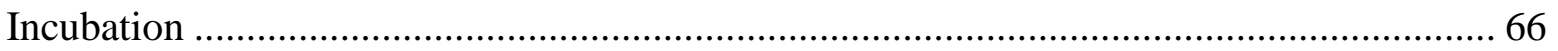

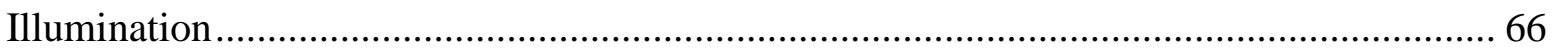

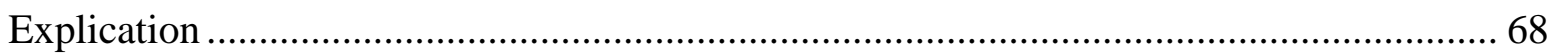

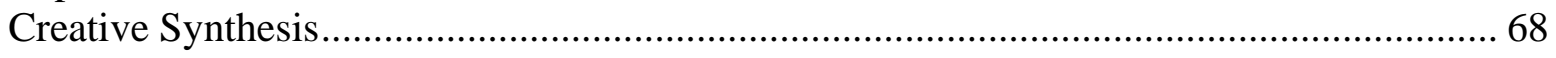

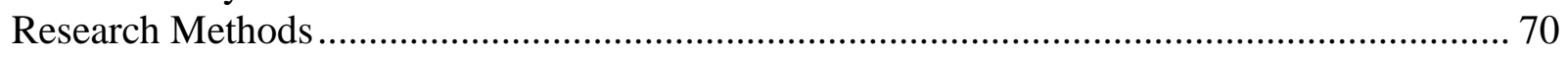

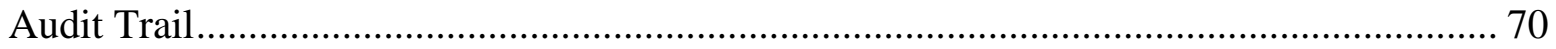

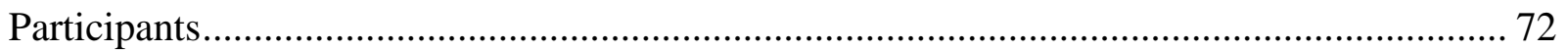




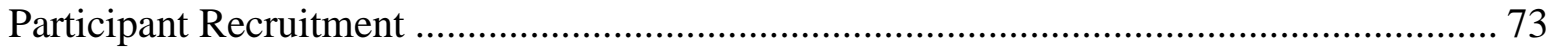

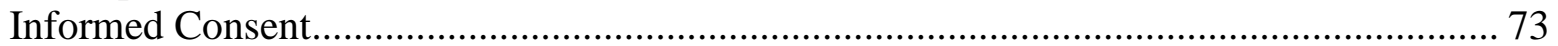

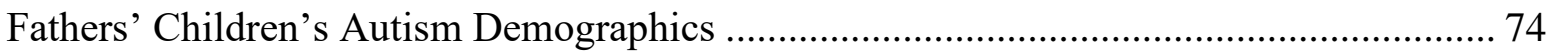

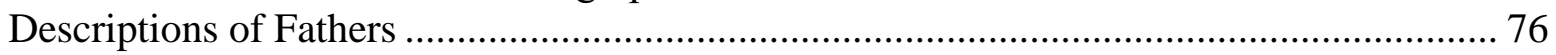

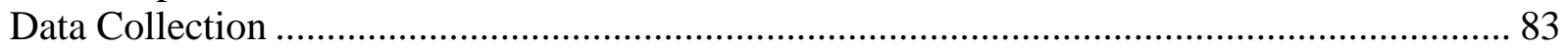

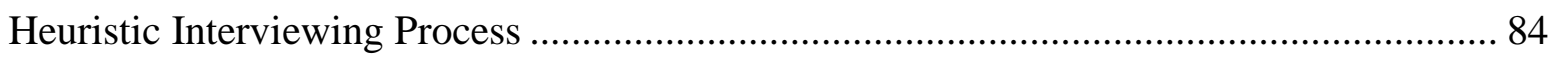

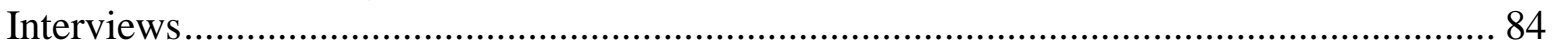

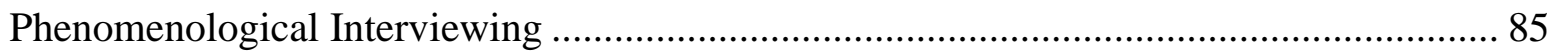

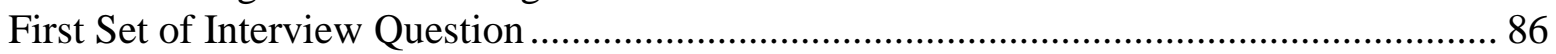

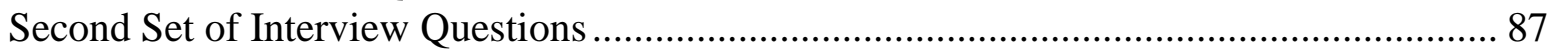

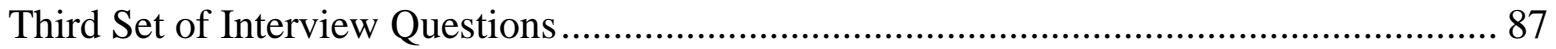

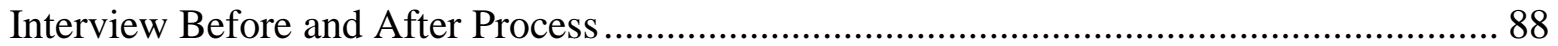

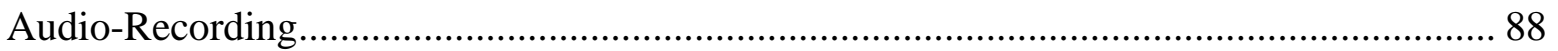

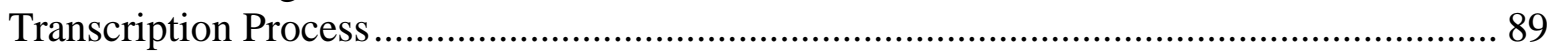

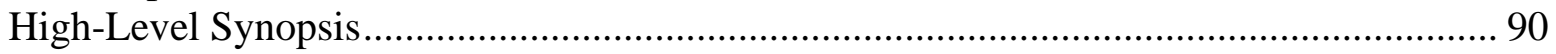

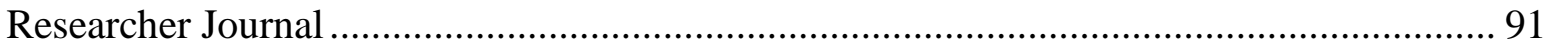

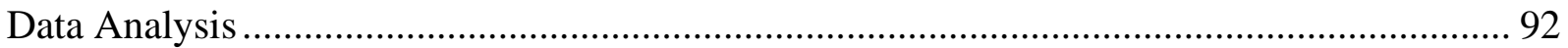

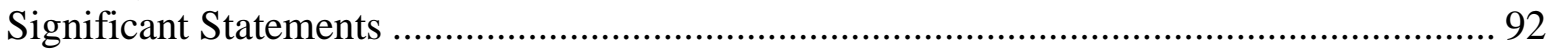

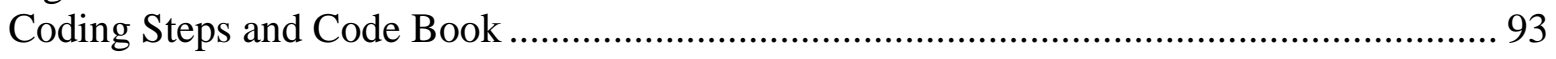

Explicit Process Thematic Construction ............................................................................... 94

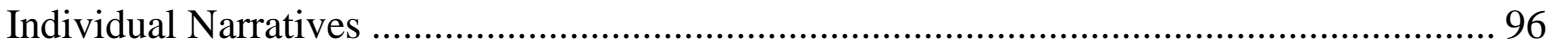

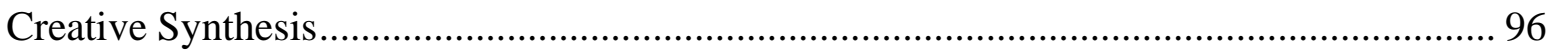

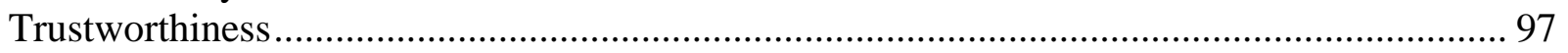

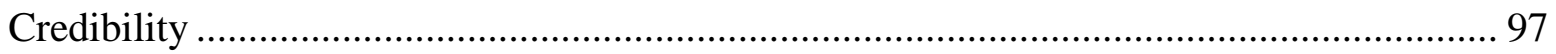

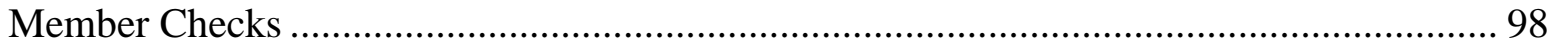

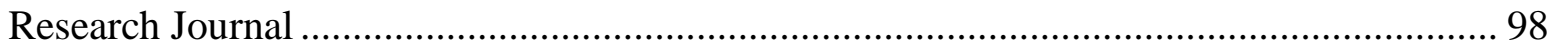

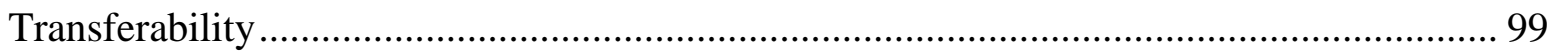

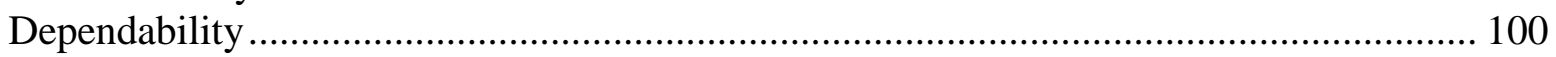

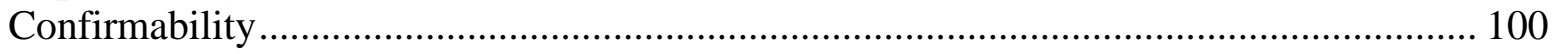

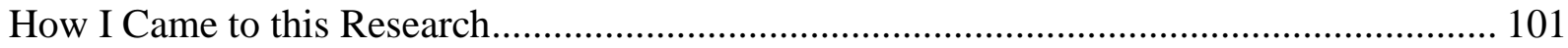

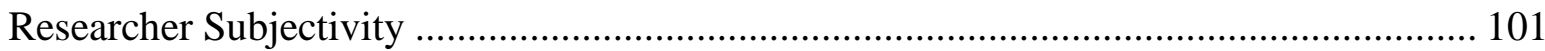

Subjectivity Statement ............................................................................................. 102

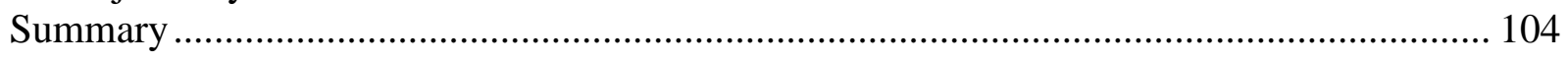

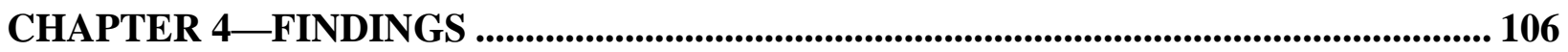

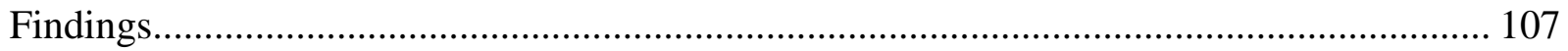

Fathers' Before and After Reactions to Child's AS diagnosis ............................................... 107

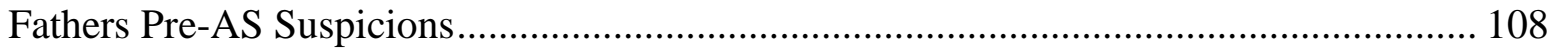

Fathers' Struggles, Post-AS Reactions, and Feelings .................................................... 109

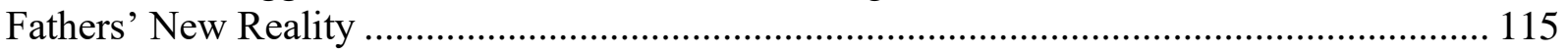

Fathers' Hopes and Dreams for Their Child .................................................................. 116

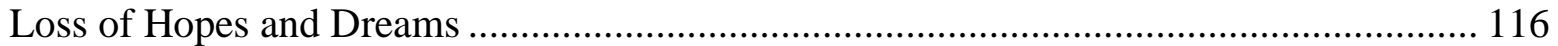

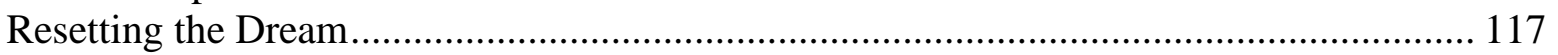

Fathers' Experiences with Child's Autism Behaviors ............................................................ 118

Child's Severe Autism Behavior ................................................................................... 118

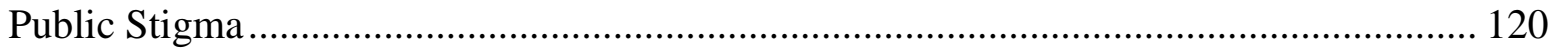

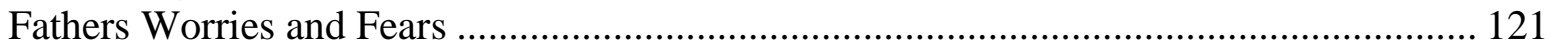




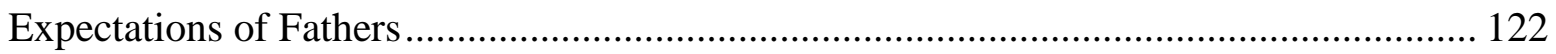

Fathers' Concerns of Personal Safety and Concern for Personal Safety ............................ 123

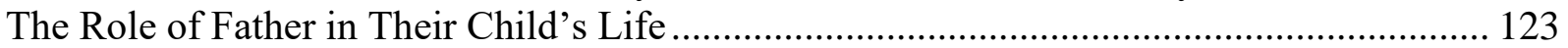

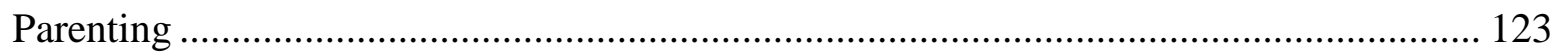

Community Leaders and Mentors.................................................................................. 125

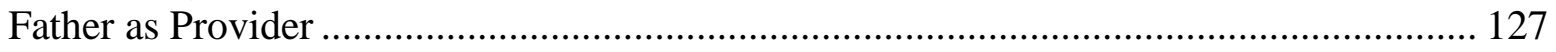

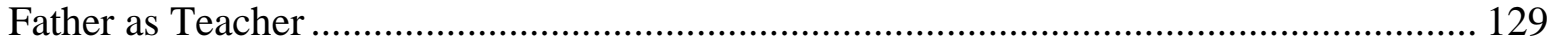

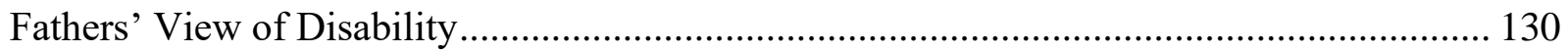

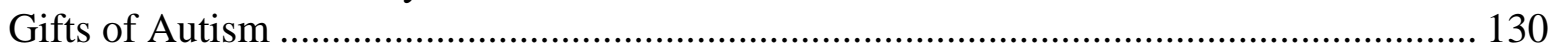

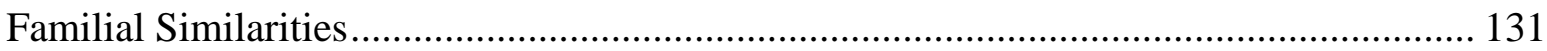

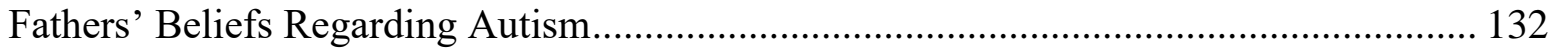

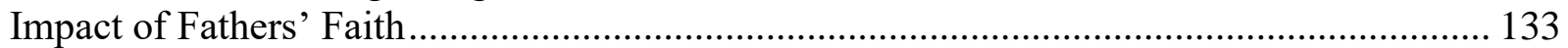

Distinctive Experiences of Fathers who have Two Children on the AS................................. 134

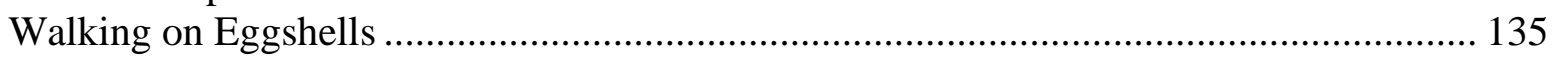

Constant Vigilance and Awareness of Behavioral Issues ................................................ 135

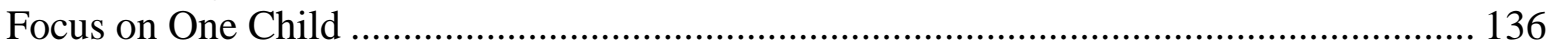

Lacking a Neurotypical Frame of Reference ................................................................ 136

Unpredictable Behavioral Concerns ................................................................................. 137

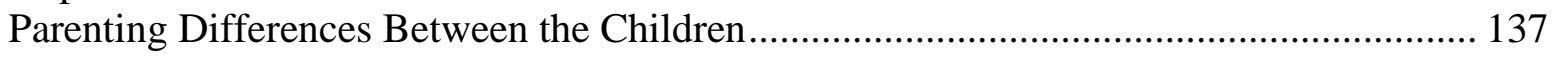

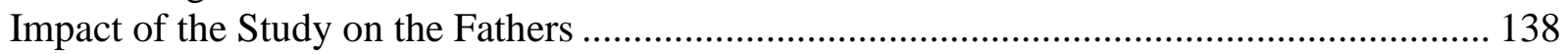

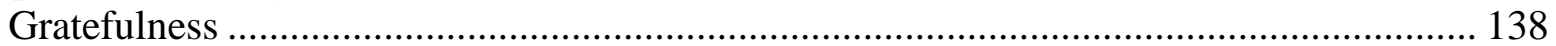

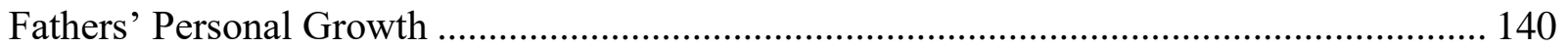

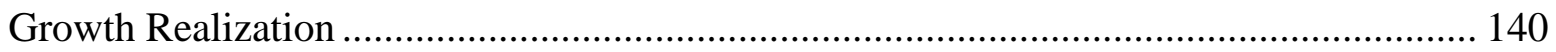

Need for Physical Time Out ...................................................................................... 140

Overcoming Experiences of Public Stigma ................................................................ 141

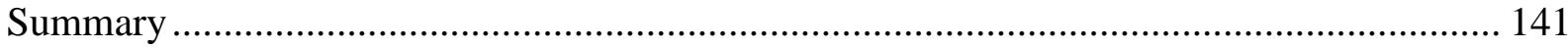

CHAPTER 5-DISCUSSION AND CONCLUSION.............................................................. 142

Central Research Question and Eight Subquestions ............................................................ 142

Subquestion 1: What Were the Reactions of the Fathers Before and After Their Child's AS

Diagnosis? After the Diagnosis, Did the Fathers Experience Challenges in Having a Child on the AS? If so, What Were They? ........................................................................ 143

Subquestion 2: Did the Fathers Experience a "New Reality" as a Result of Their Child's Diagnosis? If so, What Did This New Reality Look Like? .................................................. 149

Subquestion 3: What Roles Did the Fathers Play as a Result of having a Child on the AS?

Subquestion 4: What Are the Fathers' Views on Disability? .......................................... 157

Subquestion 5: Did the Fathers have a Belief System that Impacted Their Journey in Raising a Child on the AS? If so, How? 161

Subquestion 6: Do Fathers Who Have More than One Child on the Autism Spectrum have a Significantly Different Lived Experience Compared to Fathers Who have Only a Single Child on the Autism Spectrum? ................................................................................... 163

Subquestion 7: Did the Fathers Experience Personal Growth as a Result of Having a Child on the Autism Spectrum? If so, What Growth Did They Experience?................................ 166 Subquestion 8: Does the Severity of Autism Create a Different Lived Experience Among

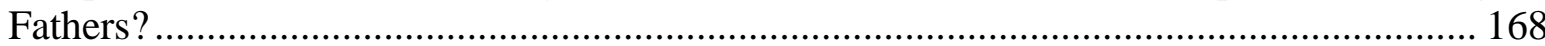

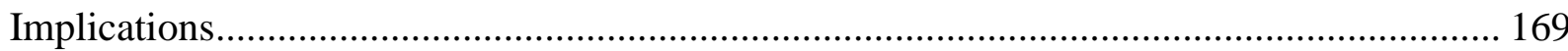


Implications for Teachers, School Psychologists, School Counselors, Administrators, and

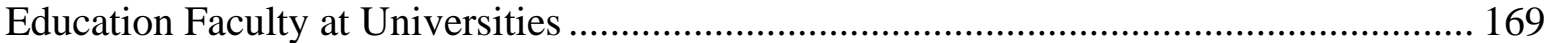

Implications for the Medical Profession ................................................................. 170

Implications for Extended Family Members, Friends, and Neighbors ................................ 171

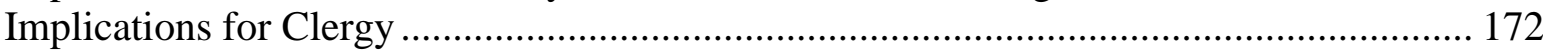

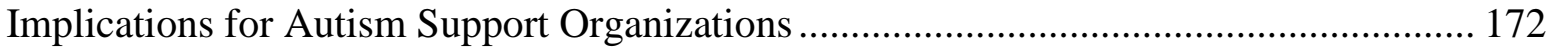

Implications for Fathers of Children with Severe Disabilities on the AS.......................... 173

Implications for Fathers with Children who do Not have Autism..................................... 173

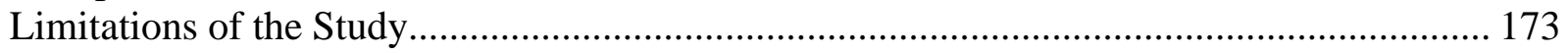

Small Sample Size and Limited Population................................................................. 174

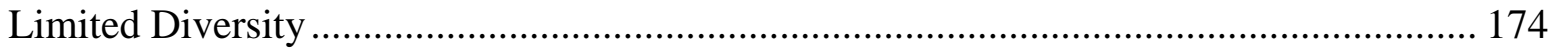

Participants Limited to Three Geographical Areas.......................................................... 174

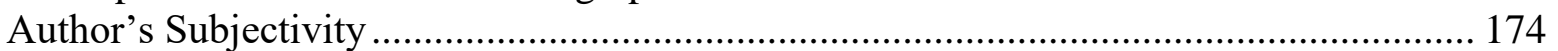

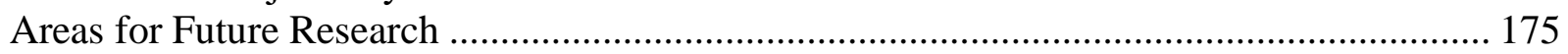

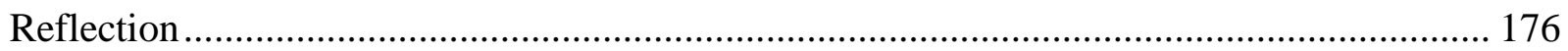

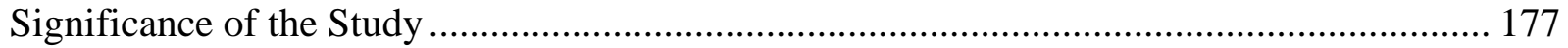

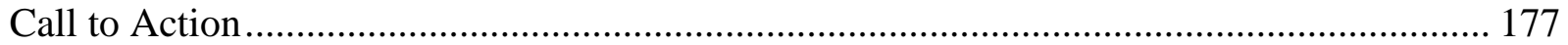

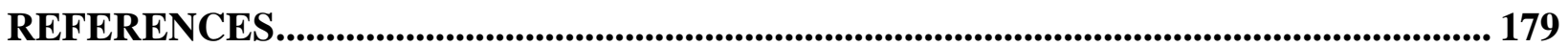

APPENDICES...................................................................................................................................................200 


\section{LIST OF TABLES}

Table 1. Differences Between the Medical Model and the Social Model of Disability............... 16

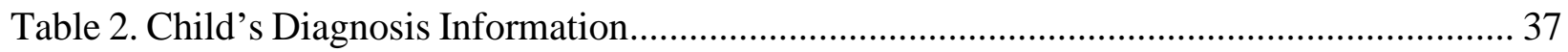

Table 3. Themes of Fathers' Experiences Pre- and Post-Autism Diagnosis.............................. 39

Table 4. Heuristic Phenomenology Versus Phenomenology.............................................. 55

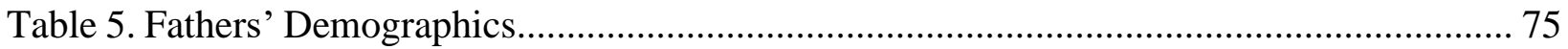

Table 6. Fathers' Children's Autism Demographics........................................................ 76

Table 7. Total Number of Interview Pages Per Father.......................................................... 86

Table 8. Total Number of Significant Statements Listed per Interview in Excel...................... 93

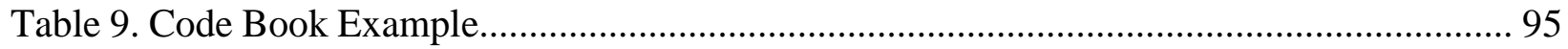




\section{CHAPTER 1-INTRODUCTION}

To have one's voice unheard, to stay in the silence is a difficult place in which to exist. When thinking about my dissertation topic, I returned to the literature and noticed a paucity in the representation of fathers who have a child along the complex spectrum called autism. This study's purpose is to examine the life experience of fathers who have a child with an official autism spectrum (AS) diagnosis. In the last year, the prevalence rates of autism among children ages 3 to 17 increased (Baio et al., 2018; Kogan et al., 2018). In interviewing fathers, I hope to gain insight into their experiences and discern how having a child along the AS has impacted their lives.

\section{Statement of the Problem Defined}

In November 2018, a report based on 43,000 parent-reported responses on autism spectrum disorder among U.S. children ages 3 to 17 suggested 1 in 40 children have been diagnosed with autism spectrum disorder (Kogan et al., 2018). According to a new government national study, 1.5 million children (about 2.5\%) have autism; however, "this increase in the

numbers may not be exact because there is no biological marker for autism" (Kogan et al., 2018, p. 2).

Earlier in 2018, the Centers for Disease Control and Prevention (CDC) reported an increase in the prevalence rates of autism in children as 1 in 59 (Baio et al., 2018). This statistic illustrated a 20-fold to 30-fold increase from the earliest statistics, which date back to the "late 1960s and early 1970s" and plateaued in 2015 (Baio et al., 2018). With the increased prevalence of autism, current CDC statistics in the United States show boys are six times more frequently diagnosed than girls (CDC, 2014). According to data from the California Department of Education (2016): 
more than 97,000 California public school students were diagnosed as autistic, a number that has risen seven-fold since 2001, according to the latest special education data from the California Department of Education. The figure represents a jump of about 6,500, or 7\%, from 2014-15 to 2015-16. (p. 40)

As AS rates continue to rise research on fathers and the roles they play in their child's life is important.

Historically, autism research is absent regarding fathers and their experiences with having a child along the AS (Fyre, 2016; Hannon \& Hannon, 2017). The role of father is a significant and potentially life-changing experience for a man as a parent of a child with or without autism; as a result, a higher number of men are taking on more responsibilities in the raising of their children (Fyre, 2016; Hannon \& Hannon, 2017). As autism rates increase, fathers are extending their roles as one of the primary caregivers in the family and taking on extra responsibilities; having a child along the AS brings some fathers additional opportunities for personal growth (Fyre, 2016, Hannon \& Hannon, 2017; Shave \& Lashewicz, 2016).

\section{Purpose Statement}

There are compelling and pragmatic reasons for conducting this study. There is a paucity of literature regarding the qualitative experiences of fathers who have a child or young adult on the AS in the United States (Braunstein, Peniston, Perelman, \& Cassano, 2013; Burrell, Ives, \& Unwin, 2017; Flippin \& Crais, 2011; Hannon \& Hannon, 2017; Lashewicz, Shipton, \& Lein, 2019; O’Halloran, Sweeney, \& Doody, 2013; Preece, 2014).

Autism rates are increasing, and the roles and definitions of fatherhood continue to change; old definitions of fatherhood are expanding to be more inclusive (Braunstein et al., 2013; Meadan, Stoner, \& Angell, 2015). However, there are remaining questions, such as how is the 
inner life and the mindset of a father impacted as a result of having a child along the AS? Did the essence of his life change after his child received an AS diagnosis? If it did change, what were the changes? Did those changes impact the relationship that he had with himself, his spouse, and his other children?

Using heuristic phenomenology, I wanted to understand the experiences of fathers who have a child or children on the autism spectrum. The ages of the 10 children in this study ranged between the ages of 7 and 32 . The fathers in this study contributed their opinions, views, and experiences, as all too often, the voices of fathers are silent. I wanted to: (a) understand the inner journey of fathers who have a child on the AS, (b) discover their narratives, and (c) gain insight into what fathers want others to know about their specific experiences.

\section{Phenomenological Research}

Phenomenological research is the study of individual experiences and how human consciousness is understood (Giorgi, 2005; Van Manen, 2014). The focus of study is the description of the lived experience of an individual utilizing everyday language (Finlay, 2009). Other studies on fathers of children with AS have been completed in non-U.S. countries and have used phenomenology. This research is important to continue as the experiences of fathers and the expanding roles they are playing in their child's life are continuing to expand. My study differed as I am using heuristic inquiry as the study's methodology.

The study of fathers with children on the AS has been studied in international contexts. Cheuk and Lashewicz (2016) compared 28 fathers of children not on the spectrum to children with an AS diagnosis using experiences of fathers who have offspring with autism spectrum disorder. Van Manen's (2014) selective highlighting approach in interpretive phenomenological analysis, was used by Burrel, Ives, and Unwin (2017) as they focused on eight fathers who had a 
child on the AS. Mackey's (2016) dissertation also used interpretive phenomenological analysis to study the experiences of seven British fathers of adults diagnosed with Asperger's syndrome. Irish researchers, O'Halloran, Sweeney, and Doody (2013) explored nine fathers' perceptions of parenting a child with Asperger syndrome with a Husserlian descriptive phenomenological approach, applying Colaizzi's (1978) method. The final international study, by Martins, Walker, and Fouché (2013) in South Africa, focused on coping strategies of five fathers with children on the AS and used interpretative phenomenology. In Chapter 2, I will go into greater detail, laying out what these studies discovered, further illustrating the scarcity in the literature on the experiences of fathers who have a child or children on the AS.

\section{Description of Study}

This study examined the impact and experiences of fathers who have a child or young adult on the AS utilizing heuristic phenomenology. I used Seidman's $(1998,2013)$ in-depth, three interview process. This process entailed a series of questions on a focused life history of the fathers (e.g., What was your initial reaction to your child's diagnosis [first interview]), the detailed experiences of the fathers' reaction to their child's AS diagnosis (e.g., What are the challenges as a parent of a child along the autism spectrum [second interview]), and the fathers' reflections on the meaning of their experiences, (e.g., Did your hopes and dreams for your child change? If so, how did your hopes and dreams change? [third interview]. The study's purpose explored the role and relationship fathers have with their children on the AS. My goal is to expand the existing literature on fathers who have a child with an official AS diagnosis.

\section{Research Questions}

The central research question is: What are the lived experiences of fathers who have a child on the autism spectrum? 
There are eight subquestions:

1. What were the reactions of the fathers before and after their child's AS diagnosis? After their reactions, did the fathers experience challenges in having a child on the AS? If so, what were they?

2. Did the fathers experience a "new reality" as a result of their child's diagnosis? If so, what did this new reality look like?

3. What roles did the fathers play as a result of having a child on the AS?

4. What are the fathers' views on disability?

5. Did the fathers have a belief system that impacted their journey in raising a child on the AS? If so, how?

6. Do fathers who have more than one child on the AS have a significantly different lived experience compared to fathers who have only a single child on the AS?

7. Did the fathers experience personal growth as a result of having a child on the AS? If so, what growth did they experience?

8. Does the severity of autism create a different lived experience among fathers?

\section{Definitions}

For this study, four terms need to be defined: autism spectrum, severe autism, fathers, and experiences.

\section{Autism Spectrum Defined}

The word autism originates from the Greek word autismus. It is defined as "meaning morbid self-admiration, with a self-identified that is described as separate from the world, while still existing in the world" (Vatanoglu-Lutz, Ataman, \& Bicer, 2014, p. 427). In 2015, the APA published a new set of criteria for autism in the latest edition of the DSM-5. The 5th edition of 
the Diagnostic and Statistical Manual of Mental Disorders (DSM-5) of the American Psychiatric Association outlines the medical model specific diagnostic criteria for the characterization of autism. According to the DSM-5, Autism is a life-long neuro-developmental disorder depicted through distinct behaviors, "severe and pervasive impairments in several areas of development that can include: reciprocal social interaction skills, communication skills, or the presence of stereotyped behavior, interests, and activities" (American Psychiatric Association [APA], 2015, p. 69; Yaylaci \& Miral, 2016). This dissertation will provide additional information regarding the DSM-5 and how diagnostic changes have impacted prevalence rates.

The medical model presented in the DSM-5 informs my view of autism; however, AS has a much broader definition based on a social construction as defined by the neurodiversity movement and represented by the Autistic Self Advocacy Network (ASAN, 2020) as "nothing about us, without us." The autism spectrum is beyond a listing of terms, definitions, behaviors, and characteristics. The definition of autism is not linear or bounded; it is a range, and its changing definition and acceptance continue beyond a dictionary and measurable professional characteristics (Vatanoglu-Lutz et al., 2014).

\section{Severe Autism Defined}

The DSM-5 identifies severe autism as children who require substantial support, have severe deficits in the area of social communication (e.g., little speech), and show repetitive behaviors (e.g., hand flapping; APA, 2013).

\section{Fathers Defined}

The term Fathers in this study is defined as the biological father of the child. 


\section{Experiences Defined}

In this study, experiences are defined as events in the fathers' lives including the fathers' participation in the child's life and lessons learned by being a father of a child(ren) on the AS.

\section{Study's Significance}

The relationship between a father and his child who is along the AS is a life-changing and compelling experience (Fyre, 2016; Shave \& Lashewicz, 2016). This area of study is new; therefore, there is a paucity in the literature on the topic. This study will add knowledge to the field and contribute to this significant and needed area of research on: (a) the growth of fathers in their role as caretakers in the family, (b) their relationships with family members and friends, (c) how they viewed their children before and after diagnosis, and (d) the impact of the communities to which they belong. Those communities included: school, faith, community based, sports based, family, and the community at large. Too often, voices of fathers with children with AS are ignored, or their roles are viewed as an extension of the role that their wives and partners play in their children's lives (Burrell et al., 2017; Paynter, Davies, \& Beamish, 2018; Thackerary \& Eatough, 2018).

\section{Summary}

In Chapter 1, I have discussed the importance of the study's purpose, outlined the study's main research question and subquestions and defined key terms that will be used throughout the dissertation.

In Chapter 2, I examined the literature regarding fathers who have a child on the AS. This includes: (a) a concise history of autism, (b) autism prevalence rates, (c) diagnostic criteria, (d) models of disability, (e) parenting perspectives, (f) fathers' experiences of the grief cycle, $(\mathrm{g})$ 
parents' perspectives of families and autism, (h) the historical absence of fathers with a child on the AS in the literature, and (i) a review of phenomenological studies in the literature.

Chapter 3 includes details framing the use of heuristic phenomenology and discussing key aspects of the method. I shared how and where I connected with my participants and how I implemented the three separate interviews with each participant. I also addressed the data collection process. Finally, I discussed coding and analyzing the data.

In Chapter 4, I outlined my findings, and presented the narratives of the fathers and their experiences with autism.

In Chapter 5, the results of the study, in connection with the theoretical frameworks and existing literature used to guide this study, are presented along with deliberation of the importance of the findings. I also presented the limitations of the study and made recommendations for future research in the areas of fathers who have a child on the AS.

As I constructed this study, I kept in mind a story one father told me after his third and final interview. He talked about how I was the first person who had ever asked him about his experiences with his son, how he had attended every one of his child's school academic individualized educational plan (IEP) meetings with his wife and not once did others inquire about his thoughts and opinions regarding his son. The voices of fathers who have a child on the AS need to come out of their held silences. This father's experience was poignant and made me eager to gain insight into the experiences other fathers have. 


\section{CHAPTER 2-LITERATURE REVIEW}

This literature review will address the issues, gaps, and relevant research that inform an understanding of the experiences of fathers who have a child on the AS in the following areas: (a) mindsets, (b) relationships with family members and friends, (c) how they viewed their children before and after diagnosis, and (d) the communities in which they were involved. In this literature review, I will first begin with (a) a concise history of autism, (b) diagnostic criteria, (c) autism prevalence rates, (d) models of disability, (e) mindsets, (f) parenting perspectives, (g) fathers' historical absence in the literature, (h) fathers' experiences of their children and autism, (i) parents' perspectives on families and autism, (j) autobiographical texts, and (k) phenomenological studies in the literature. There are gaps in the research regarding the experiences of fathers who have a child on the AS (Braunstein et al., 2013; Burrell et al., 2017;

Flippin \& Crais, 2011; Hannon \& Hannon, 2017; Lashewicz et al., 2019; O’Halloran et al., 2013; Preece, 2014). My dissertation aims to provide greater depth and insight into the fathers' journeys and identities as a result of being a father to a child on the AS.

\section{Concise History of Autism}

The discovery and recognition of autism have been long and complicated processes. Four doctor: Paul Eugene Bleuler, Eugene Murkowski, Leo Kanner, and Hans Asperger, were instrumental in connecting their observations and research and paved the way for our understanding of the rich and complex spectrum called autism "beginning in 1911" (Al Ghazi, 2018, p. 1; Greydanus \& Toledo-Pereyra, 2012; Silverman, 2015). However, before a review n of the primary doctors in autism's history, one doctor needs to be mentioned due to recently discovered scholarship of her early contributions in 1926 regarding the discovery of autism. 


\section{Grunia Sukhareva: An Overlooked Researcher}

There is one woman whose voice has been absent in the story of autism, Russian psychiatrist, Grunia Sukhareva (Al Ghazi, 2018; Manouilenko \& Bejerot, 2015; Simmonds \& Sukhareva, 2019). Due to newly published research that told her story, I would be remiss not to include Sukhareva in my concise history of autism (Al Ghazi, 2018; Manouilenko \& Bejerot, 2015; Simmonds \& Sukhareva, 2019). From as early as 1926, she published her research on children who had autistic traits. This research was conducted before Bleuler described those who exhibited "social withdraw and self-centeredness" in patients who had Schizophrenia (BarahonaCorrea \& Filipe, 2016, p. 1). Grunia Sukhareva, described six cases of "schizoid psychopathy" in children who kept to themselves in 1925, two decades before Kanner began his research in 1945 (Al Ghazi, 2018; Manouilenko \& Bejerot, 2015; Simmonds \& Sukhareva, 2019). Additionally, Sukhareva (2018) was the first autism researcher to describe an account of Asperger syndrome. She included girls in her research, where Asperger and Kanner's research focused on boys (Al Ghazi, 2018; Manouilenko \& Bejerot, 2015; Simmonds \& Sukhareva, 2019). Sukhareva’s contribution is essential to the history of autism because she was one of the earliest researchers on autism, and she had female participants (Al Ghazi, 2018). Along with Sukhareva, four leading doctors are recognized in the history of autism.

\section{Early Autism Researchers}

Of the four doctors mentioned, in the opening of this concise history, Kanner and Asperger are the most recognized (Lyons \& Fitzgerald, 2007; Robison, 2017; Silverman, 2015; Vatanoglu-Lutz et al., 2014). The earliest research into the understanding of autism was nonlinear due to its origination in first being confused with schizophrenia (Achkova \& Manolova, 2014; Donvan \& Zucker, 2016; Fitzgerald 2014; Greydanus \& Toledo-Pereyra, 2012; 
Lyons \& Fitzgerald, 2007; Silverman, 2015). It was Bleuler (1910) who first introduced the term autism to describe how his patients formed their thought patterns. However, Bleuler is seldom credited with identifying the origins of autism (Achkova \& Manolova, 2014). His research centered on individuals with schizophrenia who were extremely withdrawn socially and who had tendencies to retreat inward in social settings and lacked the capacity to communicate with others (Achkova \& Manolova, 2014; Donvan \& Zucker, 2016). In 1927, Murkowski stated that individuals with autism and schizophrenia had similar issues, including a lack of common sense and connection (Fitzgerald, 2014). The same association between autism and schizophrenia was noted by Kanner in 1943 and Asperger in 1944 and (Blacher \& Christensen, 2011; Fitzgerald, 2014; Nadesan, 2005; Olmsted \& Blaxil, 2016; Silverman, 2015; Waltz, 2013). Murkowski’s early research regarding schizophrenia and autism revealed autism involved a fundamental loss of connection with reality (Blacher \& Christensen, 2011; Donvan \& Zucker, 2016; Fitzgerald, 2014; Nadesan, 2005; Olmsted \& Blaxil, 2016; Silverman, 2015).

The terms autistic originated in the work of Bleuler (1910); both Kanner in 1943 and Asperger in 1944 equally borrowed it (Barahona-Correa \& Filipe, 2016). Kanner, a child psychiatrist, and Asperger, a pediatrician, became two of the most prominent pioneers and influential doctors in the observation of autism, now called autism spectrum disorder (Lyons \& Fitzgerald, 2007; Silverman, 2015). However, it was Kanner, in 1943, who made the differentiation between autism and schizophrenia, due to his realization that individuals with schizophrenia illustrated a gradual loss of control and that those with autism lacked control from the beginning (Lyons \& Fitzgerald, 2007). Within a few months of one another (Kanner in 1943 and Asperger in 1944), these two doctors published research detailing descriptions of autism (Fitzgerald, 2014; Robison, 2017). Those similar descriptions included an individual's ability to 
detach from other people, a need and love of routine, and a lack of understanding of the unspoken cues of others (Robison, 2017). Those traits remain vital elements of the diagnostic criteria for AS (Lurigio, 2015).

\section{Autism Diagnostic Criteria}

The process of creating specific autism diagnostic criteria has continued with every iteration of the Diagnostic and Statistical Manual of Mental Disorders, currently in its 5th edition. However, the current definition has developed over time.

\section{History of Autism Diagnostic Criteria}

The process of diagnosing autism has gone through several changes. In 1990, the passage of The Americans with Disabilities Act further expanded the civil rights of those with disabilities (Greydanus \& Toldeo-Pereyra, 2012). The definition of autism has likewise expanded and changed. In 1990, the United States Congress also amended federal education law, creating the Individuals with Disabilities Education Act (IDEA, 2004; Pennington, Cullinan, \& Southern, 2014) and autism became a category of educational disability The federal definition of autism has remained relatively unchanged since 1990 and is defined in IDEA (2004) in section 300.8 (c)(1) as:

(i) Autism means a developmental disability significantly affecting verbal and nonverbal communication and social interaction, generally evident before age three, that adversely affects a child's educational performance. Other characteristics often associated with autism are engagement in repetitive activities and stereotyped movements, resistance to environmental change or change in daily routines, and unusual responses to sensory experiences. 
(ii) Autism does not apply if a child's educational performance is adversely affected primarily because the child has an emotional disturbance, as defined in paragraph (c)(4) of this section.

(iii) A child who manifests the characteristics of autism after age three could be identified as having autism if the criteria in paragraph (c)(1)(i) are satisfied.

\section{Concise History of Autism's Diagnostic Changes}

As IDEA (2004) has brought changes to the definition of autism, the Diagnostic and Statistical Manual for Mental Disorders has brought autism diagnostic criteria into a new era (APA, 2013; Miller et al., 2013). These changes have resulted from information obtained from research and clinical experiences (Yaylaci \& Miral, 2016). In 1980, the term infantile autism was listed in the DSM-III for the first time (APA, 1987; Miller et al., 2013; Verhoeff, 2013). Autism was described per the DSM-III as "a pervasive lack of responsiveness to other people" (Miller et al., 2013, p. 201; Verhoeff, 2013). With a revision to the DSM-III, this definition further expanded into "qualitative impairment in reciprocal social interaction" as, for instance, manifested by "no or abnormal seeking of comfort in times of distress" or "gross impairment in ability to make peer friendships" (Verhoeff, 2013, p. 452). Additionally, in the DSM-IIIR (APA, 1987), the new definition included "marked abnormal nonverbal communication" and "marked impairment in the ability to initiate or sustain a conversation with others despite speech" (Verhoeff, 2013, p. 452). The DSM-III had required an onset of autism before the age of 30 months (Miller et al., 2013; Verhoeff, 2013). With this change, the term autistic disorder replaced infantile autism (Miller et al., 2013; Verhoeff, 2013). In 1994, the DSM-IV changed the clinical criteria regarding autism (Miller et al., 2013; Pennington et al., 2014; Verhoeff, 2013). Autism categories became more specific, including: (a) autistic disorder, (b) Asperger's, (c) 
Rett's disorder, (d) childhood disintegrative disorder, (e) PDDNOS (Pervasive Developmental Disorder - Not Otherwise Specified), and (f) autism spectrum disorder (APA, 1994; Miller et al., 2013). The DSM-IV, released in 1994 and revised in 2000, was the first edition to categorize autism as a spectrum (Miller et al., 2013). In 2013, the DSM-5 changed the criteria regarding the diagnosis of autism by the addition of " sensory interests and strong aversions, combined with deficits in social interaction and communication ... the DSM-5 is now more focused on descriptions of specificities and deficits in functioning” (Achkova \& Manolova, 2014, pp. 113114). The definition of autism through the years in the DSM has continued to change. With each new edition of the DSM, and the addition of a definition of autism in IDEA (2004), the definition has evolved and continues to be refined.

\section{Autism Spectrum}

The origins of the word autism have been defined in Chapter 1. Autism is a Greek word, coming from the word autismus, translated as morbid self-admiration, with a self-identity and is described as distinct from the world, while remaining in the world (Vatanoglu-Lutz et al., 2014). The medical model of autism is outlined in the DSM-5. Autism is characterized as a lifelong neurodevelopmental disorder with "severe and pervasive impairments in several areas of development that can include: reciprocal social interaction skills, communication skills, or the presence of stereotyped behavior, interests, and activities" (APA, 2015, p. 69).

In 2013, the APA published a new set of criteria for autism (Bent, Barbaro, \& Dissanayake, 2017; Pennington et al., 2014; Wakefield, 2013). The latest edition of the DSM-5 defines autism as a disorder inclusive of autistic disorder, Asperger syndrome, and childhood disintegrative disorder (Bent et al., 2017; Wakefield, 2013). The collapsing of the previous autism categories (i.e., "autistic disorder, Rhett syndrome, childhood disintegrative disorder, 
Asperger syndrome, and PDD-NOS" [Yaylaci \& Miral, 2016, p. 101]) into a single diagnosis of autism spectrum disorder was decidedly controversial among those with a previous diagnosis of Asperger syndrome, given that Asperger syndrome had been seen as a milder form of autism (Bent et al., 2017; Wakefield, 2013). The new diagnostic criteria for autism in the DSM-5 includes a requirement to be fulfilled in both criteria areas of: "social interaction, and communication deficits and in at least two of the four criteria areas in restrictive and repetitive patterns of interest, behavior, and activities" (Yaylaci \& Miral, 2016, p. 101). Autism spectrum and its definition continues to change and be updated as more and more is learned through research.

\section{Autism Prevalence Rates}

Autism prevalence rates continue to rise in the United States. In 2018, the Centers for Disease Control and Prevention (CDC) reported the prevalence rates of autism in children as 1 in 59 (Baio et al., 2018). This recent statistic illustrated the increase of autism as a "twentyfold to thirtyfold" increase from the earlier statistics, which dated back to the "late 1960s and early 1970s" and plateaued in 2015 (Baio et al., 2018, p. 2). With an increase in the prevalence rates of autism, current CDC (2014) statistics in the United States show boys are six times more frequently diagnosed than girls. In 2016, California released data regarding the prevalence of autism in California public school. According to data from the California Department of Education (2016), more than 97,000 California public school students have been diagnosed as autistic, a number that has risen seven-fold since 2001, according to the latest special education data from the California Department of Education. The figure represents a jump of about 6,500 or $7 \%$ in prevalence rates dating from $2014-15$ to $2015-16$. The increasing number of children being diagnosed with autism spectrum disorder has also shed light on the growing complexity of 
raising a child on the AS. Fathers have significant opportunities for personal growth when acting as a primary caregiver for a child with AS (Fyre, 2016; Hannon \& Hannon, 2017; Shave \& Lashewicz, 2016). As AS rates continue to rise it is helpful to be aware of two different models of disability, the medical and social model of disability that are referred to after a AS diagnosis. These will be models discussed in the next section.

\section{Models of Disability}

There are two primary models of disability applied to the discussion of autism and autism diagnosis. These include the medical model which is most likely to be view disability through impairment and the social model which is most likely to view disability as constructed by society. Table 1 illustrates the differences between the medical model of disability and the social model of disability.

Table 1

Differences Between the Medical Model and the Social Model of Disability

\begin{tabular}{lll}
\hline Term & Medical Model & Social Model \\
\hline Impairment & $\begin{array}{l}\text { A physical or mental condition, } \\
\text { deficit, or limitation that requires } \\
\text { treatment or fixing. }\end{array}$ & $\begin{array}{l}\text { Lacking part or all of limb, organ, or } \\
\text { mechanism of the body. }\end{array}$ \\
Disability & $\begin{array}{l}\text { The condition of being unable to } \\
\text { perform a task due to an } \\
\text { impairment which is an individual } \\
\text { burden, personal tragedy, or } \\
\text { individual problem. }\end{array}$ & $\begin{array}{l}\text { The disadvantage or restriction of } \\
\text { activity caused by design of } \\
\text { environments which exclude disabled } \\
\text { persons from participation in } \\
\text { mainstream social activities. }\end{array}$ \\
& $\begin{array}{l}\text { The individual must adjust or } \\
\text { become more normal to fit into } \\
\text { society and the established }\end{array}$ & $\begin{array}{l}\text { Society must adapt the design of } \\
\text { environments. Individual differences are } \\
\text { environments. }\end{array}$ \\
& $\begin{array}{l}\text { considered normal and accepted through } \\
\text { the design of inclusive and flexible } \\
\text { environments. }\end{array}$ \\
\hline
\end{tabular}

Note. Adapted from The Social Model of Disability, by Democracy Disability and Society

Group, 2003, http://ddsg.org.uk/taxi/social-model.html. 


\section{The Medical Model of Disability}

The medical model of disability has been applied to the social sciences since the beginning of the $20^{\text {th }}$ century (Shyman, 2016). This model of disability stems from research conducted by the doctors whose discovery of autism shaped its earliest definitions (Miller et al., 2013). Since the medicalization of autism began in 1943, the diagnosis of autism became more associated with curing and fixing individuals (Straus, 2013). This medical model of disability is regressive and restrictive and defines disability as a deficit, that is, something that needs to be fixed or healed (Barnes, Mercer, \& Shakespeare, 1999; Davis, 2013; P. Ferguson, 2002; Linton, 1998; Shakespeare, 2014; Siebers, 2011). In the medical model of disability, the problem belongs to the individual and any resulting disability is due to physical, sensory, and mental impairments (Järvinen, 2017). The applying of the medical model of disability places disability and the interpretation of disability on the individual with the disability (i.e., autism) and therefore autism is viewed as a disability.

\section{The Social Model of Disability}

The social model of disability is a progressive approach to the definition of disability (Davis, 2013; Shakespeare, 2014; Siebers, 2011). This model of disability places the discourse and definition of impairment upon society, not the individual, as disability is a social and cultural phenomenon (Barnes et al., 1999; Davis, 2013; Goodley, 2010). The social model of disability views disability not as a condition of individual pathology but as a construct viewed through a variety of lenses, such as society (i.e., how society constructs disability), the economy (i.e., how economic measures discriminate those receiving disability aide), politics (i.e., segments of American political parties), and social aspects of society (i.e., aligning disability with discriminatory beliefs; Davis, 2013; Goodley, 2010; Johnstone, 2001). This model of disability 
views disability as an identity, something in which an individual can take pride (Linton, 1998). The social model of disability places a greater emphasis on the social factors involved with the experience of disability and connects to disability studies.

\section{Disability Studies}

Disability studies is defined as an interdisciplinary area of scholarship that draws from both the social sciences and the humanities and combines literature, art, legal studies, and women's studies (Davis, 2013; Ware, 2011, 2012). A disability studies perspective centers on four critical tenets: (a) it maintains that society constructs barriers to individuals with disabilities, (b) it is interdisciplinary, (c) it honors the voices of those with disabilities and encourages individuals with disabilities to be researchers and writers, and (d) it recognizes and critiques occurrences of ableism (Davis, 2013; Hernández-Saca \& Cannon, 2016; Linton, 1998). In a wide-ranging sense, disability studies is defined through a nonabelist lens that breaks away from the medical model of disability (Davis, 2013; Ware, 2011, 2012). In disability studies, disability is a social construction (Davis, 2013; Shakespeare, 2014; Siebers, 2011; Ware, 2012). While the medical model of disability has historically dominated social science research on autism disability (Davis, 2013), as a disability studies scholar, I use a social model of disability in my dissertation. Guided by this perspective, I refer to autism as a spectrum (written throughout this dissertation as AS).

\section{Mindsets}

According to Dweck (2016), the mindsets people have impact their beliefs, motivation, and personal growth. Three different types of mindsets have been identified in the literature that may affect the choices and experiences an individual makes. These three mindsets include (a)

fixed (Dweck, 1998, 1999, 2012, 2016, 2019), (b) growth (Dweck, 1998, 1999, 2016, 2019), and 
(c) stress (Crum, Salovey, \& Acho, 2013). A fixed mindset, "creates an urgency to prove yourself over and over" (Dweck, 2016, p. 6). A growth mindset, "is based on the belief that your basic qualities are things you can cultivate through your efforts, your strategies, and help from others" (Dweck, 2016, p. 7). A stress mindset, "focuses on the nature of stress itself (i.e., whether stress is enhancing or deliberating)" (Crum, Akinola, Martin, \& Fath, 2017, p. 380).

The history of mindsets dates back to the Renaissance, where there was a belief that human beings have turning points in their lives and have the power to transform themselves (Dweck \& Yeager, 2019). Modern-day origins of mindsets have been traced back to the Wurzburg School of cognitive psychology in the early twentieth century (French, 2016). Fundamental to the original Wurzburg school, mindset is connected to a specific task. That is, mindset theory and the way it is characterized attempts "to identify both a task and the cognitive mechanisms that were activated to successfully perform said task" (French, 2016, p. 674).

Dweck and Yeager (2019) traced mindset lineage back to the late 1960s. At this time behaviorism was losing its dominance in Psychology and the field was searching for additional explanations as to why people behave the way they do. Dweck believed mindsets held the key to the deeper understanding of human behavior. Dweck $(1998,1999,2012,2016,2019)$ stated that mindsets are the conceptualization and characterization of growth in an individual's life and essential aspects of an individual's personality combined with an inherent belief in their flexibility in changing an individual's characteristics. Dweck's (1998, 1999, 2011, 2012, 2016, 2019) theory was that there are two mindsets, that is a fixed mindset and a growth mindset. Dweck (2019) also studied how the mindsets people have impacted their beliefs, motivation, and personal growth, (e,g., applying to only one graduate school, the one an individual has set their 
heart on only to be rejected. Growth mindset has the individual reexamine what actions will be required to get accepted at graduate school).

Dweck's early work centered on the "understanding the psychology between individuals who sought" challenges and resilience and those who did not. That is, "why some individuals run from difficulty and others embrace difficulty" (Dweck, 2019, p. 483). As time progressed, mindset work moved to group work (e.g., in business settings), and into the area of public outreach addressing real-world problems, including academic risk, and mental health (Dweck 2019, 2018, 2016). Dweck and Yeager (2019) indicated that mindsets are the core of how individuals create meaning systems. Those meaning systems are then connected to the individuals' specific growth or fixed mindset.

However, Dweck's $(2016,2019)$ research has indicated that individuals have a mixture of both mindsets in which they operate which adds another level of complexity to behavior. Dweck and Leggett (1988) illustrated how mindsets are more prominent during times that are challenging and difficult than when times are easier for individuals. An individual's mindset frequently can define an individual's response to life events (i.e., reactions to challenges and setbacks; Dweck, 2012, 2016; Dweck \& Leggett, 1988). Some life events have the power to change and shift an individual's life and the meanings they construct regarding the events in their lives. Benson and Dvesdow (2003) and Crum et al. (2013) also defined mindset as a frame of reference, a way of conceptualizing an individual's beliefs, and how the individual perceives the events in their life guiding of an individual's experiences. Those events are often viewed by the individual as positive or negative. Thus, the mindset an individual holds impacts their ability to grow and change throughout the events and challenges that occur in their life. In the following sections the concepts of fixed, growth, and stress mindsets will be further defined. 


\section{The Fixed Mindset}

According to Dweck $(1998,2012,2016,2019)$ and Kammrath and Dweck (2006), a fixed mindset is a belief that an individual can learn new things. However, people believe their qualities, abilities, and intellect remain consistent, and therefore are fixed traits. Dweck and Leggett (1988) stated, "The fixed mindset, creates an urgency to prove yourself over and over" (p. 6). For example, individuals or students with a fixed mindset may have to prove to themselves and others, over and over again, that they are smart and successful.

\section{The Growth Mindset}

A growth mindset purports that human beings have the potential to develop their talents and abilities through their understanding of self (Dweck, 1988,1999, 2006). That is, the deeper one understands themselves, the greater the possibility for growth and change. An individual's mindset is guided by their thoughts. Those thoughts can influence their interpretation of experiences, which allows for the expansion of their mindset. Thus, growth mindsets have the potential to buffer against adverse life events (Burnette, Knouse, Vavra, O’Boyle, \& Brooks, 2020; Dweck, 1999, 2008, 2016, Schroder et al., 2017). For example, the birth of a child on the AS may be viewed by some people as potentially an adverse life event. For Dweck (2016), individuals who have a growth mindset face setbacks as motivating experiences, a personal wake-up call. For example, when a father receives the news from a professional in the autism field, that upwards of $\$ 3$ million will be needed for the lifetime care of his child, fathers with a growth mindset, may view this news as a wake-up call to pursue a job that would monetarily provide for their child; as a result, their employment trajectories may shift. 


\section{Stress Mindset}

Researchers Crum et al. (2013) discussed the role mindsets play in determining how individuals respond to events in their life (i.e., a stress mindset). This mindset can impact the beliefs an individual holds regarding their health, wellbeing, learning, and growth. This mindset relates to the amount and intensity of the stress an individual is experiencing and how the individual copes with that stress. For individuals who have the mindset that their stress is enhancing, they can adapt more physiologically in their response (Crum et al., 2017; Crum et al., 2013).

\section{Fathers' Mindsets in the Present Study}

In the final analysis Dweck (2012) stated who we become as an individual is not built-in; perhaps what each individual possesses, is the capacity to adapt, to change, and grow depending upon the world the individual lives in. For example, in this present study, as will be demonstrated in Chapters 4 and 5, fathers who had a child on the AS, adapted and developed as a result of their experiences. The mindsets of fathers in this study appeared to reflect a combination of growth, fixed, and stress mindsets. As a result, each father had opportunities to grow, dependent on their circumstances and how they viewed their experiences of having a child on the AS.

\section{Parents' Perspectives}

There is a paucity in the literature regarding the experiences of fathers who have a child on the AS (Braunstein et al., 2013; Hannon \& Hannon, 2014; Lashewicz et al., 2019; Meadan et al., 2015; O’Halloran et al., 2013; Vacca, 2013). Therefore, it is necessary to bring in perspectives from parents who have a child on the AS before discussing fathers more specifically. When a parent receives their child's official AS diagnosis, their lives are being 
impacted in multiple ways. Parents experience an impact on their relationship and on their families (Broady, Stoyles, \& Morse, 2015; Russells \& Norwich, 2012). Parenting a child on the AS and with severe autism can cause the father or the mother to experience stigma (Gray, 2002). The following sections presents these parental experiences more fully.

\section{Stigma}

In studies by Robinson, York, Rothenberg, and Bissell (2015) and Russells and Norwich (2012), parents associated feelings of stigma with their child's AS diagnosis. Some families who have a child on the AS are faced with trials outside of the family system. The ancient Greeks first originated the term stigma (Gray, 2002); however, the psychological research work of Goffman (1963) brought the discourse of stigma into the literature. This occurrence centers around four specific realms: (a) lack of knowledge, (b) judgment by others, (c) rejection, and (d) lack of support (Broady et al., 2015; Gray, 2002).

Many parents with a child on the AS have experienced the lack of AS knowledge, judgment, and absence of support for their child from schools, while in public, and in their family (Broady et al., 2015). The nature of their child's autism played a role in how stigma impacted parents (Broady et al., 2015). For example, parents in Gray's (2002) study reported higher cases of stigma if they had a child with more severe autism. Parents who had a child with less severe autism experienced fewer internal feelings of stigma.

\section{Impact on Couples' Relationships}

Couples raising a child on the AS often face challenges in their relationships (A Father, 1945; Broady et al., 2015; Cummings, 1976; Robinson et al., 2015). Those challenges involve intimacy, commitment, stress, and financial issues, all of which are factors that already impact couples and their relationships (A Father, 1945; Cummings, 1976; Hock, Timm, \& Ramisch, 
2012; Robinson et al., 2015). According to Hock et al. (2012), the time following the diagnosis of their child was the most stressful for parents. An additional impact on the couples' relationships included the scenarios in which one parent becomes the primary caregiver, and, for some couples, this created dissatisfaction in the couple's relationship (Gray, 2002; Hock et al., 2012; Robinson et al., 2015).

\section{Impact on the Family}

When a child receives an AS diagnosis, there is an impact upon the family system, for the siblings and the parents (Gray, 2002; Preece, 2014; Robinson et al., 2015; Seligman \& Darling, 2007). One of the impacts included a new definition of normalcy (Gray, 2002). Gray's studies (2002) described the impact upon the family, siblings, and each parent. Those findings included the following: (a) changes in the family's routine as services are needed for their child, (b) impact on siblings (i.e., change in family routine, more time focused on the child on the AS), (c) new definitions of normal, (4) changing roles between parents while parenting, and (5) greater financial stress on the family due to mothers quitting their jobs (Gray, 2002; Preece, 2014; Russell \& Norwich, 2012; Seligman \& Darling, 2007). Having a child on the AS presents parenting challenges which will be discussed next.

\section{Parenting a Child}

Robinson et al. (2015) found that parenting a child on the AS was a balancing act for the family; families lost their sense of balance. However, they then regained their equilibrium as their child on the AS became older; parents had, through trial-and-error, found a balance in their parenting styles (Hock et al., 2012; Robinson et al., 2015; Seligman \& Darling, 2007). Parents also experienced a period of searching for answers regarding their child's AS diagnosis, and, as a couple, they would decide on specific interventions for their child (Hock et al., 2012; Preece, 
2014; Robinson et al., 2015; Seligman \& Darling, 2007). Some parents experienced a sense of parenting defeat because of their ongoing lack of parenting success with their child on the AS (Robinson et al., 2015; Seligman \& Darling, 2007). After the mothers quit their full-time jobs due to their child's AS diagnosis, the burden of parenting responsibility shifted (i.e., the mother was more available for their child than the father; Gray, 2002). The voices of fathers are generally absent in this literature, therefore a study on fathers who have a child(ren) on the AS adds to and provides insights from a specific population to the literature (Braunstein et al., 2013; Burrell et al., 2017; Cheuk \& Lashewicz, 2016; Flippin \& Crais, 2011; Fyre, 2016; Hannon \& Hannon, 2017; Hornby, 1992; Lashewicz et al., 2019; Meadan et al., 2015; O’Halloran et al., 2013). Having a child on the AS brings parenting challenges to the lives of mothers and fathers.

\section{Impact of a Child with Severe Autism}

Regarding the impact of having a child with severe autism (children who require substantial support) on fathers, there continues to be a paucity in the literature. The extant literature focuses on the impact of a child with complex disabilities when autism was listed as one of the complex disabilities (Gorlin, McAlpine, Garwick, \& Wieling, 2016). For example, Gorlin et al. (2016) focused only on the father's involvement in their child's educational and learning experiences, not the experiences of the father. In addition, Gorlin et al. (2016) found that a father's work schedule played a major role in their level of involvement in their child's education. The findings further stated how mothers had the bulk of the responsibilities and their voices continued to be more represented than the experiences of fathers (Gorlin et al., 2016).

Wang and Michaels (2009) examined Chinese mothers and fathers who had a child with severe disabilities in connection with the support their families needed. The study's qualitative focus was on greater involvement by skilled professionals in the lives of children on the AS (i.e., 
doctors and therapists), the need for support for the whole family, and the need for greater levels of independent living for their child (Wang \& Michaels, 2009).

Gorlin et al. (2016) also explored the family's lived experience with their child with a severe AS diagnosis. Of the 11 families they studied, 22 mothers and fathers participated. They found that the family, as a whole, viewed autism as complex and a mystery (Gorlin et al., 2016). Along with the experiences of families that have a child with a severe AS, there are parents who experienced a grief cycle in having a child with an AS diagnosis. Gorlin et al. (2016) found that families in their study experienced extreme stress stemming from having to deal with eloping behaviors (i.e., wandering off) and significant communication challenges. Having a child on the AS led families in the study to live in severe isolation, not being able to leave their home due to their child's severe behavior (Gorlin et al., 2016). This study revealed that the families also learned from other families who had a child on the AS. As the aforementioned studies illustrate, there continues to be a paucity in the literature in specifically regarding the experiences of fathers who have a child with severe autism. Families with a child on the AS with severe autism experienced many challenges in their lives and in the life of their families.

\section{Grief Cycle}

There are some parents who, when they receive the diagnosis that their child is on the AS, experience the cycle of grief. According to researchers (Boushey, 2001; Fernandez et al., 2016), parents experienced the five stages of the grief cycle including denial, anger, bargaining, depression, and acceptance (Kübler-Ross, 1969). However, not all parents experience the traditional cycle of grief as described by Kübler-Ross (1969) and Kübler-Ross and Kessler (2005). 
Krishnan, Russell, and Russell (2017) found that parents experienced phases of grief instead of the traditional cycle of grief. Their research found that the grief included three stages: a primary phase, secondary phase, and a tertiary phase. The primary phase was described as the initial reaction to their child's diagnosis that parents go through and encompasses "shock, denial, projection of blame, guilt feeling, social withdrawal, sense of rejection, and acceptance" (Krishnan et al., 2017, p. 268). The secondary phase was a stage of emotional disorder. In this stage, parents often explore interventions and treatments for their child (Krishnan et al., 2017). The third and final phase was the tertiary phase; in this phase, parents arrive at acceptance of their child's AS diagnosis.

\section{Summary}

Parents who have a child on the AS dealing with many aspects in their lives: (a) experiences of stigma, (b) the impact upon their child's autism on their relationship, (c) the impact of autism in the family, (d) parenting a child on the AS, the impact of a child with severe autism, and for some the experience of grief.

\section{Fathers' Minimal Presence in the Literature}

The voices of fathers who have a child on the AS is sparse in the literature (Braunstein et al., 2013; Burrell et al., 2017; Cheuk \& Lashewicz, 2016; Flippin \& Crais, 2011; Fyre, 2016; Hannon \& Hannon, 2017; Hornby, 1992; Lashewicz et al., 2019; Meadan et al., 2015; O'Halloran et al., 2013). Instead of focusing on the direct experiences of the father, most research has centered on (a) parental perspectives of parents who have a child on the AS, including parental reactions; (b) the impact upon the couple's relationship; and (c) the impact upon family life (Broady et al., 2015; Gray, 2002; Robinson et al., 2015). I will begin this section 
with a discussion on the research regarding fathers in the 1940s, 1950s, and the 1960s and conclude with research from the 1970s and beyond.

\section{Fathers and Children with a Disability The 1940s, 1950s, and 1960s}

Literature from the 1940s, through the 1960s was limited. The few studies I was able to find will be discussed in this section. In 1945, an anonymous father published his experiences and decision, along with his wife, to commit their daughter to a state-run hospital due to an unspecified brain condition the doctors had defined as helpless (A Father, 1945). This father felt if his daughter was kept at home, the family would suffer. The father had witnessed the ridicule of others in the community who considered the daughter as "the village half-wit, and we understood what keeping her with us would mean to our family" (A Father, 1945, p. 3). The father ended his account, "and so tragedy came into a family that barely knew the word. We think we pray, we have faced it wisely" (A Father, 1945, p. 4). This early account of one anonymous father illustrated the impact on this family of having a child with a disability. However, nowhere in the account does the father mention his specific thoughts, feelings, or experiences. The words he used were "the family" and "we." It would take until 1957 before the specific voices of fathers would be represented in the literature.

Eisenberg (1957) conducted a case study of three fathers who each had a child with a disability/on the AS and the researcher used the term infantile autism. The study looked at the behavior and the role of the father in the family regarding the formation of meaningful relationships with his autistic child. Up to this point in history, fathers were the forgotten parent and blaming the mother for the child's disability was commonplace (Eisenberg, 1957). PriceBonham and Addison (1978) reported that the research during this period of the 50s still had a significant focus on the mother's relationship with her child, who had a disability. This reported 
research by Eisenberg (1957) is now considered outdated that the impact on fathers produced inaccurate advice to fathers in child rearing from medical professionals, the acceptance that their child is "retarded [sic]" (p. 1080), economic stress on fathers, emotional tension, religious conflicts, and full-time care issues.

As the 1950s drew to a close and the 1960s began, the studies on fathers and autism were absent in the literature. However, fathers who had a child with a disability were studied with their connection to the medical model perspective under the term mental retardation [sic p.223] (Price-Bonham \& Addison, 1978). In the 1960s, researchers used different terms regarding disability. These words today would be considered inappropriate and outdated, including the use of the word mental retardation (Davis, 2013). There were few research efforts focused on the relationship between fathers and their children with autism in the 1960s.

\section{Fathers and Children with a Disability in the 1970s and Beyond}

Upon hearing the news that their child was on the AS fathers and had reactions to this news and their lives were impacted. Cumming (1976) focused on the psychological impact of having a child with a disability on fathers. This researcher found that: (a) fathers were psychologically impacted by their child's disability and were depressed, (b) the relationship that fathers had with other family members was affected, and (c) fathers found less satisfaction with their life (Cummings, 1976). Price-Bonham and Addison (1978) similarly addressed the relationship that fathers had with their child with a severe disability, noting that fathers who have a child with a disability view disability differently than mothers. These fathers viewed their children as a crisis in the family, not an event, while mothers saw the birth of their child as an event. Price-Bonham and Addison (1978) also noted that because fathers were seen as the primary wage earner, they experienced the economic burden more significantly than mothers did. 
Fathers also experienced higher emotional tension in the family than their wives (Price-Bonham \& Addison, 1978). Additional findings from this literature review found that couples counseling did not make an impact, and the couple's feelings of anxiety were an expected experience (PriceBonham \& Addison, 1978). In a study of 66 Israeli fathers, Margalit, Leyser, and Avraham (1989) studied the perceptions of family climate, sense of coherence, and satisfaction from family life in fathers with a child with a disability. Their study on the classification and validation of family climate subtypes in kibbutz fathers of disabled and nondisabled children also investigated the impact of children who had a disability upon fathers. The study's findings illustrated that fathers had less connection to family life and had experienced less satisfaction with family life and personal growth (Margalit et al., 1989). In another study, Hornby (1992) discussed the relationship that British fathers had with their child who had a disability and found that little to no attention had been placed on the accounts and experiences of fathers who had a child with a disability. The effect of having a child on the AS impacted fathers and the family climate. Having a child on the AS impacted the family climate during the 1970s. In the next section, the literature on fathers' experiences with their children will be discussed.

\section{Literature on Fathers' Experiences of Their Children and Autism}

Fathers who have a child on the AS face many internal challenges and experiences. This section includes research on the fathers' experiences of his child and autism in five key areas: (a) fathers' awareness of their child's difference prediagnosis of AS, (b) facing uncertainty, (c) fathers' feelings of their child post AS diagnosis, (d) behavior issues perceived by other family members and friends, and (e) the relationship with their child. 


\section{Fathers' Awareness of their Child's Difference Prediagnosis of AS}

Before their child's official AS diagnosis, the fathers recognized their children were different from their siblings or other children that they encountered, (Cheuk \& Lashwicz, 2016). An early study conducted by Eisenberg (1957) involved three fathers whose children would later be diagnosed as autistic. Eisenberg's study revealed only one father out of the three was aware there was something different about his son from the very beginning; however, no direct evidence of the father's awareness was listed.

Fathers of a child later diagnosed on the AS were aware of their children's differences in the areas of nontypical development and milestones being missed (Cheuk \& Lashewicz, 2016; Donaldson, Elder, Self, \& Christie, 2011; Hannon \& Hannon, 2017; O’Halloran et al., 2013), delayed toilet training (O'Halloran et al., 2013), and the child's failure to interact with other children or animals (O' Halloran et al., 2013). As a result of their children's missed milestones and areas of nontypical development, combined with their inner awareness, the fathers frequently were left feeling uncertain about their child's delayed development (Burrell et al., 2017; Cheuk \& Lashewicz, 2016; Donaldson et al., 2011; Hannon \& Hannon, 2017; O’Halloran et al., 2013).

\section{Facing Uncertainty}

After the fathers realized their children were different, they faced uncertainty and asked questions like, "Why is my child not acting like other children?" and "Why is my child acting different?" (Burrell et al., 2017; Cheuk \& Lashewicz, 2016; Donaldson et al., 2011; O’ Halloran et al., 2013; Hannon \& Hannon, 2017). This uncertainty prompted the fathers to explore a reason, a cause, or an explanation for their children's missed milestones and to acknowledge their gut feeling that something was different about their children. The next step these fathers 
took was seeking and getting a possible AS diagnosis for their children. After the fathers received their child's AS diagnosis, a new journey would begin.

\section{Fathers' Feelings Post-Autism Spectrum Diagnosis}

Upon receiving the news that their thoughts and suspicions were real regarding their child, fathers experienced a whole new set of reactions (Cheuk \& Lashewicz, 2016; Fyre, 2016). The announcement of their child's AS changed the fathers' lives forever (Frye, 2016). After receiving the news that their child was on the AS, some of the fathers experienced a cycle of grief (Frye, 2016).

The grief cycle was first introduced through the work of Kübler-Ross (1969). As mentioned previously, the five stages of the grief cycle include denial, anger, bargaining, depression, and acceptance. The grief cycle was often connected to the feelings and deeply experienced emotions that occurred for fathers after hearing the news their child was on the AS (Burrell et al., 2017; Fyre, 2016; Martins et al., 2013; O’Halloran et al., 2013). However, it is necessary to note that the stages in the grief cycle are not linear (Kübler-Ross, 1969; KüblerRoss \& Kessler, 2005). Kübler-Ross (1969) identified denial as the first stage in the grief cycle. It encompasses the feelings of not being able to comprehend the loss of the loved one (KüblerRoss \& Kessler, 2005). For the fathers who had a child on the AS, it was a different kind of the loss; that is of what and how they thought their child would be. Researchers reported fathers experienced denial upon hearing their child was on the AS (Burrell et al., 2017; Fyre, 2016; O'Halloran et al., 2013). Anger is the second stage in the grief cycle (Kübler-Ross, 1969; Kübler-Ross \& Kessler, 2005). Fathers reported experiencing frustration (i.e., anger) after hearing the news that their child was on the AS (Burrell et al., 2017; Fyre, 2016; O'Halloran et al., 2013). In reference to a child's AS diagnosis, anger often is connected to feelings of loss, that 
the hopes and dreams fathers had for their child now will be different. Bargaining is the third stage in the grief cycle; bargaining is the what-if question (Kübler-Ross, 1969; Kübler-Ross \& Kessler, 2005). Fathers experienced bargaining (i.e., was there something they could have done differently so their child wouldn't have been on the AS) as an increase or decrease regarding their hope for their child (Fyre, 2016). For fathers of a child with an autism diagnosis, the what-if can turn into "what if we try this intervention" (Burrell et al., 2017; Fyre, 2016). After the bargaining stage, depression is the fourth stage in the grief cycle. For the fathers who experienced it, depression was a deeper stage of loss, of feeling like things will never change (Burrell et al., 2017; Kübler-Ross, 1969; Kübler-Ross \& Kessler, 2005; Martins et al., 2013). After depression, acceptance is the final stage of the grief cycle (Kübler-Ross, 1969; KüblerRoss \& Kessler, 2005). Acceptance for fathers was the reality that their child has an official AS diagnosis. As fathers moved through the previous stages of grief, they ultimately experienced acceptance that their child was on the AS. This acceptance did not happen overnight; it occurred over a period of time (Burrell et al., 2017; Fyre, 2016; Martins et al., 2013; O’Halloran et al., 2013).

\section{Behavioral Issues as Perceived by Other Family Members and Friends}

Fathers who have a child on the AS experienced reactions from family members regarding their child on the AS (Cheuk \& Lashewicz, 2016; Mitchell \& Lashewicz, 2018; Preece, 2014; Robinson et al., 2015). After the fathers' children had received their official AS diagnosis, another set of feelings and experiences were experienced by the fathers. Fathers reported that family members and friends viewed their child's behavior as inappropriate (Cheuk \& Lashewicz, 2016; Mitchell \& Lashewicz, 2018; Preece, 2014; Robinson et al., 2015; Shave \& Lashewicz, 2016). Children along the AS may present behavioral issues, including expressions 
of anger and loss of control and (Cheuk \& Lashewicz, 2016; Mitchell \& Lashewicz, 2018; Shave \& Lashewicz, 2016). Many children on the AS are rules governed, and when faced with situations outside of the rule, behavioral issues can result (Martins et al., 2013). Due to their child's behavioral problems (e.g., poor emotional regulation, temper tantrums, and aggression), fathers reported a lack of support from other family members and friends regarding their children (Cheuk \& Lashewicz, 2016; Martins et al., 2013; O’Halloran et al., 2013) and sought informal support from other fathers who had a child on the AS (Burrell et al., 2017; Cheuk \& Lashewicz, 2016; Shave \& Lashewicz, 2016).

\section{Fathers and their Relationship with their Child}

The relationship a father forms with his child on the AS is essential in the process of parenthood. Upon hearing the news their child was on the AS, some fathers experienced a deeper and more profound acceptance of their child (Boström \& Bromberg, 2014; Burrell et al., 2017; Donaldson et al., 2011; Fyre, 2016; Hannon \& Hannon, 2017; O’Halloran et al., 2013; Martins et al., 2013; Robinson et al., 2015; Shave \& Lashewicz, 2016). This journey of acceptance opened new pathways for the fathers (Burrell et al., 2017). When a father accepted his child's place on the AS, he changed the narrative of his child from one of nonacceptance to acceptance (Donaldson et al., 2011; Fyre, 2016; Hannon \& Hannon, 2017).

Some fathers had a shift regarding the narratives of their children after they accepted their child's AS diagnosis (Boström \& Bromberg, 2014; Donaldson et al., 2011; Fyre, 2016; Hannon \& Hannon, 2017; O’Halloran et al., 2013; Martins et al., 2013; Robinson et al., 2015; Shave \& Lashewicz, 2016). Upon shifting their narratives in a positive light, the fathers experienced more significant connections to their child. 
The research studies on fathers who have a child on the AS suggested involvement in the community as a priority in their lives (Boström \& Bromberg, 2014; Fyre 2016; Hannon \& Hannon, 2017; Shave \& Lashewicz, 2016). For example, Fyre (2016) and Shave and Lashewicz (2016) illustrated how fathers and their participation in the community provided the fathers with a place and opportunity to become involved. This involvement resulted in the fathers taking action, such as taking time off from work to attend their child's medical appointments and meeting with additional service and intervention providers regarding services for their child (Fyre, 2016).

When the fathers accepted their children, their feelings of acceptance brought feelings of hope for some of the fathers (Cheuk \& Lashewicz, 2016; Donaldson et al., 2011; O'Halloran et al., 2013; Robinson et al., 2015; Russell \& Norwich, 2012; Shave \& Lashewicz, 2016). A father's hope opened up new thoughts and possibilities for their child (Donaldson et al., 2011). Those potential opportunities included full assimilation into society, mainstreaming, and even the feeling that the child had no limits in his or her life (Donaldson et al., 2011).

In the next section, I will discuss the 24 autobiographical books chosen to illustrate the experiences of fathers. Inclusion of these books was designed to supplement the lack of research literature about fathers' lived experiences and provide a more complete picture of fathers who have a child(ren) on the AS.

\section{Autobiographical Texts}

There is an underrepresentation in the literature regarding the personal accounts of fathers who have a child on the AS (Braunstein et al., 2013; Hannon, \& Hannon, 2014; Lashewicz et al., 2019; Meadan et al., 2015; O’Halloran et al., 2013; Vacca, 2013). My study will be a significant contribution to this research literature because it includes the personal experiences of 10 fathers 
with children on the AS. To expand upon the limited research in this area. I included 24 books written by 23 fathers who have a child or children on the AS in this literature review as outlined in Table 2, one father authored two books. The autobiographical texts written by the fathers brought a fuller picture to the life experiences of fathers who have a child on the AS.

I added these additional 24 autobiographical books written by fathers because I sought to learn more than what was available in the research literature regarding fathers who had a child or young adult on the AS. Due to this paucity of research studies, my dissertation chair and I decided I would read additional narratives to bring a greater depth of understanding of the phenomenological experiences of fathers who had a child on the AS. I generated a list utilizing the Amazon search tool during the summer of 2018 as their selection appeared comprehensive. I made my selections using specific criteria for inclusion: (a) the fathers' children all had to have an official AS diagnosis or a Pervasive Developmental Disorder diagnosis, and (b) the books would be self-published books by fathers because I wanted their voices to be heard and selfpublished books tended to be more straightforward and less edited than books published from well-known publishers. I noted there was a rawness in the writing of self-published fathers versus the books that were published by mainstream publishers. However, I also choose two books by prominent authors who were published by known publishers. I also wanted to include fathers who were outside of the United States; two books met these criteria.

For each of the 23 books, I summarized the child's specific name, diagnosis, age, and gender, one father wrote two books regarding his journey with his son's autism (see Table 2). There were a total of 20 boys and three girls represented in these books; this representation demonstrates and supports the earlier statistic of the current prevalence rates for boys compared to girls in the United States, as autism is reported less in girls than in boys (Fombonne 2009). 
Table 2

\section{Child's Diagnosis Information}

\begin{tabular}{|c|c|c|c|}
\hline Child's Name & Diagnosis Of Child & Age of Autism Diagnosis & Gender \\
\hline Aaron Ambersley & $\begin{array}{l}\text { Pervasive Developmental Disorder (PDD), } \\
\text { Speech and Language Delays, ADHD, Autism }\end{array}$ & $\begin{array}{l}\text { Age not stated; Prior to } \\
\text { Pre-Kindergarten }\end{array}$ & Boy \\
\hline Connor Anderson & Nonverbal Autism & 3 & Boy \\
\hline Kyler Bayardo & Autism, ADHD, Tourette Syndrome, Depress $1 / 2$ & $21 / 2$ & Boy \\
\hline Ben Burns & Regressive Autism & 3 & Boy \\
\hline Koleden Bayardo & $\begin{array}{l}\text { Late-onset Autism, later Depression, and High } \\
\text { Functioning Autism }\end{array}$ & At birth & Boy \\
\hline Tyler Fournier & High Functioning Autism/Asperger's & 12 & Boy \\
\hline Carly Fleischmann & $\begin{array}{l}\text { Global Developmental Delay (GDD,) Apraxia, } \\
\text { OCD, Nonverbal Autism }\end{array}$ & 2 & Girl \\
\hline Gabriel Freihow & Autism & Not stated & Boy \\
\hline DJ Savarese & Nonverbal Autism & 3 & Boy \\
\hline Dylan Volk & Autism/Asperger's, OCD & 8 & Boy \\
\hline Raun Kaufman & Autistic, Severely mentally retarded & 1 & Boy \\
\hline Rowan Isaacson & Aut $1 / 2$ & $21 / 2$ & Boy \\
\hline Sam Wilson & $\begin{array}{l}\text { Hydrocephalus - "condition where cerebral-spinal } \\
\text { fluid doesn't circulate from the brain down the } \\
\text { spinal column but instead builds up in the brain" } \\
\text { (Wilson, 2008, p. 26). Autistic like behaviors- } \\
\text { diagnosis given, educational handicap, IQ listed } \\
\text { as } 79\end{array}$ & 5 & Boy \\
\hline Jonah Yanofsky & High-Functioning ASD & $31 / 2$ almost 4 & Boy \\
\hline Isabel Grinker & $\begin{array}{l}\text { First was diagnosed with PDD- NOS (Pervasive } \\
\text { Developmental Disorder Not Otherwise } \\
\text { Specified) then changed to Autism }\end{array}$ & 2 & Girl \\
\hline Ian Smith & Autism/Autistic & First grade, age not listed & Boy \\
\hline Alex Mont & Autistic/Twice Exceptional & $31 / 2$ & Boy \\
\hline Chubby Robison & Asperger's & $\begin{array}{l}\text { Teenager- Age Not } \\
\text { specified }\end{array}$ & Boy \\
\hline Zach Bissinger & $\begin{array}{l}\text { Trace brain damage at birth comprehends at an } \\
\text { eight or 9-year-old as an adult, IQ is about } 70 \text {, } \\
\text { Autistic }\end{array}$ & $\begin{array}{l}\text { Started seeing doctors at } \\
\text { age } 2 \text {; received diagnosis } \\
\text { after age } 5\end{array}$ & Boy \\
\hline Jack Hague & $\begin{array}{l}\text { Severe Autism, regression, epilepsy, severe } \\
\text { anxiety, obsessive-compulsive disorder }\end{array}$ & After age 2, not specified & Boy \\
\hline
\end{tabular}




\begin{tabular}{llll}
\hline Child's Name & Diagnosis Of Child & Age of Autism Diagnosis & Gender \\
\hline Maria Gallardo & Autism & Age not specified & Girl \\
Will Shinn & Moderate to Severe Autism & 2 & Boy \\
John Pakkala & Autistic, Severe Autism & $31 \frac{1}{2}$ & Boy \\
\hline
\end{tabular}

\section{Mismatch Between Initial Themes and Current Study's Research Findings}

I took notes on nine out of 10 autobiographical books, then I did some initial coding. I continued to read books written by fathers and take notes. However, I did not code the entire collection of 24 books until I had completed the interviews of my study participants. The themes I initially saw in the first 10 books were somewhat naïve in my beginning analysis, that is, it was what I saw at that time. This decision of returning to those first 10 books was based on later refinement on newer information and new theoretical understandings. For example, initially I placed a heavy emphasis on the food struggles the children had, the major communication struggles, the child's accomplishments and growth, the counter-narrative of exceptionality, the grief cycle as outlined by the work of Kübler-Ross (1969), the stages of the grief cycle not mentioned or written about, fathers-only experiences, and the dual stories of parent and child. Thus, the original themes included: (a) father as teacher, (b) hopes and dreams for their child, (c) the experience of denial of their child's autism, (d) acceptance of their child's autism, and I the fathers" use of the word "we" in describing his spouse. In retrospect, these themes were incomplete, as a result I returned to the books for a deeper analysis.

After I coded this dissertation's research findings, I decided to return to these texts and code all 24 books thematically utilizing the child's or children's two stages of pre-AS diagnosis and post-AS diagnosis (see Table 3). After coding each of the 24 books' major themes in Excel, I had two overarching categories. In the first overarching category of pre-AS diagnosis, my analytical book themes included the following: (a) father's hopes and dreams for their child, (b) 
missed milestones and developmental stages, (c) denial, (d) expectations of fatherhood, (e) father knew something was off about his child, and (f) child's behavioral issues. In the second overarching post-AS diagnosis category, the analysis of book themes included the following: (a) embracing the new journey, (b) autism as a gift, (c) role of father, (d) absence of grief cIe, (e) grief cycle, (f) father wanting connection with child, (g) community, and (h) the impact of a child's having severe autism.

Table 3

Themes of Fathers' Experiences Pre- and Post-Autism Diagnosis

\begin{tabular}{|c|c|c|c|}
\hline Author (Year) & Book & $\begin{array}{l}\text { Pre-AS Diagnosis Book } \\
\text { Themes }\end{array}$ & Post-AS Diagnosis Book Themes \\
\hline $\begin{array}{l}\text { Ambersley } \\
(2013)\end{array}$ & $\begin{array}{l}\text { Autism: Turning on } \\
\text { the Light. A Father } \\
\text { Shares his Son's } \\
\text { Inspirational Life's } \\
\text { Journey Through } \\
\text { Autism }\end{array}$ & $\begin{array}{l}\text { - Preconceived dreams for } \\
\text { son } \\
\text { - Hope that autism would } \\
\text { go away and hope for a } \\
\text { cure }\end{array}$ & $\begin{array}{l}\text { - Pride } \\
\text { - Denial } \\
\text { - Questioning } \\
\text { - Depression } \\
\text { - Dream changed } \\
\text { - Embracing autism } \\
\text { - Father as an advocate } \\
\text { - Enjoy the journey } \\
\text { - Lowered expectations }\end{array}$ \\
\hline $\begin{array}{l}\text { Anderson } \\
(2015)\end{array}$ & $\begin{array}{l}\text { Connor, Brave \& } \\
\text { Kind: A Love Letter } \\
\text { from Devoted } \\
\text { Father }\end{array}$ & $\begin{array}{l}\text { - Fog of Autism: son } \\
\text { changed almost } \\
\text { overnight }\end{array}$ & $\begin{array}{l}\text { - Autism as gift } \\
\text { - Loss of the dream } \\
\text { - Failed his son } \\
\text { - Guilt } \\
\text { - Felt sorry for self } \\
\text { - Hope }\end{array}$ \\
\hline Bayardo (2014) & A Dad's Journey & $\begin{array}{l}\text { - Hopes and dreams for } \\
\text { son to carry the family } \\
\text { name } \\
\text { - Son's missed milestones } \\
\text { - Denial }\end{array}$ & $\begin{array}{l}\text { - Father as provider and advocate } \\
\text { - "We" used } \\
\text { - A career change for father } \\
\text { - Denial, depression, and acceptance } \\
\text { - Want for normal } \\
\text { - Impact on the spouse }\end{array}$ \\
\hline $\begin{array}{l}\text { Bissinger } \\
(2012)\end{array}$ & $\begin{array}{l}\text { Father's Day: A } \\
\text { Journey into the } \\
\text { Mind and Heart of } \\
\text { My Extraordinary } \\
\text { Son }\end{array}$ & $\begin{array}{l}\text { - Father's struggles to } \\
\text { accept his son }\end{array}$ & $\begin{array}{l}\text { - Father's shame } \\
\text { - Loss of hope and dreams } \\
\text { - Guilt } \\
\text { - Son's gift }\end{array}$ \\
\hline
\end{tabular}




\begin{tabular}{|c|c|c|c|}
\hline Author (Year) & Book & $\begin{array}{l}\text { Pre-AS Diagnosis Book } \\
\text { Themes }\end{array}$ & Post-AS Diagnosis Book Themes \\
\hline Burns (2009) & $\begin{array}{l}\text { Saving Ben: A } \\
\text { Father's Story of } \\
\text { Autism }\end{array}$ & $\begin{array}{l}\text { - Father's frustration with } \\
\text { his son }\end{array}$ & $\begin{array}{l}\text { - Hope son would emerge out of autism } \\
\text { - Loss of dreams } \\
\text { - Father wasn't going to get used to } \\
\text { autism } \\
\text { - Searched for a cure, tried various } \\
\text { therapies for son } \\
\text { - Struggled with his faith } \\
\text { - Was going to beat autism }\end{array}$ \\
\hline $\begin{array}{l}\text { Fields-Myer } \\
(2011)\end{array}$ & Following Ezra & $\begin{array}{l}\text { - Missed autism signs } \\
\text { - Denial } \\
\text { - Father's expectations }\end{array}$ & $\begin{array}{l}\text { - No grief } \\
\text { - Hope } \\
\text { - Son's gift of visual memory } \\
\text { - Support group attended }\end{array}$ \\
\hline $\begin{array}{l}\text { Fleischman \& } \\
\text { Fleischman } \\
\text { (2012) }\end{array}$ & $\begin{array}{l}\text { Carly's Voice: } \\
\text { Breaking Through } \\
\text { Autism }\end{array}$ & $\begin{array}{l}\text { - Father wanted } \\
\text { connection } \\
\text { - Father as an advocate } \\
\text { - Missed milestones } \\
\text { - Impact on the } \\
\text { relationship with spouse }\end{array}$ & $\begin{array}{l}\text { - Father and daughter become a team } \\
\text { - Daughters AS gift became a typer to } \\
\text { communicate, then a speaker }\end{array}$ \\
\hline Fournier (2016) & $\begin{array}{l}\text { Love that Boy: What } \\
\text { Two Presidents, } \\
\text { Eight Road Trips, } \\
\text { and My Son Taught } \\
\text { Me About a Parents } \\
\text { Expectations }\end{array}$ & $\begin{array}{l}\text { - Fear } \\
\text { - Not wanting an AS } \\
\text { diagnosis } \\
\text { - Overlooked AS signs } \\
\text { - Embarrassed about his } \\
\text { son } \\
\text { - Used we (i.e., he and his } \\
\text { wife) } \\
\text { - Father's dreams }\end{array}$ & $\begin{array}{l}\text { - Parenting } \\
\text { - The journey to acceptance } \\
\text { - Denial } \\
\text { - Son teaches father } \\
\text { - Advice to other fathers }\end{array}$ \\
\hline Freihow (2006) & $\begin{array}{l}\text { Somewhere Over the } \\
\text { Sea: A Father's } \\
\text { Letter to His Autistic } \\
\text { Son }\end{array}$ & $\begin{array}{l}\text { - Want to connect with son } \\
\text { - Needing help how to ask } \\
\text { - The shock of his son's } \\
\text { diagnosis }\end{array}$ & $\begin{array}{l}\text { - Growth Mind Set } \\
\text { - Grief } \\
\text { - Loss of hope } \\
\text { - Acceptance } \\
\text { - Son's gift } \\
\text { - Impact on relationship with wife }\end{array}$ \\
\hline Errea (2011) & $\begin{array}{l}\text { Adventures in } \\
\text { Raising an Autistic } \\
\text { Son }\end{array}$ & $\begin{array}{l}\text { - Autism signs } \\
\text { Missed milestones }\end{array}$ & $\begin{array}{l}\text { - No grief } \\
\text { - Impacted couple's relationship } \\
\text { - Wanted the son to be normal } \\
\text { - Sought alternative therapies }\end{array}$ \\
\hline $\begin{array}{l}\text { Gallardo \& } \\
\text { Gallardo (2018) }\end{array}$ & $\begin{array}{l}\text { Maria and Me: A } \\
\text { Father, A Daughter } \\
\text { (and Autism) }\end{array}$ & $\begin{array}{l}\text { - } \quad \text { Missed milestones } \\
\text { - } \quad \text { Autism signs }\end{array}$ & $\begin{array}{ll}\text { - } & \text { Acceptance } \\
\text { - } & \text { No grief }\end{array}$ \\
\hline Grinker (2007) & $\begin{array}{l}\text { Unstrange minds. A } \\
\text { father, a daughter, } \\
\text { and a search for } \\
\text { new answers. }\end{array}$ & - $\quad$ Missed milestones & $\begin{array}{l}\text { - } \quad \text { No grief } \\
\text { - Acceptance }\end{array}$ \\
\hline
\end{tabular}




\begin{tabular}{|c|c|c|c|}
\hline Author (Year) & Book & $\begin{array}{l}\text { Pre-AS Diagnosis Book } \\
\text { Themes }\end{array}$ & Post-AS Diagnosis Book Themes \\
\hline & $\begin{array}{l}\text { Remaking the world } \\
\text { of autism. }\end{array}$ & & \\
\hline Hague (2018) & $\begin{array}{l}\text { Aching Joy: } \\
\text { Following God } \\
\text { Through the Land of } \\
\text { Answered Prayer }\end{array}$ & $\begin{array}{l}\text { - Denial } \\
\text { - Missed AS signs } \\
\text { - Growth Mind Set }\end{array}$ & $\begin{array}{l}\text { - Wanted his son fixed } \\
\text { - Wanted God to fix son } \\
\text { - Grief } \\
\text { - Autism fog } \\
\text { - Depression } \\
\text { - Running away } \\
\text { - Questioning } \\
\text { - New Dreams } \\
\text { - Community } \\
\text { - Belief in God }\end{array}$ \\
\hline Isaacson (2009) & $\begin{array}{l}\text { The Horse Boy: A } \\
\text { Father's Quest to } \\
\text { Heal His Son }\end{array}$ & $\begin{array}{l}\text { - Awareness son was } \\
\text { different } \\
\text { - Projected dreams onto } \\
\text { son }\end{array}$ & $\begin{array}{l}\text { - Father wanting connection with son } \\
\text { - Loss of dream } \\
\text { - Growth Mind Set } \\
\text { - Father shifting journey } \\
\text { - Wanted his son healed } \\
\text { - Wanted a cure } \\
\text { - Hope } \\
\text { - Liminal spaces } \\
\text { - Fears } \\
\text { - Acceptance } \\
\text { - Community }\end{array}$ \\
\hline Isaacson (2016) & $\begin{array}{l}\text { The Long Ride } \\
\text { Home: The } \\
\text { Extraordinary } \\
\text { Journey of Healing } \\
\text { that Changed a } \\
\text { Child's Life }\end{array}$ & - Sought a cure & $\begin{array}{l}\text { - Journey to Mongolia } \\
\text { - Find shamans to cure his son } \\
\text { - Son and father's journey to connection } \\
\text { - Impact on couple's relationship } \\
\text { - Community }\end{array}$ \\
\hline $\begin{array}{l}\text { Kaufman } \\
(1994)\end{array}$ & $\begin{array}{l}\text { Son Rise: The } \\
\text { Miracle Continues }\end{array}$ & $\begin{array}{l}\text { - Autism signs } \\
\text { - Father's pain }\end{array}$ & $\begin{array}{l}\text { - Hope } \\
\text { - No labeling } \\
\text { - Father as advocate and teacher } \\
\text { - Pilgrimage }\end{array}$ \\
\hline Mont (2002) & $\begin{array}{l}\text { A Different Kind of } \\
\text { Boy }\end{array}$ & $\begin{array}{l}\text { - Father's awareness } \\
\text { - Grandparents' awareness } \\
\text { - Denial }\end{array}$ & $\begin{array}{l}\text { - Want of community } \\
\text { - Impact on couple } \\
\text { - Pain } \\
\text { - Fears about son's future } \\
\text { - Autism consumes family } \\
\text { - Father's need to talk }\end{array}$ \\
\hline Pakkala (2015) & $\begin{array}{l}\text { Broken by Autism: A } \\
\text { Father and Son } \\
\text { Story }\end{array}$ & $\begin{array}{l}\text { - Father knew something } \\
\text { was wrong/Awareness } \\
\text { - Pride in son }\end{array}$ & $\begin{array}{l}\text { - Autism as brokenness } \\
\text { - Father's isolation and grief } \\
\text { - Struggled to accept son } \\
\text { - Growth Mind Set } \\
\text { - Autism's gift to father }\end{array}$ \\
\hline
\end{tabular}




\begin{tabular}{|c|c|c|c|}
\hline Author (Year) & Book & $\begin{array}{l}\text { Pre-AS Diagnosis Book } \\
\text { Themes }\end{array}$ & Post-AS Diagnosis Book Themes \\
\hline Robison (2013) & $\begin{array}{l}\text { Raising Cubby: A } \\
\text { Father and Son's } \\
\text { Adventures with } \\
\text { Asperger's Trains, } \\
\text { Tractors, and High } \\
\text { Explosives }\end{array}$ & $\begin{array}{l}\text { - Denial } \\
\text { - Fatherhood expectations } \\
\text { - Behavior }\end{array}$ & $\begin{array}{l}\text { - Both father and son on are on AS } \\
\text { - Both wanted to fit in }\end{array}$ \\
\hline Savarese (2007) & $\begin{array}{l}\text { Reasonable People: } \\
\text { A Memoir of Autism } \\
\text { and Adoptions: On } \\
\text { the Meaning of } \\
\text { Family and the } \\
\text { Politics of } \\
\text { Neurological } \\
\text { Difference }\end{array}$ & $\begin{array}{l}\text { - Son was adopted } \\
\text { - Father had a lack of } \\
\text { autism and trauma } \\
\text { knowledge of child }\end{array}$ & $\begin{array}{l}\text { - Autism's gifts } \\
\text { - Father as an advocate } \\
\text { - Community }\end{array}$ \\
\hline Shinn (2014) & $\begin{array}{l}\text { We win: A Father's } \\
\text { Journey Through } \\
\text { Autism }\end{array}$ & $\begin{array}{l}\text { - Denial } \\
\text { - Blaming God }\end{array}$ & - Acceptance of son \\
\hline Smith (2015) & $\begin{array}{l}\text { Sticks and Stones: A } \\
\text { Father's Journey } \\
\text { into Autism }\end{array}$ & $\begin{array}{l}\text { - Denial } \\
\text { - Severe autism signs } \\
\text { - Father's fears } \\
\text { - Delayed milestones } \\
\text { - Use of we (i.e., his } \\
\text { spouse) }\end{array}$ & $\begin{array}{l}\text { - Father's Growth Mind Set } \\
\text { - Acceptance } \\
\text { - Love for son } \\
\text { - Pain } \\
\text { - Impact on a sibling }\end{array}$ \\
\hline $\begin{array}{l}\text { Volk \& Volk } \\
\text { (2015) }\end{array}$ & $\begin{array}{l}\text { Chasing the Rabbit: } \\
\text { A Dad's Life } \\
\text { Raising a Son on the } \\
\text { Spectrum }\end{array}$ & $\begin{array}{l}\text { - Son's severe behavior } \\
\text { - Blame } \\
\text { - Suspecting son was } \\
\text { different }\end{array}$ & $\begin{array}{l}\text { - Loss of hope and dreams } \\
\text { - Son's gift adds to father's book } \\
\text { - Father as an advocate. }\end{array}$ \\
\hline Wilson (2008) & $\begin{array}{l}\text { Weather Reports } \\
\text { from the Autism } \\
\text { Front: A Father's } \\
\text { Memoir of His } \\
\text { Autistic Son }\end{array}$ & $\begin{array}{l}\text { - Child's severe AS } \\
\text { behaviors } \\
\text { - Missed milestones }\end{array}$ & $\begin{array}{l}\text { - Child's severe AS behaviors } \\
\text { - Missed milestones }\end{array}$ \\
\hline $\begin{array}{l}\text { Yanofsky } \\
(2012)\end{array}$ & $\begin{array}{l}\text { Bad Animals: A } \\
\text { Father's Accidental } \\
\text { Education in Autism }\end{array}$ & $\begin{array}{l}\text { - Denial } \\
\text { - Hope } \\
\text { - Father's awareness, } \\
\text { knew something was off }\end{array}$ & $\begin{array}{l}\text { - Father's growth mindset } \\
\text { - Want for answers } \\
\text { - Shame as a couple } \\
\text { - Son's gift of autism to father } \\
\text { - Journey } \\
\text { - Impact on the spouse } \\
\text { - Father and wife sought therapy } \\
\text { - Wished to take away autism }\end{array}$ \\
\hline
\end{tabular}

The 23 fathers wrote about their triumphs and challenges in having a child on the AS, each was on a journey, one that changed their lives forever. Their journey was one of hope and 
transcendent change. As a result, my current study of 10 fathers with children on AS adds vital and valuable information to the existing research in this growing and expanding field of study connected to fathers' experiences with children with autism.

\section{Review of Phenomenological Studies in the Literature}

Because my study will use heuristic phenomenological methods, this section of the literature review focuses on phenomenological studies of fathers who have a child on the AS. Only two studies were found from the United States (Frye, 2016; Keller, Ramisch, \& Carolan, 2014). Frye (2016) explored the fathers' experiences with a child on the AS, and Keller et al. (2014) examined the relationship between fathers and sons. During the review of the research literature, my analysis revealed there were no studies that used heuristic phenomenology for researching fathers who had a child on the AS. Consequently, due to the shortage of phenomenological studies in the United States literature, five international studies were located and will be discussed. Cheuk and Lashewicz's (2016) study compared 28 Canadian fathers who had children with AS to fathers whose children were typically developing. Burrell et al. (2017) study focused on eight fathers in the United Kingdom who had a child on the AS, using Van Manen's selective highlighting approach in interpretive phenomenological analysis. Mackey (2016) used interpretative phenomenological analysis to examine the experiences of seven British fathers whose adult children had been diagnosed with Asperger syndrome. O'Halloran et al. (2013) explored nine Irish fathers' perceptions of parenting a child with Asperger syndrome with a Husserlian descriptive phenomenological approach. Martins et al. (2013) focused on coping strategies of five South African fathers who had children on the ASD using interpretative phenomenology. In these collective studies the relationship between fathers and their child along 
with the fathers' observations of their children on the AS were discussed. To begin, I will discuss the two U.S. studies.

\section{United States Studies}

Frye's (2016) study was a phenomenological small single-case study consisting of a single interview with each of 10 White, non-Hispanic fathers living in the home with their child who has an official AS diagnosis using semistructured interviews. The study focused on two main aspects: the challenges faced by fathers, and their advice for other fathers who had a child on the AS. Fyre's (2016) three key themes included the family experience in: "making adjustments, a father's needs, and grief and loss" (p. 457). Regarding the first theme, adjustment included economic challenges regarding services for their child, teacher meetings, transportation needs of their child to service providers, and career sacrifices as they became caregivers to their child (Fyre, 2016). The second theme of the fathers' needs involved acquiring money to provide for (a) their child's necessary services and AS interventions, and (b) expenses related to taking action and becoming involved in the care of their child (Fyre, 2016). The final theme of grief and loss included the fathers' feelings of anger, denial, isolation, anger, bargaining, depression, and acceptance (Frye, 2016). Fyre (2016) compared the third theme with Kübler-Ross's (1969) work on the grief process associated with death and dying.

The second study from the United States, conducted by Keller et al. (2014), was a phenomenological study of seven fathers consisting of a single in-depth, semistructured interview. The aim of the study was to investigate the relationship between fathers and sons. The seven major themes of the study included: (a) father and son shared activities included electronic games, (b) developmental sensitivity encompassed understanding the child's functioning level, (c) the emotional understanding between father and child included the father's awareness of their 
child's needs, (d) the fighting of the son's AS label thus advocating for their child, (e) expectations of fatherhood which included understanding their son's developmental needs, (f) parenting responsibility required for balancing their other roles, and $(\mathrm{g})$ the isolation of fatherhood including times when the father felt sadness combined with isolation. The first study focused on fathers and the challenges they faced. While the second study focused on the relationship the fathers and sons had.

\section{International Studies}

There were five international studies examined regarding fathers who have a child on the AS: Cheuk and Lashewicz (2016), Burrell et al. (2017), Mackey (2016), O'Halloran et al. (2013) and Martins et al. (2013). Cheuk and Lashewicz (2016) conducted a social comparison framework study on fathers in a large urban center in Canada. They compared the phenomenon of 28 fathers who had children with ASD to fathers whose children were typically developing using a single interview. The study focused on, "How has your experience been similar to or different from that of other fathers of typically developing children?” (Cheuk \& Lashewicz, 2016, p. 1). The four themes from Cheuk and Lashewicz's (2016) from this study included: (a) the fathers' loss of hope and dreams, (b) extreme tiredness and the need to "soldier on" (p. 348), (c) the necessary need of paying closer attention to the needs of their child, and (d) the need to be heard.

Burrell et al. (2017) used interpretive phenomenological analysis to examine firsthand experiences of being a father to someone with ASD. The study was comprised of eight participants who identified as White British and one participant who identified as White Other. The study focused on "The experiences of fathers who have offspring with Autism Spectrum disorder" (Burrell et al., 2017, p. 1135). The themes in the study included: (a) fathers' path of 
acceptance, which included anger, guilt, and loss attributed to Kübler-Ross's (1969) work on death and dying; (2) role of father as teacher creating avenues of "independence and integration for their child" (p. 1140); (3) utilization of military words describing their journey, including "fight, battle, and navigate" (p. 1141); and (4) fathers' preferred types of informal support involving friends or no support at all.

The third international study was a dissertation by Mackey (2016). Using interpretative phenomenological analysis of the experiences of fathers of adults diagnosed with Asperger's syndrome or high functioning autism, Mackey (2016) interviewed seven fathers in single, semistructured interviews. The ethnicity of the participants was not provided in this British dissertation. The study's research question focused on the in-depth experiences of fathers to begin building a knowledge base regarding fathers who had a child diagnosed with AS. The study's four themes included: (a) how the fathers' role of fatherhood was perceived in relation to their child, (b) the need to understand their child connected to the need for others to understand their child, and (c) the role of support from support services and from family and friends (Mackey, 2016).

Researchers O'Halloran et al. (2013) employed a Husserlian phenomenological approach through semistructured single interviews of nine Irish fathers in the west region of Ireland. The study focused on exploring the fathers' perceptions of parenting a child with Asperger syndrome (O'Halloran et al., 2013). The study's three themes included: (a) the father's journey from awareness to having his child receive a diagnosis; (b) living with his child on the AS; and (c) the impact of services, having to fight for services for their children.

The final international study conducted by Martins et al. (2013) is the final international study utilizing phenomenology. Implementing a case study design, Martins et al. used 
semistructured interviews in an interpretative phenomenological analysis of five South African fathers. The study focused on exploring the experiences of fathers who had preschool children with ASD to gain a better understanding of how the fathers attempted to cope with having a child on the AS. Martins et al. identified three themes: (a) experiences of fathering a child on the AS, feelings of anxiety, confusion and disappointment; (b) challenges of fathering a child on the AS, including child's behavior issues and a limit of the child's interests; and (c) coping, which included focused coping strategies as a result of parenting challenges.

\section{Summary}

The aforementioned studies, that is, included two U.S. studies and the five international studies illustrate the paucity in the literature on the experiences of fathers who have a child on the AS (Burrell et al., 2017; Fyre, 2016; O'Halloran et al., 2013). Two studies (i.e., Burrell et al., 2017; Fyre, 2016) had a similar theme of grief and loss as represented by Kübler-Ross (1969). The collective findings of these studies provide insight into how the role of fatherhood is a vital and complex journey for fathers raising a child on the AS and the need for further exploration.

\section{Conclusion}

The findings from this literature review indicate that while life experiences of fathers of children on the AS are beginning to emerge in research, their voices are still underrepresented in the research. Bringing disability studies and mindset perspectives to the literature and adding the voices of fathers as expressed in narrative or autobiographical writings, brings new layers of understanding to the experiences of fathers who have a child on the AS.

Chapter 3 includes how and where I connected with the 10 fathers who participated in the study, followed by how I conducted the three separate interviews with the fathers. I also address the data collection process. Finally, I discuss coding and the analysis of the data. 


\section{CHAPTER 3-METHODOLOGY}

\section{Introduction: Heuristic Phenomenology}

To be a researcher involves asking much of oneself; it requires a determined focus to answer questions that keep one up at night. Often, it is a single question, a single word that enters from the unconscious to the conscious state. This authentic and genuine wanting to know drives every aspect of this progression from the initial question to the finalization of data analysis. After explaining the driving force underlying this study, Chapter 3 continues with a discussion of the principles of phenomenology, the two main figures in the development of phenomenology, my positionality as researcher, the specifics of heuristic research and phenomenology, and my research procedures, data collection, and steps of data analysis.

\section{Wanting to Know}

The process of any journey begins with an initial thought, a personal question, a desire so strong it cannot be deterred, and a question or questions that require the living of its pure experience - its essence. Throughout his life and teachings, Indian philosopher Krishnamurti (1956) discussed this construct that, to live and experience the essence of life, individuals were to live the question. Through this living of the question, the essence and experiences would reveal the inner and external truth. It is in this spirit that I proceed along my research journey. This wanting to know the essence of a phenomenon is the foundation of phenomenology (Creswell \& Poth, 2018; Moran, 2000; Moustakas, 1990, 1994; Phillips-Pula, Strunk, \& Pickler, 2011; Vagle, 2014; Van Manen, 2014). This wanting to know drives the researcher. I wanted to know: (a) what were the life experiences of fathers who have a child on the AS; (b) did the fathers change as a result, and if they changed, how did they change; (c) did community play a role in their lives and (d) what was it like to be a father for two children on the AS. 


\section{The Principles of Phenomenology}

Phenomenology is built on four main principles and foundations: (a) consciousness, (b) intentionality, (c) the context of the individual, and (d) the situation of the individual's experience (Paul, Kleinhammer-Tramil, \& Fowler, 2009; Phillips-Pula et al., 2011; Reiners, 2012). The discourse of phenomenology involves the philosophical, epistemological, and methodological perspectives that attempt to explore and structure an individual's conscious experience (Paul et al., 2009). Consequently, phenomenology is the study of experiences; the focus is on the process of human subjectivity and how human consciousness is understood (Giorgi, 2005; Van Manen, 2014). Furthermore, a phenomenological view holds that knowledge is obtained through the interactions between researcher and participants (Sultan, 2019).

As a result of the interaction and awareness between researcher and participant, transcendental phenomenology uses epoche to retain objectivity. Therefore, a system of epoche, or bracketing, is used by the researcher to separate the researcher's thoughts, feelings, and assumptions from the data compiled from the study's participants (Crotty, 1998; Paul et al., 2009; Phillips-Pula et al., 2011; Vagle, 2014). Throughout my study, I bracketed my thoughts by keeping an electronic journal. This electronic journal was kept password protected on my iPhone in the Notes application and in a Word document on my iMac. I maintained this journal (see examples from my journal in Appendices, A, B, C, D, E, F, and G) throughout each stage of my dissertation study: (a) research, (b) writing, (c) interviewing, (d) data analysis, and (e) the final copy of my dissertation. In my electronic journal I placed my (constructivist understanding) thoughts and feelings regarding each step of my dissertation as my narrative writing served as the process in bracketing. Because of the importance of this concept the next section elaborates this idea in greater detail. 


\section{Bracketing}

Bracketing, originating from mathematics, is a central principal in transcendental phenomenology as described by Edmund Husserl (Hamil \& Sinclair, 2010; Moran, 2000; Van Manen, 2014). Bracketing is an action we strive to accomplish as much as possible because a researcher can never be fully objective. Researchers strive to be objective to create a clear space for research to happen while also critically recognizing their personal experience (Baud \& Anderson, 1998; Creswell \& Poth, 2018; Paul et al., 2009; Phillips-Pula et al., 2011; Sultan, 2017, 2019). Bracketing offers the researcher an additional transparent process of checks and balances and an opportunity to objectify the research findings, therefore, upholding scientific rigor (Creswell \& Poth, 2018; McConnell-Henry \& Chapman, 2009; Moustakas, 1994; Paul et al., 2009; Phillips-Pula et al., 2011).

The steps involved in phenomenological bracketing are similar to mathematics when separating one part of the equation from another, the phenomenon and the researcher (Hamil \& Sinclair, 2010). The use of bracketing offers the researcher opportunities to be: (a) self-aware and self-critical, (b) insightful, (c) wrong, (d) honest and transparent, and (e) add to the researcher's audit trail (Hamil \& Sinclair, 2010). As a result, the researcher uses specific opportunities to record and list suppositions (LeVasseur, 2003), conclusions (Moran, 2000), beliefs (Beech, 1999), opinions (Rose, Beeby, \& Parker, 1995), and personal experiences and knowledge (Beech, 1999). However, experiences could be challenged because the researcher brings their own assumptions to the interpretation of data (Creswell, 2013; Le \& Vasseur, 2003; Moustakas, 1994; Sultan, 2019; Van Manen, 2014). In the $b^{\text {eg }}$ inning of the 20th century, it was Franz Brentano, Edmund Husserl's teacher who brought this form of psychological phenomenology to light (Moustakas, 1994, Van Manen, 2014). 


\section{Brentano and Psychological Phenomenology}

In the early 20th century, a shift from empiricism to phenomenology originated with Franz Brentano (Giorgi, 2005; Moran, 2000; Van Manen, 2014). The emergence of phenomenology evolved as a result of the protest to the positivist paradigm (Reiners, 2012). Roche (1973) discussed Brentano work on the construct of phenomenology in Brentano's book, Psychology from an Empirical Standpoint. Brentano described phenomenology as a purely descriptive process of psychological study and saw consciousness as an activity of the individual (Roche, 1973). In this way, the meaning of the individual's experience remains inside the individual's context (Paul et al., 2009).

Edmund Husserl, a student of Brentano's, continued the shift in phenomenological ideas. Husserl's writing facilitated the shift by describing his idea that the meanings of phenomena could be understood through consciousness (Giorgi, 2005; Moran, 2000; Moustakas, 1994; Van Manen, 2014). As a result of Husserl's change in thinking, he broke away from Brentano. Husserl subsequently expanded and established a system of philosophy that centered on subjective openness and objective knowing called transcendental phenomenology (Moran, 2000; Moustakas, 1994; Phillips-Pula et al., 2011; Reiners, 2012).

\section{Husserl and Transcendental Phenomenology}

Edmund Husserl (1859-1938) was born into a Jewish family and, in 1883, was initially drawn to the fields of physics and astronomy. Husserl is recognized as the father of phenomenology, and his academic lineage can be traced to his teacher Franz Brentano (Farber, 1943; Moran, 2000; Reiners, 2012; Van Manen, 2014). While studying at the University of Vienna, he received his doctorate in mathematics (Moran, 2000; Roche, 1973; Van Manen, 2014). Husserl's study of astronomy and math led to his disillusionment with the natural 
sciences. This was due to the Galilean view that the nature of being could only be understood through mathematics thus circumventing the world of the individual (Heelan, 1987). Husserl was taught in the dominant Cartesian model, which held that the world is unchangeable (Moran, 2000). This teaching led to his disenchantment with mathematics and changed his academic path and led him to study human experiences (McConnell-Henry, Chapman, \& Francis, 2009; Giorgi, 2005; Reiners, 2012; Roche, 1973).

During, this time, Husserl met Franz Brentano, a psychologist and philosopher, and became his student (Van Manen, 2014). Husserl felt disenchanted with the Cartesian model, this feeling prompted a more in-depth searching and development of transcendental phenomenology. Therefore, in his development of transcendental phenomenology, Husserl wanted to reserve an appreciation of objectivity while addressing the essence of human consciousness (McConnellHenry et al., 2009; Moran, 2000; Van Manen, 2014). Husserl's called his branch of phenomenology Zu den Sachen, meaning a return back to things themselves (Van Manen, 2014). Therefore, phenomenology is not the study of the what, but rather, the experience, an event that comes into and appears in an individual's consciousness and inner perceptions (Sultan, 2019; Van Manen, 2014). Phenomenology places the focus on the process of human subjectivity and how human cognizance is understood (Giorgi, 2005; Moustakas, 1994; Reiners, 2012).

Husserl further defined phenomenology as the descriptive process of capturing the essence of an experience without theorizing, explaining, or interpreting (Roche, 1973; Van Manen, 2014). He viewed phenomenology as a demanding human science. Husserl made it a point of wanting to know how consciousness was experienced, believing it was through the individual's experience that consciousness was known to the individual (Giorgi, 2005; Moran, 2000; Van Manen, 2014). Rockmore (2005) stated, "Husserlian phenomenology is 
constructivist” (p. 47). In this manner, Husserl sees the subject as a whole person capable of having an internal and external world (Rockmore, 2005). This world is viewed through conscious intentions. Furthermore, for Husserl nothing existed without consciousness, believing that what was dealt with in the world made its entrance through consciousness (Giorgi, 2005; Moran, 2000; Van Manen, 2014). Phenomenology pays careful attentiveness to the dimensions of the experience itself (Moran, 2000). Husserl's tenets of phenomenology are expanded in the next section.

\section{Tenets of Transcendental Phenomenology}

In large measure, Husserl brought an additional dimension to the qualitative research process through the philosophical tenets of noema, noesis, noetic, and epoche (Moustakas, 1994; Sheean, 2014). Moustakas (1994) connected Husserl's tenets of transcendental phenomenology through his creation of heuristic inquiry. Defined not as a real object, noema is the phenomenon. For example, the wall is not a wall; it is the appearance of the wall and perceived as the experience of the object (Moustakas, 1994; Sheean, 2014). Noesis, defined as the perfect evidence in the acts of feeling, thinking, and recalling, is a way of bringing an individual's conscious state to things and describes something as experience (Moustakas, 1994; Sheean, 2014). Through noesis, the researched phenomenon is experienced and brought to a conscious state. Noetic originates from the noesis, which connects with noema to build the connection between individuals and the world (Moustakas, 1994; Sheean, 2014). Epoche, as previously

mentioned, sets aside the researcher's beliefs and thoughts on the subject of study.

Moustakas (1990) constructed a formal process for heuristic inquiry. He followed Husserl's phenomenological tradition in his use of noema, noesis, noetic, and epoche. It is worth noting there are evolving and contemporary versions of Husserl's approach. For example, Sultan 
(2019) uses a contemporary version of noema, noesis, noetic, and epoche in her application of arts-based methods through the gathering of participant artifacts (e.g., stories, poems, artwork, photographs, letters, and journal reflections). In contrast, Moustakas (1990) constructed a formal process for heuristic inquiry. My dissertation will not include any participant artifacts; therefore, I am following Moustakas's formal process of heuristic inquiry which traces its interpretation back to Husserl.

\section{Transcendental Phenomenology vs. Phenomenology}

With similar roots, there are important distinctions between Husserl's and Moustakas's approaches. First, Husserl's (Douglass \& Moustakas, 1985; Moran, 2000) approach to phenomenology maintains a detachment from the data, whereas heuristics focuses on the connection and the relationship with the data and the participant (Douglass \& Moustakas, 1985; Sultan, 2019). Phenomenological research studies the ordinary phenomena to uncover the real meaning of the event, as it appears with an unbiased looking at the data through detachment (Douglass \& Moustakas, 1985). Phenomenological research is situated in presenting a structured detached presentation of the data and the individual participant is lost in the process. Second, phenomenology has the researcher construct intuitive descriptions (Douglass \& Moustakas, 1985). Third, phenomenological research completes with a condensed data presentation; heuristics synthesizes intuition and implicit knowing. Lastly, the participant is lost in the inner workings of phenomenology, where in heuristic inquiry the participant is written up as a whole individual (Douglass \& Moustakas, 1985; Moustakas, 1990). Table 4 summarizes the different characteristics of these approaches. 
Table 4

Heuristic Phenomenology Versus Phenomenology

\begin{tabular}{|c|c|}
\hline Heuristic Phenomenology & Phenomenology \\
\hline $\begin{array}{l}\text { Focus on the connection and the relationship } \\
\text { with the data and the participant }\end{array}$ & Maintains a detachment from the data \\
\hline $\begin{array}{l}\text { Data are synthesized through intuition and } \\
\text { implicit knowing }\end{array}$ & Condenses data \\
\hline Participant is written up as a whole individual & $\begin{array}{l}\text { Participant is lost in the inner workings of } \\
\text { phenomenology }\end{array}$ \\
\hline
\end{tabular}

\section{Moustakas and the Heuristic Approach}

Life experiences often propel individuals into the most profound aspects of self and the quest for understanding. Moustakas's journey into heuristic research began while he was searching to describe the significant process he was experiencing during his investigation of the human experience of his loneliness (Moustakas, 1990). His encounter with loneliness led him to search for the word that would encompass what he was feeling and into the heuristic approach. Moustakas $(1990,1994)$ first outlined and used the word heuristic in his book, Heuristic Research: Methodology, and Applications. The word heuristic is derived from the Greek word heuriskein, meaning "to discover or to find" (Moustakas, 1990, p. 9). This process is an internal searching for the nature of a phenomenon which the researcher encounters through self-dialogue, self-discovery, self-meaning, and in their thoughts and experiences (Moustakas, 1990, 1995). This flash of discovery is derived from heuristic's cousin word eureka the "aha" moment when discoveries are made, unconscious understandings coming to life from the deep essences of self (Moustakas, 1990, 1994). 
Moustakas's daughter Kerry was in the hospital on a heart ward for young children awaiting her parents' decision on her open-heart surgery (Kenny, 2012; Moustakas, 1994, 1995). During this time, hospital practice was to ban parents, and visiting hours were limited (Moustakas, 1994, 1995). Moustakas and his wife battled the medical staff to stay with their daughter (Moustakas, 1995). By staying with his daughter at the hospital, Moustakas observed deep experiences of loneliness and abandonment in other children whose parents were absent, having left their child according to medical staff orders (Moustakas, 1995). Moustakas faced a life changing decision on his daughter's heart surgery, and during this time he experienced a deep sense of seclusion. Out of his studies of loneliness, Moustakas wrote a series of heuristic books, Loneliness and Love (1972), and The Touch of Loneliness (1975). As a result of his studies, experiences, observations, and writings on loneliness, he developed the heuristic inquiry research process (Moustakas, 1990, 1994, 1995).

\section{Heuristic Inquiry}

Heuristic inquiry research is a multilayered scientific approach used in an effort to know an aspect of life by posing and answering of questions. The researcher is passionate and personally involved in a specific experience (Douglass \& Moustakas, 1985; Moustakas, 1990, 1994). This type of research requires the researcher to take an internal and profound journey through the researcher's self. Heuristic research seeks to discover the essence in meaningful human experiences (Douglass \& Moustakas, 1985; Moustakas, 1990, 1994). It requires the researcher to be subjective, to reflect on the journey of the researcher and the data collected during the study, to dialogue with others, and to explore the chosen phenomenon of autism and fathers who have a child on the AS under investigation (Douglass \& Moustakas, 1985;

Moustakas, 1990, 1994; Vagle, 2014; Van Manen 2014). This inner process is demanding in 
nature. Heuristic research at its very core is pursued through an intimate and authentic immersion in the data that emerges through autobiographical descriptions of the lived experience. This knowledge is acquired through the searching of written descriptions of the experience for example interviews, which results in a methodical discussion between the researcher's and participant's narratives (Douglass \& Moustakas, 1985; Moustakas, 1990, 1994). This multilayered process requires the researcher to live the question, follow hunches, and generate ideas. Then, the researcher enters into a dialogue with others in connection with this specific phenomenon.

\section{Process of Heuristic Inquiry Research}

Heuristic inquiry research methodology encompasses seven processes that serve as a guide for the researcher and for the design of a heuristic study (Douglass \& Moustakas, 1985, 1990, 1994). The researcher: (a) identifies with the focus of the study, (b) engages in selfdialogue, (c) utilizes tacit knowing, (d) utilizes intuition, (e) practices indwelling, (f) engages in focusing, and (g) acknowledges the researcher's internal frame of reference (Douglass \& Moustakas, 1985; Hiles, 2001; Moustakas, 1990). The process of heuristic inquiry is recursive and reiterative and has the researcher engage in this seven-step process as cited by (Sultan, 2019) which is outlined in the following sections.

Researcher identification. To become one with the research and craft research questions and subquestions, the researcher enters into the topic deeply and identifies with the focus of their study (Moustakas, 1990; Sultan, 2019). Subsequently, the researcher becomes one with their topic. Then, a series of questions are addressed: (a) what do I know about the topic? (b) how do I know what I know the information? and (c) what have others written on the topic? (Sultan, 2019). The listed questions provided a path for the beginning of immersion in my study. 
As a result of deep immersion, in the first step, I identified with the focus of inquiry/study through the researching of the literature. I researched and wrote a literature review on autism. Second, I conducted a pilot study in the fall of 2017 with three fathers with children on the AS with an official autism diagnosis. This pilot study provided opportunities to identify and become one with the research question and subquestions that were subsequently created in my dissertation (Hiles, 2001; Moustakas, 1990; Sultan, 2019). This heuristic manner of looking inward provides the researcher an opportunity to connect the next process of heuristic methodology, the process of self-dialogue.

Self-dialogue. Through self-dialogue, the researcher has the opportunity to talk through the phenomenon with written notes and journal entries which is an integral process in heuristic methodology (Hiles, 2001; Moustakas, 1990; Sultan, 2019). Through this process, the researcher connects with the phenomenon and engages in discovery, stimulating the researcher's curiosity and providing for attunement, trust, and receptivity (Sultan, 2019). Therefore, through selfdialogue, the researcher can understand the research in greater depth. The essential purpose of self-dialoguing is to have a holistic understanding of the phenomenon. This was accomplished through the following steps: (a) I kept an electronic researcher's journal, and (b) in this journal, I maintained a record of my self-dialogue, dreams, thoughts, and my self-reflections which are all considered core aspects in heuristic research (Moustakas, 1990, 1994; Sultan, 2019). I wrote in my electronic journal each week from July 2019 to October 2019, for a total of 122 double spaced pages in my journal including 30 narrative poems written in Notes on my iPhone. In my researcher's journal, I learned and had an opportunity to separate my own thoughts and projections upon the data (see Appendix A). Poetry also afforded me space to place my unconscious thoughts on paper and see what I was thinking and feeling (see Appendix B). 
Tacit knowing. Tacit knowing is the very basis of heuristic research, according to Moustakas (1990). The core concept of tacit knowing involves the area of the unknown and the holistic experience of the researcher (Hiles, 2001; Moustakas, 1990; Sultan, 2019). The use of a research journal is a tool for collecting tacit experiences. Tacit knowing is the personal experience of the phenomenon, which I as researcher, understand at a deep level from my past and present experiences of the phenomenon of autism (Hiles, 2001; Moustakas, 1990; Sultan, 2019). I drew upon my tacit knowing from my experiences exploring the writing of my master's thesis, research on autism conducted by my university's Thompson Policy Institute for Disability and Autism, and the grounded theory pilot study I conducted with fathers of children on the AS in the fall of 2017.

Tacit knowing is undetermined (i.e., a knowing in which we know more than we can tell, a knowing that occurs beyond our words) and has the potential to guide the researcher in unconscious ways of understanding and meaning. This area of tacit knowing is "highly subliminally known, or the unknown known, dimensions of the experience" (Sultan, 2019, p. 87). Tacit knowing is implicit and occurred through: (a) my own experiences of being a woman on the AS, (b) my knowledge as a graduate research assistant in the field of autism, (c) researching autism, and (d) reading on this topic. Tacit knowing is additionally a part of the subconscious; however, a trusting of self is required as the experiences are tacit and implicit through the researcher's past and present experiences (Sultan, 2019). In this manner, tacit knowing offers the researcher a process to evaluate their experiences, this was accomplished through written reflection in my researcher's journal (see Appendix C). This significant tacit knowing is implicit and is represented in what we do or think and underscores intuition. The core 
process of tacit knowing encompasses, operates, and precedes intuition (Moustakas, 1990; Sultan, 2019).

Intuition. My intuition facilitated through writing in my research journal. I then compared my intuitive thoughts with the data from my participants' interviews. I knew my intuition was at work when my participants' words were consistent with my intuitive thoughts. I immediately knew something was genuine when my thoughts were true, as Moustakas (1990) described intuition as "the bridge between the explicit and the tacit" (p. 23) and "the realm of the between" (p. 23). Through the integration of my intuition and interaction with the data, I knew my intuition was at work and accurate (Sultan, 2019). Moustakas (1990) further described intuition, "As I come to know this thing before me, I also come to know myself as the being who intuits, reflects, judges, and understands" (p. 32). Being a woman also on the AS, offered me the ability to connect pieces of my intuition, combined with a reflection of the data that others may not have seen. Intuition serves as an internal guide for the researcher. My researcher's journal illustrates how I engaged in moments of quiet time (see Appendix D). This silence provided an opportunity to listen to my intuition as I dove deeper into the data and the experiences of the fathers.

It is through intuition that individuals become whole and integrated (Hiles, 2001; Moustakas, 1990; Sultan, 2019). The researcher is internally guided through their intuition process as knowledge is integrated across experiences, and in the case of this dissertation as inner explicit knowledge and experience of autism connects with literature, and as continuing themes and patterns begin (Sultan, 2019). The researcher is internally guided through their intuition process as knowledge is integrated across experiences, as inner explicit knowledge and experience of autism connects with literature, and as continuing themes and patterns begin 
(Sultan, 2019). The steps of my intuition encompassed: (a) I listened to my hunches, (b) examined the data as a whole, (c) connected with the literature, (d) connected with my own experiences on the AS, and (e) continued to read the notes taken in my researcher's journal. As a result, I am connected in the world of the between, the world that is contained in my intuition (Hiles, 2001; Moustakas, 1990; Sultan, 2019). The outcomes of this process revealed meanings and added to my knowledge base as intuition makes this possible, and I am therefore connected in the world to perceive things as a whole (Moustakas, 1990).

Indwelling. During the core process of indwelling, the researcher turns inward and seeks a more profound and greater understanding of the themes of human experience (Hiles, 2001; Moustakas, 1990; Sultan, 2019). Mystic Thomas Merton (1979) suggested research practices could be, in their fundamental design, contemplative. During indwelling, I adapted the sixthcentury Benedictian practice of contemplative meditation known as lectio divina (Allan, 2015; Casey, 1996; Dalton, 2018; Flanagan, 2014; Kelly, 2019). The historical four-step practice of lectio divina includes: (a) reading of the text (lectio), (b) a practice of reflection (meditation), (c) seeking counsel (oratio), and (d) contemplation (Allan, 2015; Casey, 1996; Dalton, 2018; Flanagan, 2014; Kelly, 2019).

The practice of indwelling is highly focused, requires patience, and is essential in conducting heuristic research. Indwelling is the researcher's result looking upon the phenomena through the researcher's experiences (i.e., mental, emotional, and spiritual). Using the adapted practice of lectio divina meditation during indwelling provides for an in-depth utilization and is nonjudgmental (Kabat-Zinn, 1982; Lutz, Jha, Dunne, \& Saron, 2015). Indwelling was accomplished through the use and practice of lectio divina (see Appendix $\mathrm{H}$ for an example of listed days and times). I used the method of lectio divina. 
The detailed exercise of lectio divina meditation served as a pragmatic function during indwelling, providing an avenue to pay attention to the significant statements. This was accomplished through a series of steps. First, I read and reread each of the 30 participant interviews. I chose five significant statements from each interview from the 2,155 total significant statements. I read and reread through each of the significant statements from each of the fathers a total of 5 times. This equaled a total of 50 significant statements I reflect deeply upon through the practice of lectio divina. Each of those five significant statements represented the overarching data collected during their three separate interviews. Second, the practice of lectio divina facilitated my more in-depth understanding of the selecting of 5 significant statements as I read and reread the text chosen. Third, I reflected in the quiet silence provided through the use of this meditative process. In the fourth step, I sought out my dissertation chair and committee members in seeking counsel while I contemplated the fathers' experiences of having a child the AS. I dialogued with my dissertation chair and two of the three committee members after my period of meditative reflection for each of the five significant statements. I spent fifteen minutes per significant statement. This equaled a total of 750 minutes, equaling 12.5 hours spent during my practice of lectio divina. Fifth, I entered into contemplation by focusing on Sultan's (2019) process of interacting with the data on cognitive, emotional, sensory-kinesthetic, perceptual, spiritual, and social-relational levels. Lastly, I recorded my insights into a narrative in my electronic research journal.

This process of interacting with the data was accomplished through the practice of lectio divina, writing in my research journal, and listening to my inner voice. The tradition of lectio divina gives a consistency to the reading of the participants' texts while honoring and respecting the integrity of each participant's unique voice and experience (Allan, 2015; Casey, 1996; 
Dalton, 2018; Flanagan, 2014; Kelly, 2019). This tradition is rich in intellect and consciousness, which combine to produce a deeper rereading of participant narratives. Through the deliberate and focused rereading of the participants' words in lectio divina, the researcher has a greater opportunity to connect during indwelling (Allan, 2015; Casey, 1996; Dalton, 2018; Flanagan, 2014; Kelly, 2019). Using lectio divina offers a pre-established schema (i.e., included my processing of the details and my thoughts and feelings after each interview in my research journal) to each of the five chosen significant statements that were highlighted and were the subject of reflection by the researcher (see Appendix E). The result of indwelling and the specific practice of lectio divina brings a deliberate, reflective, and critical approach, carrying the researcher into the process of focusing (Hiles, 2001; Moustakas, 1990; Sultan, 2019).

\section{Focusing}

Focusing is an open process that requires patience and persistence from the researcher (Sultan, 2019). During this time, the researcher returns to the verbatim transcripts allowing for the researcher to have a clear mind. The use of focus allows the researcher to then enter into their own internal frame of reference.

Internal frame of reference. The researcher's internal frame of reference is the concluding step in the seven processes of heuristic inquiry and the outcome of the heuristic process. This internal frame of reference is reflected in the writing of my subjectivity statement. The researcher's knowledge of the topic is a result of participant interviews, the researcher's tacit knowing, intuition, indwelling and the observation of the phenomenon. Here, the participant's experiences are examined because of a direct connection with the participant. This process is facilitated through the creation of internal trust and respect for the data, as a result of the researcher's continual cycle of returning to self while also seeking a deeper understanding of the 
researchers "perceptions, feelings, thoughts, decisions, and actions" (Sultan, 2019, p. 92). The researcher can now place the research context into her inner frame of reference (Hiles, 2001; Moustakas, 1990) as, I have done with my subjectivity statement, which additionally provided a space to include my internal frame of reference and assist while the indwelling was occurring. Engaging in these seven core processes as outlined by Moustakas and Sultan prepared me and guided me in designing the six phases of heuristic inquiry.

\section{Six Phases of Heuristic Research}

Heuristic inquiry is made up of six phases: (a) initial engagement, (b) immersion, (c) incubation, (d) illumination, (e) explication, and (f) creative synthesis (Douglass \& Moustakas, 1985; Kenny, 2012; Moustakas, 1990, 1994; Sultan, 2019; West, 2001). These six phases draw the researcher into higher states of understanding and focus and are recursive and reiterative throughout the process of heuristic inquiry.

\section{Initial Engagement}

Initial engagement is the first connection with the topic of fathers' experiences with a child on the autism spectrum (AS). I began a process of inner dialogue thinking about my research interests (Kenny, 2012; Sultan, 2019; West, 2001). This was followed with the writing of my research questions. This phase was autobiographical as I engaged in the inner search of the topic while thinking about the question: What is the human experience (Moustakas, 1990, 1994; Sultan, 2019)? A disciplined inner dialogue, combined with an intense engagement, led to the development of a research question followed by the writing of a literature review (Moustakas, 1990, 1994; Sultan, 2019). The research question was informed by the researcher's inner dialogue and engagement. As a result of the initial phase of the engagement, I was ready to begin, the second phase of immersion. 


\section{Immersion}

In the immersion phase, the researcher lives the question on all levels of her being, including the subconscious and conscious levels of being and existing (Moustakas, 1990, 1994; Sultan, 2019; West, 2001). First, during immersion, I read and reread my data. (Data collection methods are described in the next section.) Data were collected from early July 2019 through October 2019. Throughout this period in time, I considered possible opportunities (i.e., possible themes, and analysis) regarding the phenomenon. Across this phase, as with the initial engagement phase, I engaged in and continued the process of self-dialogue and self-searching (Douglass \& Moustakas, 1985; Moustakas, 1990, 1994; Sultan, 2019). Second, while in the immersion phase, I used bracketing in my electronic journal (for an example of bracketing see Appendix F), as a means of keeping my thoughts separate from the transcripts of my participants (Douglass \& Moustakas, 1985; Moustakas, 1990, 1994; Sultan, 2019).

Listening to one's intuition plays a critical role as the study continued. Third, I listened to my intuition as it played a critical role when I began to explore the research questions and sub questions (Douglass \& Moustakas, 1985; Moustakas, 1990, 1994; Sultan, 2019). Moustakas (1990) wrote that the researcher stays aware of all the possibilities of data interpretation while maintaining a continual focus. Here, themes emerge and surface as the researcher is immersed in the data. This is a tacit dimension of being where greater states of intuition and inference may occur (Douglass \& Moustakas, 1985; Moustakas, 1990; Sultan, 2019). Finally, in the tacit dimension, inner states of focus and self-dialogue are centered upon as I turned inward in immersion (Douglass \& Moustakas, 1985; Moustakas, 1990; Sultan, 2019). 


\section{Incubation}

The incubation phase draws the researcher away from intense inner focus. This is the phase of stepping away from (Moustakas, 1990, 1994; Sultan, 2019). Retreating allows the tacit dimension and intuition opportunities to become transparent and more refined as greater understanding occurs (Hiles, 2001; Kenny, 2012; Moustakas, 1990; Sultan, 2019). The incubation phase provides the researcher an opportunity for silence while intuition continues to happen at an unconscious level. In this phase, the researcher takes a break from active thinking and passes through a process of letting things be-a letting go. The researcher knows this phase is complete when clarity occurs (Moustakas, 1990; Sultan, 2019). This is achieved as the researcher steps aside from the literature and data and engages in activities other than the research (Moustakas, 1990; Sultan, 2019). In pragmatic terms, it is the place of "sleeping on it" and "letting it be" (Sultan, 2019, p. 96). During incubation, I stepped away from the data, including the recorded and transcribed interviews. I entered into a place of silence, in the quiet of the silence, I allowed the data to incubate. The stepping away provided a space for my mind to unconsciously process recorded and transcribed interviews and write in my research journal. I arrived at clarity when my mind began the process of illumination.

\section{Illumination}

After initial engagement with the data, immersion, and incubation occurs, and the researcher experiences a breakthrough, an illumination (Moustakas, 1990; Sultan, 2019). In this phase, I read and reread the fathers' interview transcripts. I also listened once again to as audio recordings before transcription. Since each of the fathers was interviewed on three separate occasions, there were a total of 30 interview transcripts. I also read and reread the 122 pages of my research journal. The rereading of transcripts, the listening of the audio recordings, and the 
rereading of my researcher's journal offered an emerging window for aha moments (Sultan, 2019). As I read, I paid close attention to any of my thoughts and feelings utilizing bracketing (Douglass \& Moustakas, 1985; Moustakas, 1990, 1994; Sultan, 2019). This resulted in new and deeper understanding of the data through my emotional, intellectual, and spiritual understanding. My emotional understanding resulted after the fathers' interviews were recorded in my researcher's journal and in discussions with my dissertation chair. My intellectual understanding occurred through the reading and rereading of the literature combined with writing in my researcher's journal. My spiritual knowledge resulted from discussions with my reverend in which we discussed the impact the 10 fathers had on my life and the instances of transference when it occurred. My reverend kept our conversations in what she called reverend silence. The key to this phase is the receptiveness of the researcher to tacit knowing, as illumination opens new passageways and knowledge becomes synthesized (Hiles, 2001; Kenny, 2012; Moustakas, 1994; Sultan, 2019). As a result of illumination, a mental, emotional, or spiritual door opens; the researcher's unconscious connects with the mind's conscious state (Moustakas, 1990; Sultan, 2019). At this juncture, when new doors open, moments of prior confusion become clear, the moments of illumination. For example, in one such illuminating instant I realized how much pain a father experienced after our interview ended. I would sometimes cry as I felt a father's pain in describing difficult emotions such as stigma. This experience arrived due to my connection with the father. Sultan (2019) stated, "Discovery takes place in moments of elucidation as the researcher awakens to new, previously unrevealed dimension of the experience" (p. 97). As illumination coalesces, the next phase of explication begins to occur naturally. 


\section{Explication}

After the researcher has passed through the previous phases, explication ensues. The researcher examines all that has occurred through indwelling, focusing (Hiles, 2001; Kenny, 2012; Moustakas, 1990; Sultan, 2019; West, 2001). In this phase, dialogue was conducted with my dissertation chair and another committee member who served as my methodologist on emerging themes that resulted from each round of coding the data. Data was coded in a series of rounds beginning with: (a) a total of 2,155 significant statements pulled from each of the three separate interviews of the fathers, (b) abbreviated statements, (c) followed by detailed abbreviated statements, and (d) the final round of data coding resulted in the formation of categories (see Appendix I). This is the state of awakened unconscious and consciousness. At this point, I began to look at the emerging themes, examined the data, and tested out the layers of meaning, as dominant themes presented (Hiles 2001; Moustakas, 1990; Sultan, 2019; West, 2001). During explication I used bracketing again, giving space for the participants' words to walk me into creative synthesis, the final phase in heuristic inquiry (see Appendix $\mathrm{F}$ from an example of bracketing in explication; Douglass \& Moustakas, 1985; Moustakas, 1990, 1994; Sultan, 2019).

\section{Creative Synthesis}

The researcher enters into the phase of creative synthesis when all the data are familiar and when the themes and the meaning of details are understood as a whole (Kenny, 2012; Moustakas, 1994; Sultan, 2019; West, 2001). In this phase, the researcher explains "the what and how of the phenomenon," through the gathering of all data and generated themes, (Sultan, 2019, p. 154). In creative synthesis, the researcher draws upon: (a) deep descriptions of the participants' narratives, (b) their experiences with them, (c) the seven core processes, and (d) the 
six phases of heuristic inquiry (Douglass \& Moustakas, 1985; Kenny, 2012; Moustakas, 1990, 1994; Sultan, 2019; West, 2001). The researcher asks: Have I reached a place of data saturation? This is the place famed anthropologist Clifford Geertz called, "'turtles all the way down" (Geertz, 1973; p. 29). Geertz (1973) told an Indian story, which metaphorically connects with this deep method of researching and knowing:

about an Englishman who, having been told that the world rested on a platform which rested on the back of an elephant which rested in turn on the back of a turtle, asked (perhaps he was an ethnographer; it is the way they behave), what did the turtle rest on?

Another turtle. And that turtle? ah, Sahib, after that it is turtles all the way down. (pp. 2829)

During this process, I asked myself, "Have I dug deep enough into the essence of the specific phenomenon (i.e., fathers who have a child/young adult with an official AS diagnosis)?" I can only answer the question as the researcher. Have I explored this phenomenon while looking deeply inside of myself? Have I interacted with the data, filled pages with deep descriptions, written pages of thoughts and feelings in my researcher's journal, and immersed myself in the process with a passionate disciplined search? Only I can answer the question of whether it is truly "turtles all the way down." This can only be answered through the researcher's inner awareness and subjectivity as the seven core processes and the six phases of heuristic inquiry continue to be in the researcher's conscious state (Douglass \& Moustakas, 1985; Kenny, 2012; Moustakas, 1990, 1994; Sultan, 2019; West, 2001). To answer this research question, I ensured that I interacted with the data by reading and rereading the fathers' interviews, I used my electronic journal to fill 122 pages of deep descriptions about the fathers throughout the interview process. In the same journal, I captured my thoughts and feelings about these fathers' 
words through self-dialogue (see Appendix G for an example). I explored my inner frame of reference in writing my subjectivity.

During this final phase, the researcher draws inward into meditation and embraces a state of silence before the data are written. While the process of data writing for Moustakas (1990, 1994) can entail the use of poetry, storytelling, and drawings, in my dissertation the creative synthesis for this study was the writing of the 10 fathers' descriptions and narratives. This last phase encompasses the researcher's deep understanding of the data and is represented in the narratives of each of the participants in creative synthesis.

\section{Research Methods}

My dissertation study used heuristic research methods and procedures. The research procedures governing the study included the following: a series of interviews, a verbatim transcription of the transcripts, and the six steps in a heuristic analysis of the data. The interview procedure used Seidman's $(1998,2013)$ in-depth, modified three interview processes. This process entailed a focused life history (first interview), the establishment of concrete details (second interview), and the reflection on the meaning of their experiences as a fathers of a child diagnosed with AS (third interview). In other words, the participants looked at life factors that brought them to the present situation (Seidman, 1998). The next section begins by describing the audit trail, how it connects to the six phases of heuristic research, its inclusion in my research journal, and notes from meetings with my dissertation committee members.

\section{Audit Trail}

A common practice in conducting qualitative research is the keeping of an audit trail (Creswell \& Poth, 2018; Lincoln \& Guba, 1985). An audit trail allows the researcher to retrace the process employed throughout the study and details how the researcher arrived at their 
findings. In this study the audit trail connects to each of the six phases of heuristic research. My audit trail included: my researcher's electronic journal, the writing of poetry, email correspondence with participants, audio-recorded interviews, participants' transcripts, dialogues with dissertation committee members, significant statement documents, transcripts, analysis documents, codebook, and my high-level synopsis (Creswell \& Poth, 2018; Lincoln \& Guba, 1985; Sultan, 2019).

In the initial engagement phase, the audit trail was illustrated by the writing of my research questions and followed with the writing of my literature review (Creswell \& Poth, 2018; Lincoln \& Guba, 1985). In the immersion phase, I read and reread my data from my research journal, which included the poems I had written and the transcripts from the fathers' three separate interviews (Sultan, 2019). The writing of poetry was a part of the audit trail and the narratives I wrote in my journal. The combined participant narrative descriptions and the writing of poetry entered into this step (Sultan, 2019). In the illumination phase, I wrote this poem.

\section{Sometimes}

Sometimes when the house grows dark, And the thoughts of the day, Are laid to rest.

The earth and I breathe a quiet sigh. With thoughts swirling about my mind, And fears I say, "please subside" I reflect.

The night brings a silence, The day cannot offer.

This slice of the clock's hour, Its own impermanence.

Illumination occurs. This time is sacred. A time for honor. And sometimes a time for tears, The father's words, Come alive in a different way, Separated out, from long transcribed pages, 
They are so much more alive.

I feel their falling presence,

Set upon my face,

And the responsibility of honoring,

Theses 10 fathers' words.

For it is their stories,

Who make the work possible.

During the intuition process, I corresponded with my participants through email, and dialogued with my dissertation committee members (Creswell \& Poth, 2018; Lincoln \& Guba, 1985; Sultan, 2019). Next, in the incubation phase, I stepped away from the data and made a note of this in my researcher's journal. Followed by the illumination phase, the audit trail is represented by my reading and rereading of my 30 interview transcripts. The audit trail is also represented and documented in my research journal. Explication in the audit trail is represented by the communication (e.g., meeting with my dissertation chair and committee members) and the writing in my researcher's journal. Lastly, creative synthesis was represented by: (a) the writing and drawing upon the writing of the fathers' deep descriptions and the applying of the seven core processes and six phases of heuristic inquiry (Sultan, 2019).

\section{Participants}

My heuristic phenomenological study included fathers who have a child with an official AS diagnosis. As noted in Chapter 1, an official AS diagnosis, outlined by the DSM-5 manual as a lifelong neuro-developmental disorder depicted through distinct behaviors, is indicated by "severe and pervasive impairments in several areas of development that can include: reciprocal social interaction skills, communication skills, or the presence of stereotyped behavior, interests, and activities" (American Psychiatric Association, 2015, p. 69). Fathers were selected as participants due to the growing rates of autism and the minimal research on fathers and their experiences of raising a child on the AS (Burrell et al., 2017; Cheuk \& Lashewicz, 2016; Flippin 
\& Crais, 2011; Fyre, 2016; Hannon \& Hannon, 2017; Hornby, 1992). The selection criteria included: (a) biological fathers 18 years old or older, (b) children of any age, (c) fathers and children of any racial background, and (d) the father's child could be a girl, boy, or a transgender child. The total number of participants included 10 biological fathers who had one or more children with an official AS diagnosis.

\section{Participant Recruitment}

Participants were recruited through the researcher's professional connections at three different institutions. This network included two autism research centers in southern California and a university in California. Participants were recruited through the researcher's professional connections. The specific sampling method included making initial contacts through these three institutions and then snowballing occurred. Potential participants were asked to respond to an email invitation within two weeks and to return the signed consent form if they agreed to participate in the study (see Appendix J).

\section{Informed Consent}

Once I determined participants, I arranged to meet in person with three of the 10 fathers at a location of their choosing (e.g., coffee shop, and their home) the remaining seven were interviewed over the phone, two of the fathers lived out of state and the remaining five wanted phone interviews due to their schedules. I handed three of my participants an informed consent paper to read and sign. Seven of the participants were emailed their consent forms and returned them with an electronic signature. This form included the purpose of my study, the procedures in the study, the minimal risks and potential benefits of the study, the provisions for participant confidentiality, the storage of personal information along with data retention periods and access to study data, and a section for the participants to agree to participate. The study and informed 
consent had been approved through the institution's Institutional Review Board (see Appendix K). Next, I will discuss the demographics of the fathers who participated in the study and their children.

\section{Fathers' Children's Autism Demographics}

This section describes the fathers' children and their demographics. The demographic data was captured in an email that had a list of demographic questions that was sent out prior to the fathers' first interview. The decision to gather demographic information through an email was made to capture initial information prior to the first interview which allowed the researcher a longer period of time in the first interview to ask questions. In addition, by collecting demographic data prior to the fathers' first interview it offered the researcher an opportunity to begin to establish rapport and connect with the fathers. I also wanted to be respectful of the fathers' time they were going to be spending with me during the three interviews, so gathering demographic data through an email seemed to be an efficient way to obtain this information.

Table 5 outlines the fathers' demographic information. The table includes participants' pseudonym, ethnicity, home state, occupation, education level, and marital status. Eight of the 10 fathers self-identified as Caucasian, one self-identified as Mexican/Latino and the last father selfidentified as an African American. The fathers had a range of occupations ranging from school administrators to businesses executives and others working in the insurance industry. One father declined to mention his occupation. Eight of the 10 participants were from southern California; one participant was from Utah and one participant was from Illinois. Five of the fathers had a master's degree, one father had training in the military, two fathers stated they had some college and on them also had vocational training, another father was currently working on his Master of 
Arts., of the 10 fathers, eight were currently married, one was divorced, and another was currently separated from his wife.

Table 5

Fathers' Demographics

\begin{tabular}{|c|c|c|c|c|c|c|}
\hline Name & Age & Ethnicity & $\begin{array}{l}\text { Home } \\
\text { State }\end{array}$ & Occupation & Education Level & Marital Status \\
\hline William & 69 & Caucasian & IL & $\begin{array}{l}\text { Former VP Major } \\
\text { Fortune } 500 \text { Company }\end{array}$ & MBA & Married \\
\hline Gabriel & 43 & Caucasian & $\mathrm{CA}$ & $\begin{array}{l}\text { High School English } \\
\text { Teacher/ } \\
\text { Administrator }\end{array}$ & $\begin{array}{l}\text { Master's in } \\
\text { education: Gen ED }\end{array}$ & $\begin{array}{l}\text { Divorced from } \\
\text { children's } \\
\text { mother. } \\
\text { Remarried }\end{array}$ \\
\hline Mark & 37 & Caucasian & CA & $\begin{array}{l}\text { Facilities Manager at a } \\
\text { University in CA }\end{array}$ & $\begin{array}{l}\text { Prior Military, } \\
\text { "conventionally } \\
\text { uneducated" }\end{array}$ & Married \\
\hline John & 53 & Caucasian & CA & $\begin{array}{l}\text { Vice President of } \\
\text { Personal Property } \\
\text { Insurance Company }\end{array}$ & Bachelor's & Married \\
\hline Scott & 60 & Caucasian & UT & Real Estate Developer & MBA & Divorced \\
\hline Anthony & 43 & $\begin{array}{l}\text { Mexican/ } \\
\text { Latino }\end{array}$ & $\mathrm{CA}$ & Declined to State & $\begin{array}{l}\text { Some College, } \\
\text { Vocational } \\
\text { Training }\end{array}$ & Married \\
\hline Wilson & 54 & Caucasian & $\mathrm{CA}$ & $\begin{array}{l}\text { Environmental } \\
\text { Insurance }\end{array}$ & Some College & Married \\
\hline David & 60 & $\begin{array}{l}\text { African } \\
\text { American }\end{array}$ & CA & School Administrator & Master's, MFT & Married \\
\hline Paul & 59 & Caucasian & CA & Screen Writer & $\begin{array}{l}\text { Working on MA in } \\
\text { Screen Writing }\end{array}$ & Separated \\
\hline James & 37 & Caucasian & CA & Engineer & MBA & Married \\
\hline
\end{tabular}

Table 6 illustrates information regarding the fathers (pseudonym), gender and age of their child, the age of each child's AS diagnosis, the specific diagnosis given to the child, and the age at which each child was diagnosed. Three of the fathers, Gabriel, Mark, and Wilson, have two children on the AS. In addition to having a child with AS, some fathers had multiple children in the family who were not on the AS. William has two daughters not on the AS along with his son who is on the AS. John has a son and a daughter not on AS and a son on the AS. Scott has a 
daughter not on the AS and a son on the AS. Anthony is a father to a son on the AS but also has a daughter not on the AS. David's only son is on the AS. Paul has four kids not on the AS and one son on the AS, and James has two children not the on AS and one son on the AS.

Table 6

Fathers' Children's Autism Demographics

\begin{tabular}{|c|c|c|}
\hline Father's Name & Child's Current Age & $\begin{array}{l}\text { Age of Child's AS Diagnosis, Label of Diagnosis, } \\
\text { and Year of Diagnosis }\end{array}$ \\
\hline William & Son, 32 & $\begin{array}{l}3 \text { years old, PPD (Pervasive Developmental } \\
\text { Disorder; 1991) }\end{array}$ \\
\hline \multirow[t]{2}{*}{ Gabriel } & Son, 14 & $\begin{array}{l}16 \text { months, Severe Autism, Intellectual Disability, } \\
\text { and Severe ADHD (2006) }\end{array}$ \\
\hline & $\begin{array}{l}\text { Daughter, } 17 \text { (functions at } 8 \text {-year-old } \\
\text { level) }\end{array}$ & 3 years old, ASD (2005) \\
\hline \multirow[t]{2}{*}{ Mark } & Son, 9 & 5 years old, ASD, ADHD (2015) \\
\hline & Daughter, 7 (functioning at age 4) & $\begin{array}{l}5 \text { years old ASD, } 15 \mathrm{q} 13.3 \text { chromosomal micro- } \\
\text { deletion, epilepsy (2017) }\end{array}$ \\
\hline John & Son, 24 & 3 1⁄2 years old, Severe Autism (1998) \\
\hline Scott & $\begin{array}{l}\text { Son, } 21 \text { (functions at below } \\
\text { chronological age) }\end{array}$ & 3 years old, Very Severe Autism (2001) \\
\hline Anthony & Son, 13 & 3 years old, Autistic Mild/Moderate, Dyslexia \\
\hline \multirow[t]{2}{*}{ Wilson } & Daughter, 29 (functions at teen age) & More Severe Autism \\
\hline & Son, 27 & 4 years old, Autism, Severe ADHD (1996) \\
\hline David & Son, 14 & $\begin{array}{l}3 \text { years old, Autism Spectrum-High Functioning } \\
\text { (2008). }\end{array}$ \\
\hline Paul & Son, 21 & 2 years old, Severe AS, Auditory disability (1998) \\
\hline James & Son, 7 & $\begin{array}{l}21 / 2 \text { years old initially diagnosed PPS/NOS under } \\
\text { DSM-IV, then became Autism Spectrum under } \\
\text { DSM-5 (2015). Later son was diagnosed with } \\
\text { Dyslexia (date not given) }\end{array}$ \\
\hline
\end{tabular}

\section{Descriptions of Fathers}

Before writing descriptions of the 10 fathers, I revisited each of their three interview transcripts and reread a total of 830 transcribed interview pages to construct each of their narratives. In addition, I reread the notes in my electronic research journal. For each father, I 
chose a quote from one of their interviews representing one aspect of their character. There are 10 fathers and 10 descriptions of men whose passages into the world of autism changed and impacted their lives and identities. They are men of strength and deep feelings. To describe each man is a testament to honor their unique personalities as fathers and their journeys as men.

William. William was easy to talk with and his regional accent shined throughout our conversations. His early character formation was shaped by the two years he spent in the Peace Corps. While abroad, William lived with a farmer who played chess with him. William practiced and practiced. One day, while they were playing, the farmer told him, 'I've noticed that you're getting better, and you're very thoughtful about your moves, and you're planning them out. But you're forgetting one thing." "So, what's that?" William asked. The farmer replied, "There are two people playing this game." That statement, he claimed, was one of the wisest things he had ever heard in his life. His life's journey is a two-way relationship, meaning we are not alone in the relationship we have with one another. William then described the specific lessons he realized regarding autism. He learned three lessons from autism: (a) the things in life one cannot control, (b) the gift of patience, and (c) the awareness of his role as a father.

William holds the belief that autism is another evolution in the brain. He is a father whose son continues to surprise him. He was told his son would never drive, yet today not only does his son drive, but he also holds down a full-time job. William continues to believe in the capacity of his son's growth. With the support of his wife and their strong marriage, he walks through the passages of their son's autism. He is a father who admitted his fathering doubts and could articulate the lessons learned under the umbrella called autism.

Gabriel. Gabriel is the father of two children on the AS. The trials of autism impacted his marriage. Those challenges included how to raise their children. As a result of child-rearing 
differences along with the impact of having a child with autism, their marriage ended in divorce, Gabriel has since remarried to another woman who is in the autism field. His son's severe and nonverbal autism, intellectual disability, and severe ADHD impact each moment of his son's life from the day's beginning until the day's end. Gabriel shared how he, "at times, hates autism and the impact on his son." Gabriel also has a daughter whose chronological age is 17 , yet her mental age is that of a younger child. One of Gabriel's greatest fears is what could happen to his son when a prone restraint needs to be used to restrain him due to his behavioral challenges. He lives for the quiet moments with his children, such as taking a walk-in nature where his son and daughter can be themselves away from public eyes, stares, and the comments that are not always kind. Gabriel is a coach in a local sports league for kids with disabilities where he guides and mentors youth. He shares this coaching space only with his daughter, as his son's autism is too severe for him to participate in the local sports league. He hopes for the existence of a heaven so, "one day when I die, when we all die, I would love to meet my kids without autism and really see who they are."

Mark. Mark is a father of two children on the AS, a boy and a girl. Being a father for him, is to be of service and be the provider for his children and his wife. Memories of boat rides with his son and quiet moments connecting with his daughter playing with walkie talkies brought a smile to his face when he spoke of his children. It is in the moments of solace sought and solace found that Mark recharges his batteries and finds peace in being a father and husband. In strength, he raises the metaphorical white flag, signaling to his wife he requires a much-needed time out. Being a father to two kids on the AS often produces challenges. He shared a moment of joy he had recently experienced as a father. His work schedule changed and afforded him the opportunity to see his kids off to school. He "got hugs and kisses from everybody 'cause I don't 
normally get to see them off in the morning 'cause I'm gone well before they're even awake." Mark faces the challenges that autism brings him and his children with a fierce determination, that each day is another day to learn how to be a better father.

John. John is a soft-spoken man who sees his son with severe autism from the perspective that God sees him, that is, perfect and complete. He is a man of faith, a faith that sustained him through difficult times of uncertainty and doubt. John shared his feelings regarding his faith and how it impacts the view he holds of his son commenting, "He has a very special place in God's eyes, the Bible says he does." He continued sharing about his belief in heaven, and how his child is going to live eternally. John also imagines a different way of someday communicating with his son and "thought about what kind of conversations I'd have with him. I mean in heaven." The stable marriage he and his wife have continues to sustain him through the difficult times. Having a child on the AS changed the dreams he had, along with the plans he and his wife had made. Out of the trials of autism, his faith continues to sustain the relationship he has with himself, his wife, and his three children. His journey is ever continuing.

Scott. Scott is the father to a son with severe autism and meets each of his son's challenges like a warrior going into battle. He stated 'it's hard when you're, you know, when he was 4 or 5 and he's trying to kill me. I'm bleeding cause he bit a chunk out of my arms. It's hard not get mad and yell at him." His son's severe autism challenges both him and his son during the times they are together. Scott shares custody of his son with his ex-wife, for autism often brings many challenges to a relationship and, for him, divorce. Scott finds wonder in his son's ability to completely mess up their television, changing the language to French and turning the picture upside-down. There are challenging moments in which Scott has to take care of his adult son's most basic needs as his son is unable to do so independently. Then there are the moments that 
breakthrough his frustration and fears when he has a connection with his son. While getting his son ready for school in the morning, "he sits on my lap...So he sticks his arm out, and I scratch, I scratch his arm with my chin for 10 minutes and he loved it. You know, it's a connection." This moment of connection was wrapped inside the challenges and the triumphs.

Anthony. To be a father to a son on the AS is to feel pain, pain when Anthony's son told him he was sexually bullied at school. His son, "felt suicidal at one time for one year. It was hard for me. Trust me. It was hard." His son had withheld that information from his parents for three months. A father's strength is not a measurement of endurance but a strength found within self during difficult times. Anthony is ever-present, modeling to his son how to become the best person he can be. His son may have challenges, but father and son meet those challenges together as both continue learning the road map of autism, as it is filled with twists and turns, disappointments, and triumphs.

Wilson. Wilson is a father to two children on the AS. His daughter's autism is more severe than her brother. Wilson and his wife approach autism and their grown children as a team effort. Wilson talked about how he has a good partner in his wife, who is the more assertive one in their relationship; she is the one who continues finding ways to make each of their lives better. Wilson has pride in both of his children's accomplishments, from his son earning his degree to the volunteer work his daughter takes joy in. Wilson views his responsibility as a father as the breadwinner in the family, and he comments that he often feels there is not enough time in his day to do everything he would like to do. It was through the struggles Wilson faced with his children that made him the man he is today. He shared with me how, "his kids have made him a better person than I would have been." Wilson realized how his family doesn't look like other families and how those families live their lives. One of the most challenging moments was when 
his daughter was a toddler, and her speech regressed, he feared her speech would not return. Wilson had a fear of failing, that he would let down his children as their father. He worked through this fear and moved onward with the realization that he knew inside his heart he was doing the very best he could in walking the path that autism brought him.

David. David is a father whose education and faith are the guiding hands in his life and the hands with which he guides his son. Faith, along with a background in psychology, grounds him as a father to his son on the AS. To be a father is to be a teacher and guide for his son. His ability to combine the pragmatics of life skills with his use of scaffolding and patience provide moments for their connection and mutual growth. His faith is, and dependence is, on God when things are not going, that he's in charge of what we're going to be able to do in trusting him by faith, we don't understand it. Uh, cause there's a verse that says, the joy of the Lord is my strength.

He put aside his dreams of attaining his doctorate and becoming a professor to focus on his son. His dream remains but is being pursued at a much slower pace.

Paul. Paul is a man with strong opinions on the construct of disability and the oppression of special education experienced by his son throughout grade school and junior high. He is a father who never stopped advocating for his son. He disagreed with his son's doctor who suggested he and his wife place their son in a state institution. Paul pulled his son out of special education classes and mainstreamed him. He continues to support his son's education by driving him to the local community college to attend computer programming courses. Paul now spends time alone driving late at night. When he tells this story, his voice pauses, and for a moment he is silent much like the voice of his son who also spends time in the silence. He becomes like his son, he described as a "gentle giant." He told me, he has done, "my best to not resent my creator 
and not to be angry" concerning his son's autism. In his final interview, Paul shared with me he believes his son is "blessed by being here. And the fact, I believe that [my son] is such a noble soul and he preexisted before he came here that I believe his autism is the award and I believe he's being protected."

James. James is a forward-thinking father who had to fight with his wife to obtain an autism diagnosis for his son. He sees his son's autism through a different set of eyes. Autism is not a disability; it is a different ability. Having a knowledge of the DSM-5 provided James with a background regarding autism. His autism awareness was a defining moment when he knew and noticed his son was different during his son's early stages of development. James knew by the time his son was 11 months old something was different. He shared this with me, speaking with pride regarding his son's beginning ability to express his emotions through art. James shared a recent experience in which his son demonstrated expressive communication:

$[\mathrm{He}]$ brought home a really cool picture that he did. I'm actually thinking it's shaping up that he might be able to express himself well through art. Uh, which was a bit surprising cause he's got, he's got his head, his fine motor skills. He's got this kind of really abstract art style.

The legacy of his family is an important aspect of who he is as a father, a legacy he wants to pass down to his son. After his son's diagnosis, James began opening up to members of a business group he is a part of and became a disability advocate in the process, working with others in the business community. His openness and advocacy led his business partner to reveal that his daughter was also on the AS. 
Each of these fathers' brief descriptions provide a glimpse into their strong and impassioned emotions about their respective children. In Chapter 4, the narratives will provide further connections to the themes in the study.

\section{Data Collection}

The data collection process in heuristic inquiry is about immersion in the process. The process of heuristic data collection occurs through the researcher's immersion in the topic, interviews with the participants, self-dialogue, the use of a researcher's journal, and speaking with others on the topic (Moustakas, 1994; Sultan, 2017, 2019). The data collection process included multiple steps. First, I interviewed my participants using Seidman's $(1998,2013)$ threestep interview process. I chose Seidman's three interviews to obtain rich and deep conversations between myself and my participants through multiple semistructured interviews which were audio-recorded. Second, I collected all the data including: all the participant transcripts, my researchers electronic journal, the documents of participants' significant statements, and the high-level synopsis statements. The use of a researcher's journal was kept throughout the seven heuristic processes, throughout each of the six phases of heuristic research, and throughout data collection and data analysis. The researcher's journal was a place to reflect, to be with my topic, and to provide space for the six phases of heuristic inquiry: (a) initial engagement, (b)

immersion, (c) incubation, (d) illumination, (e) explication, and (f) creative synthesis (Douglass \& Moustakas, 1985; Kenny, 2012; Moustakas, 1990, 1994; West, 2001). Third, I immersed myself fully in the data until I understood it clearly. Lastly, I set the data aside, giving time to rest and allow a space for the data to incubate as I moved forward into the analysis of my data. 


\section{Heuristic Interviewing Process}

Interviewing is the most common process used in a heuristic inquiry to collect data (Moustakas, 1990; Sultan, 2019). The heuristic interviews I conducted were shaped through the relationship between myself as the researcher and the participant and were conducted through the formation of authentic connection (Sultan, 2019). I conducted a series of three interviews with each of the participants.

\section{Interviews}

The conducting of a heuristic interview requires the researcher to be prepared prior to attending each of the interviews. I followed a set of preparations in keeping with the heuristic method of interviewing. This step-by-step process held true to the rituals of heuristic interviewing: (a) I reread the set of prepared questions prior to the interviews and also prepared to ask follow-up questions as they arose; the interview questions were prepared over the course of discussions with my dissertation committee, (b) I spent 30 minutes or so prior to each interview and wrote in my researcher journal, my thoughts and concerns prior to the interview, this created a quiet space inside of self to allow for openness and rapport with each father I interviewed; (c) I centered and grounded myself in a few minutes of quiet meditation prior to meeting my participants; (d) In writing prior to the interviews I connected with my "cognitive (i.e., mind), emotional (i.e., heart), sensory (i.e., my five senses), kinesthetic perceptual [i.e., the feelings I experienced in my body throughout the process such as, crying and feelings of joy], spiritual (i.e., soul), and relational dimensions of self (Sultan, 2019, p. 126); and (e) I brought my sense of openness to each interview and actively listened with my mind, emotions, and body. During the interviews I also listened for the times of dissonance (e.g., moments when the fathers would sometimes pause in the middle of an answer to the interview question) and was attuned to 
the moments of silence. For me, their silence signaled when the father needed a space to collect their thoughts or feelings while answering the interview questions. I was alert to any occurrences of transference and countertransference (e.g., after the fathers' interviews that were so emotional I would find myself crying). I spent time after each interview to collect my thoughts and feelings that I experienced during the interview and wrote a high-level synopsis after the interview in my researcher's journal (see Appendix L). I reflected upon and wrote about the nonverbal and verbal expressions of the fathers that I interviewed, which was also included in my high-level synopsis (Sultan, 2018).

\section{Phenomenological Interviewing}

The phenomenological approach to interviewing is based upon a series of three interviews that include and combine life history, the details of the experience, and reflection upon meaning (Seidman, 1998, 2013). I used Seidman's $(1998,2013)$ three interview series to conduct my interviews. The three-interview format followed this process: I conducted face-toface, semistructured interviews with each participant in person (or via the phone if that was the only way possible; Seidman, 1998, 2013; Sultan, 2019). I used a professional company to transcribe the interviews. I reviewed each transcription by listening to the audio recording while reading the professionally transcribed interviews after they were emailed back to me. I conducted six in-person interviews and 24 interviews that were audio-recorded over my iPhone. Thus, I conducted a total of 30 interviews; each father was interviewed three separate times. Each interview lasted between 45 to 90 minutes. Table 7 illustrates the total number of single-spaced interview pages per each of the fathers' three interviews and a total number of single-spaced pages for all 30 interviews. The listing of the fathers continues to follow the listing in previous tables. 
Table 7

Total Number of Interview Pages Per Father

\begin{tabular}{lllll}
\hline Father & $\begin{array}{l}\text { First Interview } \\
\text { Single Spaced } \\
\text { Pages }\end{array}$ & $\begin{array}{l}\text { Second Interview } \\
\text { Single Spaced } \\
\text { Pages }\end{array}$ & $\begin{array}{l}\text { Third Interview } \\
\text { Single Spaced } \\
\text { Pages }\end{array}$ & Total Pages \\
\hline John & 39 & 24 & 34 & 97 \\
James & 33 & 18 & 36 & 87 \\
David & 17 & 12 & 32 & 61 \\
Scott & 24 & 21 & 34 & 79 \\
Paul & 13 & 13 & 24 & 50 \\
Anthony & 12 & 11 & 17 & 40 \\
Wilson & 18 & 21 & 27 & 66 \\
Gabriel & 19 & 48 & 28 & 95 \\
Mark & 33 & 36 & 21 & 90 \\
William & 17 & 34 & 44 & 760 \\
Total Pages & 225 & 238 & 297 & \\
\end{tabular}

Additionally, each participant and I agreed on a mutually convenient place where confidentiality would be maintained for each of the three sperate interviews. Examples of meeting places included coffee shops and one participant's home. This procedure was in keeping with the creation of a safe space for the fathers and assisted with relationship building (Moustakas, 1994; Sultan, 2018). Additionally, participants agreed to be contacted for any additional follow-up questions. The series of interviews was conducted in the I and Thou framework in this created subjective space (Buber, 1970; Seidman, 1998, 2013; Sultan, 2019). The creation of I and Thou focuses on the created space of intersubjective experience between researcher and participant. In this space, the participant is not viewed as an object (Seidman, 1998, 2013; Sultan, 2019) but rather as a whole, continually evolving person.

\section{First Set of Interview Question}

The first set of interview questions was prepared in two parts. The first part was designed to gather demographic questions about participants. It was sent via email to each participant prior 
to conducting the first two-way conversational interview (see Appendix $\mathrm{M}$ for the first set of interview questions). This interview focused on the father's life history between him and his child on the AS. A few sample questions included: (a) How old was your child when they were diagnosed along the autism spectrum? (b) Tell me about your initial reaction to your child's diagnosis, and (c) Have your feelings toward you child's diagnosis changed since that day? If so, how?

\section{Second Set of Interview Questions}

The second set of interview questions was focused on the detailed experience of the fathers (Seidman, 1998, 2013). These questions were designed to have the fathers talk more about the details of their experience as a father of a child on the AS. The second set of interviews included questions such as: (a) What are the challenges you face as a parent of a child on the AS?, (b) What are your strengths as a parent of a child on the AS?, (c) Tell me about your interactions with your child on a daily basis, and (d) What types of things do you do together and how much time do those account for?

\section{Third Set of Interview Questions}

The third and final set of interview questions were designed to have the fathers reflect on the meaning of their experience of having a child with an official AS diagnosis (Seidman, 1998, 2013). This set of questions asked the fathers to consider the contextual factors in their experience (Seidman, 1998, 2013) and reflect on changes over time in their perceptions. The third set included questions such as: (a) What is different about fatherhood since your child's diagnosis? How might you describe that shift? (b) What is different about fatherhood since your child's diagnosis? How might you describe that shift? and (c) Did your hopes and dreams for your child change? If so, how did your hopes and dreams change? 


\section{Interview Before and After Process}

In staying authentic to heuristic phenomenology, my pre-interview ritual included about a 10-minute timeframe in which I quieted my mind and turned inward prior to each interview and after, this action created a space for my mind to become quiet and enabled a state of reflection to occur before writing in my researcher's journal. Prior to the first interview meeting with each participant, I sent out a brief demographic list of questions to be answered by each participant and asked that it be emailed back to me. During the interview, I focused on creating a shared space and a sense of rapport and community (Sultan, 2019). I kept a person-centered focus during the interview (Sultan, 2019). I employed active listening with my mind and my emotions while paying attention to the nonverbal cues of my participant. I paid attention to the nonverbal forms of expression of my participants (i.e., physical signs and signals, gestures, facial expressions, pauses, and personal space) while embracing the silences and paying attention to what was not being said. These were captured in my writing after the interview had occurred (Sultan, 2019). I transcribed only four of the 30 interviews and wrote a high-level synopsis after each interview. The remaining 26 interviews were sent out electronically and were transcribed by a professional service and were emailed back to me. Upon receiving each interview, I returned to the audio recordings and doubled checked each transcript by listening to the audio recording and checking against the transcript for accuracy. I corrected any errors. My interview schedule can be found in Appendix N.

\section{Audio-Recording}

I audio-recorded each of the interviews with the participants' permission and uploaded each recording to Dropbox from my iPhone following the interview. The recordings were stored in a confidential location that was password protected. Confidentiality was assured by keeping 
the list of original participant names in a password-protected location. I transcribed the four audio files were transcribed on my iMac and my MacBook Pro, which were both passwordprotected, and only I had access to the confidential material.

\section{Transcription Process}

Sultan (2019) described transcription as an "embodied relational process" (p. 143). This means that: (a) the researcher acts as the receiver of the information; (b) the transcription process is very relational and includes a connection of engagement, presence, and being attuned to the participant; (c) "it is embodied," meaning my mind, body, and spirit are involved in the transcription as I listen for "key words, phrases or symbols;" (d) "it is multidimensional" including "pitch, variation, pace, interruption, breathing, and silence;" (e) it is holistic, meaning it goes beyond my observations and how the content connects to the interview questions, (f) "it is reflexive" requiring my own exploring of how this experience impacted my life and thoughts; (g) it makes me ask myself, what are my "biases, beliefs, values, and assumptions?” and (h) it is member checked (Sultan, 2019, p. 143).

Verbatim transcripts from each of the interviews, as is the tradition in heuristic phenomenology, were generated by myself and the professional transcription service (Moustakas, 1994; Sultan, 2019). For the four interviews I transcribed, I spent a total of over 15 hours in naturalized transcription. The use of naturalized transcriptions enabled me to hear and see the fathers' words and answers to my questions in the fathers' exact words of their responses. I reviewed the remaining 26 transcripts upon receipt from a professional transcription service and checked each transcript for accuracy. Checking the naturalized transcripts took approximately two hours for each interview. Thus, I spent approximately 60 hours reviewing the 30 transcripts. The transcripts were emailed to me from the transcription service within 2 hours 
and the transcriptions were checked against the original recordings of the interviews for transcription accuracy and to correct any mistakes created through dictation. After each verbatim transcript was completed, I wrote a high-level synopsis for each of the three separate interviews for each of the 10 fathers, as described in the next section.

\section{High-Level Synopsis}

The procedure for writing my high-level synopsis changed since my initial dissertation research proposal. In my proposal, I stated the following:

Following each interview, and after each transcription, I will write a high-level synopsis as soon as possible after the interview. In the high-level synopsis, I recorded: (a) my thoughts, (b) impressions, and (c) the nonverbal of the participants. The writing of a highlevel synopsis offers and ushers forth a place to write about the big ideas and a time to reflect and process the interview just conducted. In the high-level synopsis, I will bring my sense of curiosity and my metacognition, cognition, spiritual, and holistic listening self to all aspects of the interview process (Sultan, 2019).

Initially, I attempted to follow the step-by-step process outlined in my proposal regarding the writing of a high-level synopsis after each interview. This however, only provided me with: (a) frustration, (b) a lack of words following each interview, (c) incomplete silence, (d) incomplete thoughts, and (e) a stepping away from writing. I made a shift three weeks into data collection (interviewing), which I began during the month of July 2019. I have always been and continue to be an auditory learner. I encountered a great deal of difficulty in translating the writing process after each interview into the high-level synopsis, even with following the explicit steps outlined in my proposal. Therefore, I shifted the way in which I wrote the high-level synopsis. 
My new explicit system included listening to each interview and making notes in a Word document while listening. Those notes included my (a) impressions of the father's tone of voice, (b) thoughts, (c) feelings, (d) pauses in the fathers' conversations, (e) direct quotes, (f) observations, and (g) questions or additional follow-up questions to ask each father. Each synopsis was approximately between five and seven pages (see Appendix $\mathrm{O}$ for an example).

\section{Researcher Journal}

I kept an electronic, password-protected researcher's journal throughout my dissertation process, as this is a primary method for documentation in each of the seven heuristic processes, in each of the six phases of heuristic research, and during data collection and analysis (Sultan, 2019). According to Sultan (2019), the act of journaling by the researcher is considered an artifact and an important part of the data collection process. Journaling can include "narrative writing, notes, drawings, charts, phases, words, poetry, and symbols” (Sultan, 2019, p. 138). In my journal, I choose to use narrative writing, my notes, and poetry. I kept an electronic research journal and wrote poetry to connect with my subconscious and conscious thoughts. My writing offered a space to think, feel, and become more connected to my data and to the fathers' journey as I wrote both in narrative and in poetry. The writing and keeping of a journal honors the "social constructivist, autobiographical, exploratory, process-focused, intuitive, introspective, creative, and humanistic facets of heuristic research" (Sultan, 2018, p. 136). My journal was kept in several places. I wrote in the Notes application on my iPhone. Those notes were then transferred and saved and stored in Dropbox on my iMac or my Mac Book Pro. Any additional handwritten notes were also transferred onto either computer. By journaling, I brought transparency and a place to process details and challenges and gain insights that are critical to heuristic research. My 
journaling also added to the rigor during each of the seven heuristic processes, each of the six phases of heuristic research, and data analysis.

\section{Data Analysis}

I conducted a heuristic process of data analysis, which gives equal importance to all data from the participants. The data analysis process included the following steps: (a) significant statements were taken from each of the participants' transcripts, (b) a code book was created, (c) explicit process thematic construction, (d) individual depictions and narratives were written, and (e) creative synthesis occurred when the study's themes were integrated into a cohesive whole (i.e., writing poems in my research journal). Each is described in the following sections.

\section{Significant Statements}

While the interview occurred, I kept hand-written notes and was mindful of significant statements, pulled from each of the participants' three interviews after all 30 interviews were completed. For each significant statement, a code was created (see Appendix P). Creswell (2013) defined significant statements as "the narrow units of analysis" (p. 79). I chose and identified significant statements by using the following criteria: the significant statement addressed the main research question or one of the eight subquestions, was consistent, inconsistent, or missing in the literature (i.e., research studies and the books written by the fathers), and my experiences with autism. Two examples of significant statements from my Excel spreadsheet include Mark's second interview in which he stated "Because I don't have a sense of what's typical" and Scott's second interview in which he stated,

I can plan for the long-term and I can plan for the immediate the next five years that I don't think about that. Think about so long. Make sure there's enough there anything about getting through the day when I need to get through the day. Just one day at a time. 
These examples selected as significant statements because they addressed the main research question of the study. Table 8 shows the total number of significant statements listed per interview and the total number from the Excel spreadsheets I created.

Table 8

Total Number of Significant Statements Listed per Interview in Excel

\begin{tabular}{lllll}
\hline Father & $\begin{array}{l}\text { First Interview } \\
\text { Significant } \\
\text { Statements }\end{array}$ & $\begin{array}{l}\text { Second Interview } \\
\text { Significant } \\
\text { Statements }\end{array}$ & $\begin{array}{l}\text { Third Interview } \\
\text { Significant } \\
\text { Statements }\end{array}$ & Total \\
\hline John & 74 & 53 & 58 & \\
James & 114 & 41 & 58 & 185 \\
David & 87 & 51 & 62 & 213 \\
Scott & Didn't record & 103 & 118 & 200 \\
Paul & 81 & 54 & 66 & 221 \\
Anthony & 58 & 33 & 66 & 201 \\
Wilson & 41 & 57 & 103 & 157 \\
Gabriel & 70 & 82 & 69 & 201 \\
Mark & 57 & 106 & 52 & 221 \\
William & 84 & 110 & 147 & 215 \\
Total & 666 & 690 & 799 & 341 \\
\hline
\end{tabular}

This noting of significant statements assisted with the creation of an Excel spreadsheet which served as the code book of themes (Creswell, 2013; Creswell \& Poth, 2018). Because Scott's first interview did not record due to technical difficulties, notes were taken immediately after the interview finished. A page from my Excel sheet is provided to show how significant statements were pulled from Scott's second interview (see Appendix Q).

\section{Coding Steps and Code Book}

Coding was accomplished in the following steps. In Step 1, I printed the transcripts of each participant's interviews and bracketed my experience to help me set aside my personal experiences with autism. In Step 2, I highlighted significant statements from the participant interviews and placed them in Excel spreadsheets from the participants' verbatim transcripts. 
The significant statements were denaturalized and shortened. In Step 3, I, reviewed the significant statements, and then completed a second round of thematic coding following the initial thematic coding to ensure consistency. In Step 4, I abbreviated the significant statements. The abbreviated statements are the second round in the coding process. They are defined as statements that are reduced form the more extended first level significant coding sentences. Abbreviated statements are from four to seven words in total and are part of the series of reducing the coding rounds down to categories. Next, they were grouped into an additional Excel spreadsheet and I condensed them into categories in the third round of coding. Lastly, in Step 5, the categories became themes in the fourth round of coding. In the fifth round of coding, the data had reached saturation; as a result, only four rounds coding resulted (see Appendix R; Creswell, 2007; Moustakas, 1990, 1994; Sultan, 2018).

\section{Explicit Process Thematic Construction}

The 2,155 significant statements became abbreviated statements and further reduced to third level detailed abbreviated statements, and those became categories, which then finally became themes and complex themes. From the 19 categories, two broad themes presented, fathers' prediagnosis and postdiagnosis experiences in having a child on the AS. The two broad themes were further delineated into a total of 40 complex themes (e.g., fathers' description of the child, labeling of a child, child's severe behavior, fathers' perception of the child, the role of the father). The 40 complex themes were again combined and reduced to a total of 19 (e.g., fathers' reaction to child's diagnosis, fathers' loss of hopes and dreams, the role of father, fathers' parenting). The 19 themes were then grouped into the study's two main themes of the fathers' journey and fathers' growth mindset. Table 9 shows an example of the code book, how the 40 
complex themes were reduced to 19 themes, and how they connected corresponding eight subquestions (see Appendix S for additional example).

Table 9

Code Book Example

\begin{tabular}{|c|c|c|c|c|c|c|c|c|}
\hline $\begin{array}{l}\text { Significant } \\
\text { Statements } \\
\text { Example }\end{array}$ & $\begin{array}{l}\text { Third Level } \\
\text { Detailed } \\
\text { Abbreviated } \\
\text { Statements } \\
\text { Example }\end{array}$ & $\begin{array}{l}\text { Categories } \\
\text { Example }\end{array}$ & $\begin{array}{l}\text { Broad Theme } \\
\# 1 \\
\text { Prediagnosis } \\
\text { Example }\end{array}$ & $\begin{array}{l}\text { Broad Theme } \\
\# 2 \\
\text { Postdiagnosis } \\
\text { Example }\end{array}$ & $\begin{array}{l}\text { 40 Complex } \\
\text { Themes } \\
\text { Example }\end{array}$ & $\begin{array}{l}19 \\
\text { Themes } \\
\text { Example }\end{array}$ & $\begin{array}{l}\text { First } \\
\text { Main } \\
\text { Theme }\end{array}$ & $\begin{array}{l}\text { Second } \\
\text { Main } \\
\text { Theme }\end{array}$ \\
\hline $\begin{array}{l}\text { Father: } \\
\text { Anthony } \\
\text { Interview 1, } \\
\text { p. } 4\end{array}$ & $\begin{array}{l}\text { Father wants } \\
\text { son to feel } \\
\text { normal }\end{array}$ & $\begin{array}{l}\text { Fathers' } \\
\text { Autism } \\
\text { Reality }\end{array}$ & $\begin{array}{l}\text { Fathers' } \\
\text { Hopes and } \\
\text { Dreams }\end{array}$ & $\begin{array}{l}\text { Reality of } \\
\text { Fathers' } \\
\text { Hopes and } \\
\text { Dreams }\end{array}$ & $\begin{array}{l}\text { Fathers' } \\
\text { Realization } \\
\text { of his reality }\end{array}$ & $\begin{array}{l}\text { Fathers' } \\
\text { loss of } \\
\text { hopes and } \\
\text { dreams }\end{array}$ & $\begin{array}{l}\text { Fathers' } \\
\text { Journey }\end{array}$ & $\begin{array}{l}\text { Fathers' } \\
\text { Growth } \\
\text { Mindset }\end{array}$ \\
\hline $\begin{array}{l}\text { "our goal } \\
\text { since we've } \\
\text { had him to } \\
\text { make sure } \\
\text { that he feels is } \\
\text { normalize as } \\
\text { possible." }\end{array}$ & & & & & & & & \\
\hline
\end{tabular}

I asked myself a series of questions during the data coding which included: (a) Did the significant statements connect with my central research question and subquestions? (b) What is my impression of the data? (c) What were each of my participant's responses to each of my questions? (d) Which questions were avoided? (e) Were there any times of silence, and which question was involved? (f) What is similar and what is different in my participants' answers? (g) What were the nonverbal signals my participants gave and what made their expressions significant? (h) What was unexpected in their responses? and (i) after I have immersed myself in all the data, what is my impression of it? to accomplish all of this, I stayed focused and maintained discipline in paying attention to all the specific details contained in a heuristic study and in answering the research questions and the eight research subquestions, (j) after completion of data coding, I wrote about the what and then the how of the participants' experiences. I put the participants' transcripts together and explained their experiences using a disability studies lens to 
analyze my data, staying connected to the seven practices and six processes, and (k) I also reread my electronic researcher's journal as I analyzed the data (Creswell, 2007; Moustakas, 1990, 1994; Sultan, 2019). The rereading of my researcher's journal continued to inform the impact of the 30 interviews I had conducted during this process.

\section{Individual Narratives}

I created individual descriptive narratives of each participant. This information was drawn from: participant demographics from interview data, interaction with each participant, my researcher's electronic journal, email correspondence with participants, recorded interviews, participant transcripts, dialogues with committee members, significant statement documents, transcripts, analysis documents, my code book, and my high-level synopsis (Creswell \& Poth, 2018; Lincoln \& Guba, 1985; Sultan, 2019). While writing the individual fathers' narratives, I

additionally, asked this question: "Does the individual description fit the data from which it was developed?" In the writing of each participant's depictions, this resulted in a creative synthesis of the data, which is described in the next section.

\section{Creative Synthesis}

Creative synthesis involves the researcher transforming the data from its original form into the researcher's sense and understanding of the data. This transformation of the data into a creative synthesis "involves the heuristic processes of tacit knowing, immersion, and illumination," used throughout the study (Sultan, 2019, p. 154). This process of creative synthesis explains the what and how of my study. The use of creative synthesis enabled me to construct a narrative of each of the participants in Chapter 4. Through the writing of the fathers narratives, I was able to capture who they are as fathers and individuals. I followed the following steps as I wrote their descriptions: (a) I read and reread each of fathers three separate interviews, 
(b) I read and reread through all my field notes in researcher's journal, (c) I read and reread the narratives I had written in my research journal, and (d) I read and reread all the poetry I had written. Those steps gave me an internal space to think and process at a deeper level who these fathers were as individuals and as men. As a result, I was able to understand the fathers as individuals more fully.

\section{Trustworthiness}

The establishment of trustworthiness in a research study is a vital part in every aspect of the study. Lincoln and Guba (1985) outlined how the what needs to be in place in order during the research process to establish the construct of trustworthiness. This included the establishment of four criteria: credibility, member checks, research journal, transferability, dependability, and confirmability (Lincoln \& Guba, 1985; Moss, 2004; Sultan, 2019). The keeping of a research journal offers the researcher a place to record ongoing thoughts and experiences throughout the dissertation process. This journal, combined with member checks, provided trustworthiness and rigor for the study. The researcher is the channel from which the research is conducted, and her credibility is critical to the trustworthiness in the study.

\section{Credibility}

Credibility is concerned with the methods and approaches used to collect data and represent the findings (D. Ferguson \& Ferguson, 2000; Lincoln \& Guba, 1985). Through prolonged engagement with the data, member checking, peer review, and researcher reflexivity, the findings are therefore more credible (D. Ferguson \& Ferguson, 2000; Sultan, 2019). Polkinghorne $(1982,1989)$ listed questions that the phenomenological researcher should ask herself to determine credibility. For my study, I selected one key question from Polkinghorne 
(1989) four key questions from Creswell (2013). The Polkinghorne question I selected were the transcriptions accurate. The questions I selected from Creswell (2013) were the following:

- Does the researcher express a knowing of the philosophical tenets of phenomenology?

- Does the study have an apparent "phenomenon" to study, and is it clearly, stated?

- Did the researcher convey the overall experiences and essences of the participants? and

- Was the researcher reflexive throughout their study?

\section{Member Checks}

In maintaining the integrity, trustworthiness, and rigor of the research process with my participants, member checks were used. This procedure of member checking is a vital aspect in enhancing trustworthiness (D. Ferguson \& Ferguson, 2000; Lincoln \& Guba, 1985; Moustakas, 1990, 1994; Sultan, 2019). I sent each of the 10 participants their three naturalized transcripts. This provided the participants an opportunity to make sure their responses to the questions were accurate in the transcripts. Their transcripts were sent with a two-week window for authentication. This provided the participants an opportunity to make corrections in the transcripts or offer additional information that may have been omitted during the three interviews (Lincoln \& Guba, 1985). Five out of the 10 participants responded regarding their transcripts and only one father requested a minor change.

\section{Research Journal}

The keeping of a research journal brings trustworthiness, credibility, and allows a space of self-reporting data (D. Ferguson \& Ferguson, 2000; Polkinghorne, 1989; Sultan, 2019). In my electronic research journal, I mapped out and kept track of my hunches and thoughts using section headers that included my first impressions, and thoughts relating to each of the fathers and the impact of their interviews. This assisted in mapping out when things shifted, when 
changes occurred, when something unique happened. The research journal became the interactive space for me to reflect, bring a measure of trustworthiness to the self-study research, and provide for written evidence (Polkinghorne, 1982, 1998).

Here in my journal, the written narrative was checked by looking back at the thoughts, feelings, and the experiences that occurred during the specific timeframe in which the event or events had occurred (D. Ferguson \& Ferguson, 2000; Sultan, 2019). The research journal also allowed for an analysis of the reflected narrative and the establishing of rigor in the self-study (Polkinghorne, 1982, 1998). The utilization of a research journal aided me in answering questions of validity and rigor. These expressions included narrative writing, poems, specific words, and narratives, and can be treated as a data source (Sultan, 2019). In my research journal, I choose to use my narrative writing and poetry as an avenue to express my feelings and thoughts regarding the study. Writing in my research journal offered a place to record my reflections, possible theories, thoughts, and feelings regarding my study while establishing transparency and trustworthiness (Lincoln \& Guba, 1985; Sultan, 2019).

\section{Transferability}

Transferability is critical in heuristic research, and the construct and context of transferability is a critical aspect of trustworthiness (Sultan, 2019). Context includes where the study is set and how the study is situated (Sultan, 2019). Transferability is enriched through strategies that include sustained engagement and immersion in the data, triangulation, and the use of thick description (D. Ferguson \& Ferguson, 2000; Geertz, 1973; Lincoln \& Guba, 1985; Sultan, 2019) which were part of my data analysis process. Transferability was achieved through my prolonged engagement with the data and the writing of thick individual participant descriptions (Sultan, 2019) and through the use of triangulation of the data (e.g., interviews, 
transcripts, research journal, member checking, committee members reviewing significant statements)

\section{Dependability}

The construct of dependability examines how I justified the use of my research methodology and the data collection process. An audit trail mentioned earlier in Chapter 3 is a technique for the achieving dependability (Lincoln \& Guba, 1985, 2013) and one that I used in this study. The audit trail included raw data (i.e., interviews recorded on my phone, field notes, the narratives and poetry written in my researcher's journal). Additionally, I kept the data straight through the use of Excel sheet and I documented how many hours I spent throughout the study in my researcher's journal. My central research question supported the use of my chosen methodology including the use of thick description, researcher reflexivity, and the writing of high-level synopsis (Geertz, 1973; Sultan, 2019). Confirmability is the remaining aspect of trustworthiness.

\section{Confirmability}

Confirmability is a clear linking between the findings and the interpretation of the data (D. Ferguson \& Ferguson, 2000; Lincoln \& Guba, 1985; Sultan, 2019). Confirmability is a way of checking in with possible biases, attitudes, or experiences of the researcher. Confirmability in my study was achieved through the utilization of an audit trail, researcher reflexivity, and the exploration of the researcher's subjectivity, discussions with committee members, and my reverend who continually questioned me to ensure that I maintained a nonbiased perspective (Lincoln \& Guba, 2013). 


\section{How I Came to this Research}

I have researched the topic of autism since obtaining my bachelor's degree in human service in the spring of 2015, while working as a graduate research assistant for an autism research institute, and through the years in which my own questions grew and expanded. These experiences resulted in a pilot study with three fathers who had a child on the autism spectrum in the fall of 2017 while I was in a grounded theory class in my doctoral program. After I had finished interviewing the second father in the pilot study, I was struck by the manner in which he put on his sunglasses and thanked me. He thanked me for interviewing him and talked about how, through all the years and the many doctors, psychologists, and interventions, not once was he ever asked about his experiences as a father. It was after this father's interview that I realized that I had more questions. More importantly, I realized, it was the voices of fathers whose narratives needed to be told so that their experiences could be validated through research. It was a research study that I was compelled to conduct.

\section{Researcher Subjectivity}

Paramount to the heuristic inquiry process is the researcher's subjectivity. Inherent in this process is an open and honest dialogue with the self. The researcher pays attention to her thoughts while being flexible in the discovery of knowledge (Moustakas, 1990, 1994; Sultan, 2019). Discovery offers the researcher opportunities and challenges for growth. The researcher holds her subjectivity while simultaneously remaining open, and this is the challenge of using the heuristic methodology (Moustakas, 1990, 1994; Sultan, 2019). As with this challenge, my subjectivity statement is a collection of my thoughts and details, my ever-growing understanding of the process, and the challenges in conducting qualitative research. 


\section{Subjectivity Statement}

My subjectivity is formed through a multilayered lens of personal experiences of autism, the philosophy and teachings of Brazilian educator Paulo Freire, and conceptual theory of knowledge through constructivism. All of these are inherent in my subjectivity and in my positionality. The formation of my world view is an interwoven tapestry based upon time and my life experiences. I call this my epistemological frame. The journey to this shore of research was fraught with moments of confusion and illusion. Inherent in this passage is the ever-arching space of puzzlement. The question of "how do I know what I know?" played an increasingly vital role in the transcendence of my inner and outer knowledge acquisition. I begin with Freire (2008) quotation, "to deny the importance of subjectivity in the process of transforming the world and history is naïve and simplistic" (p. 50). I am driven by my questions. I knew in choosing this topic, I would learn more about myself, perhaps even see and feel myself reflected in the narratives that fathers in my study would share. I did not think there would be any way to foretell and predict with absolute certainty my own feelings and internal experiences.

Freire and my world. My world is a world of internalized language, a world of Freire's (2008) praxis, that is, "the praxis which, as the reflection and action which truly transforms reality the source of knowledge and creation" (Freire, 2008, p. 100). Reflection calms the wild and overflowing rivers of my mind. My internal lens, first covered in shade, sharpens its edge of conscious thought through praxis, my own guiding hand in the world. Freire stated, "the intentionality of consciousness means consciousness is never a mere reflection of material reality but is a reflection upon materiality reality" (as cited in Crotty, 1998, p. 53). Crotty (1998) asserted, "who human beings are or what it means to be human is to ask what human beings have made of themselves" (p. 150). The understanding of my world is accomplished through 
reflection and action, through praxis in and upon the world for change to transpire.

Constructivism. During the spring of 2016, as I was taking a doctoral course in theoretical frameworks, I realized and discovered that I have always stood upon the foundation of interpretivism in my constructionist epistemology. The formation of my constructivist epistemology is, as Crotty (1998) stated, "truth, or meaning, [that] comes into existence in and out of our engagement with the realities in our world. There is no meaning without a mind. Meaning is not discovered but constructed" (pp. 4-5). In constructivism, an individual's knowledge is constructed through the interactions one has with others and their world. According to Crotty (1998), these interactions form the theoretical construct of constructivism, where the focus is on the construct layers of "interpreted sedimentation" [emphasis added] (p. 59). The layers of sedimentation connect to the lived experience of how the individual understands her world. This combines with Geertz (1973) and his use of thick descriptions, "the construct of knowing as represented by 'turtles all the way down" (p. 27).

It is through my past and present experiences that I make sense and meaning in this world, as my constructivist paradigm connects and is represented many times through the writing of narrative and heuristic tacit knowing (Moustakas, 1990; Sultan, 2019). This is my process of constructivist meaning making, the critical reflection found in Freirean praxis (Freire, 2008; Lambert et al., 1995).

Personal experiences of autism. I cannot deny my own subjectivity in this process, for it is the very substance which drove me to this work. I am a woman somewhere on the wide and complex spectrum called autism. While interviewing the 10 fathers in my study, I and my dissertation committee made the decision not to disclose my diagnosis to the fathers during the course of their interviews. I wanted the fathers to answer my interview questions freely without 
the shadow of my presence on a wide spectrum. Being a member of this complex and wide spectrum drew me into questions regarding fathers and their experiences.

Can a researcher not have any connection to the topic they are researching? Can a researcher have a wall of nonobjectivity and still conduct qualitative research? Would it not be easier to gather data (e.g., use large data sets), run it through a computer-generated platform, and write up the results? Are one's feelings then more removed in the process? I think that answer is the answer I received throughout my doctoral program, "it depends." How can I not have any connection to this work, this research? Perhaps its duality gives much and also offers much to reflect upon.

Central to my life are epistemological questions that provide open pathways to the acquisition of knowledge. As far back as I can recall, four questions central to my life have followed me. The first question, what is my ontological question of what is real/reality? Two, my epistemological question of how do I know what I know? Three, my methodological question of how is knowledge acquired? Fourth and final, my axiological question of what knowledge is truth? It is my experiences and the constructivist lens through which I view the world that makes answering those questions a reality worth continually pursuing (Lambert et al., 1995; Lincoln \& Guba, 2013).

\section{Summary}

Chapter 3 described the process and methodology of heuristic phenomenology, data collection, and data analysis that was used in this study. This study, grounded in practices and processes of heuristic inquiry, was used to develop a deeper understanding of the life experiences of biological fathers who have a child with an official AS diagnosis. In the next chapter, I present a narrative for each of the participants that captures the study's themes and subthemes and 
supports my analysis. Those written narratives will illustrate each father's journey and life experiences through the rich and deep seven processes and six practices of heuristic inquiry. 


\section{CHAPTER 4-FINDINGS}

The purpose of this dissertation was to explore and investigate the phenomenological experiences of fathers who have a child on the autism spectrum. There were 10 participants in this study which were identified by pseudonyms: William, Gabriel, Mark, John, Scott, Anthony, Wilson, David, Paul, and James (i.e., fathers who have a child with an official AS diagnosis). Three of the fathers, Gabriel, Mark, and Wilson, have two children on the AS. These fathers are busy men, and their time is allocated based on the demands of their lives and the time spent caring for their children. Therefore, it was essential to connect with them as their schedules allowed. In being flexible, this illustrated my commitment to the to their participation in the study. Establishing rapport was the first step in the development of trust (Sultan, 2019). The building of trust began from the first contact I had with each of the 10 fathers by email or phone and continued throughout the interview process. In building trust with the participants, I was able to learn about each father's journey and how they formed their identities. These data were vital to answer my research questions.

The main research question governing this study asked, what are the lived experiences of fathers who have a child on the autism spectrum? In addition to the central research question, there were eight subquestions:

1. What were the reactions of the fathers before and after their child's AS diagnosis? After their reactions, did the fathers experience challenges in having a child on the AS? If so, what were they?

2. Did the fathers experience a "new reality" as a result of their child's diagnosis? If so, what did this new reality look like?

3. What roles did the fathers play as a result of having a child on the AS? 
4. What are the fathers' views on disability?

5. Did the fathers have a belief system that impacted their journey in raising a child on the AS? If so how?

6. Do fathers who have more than one child on the AS have a significantly different lived experience compared to fathers who have only a single child on the AS?

7. Did the fathers experience personal growth as a result of having a child on the AS? If so, what growth did they experience?

8. Does the severity of autism create a different lived experience among fathers?

\section{Findings}

In this chapter, I present the overarching phenomenon of fathers' journeys and how it impacted their identities. The journey of having a child on the AS impacted fathers' identities, and these identities as men impacted their journeys. The following sections help to elucidate this phenomenon further. These sections include: (a) fathers' before and after reactions to the child's AS diagnosis, (b) fathers' new reality, (c)fathers' roles, (d) fathers' views on disability, (e) the impact of fathers' faith, (f) distinctive experiences of fathers who have two children on the AS, (g) the impact of the study on the fathers, and (h) fathers' personal growth.

\section{Fathers' Before and After Reactions to Child's AS diagnosis}

The journey of a father accepting his child's AS diagnosis begins even before the diagnosis. Often, it starts with the father's suspicions and wondering whether something is wrong with his child, marked by delays in or missing developmental milestones. Fathers struggled with their feelings after their child received their AS diagnosis. 


\section{Fathers Pre-AS Suspicions}

This section presents the early suspicions fathers had before their child was diagnosed to have autism It includes how fathers observed missed milestones and delays in their child's: (a) muscular and motor coordination, (b) communication, (c) toilet training, and (d) lack of eye contact.

Delays in muscular and motor coordination. Scott and Paul each shared how they became aware of their respective child's delays in muscular and motor coordination. Scott shared his early worries and concerns that his son, "wasn't crawling, he couldn't sit up," and "he certainly wasn't walking." While Paul shared another worry about his child's delayed development, "I was worried at about 10, 11, 12 months that he wasn't walking." As the children grew older, additional suspicions and experiences regarding delays in communication and communication regression occurred.

Delays in communication or nondevelopment. When reflecting, I realized a common topic came up from interviews with Wilson, James, Anthony, William, Mark, and Scott: each of their children began missing a milestone in communication or failed to communicate altogether. Wilson disclosed his confusion when his daughter's ability to speak regressed. Initially, "she went from being a pretty normal, a young toddler walking around," but then Wilson's daughter “lost her speech.” By comparison, James’s son, “didn’t make a lot of sounds.” Likewise, Anthony saw his son struggle with speech, "he was just like mumbling, but it wasn't clear." William's son also had a delay and missed a milestone in his communication, "he didn't, he wasn't talking; he was three years old." Mark only stated his daughter had, "kind of the speech delay." Scott's son, however, had the most profound speech delay. His son's "speech never developed. It is the hardest thing in the world for him to talk, and when he talks, he sounds like a 
deaf person, ug ooo." Of all the listed delays and missed milestones, communication was the largest category in this section, with six of the 10 fathers sharing their child's delays or missed milestones. As a result of their child's delays or missed signs, each of these six fathers became worried and concerned about the development of their child. In addition to anxieties and worries about communication, three of fathers also discussed their child's delays in toilet training.

Delay in toilet training. Paul, David, and Gabriel described how their children had delays in toilet training. Paul said, his son "wore a diaper till he was 5." David also spoke about his son's late potty-training development, "So he wasn't potty trained up to age 6." Gabriel added how his son never learned how to control his bowels and, as an adult, is still in diapers. There was an additional sign that represented their child's missed signs of delays in development: lack of eye contact.

Lack of eye contact. Wilson and James both remarked how their children missed the developmental milestone of making eye contact before their child's AS diagnosis. This lack of eye contact raised the fathers' suspicions. Wilson stated how his daughter "would not make eye contact if you tried.” While James simply said, “No, eye-contact.” As the fathers shared their children's missed and delayed milestones, after their child's official AS diagnosis, they had a series of post feelings and reactions after receiving the news their child now had an official AS diagnosis.

\section{Fathers' Struggles, Post-AS Reactions, and Feelings}

Once the fathers were given their child's official AS diagnosis, they experienced strong reactions and feelings that their early suspicions and wonderings before their child's autism diagnosis were, in fact, validated. To begin, I will discuss the fathers' struggles, the fathers' 
nonstruggle reactions, and the fathers' combined relief and hope. I will end this section with a discussion of how fathers had a new realization of their journey

Struggles. The fathers faced many struggles during the period of post-AS diagnosis in regard to their journey. They described feelings and thoughts of anger, questioning, and future fears for their children. The fathers also described future uncertainties that included the financial concerns of saving enough money throughout their child's lifetime for their care and well-being. Another struggle that fathers faced was how to process feelings of helplessness after their child's official diagnosis. As the fathers discussed their struggles, Paul, Mark, and Scott described their feelings of anger, denial, and questioning.

Anger, denial, and questioning. After the doctor stated his son's diagnosis of severe autism and an auditory disability, Paul expressed the feeling of outrage in response to the doctor's suggestion that he and his wife should be, “open to, putting him [his son] into a state facility." Paul continued sharing his anger, saying that the doctor was "an expert of nothing." However, Paul also claimed that he is still "stuck on denial." He continued with, "I told you I've been in denial ever since. I was still into that." Paul has been in denial ever since his son's doctor told him his son was on the AS, now 22 years ago.

Similar to Paul, Mark also experienced denial over his child's autism. However, Mark's denial manifested in an angry reaction towards friends when they mentioned his child was different than their own children. Mark recalled how he had "alienated so many people for suggesting that my son was autistic." Scott had a different struggle. He is resigned that his adult son will never learn necessary skills such as, "eat with a fork, instead of with his hands. I'd like, getting him to take care of himself and, you know, handle his bodily functions would be great. But I don't see that ever happening." He is angry that his son cannot and will never learn those 
life skills. In contrast to how Paul, Mark, and Scott expressed anger after their child's diagnosis, William went into question mode with his son's doctor.

When William and his wife met with their son's doctor to hear the results of their son's tests, the doctor shared with them that their son had a diagnosis of PDD (Pervasive Developmental Disorder). In 1991, autism was called PDD. The PDD diagnosis referred to a group of disorders described by delays in the development of socialization and communication skills (Achkova \& Manolova, 2014). William's question was one of hope before receiving the doctor's response. "Ever the optimist. I asked the doctor will he get better? The doctor replied. He might get worse." Upon receiving this news, William's whole world changed in an instant, "That's when the bottom falls out." Along with anger and the questioning of their child's doctor, the fathers shared with me their fears for the future.

Fears for the future. Now that the fathers' children had an official autism diagnosis, the fathers had moments in which they experienced a fear for the future. The concern the fathers had spanned from who would take care of their child when they no longer could, to placing their child in a group home, to the high cost of having a child on the AS. David spoke on his fear of what will happen when he is 70 and his son is 32 , and how that it will be more difficult for David when his son is older. He pondered, "at what point am I going to be not able to do this for him anymore?"

Wilson disclosed a different fear than David. His fear centered on the possibility of placing his daughter in a group home. He and his wife have a dream of turning their home into a group home, but what if they can't? He told me he had read about too many unsafe group homes where individuals were either sexually abused or physically abused, "those things just break your heart." He also was aware, though, that there were safe group homes where abuse didn't occur. 
In contrast, William had a different position. He viewed his future fears as "every challenge is in the context. What's going to happen after I'm gone? When I can't be there to protect them, and we can't be there?" Underlining fathers' expressed fears was a worry of not being able to provide for their children and provide for their families.

Income issues. David expressed his struggles supporting his son while being the only provider in the family as his wife had quit her job once their son received his AS diagnosis. He remarked, "The challenge is how to balance between being at home and being supportive and then moving the family forward with only one income" (i.e., moving out of their apartment and purchasing a house). In contrast, Anthony had income issues and would lose income if he took off from work when he wanted to attend his son's Individualized Education Program (IEP) meetings. Two of the fathers talked about how much money they would need to earn so their children would be taken care of throughout each child's lifetime.

Wilson and William were told how many millions of dollars they would need to save for their child's life and future by experts in the field of disability. Wilson was told by a disability expert "you're going to need a couple or \$3 to \$4 million." William was told "he would need \$4 million for the care of his son" for his son's lifetime. He continued sharing with me, "that's a pretty big number." Wilson took a different approach by taking out a life insurance policy on his grandmother in the amount of $\$ 1$ million to provide for his children's AS needs. As the fathers spoke, their voices dropped as they recalled the moment they heard such a large amount of money would be needed. They accepted this reality while feeling simultaneously overwhelmed at the daunting task of earning the needed total. As a result of this information, the fathers went into problem solving and solution-oriented mode and accepted this challenge. Along with the 
financial concerns the fathers had faced after their child's autism diagnosis, two of the fathers acknowledged feeling inadequate as the next section conveys.

Feeling dumb and "helpless." Gabriel recalled how he felt dumb because, as a teacher, he had attended a teacher training program. He had one class on Special Education and had no idea about autism. He shared with me, "I had read one chapter on autism and decided I knew all about it." Gabriel continued sharing how he had his ex-wife had made, "the dumbest mistakes, the little red flags that we missed along the way." Gabriel and his wife would pick their daughter up, and she would cry, "the more we held her, she would cry, and there's something about touch." He thought, "I was dumb because we have little signs there, but I missed them" Wilson and Mark recalled their feelings of shock and helplessness after their child's official autism diagnosis. When Wilson received the news of his son's severe autism and severe ADHD diagnoses, he remembered his experience and shared, feeling shocked. His shock was represented by the questions he asked himself. "What went wrong? Who did something wrong?" Mark recognized feelings of frustration combined with helplessness in not being able to help his child after both his children, were both diagnosed on the AS at different times during different years. He expressed, "I'm not doing what I was put here to do. I just feel like I'm not able to do what I'm here for." Wilson and Mark experienced their world changed the instant they received the news of their child's diagnosis. As the fathers expressed and recalled the struggles in their journey, they talked about when they had an absence of struggle.

Fathers' nonstruggle reactions. Just as there were fathers who struggled with their child's AS diagnosis, fathers also had experiences of no struggles. Upon receiving the news that their child was on the AS, some of the fathers did not struggle with their feelings and their reactions. They accepted the news and realized they were on a new journey not only with their 
child but for themselves as well. Also, they had times when their reactions were on the lighter side upon hearing the news their child is on the AS. Those nonstruggle reactions included: (a) no depression and feelings of trust, (b) relief, (c) relief and hope, and (d) realization of the journey.

No depression but feelings of trust. John shared his feelings regarding how he did not feel depressed after his son's severe autism diagnosis. He remarked, 'I don't think I ever got to the point of depression." John credited his faith in not experiencing feelings of depression. He, “certainly thought about it a lot but I think, ... our, faith in God was really a big thing because, well, Bible says, you know, 'I have planned for each of you.' John believed in God and this belief in God's plan averted him from feeling depressed.

William had a similar feeling to John, that is, one of trust. William shared how he processed his son's diagnosis as "courageous trust." William believed his trusting "assumes" he did not have to "see the invisible hands, but I do know it's not, it's not as bad as I think it is." In his estimation the hands were of a God. William's "courage to trust" goes back to when one of his daughters was very ill. He did not know if she would survive, but she did.

David talked about how he felt trust manifested in his life through his belief that "God, He's in charge of what we're going to be able to do in trusting Him by faith.” Having faith in things that he could not understand was a source of strength for him.

Relief. James and Gabriel commented on the feelings they processed after their child's autism diagnosis. James said his chief emotion was relief. James commented on feeling "it was a relief" to have received his son's his official autism diagnosis. Gabriel experienced two feelings after he processed his son's diagnosis, relief and unrealistic hope. The fathers' relief was attributed to their child's official AS diagnosis, as their feelings and suspicions that their child was different were true and in this truth they could move forward. 
Relief and unrealistic hope. Along with relief, Gabriel had "this unrealistic hope that things would be okay" after hearing the doctor state his son's diagnosis of "severe autism and severe ADHD." After processing his feelings of relief and unrealistic hope, Gabriel moved into problem solving and solution thinking mode. He asked, what did he need to do to provide for his child? What services did his son need and how would he access those services?

Realization of the journey. In reflecting after their child's AS diagnosis, the fathers understood they were on a new journey now. Gabriel shared how he recognized a new feeling. In reflection, he understood how he and his wife were on "a special part of the journey now" that had changed their lives. Anthony echoed Gabriel's statement, with his own, "it was a journey. It took me, me personally, it took me a long time to come to a realization that, that we have to adapt to his, his form." Anthony's realization of the journey he was now on provided his acceptance in adapting to his son's autism and the new journey they were now on. There were a myriad of responses experienced by fathers regarding their new journeys. Having faith in a God stabilized some fathers. For others, it was the strength of their marriage that helped ground their lives. William shared, “we had a strong marriage. That's what the key thing was, and then we would get through this." With an official diagnosis for their child, almost all recognized the change of direction in their lives.

\section{Fathers' New Reality}

As the fathers continued along their journey, they experienced and encountered a new reality. This shifting paradigm first included: (a) the fathers' hopes and dreams for their child, (b) the loss of their hopes and dreams, and (c) the resetting of the dream. The next new reality along their journey included the fathers' experiences with the child's autism behaviors: (a) child's severe autism behaviors, (b) public stigma, and (c) fathers' worries and fears. The final section in 
the fathers' new reality includes the expectations of the fathers: (a) men staying silent, and (b) fear of child's severe behavior toward father and safety of his child.

\section{Fathers' Hopes and Dreams for Their Child}

Fathers shared their hopes and dreams they had for their child from education to wanting to hear the words I love you from their child. Anthony shared the dream he and his wife have for their son regarding his education. "We have that hope and dream that he's going to get his diploma, but we're going to be okay if he just, you know, get the certificate of completion. We're going to be okay with that." James also mentioned his hopes and dreams for his son. He wanted his son to be a more successful entrepreneur than he is. James still holds onto his hope that his son could go to Harvard. Paul had a different dream. He dreams his son will, "have a friend and someday fall in love and get married and have a son of his own." He also imagines the day his son will tell him he loves him without Paul's prompting him. Gabriel had hopes and dreams for his children as well. While Gabriel wants and dreams his daughter to have what he called a, “a junior life.” He defined his daughter's junior life as, "Live on her own with her support like in a group home. I want her to have work or a job that she likes." While Anthony, Paul, and Gabriel discussed their hopes and dreams for their children, there is another reality the fathers spoke of that addressed the evaporation of these hopes and dreams.

\section{Loss of Hopes and Dreams}

Some fathers also had to shed their initial parental aspirations and visions for their children. Anthony is still in the process of coming to terms with the reality his son might not achieve the educational goal he had set for his son. His hopes and dreams for his son include his son earning a high school diploma not simply a certificate of completion. He shares this dream with his wife, "but we haven't come to terms that he may just not walk or just get the certificate 
and say, okay, you're done with school now." As the fathers' hopes and dreams shifted, their life plans consequently changed and were adjusted.

Scott recalled how he had mapped out his life. He stated, "I had a pretty good plan; that plan got chopped." He continued, "I do not live my life. Cause my life consisted of lots of travel, scuba diving, skiing trips, nice houses. I had it all worked out, that completely ended." William expressed how dreams change, "All the things that you build up for your children that you project onto them, and you hope for that dream, that dream has died." He had to adjust to the idea that now his son was not going to "be a CEO and they're not going to be probably the champion Star baseball player that you had envisioned."

An additional hurt the fathers talked with me about was the loss of the dream that their child would never participate in a sport during their school years. John expressed how he envisioned, "my kids grow up playing sports. At the time, it's kind of was a bummer." In reality, his neurotypical daughter and son did not play a sport either. Gabriel's loss regarding sports was the reality that his son's autism is so severe, "other autistic kids are like what's wrong with him? They're frightened of him." Anthony, too, expressed his loss of his son's athletic dream, "Like, oh my God, he's never going to be on the football team. He's never gonna be on the baseball team. He's not going to do all the regular activities like every other kid." Along with their loss of their hopes and dreams for their child, another reality was discussed during the interviews. The fathers realized that a resetting of those hopes and dreams could transpire. This resetting of the dream is discussed in the next section.

\section{Resetting the Dream}

Upon processing that the hopes and dreams the fathers had mapped out for their children might not be realized, a resetting of the dreams took place. The fathers revealed this process and 
the new dreams in their interviews. When Gabriel realized his child would not be playing sports, he took a different path involving sports. He became a coach to other children who have developmental disabilities so that he and his daughter could participate in sports activities together. John shared, how he reset his dream for his children to play sports in having his kids join a sports league for kids with disabilities.

Conversely, Paul took a different path regarding sports. Paul made his son "take a sport," but his son did not want to play any of them. He continued his conversation with me, sharing his sports experiences in school. "I wrestled, and I played tennis, and so I gave him a choice. He didn't want no part of wrestling. He would have been great. I was the bad guy making him take tennis all four years." Just as the fathers progressed through their journey by resetting their hopes and dreams regarding sports, some of the fathers also had to reset their expectations of behaviors their children displayed as a result of having autism

\section{Fathers' Experiences with Child's Autism Behaviors}

Fathers who have a child with a diagnosis of severe autism are placed in situations in which the child's behaviors have an impact on their lives and their own lives as fathers. Scott, Wilson, Mark, and Gabriel dealt with their child's severe and often violent displays of dangerous behavior. Those behaviors included: (a) child's severe autism behaviors, (b) public stigma, (c) fathers' worries and fears.

\section{Child's Severe Autism Behavior}

A child with severe autism frequently requires considerable support in the dealing with their challenges and behaviors (APA, 2013). Scott shared his experience with his son who has extreme autism behaviors. He described his struggle to use a prone restraint on his son. Prone restraint is a technique used to immobilize an individual where they are held face down upon the 
floor. His son was bucking as his father "was on top of him.... He's spread eagle on the ground, on his back, and I'm on top and trying to pick his arms because he's so in rage he will scratch." Scott's son then flipped his father over.

Similarly, Wilson recalled his daughter's behavior when she became agitated. $\mathrm{He}$ remarked,

And she'll get upset to the point where, two times she's thrown the remote control or other objects at the television and a big screen to the point now that we've got one of the, a plexiglass covers as a protector that goes over the television screen. After the second one (broke), we finally learned our lesson.

Sometimes these severe behaviors would occur in public. Gabriel shared how his son with severe autism eloped from his ex-wife's house despite round the clock care with three aides. His son figured out one of the doors was not locked and waited until it was early in the morning before going out. His son's three aides were asleep on the couch after a long night of his son's severe acting out. He escaped from the house, clad only in a shirt and his underwear, and went to a local market. He went to the bakery section, grabbed a sheet cake, and stuffed it in his mouth as he continued stimming (i.e., repetitive body movements and behavior) and running though out the market. One of the clerks in the store recognized his son. She left the store and walked to the closest neighborhood searching for his mom, as she knocked on every door at six a.m. until she found the house. Gabriel shared that the house his ex-wife lives in, where the incident took place, has every single door and window locked. Her home is a virtual prison, and his son still managed to escape. He still worries this could occur again despite all the preventive measures that are set up to keep his son safe. Those measures include: (a) having three aides providing round-the- 
clock care of his son, (b) all windows are locked, (c) the door at the back of the home is locked, and (d) the front door is always locked.

While Mark's son's impulsivity was directed at his father, "it was my son not wanting to do something, and I'm trying to keep him from running away, and all he's doing is punching me about the upper body and face.” Just as these fathers talked about their child's severe autism behaviors, the topic of public stigma was also shared.

\section{Public Stigma}

Public stigma, defined as a: (a) lack of knowledge from others, (b) judgement expressed by others in the fathers' lives, (c) feelings and experiences of rIction for their child and self, (d) rejection, and (e) experiencing a lack of support (Broady et al., 2015; Gray, 2002) was experienced by several of the fathers.. Gabriel experienced public stigma during his son's severe behavior in a parking lot where there were bystanders. His son was having a severe reaction while in the car with his father and accompanied by his three aides. The son grabbed his father while his dad was driving; Gabriel had to find a safe location to pull over and attend to his son's behavior. He found an empty parking lot and pulled in. Gabriel had engaged the child locks on both doors so his son could not get out of the car on his own. Gabriel exited the vehicle and opened the doors; his son and the three aides spilled out. Gabriel preceded to place his son in a prone restraint to protect his son from further self-injurious behavior as his son slammed, his own "head into the ground." Gabriel had, "inadvertently pulled up right next to a CrossFit studio, so I had lots of bros coming out and wondering what was going on.” In this moment, Gabriel said to the gathering crowd:

Because the first thing people they say, Get off the kid. If you don't get off that kid. I'm calling the cops," while we're doing restraint, I have to do the teachable moment, I'm his 
dad. This is my son; these men [aides] are helping me. We're having behavior right now this is a prone restraint nothing's wrong. But, people sometimes, like this last time people heard it and they were like well they were like okay. But, a lot of times people are screaming.

William recalled his experience when his son would act out while the family was eating a meal in a restaurant. People told him he was not a responsible parent. William shared how he understood, "they don't know. Let their child run free, and all that kind of stuff and you just learn to deal with it. They don't know how to do that? We could appreciate it." Fathers who have children on the AS who exhibit behavior in public regularly face the experiences of dealing with often-cruel comments from the public. Along with the public stigma, fathers described their fears and worries about their child's acting out behaviors.

\section{Fathers Worries and Fears}

Scott, Mark, Wilson, and James discussed their fears and concerns regarding their child's behavior. Scott discussed his fear of his son's aggressive behaviors, "The worst would be the aggression." Scott continued how he has to "walk on eggshells to make sure that he doesn't go off and hurt me or hurt himself." Scott talked about how his son's impulsivity is a fear he holds when his son's behavior turns against him, and how he needs to be more aware. Just as Scott is knowledgeable of his son's behavior, Mark shared his fear of his son running away as he had done previously, leaving their home and hiding at a neighbor's home. Though, in this instance of behavior, it was his son's lack of physical and emotional control over his emotions. However, in contrast, William had a differing experience from the other fathers. He did not fear or have a worry concerning his son's behavior. 
Wilson described how he felt as he shared his fear of failure as a parent to his two kids, both on the AS. His fear was that somehow, he would let them down as a parent. Fathers, moreover, experienced and expressed their doubts during their interviews and wondered if they were good fathers, were they good parents? While James discussed his misgivings, he commented on his uncertainty, wondering if, “I mean, it's hard, so hard, you know, if you're doing it right, and it's hard to know what's going on in his mind." After the fathers discussed their worries and fears combined with feelings of failure. Wilson shared, "I must be a total failure because my life doesn't look like any of these things that I see on television. I read about in the paper." While Scott felt like he had failed his son with severe autism because, "I feel like I'm not doing a very job (i.e., as a parent) because I'm afraid to take him out in public." They also discussed the expectations they had on being a father to a child on the AS.

\section{Expectations of Fathers}

When interviewing the fathers, I listened as they spoke about the expectations of being a father to a child on the AS and how those expectations impacted their growth as men. David shared how men stay silent regarding their stress level in being a father to a child on the AS. He shared, "Well nobody talks, nobody talks about the stress level of, in being a man. Fathers are silent; men don't talk about their stress levels." He continued speaking of male expectations in the African American community. "Why haven't you done that? You're supposed to do that. Why we weren't home, and they get the same thing at church. How come you're not present? Then men withdraw. Like I'm getting the same message from everywhere." Just as the fathers dealt with their expectations as fathers, fathers who had a child with severe autism had to deal with 


\section{Fathers' Concerns of Personal Safety and Concern for Personal Safety}

Fathers had concerns for their safety, including their mental/emotional and for their physical safety when dealing and interacting with their child/ren. The impact of stress had Mark seek a physical timeout from his son. He remarked, "Dad needs literally a physical time out. I need my sanctuary." Scott, as well, knew about the expectations of fatherhood and the need for a break, "I love my kids. Don't get me wrong. Do you know what, it's, it's enough already to be with them all the rest of the time? So, it's a lot to deal with. I need a break." Scott also shared his fears connected to parenting. He recalled his experiences of feeling fear in dealing with his son daily while his son was in his custody. His son's severe autism impacts Scott's safety and the safety of his son. Scott has to be careful not to raise his voice when talking to or addressing his son. When his son was four and five, it was difficult not to yell and get angry at him, "he's trying to kill me. I'm bleeding cause he bit a chunk out of my arms." Even though Scott was worried about his safety, Scott had to remember his role as a father, which is discussed in the next section.

\section{The Role of Father in Their Child's Life}

The participants in this study revealed how their role as father was vital in the life of their child. When speaking with the fathers, they discussed the roles they played in the lives of their child in four ways: (a) parenting, (b) community leaders and mentors, (c) father as provider, and (d) father as teacher.

\section{Parenting}

When the fathers shared their stories, they recalled parenting struggles. The fathers shared being a parent to a child on the AS often can be intense and it is difficult being consistent in the raising of their child. Paul recollected how he is committed to his son, that is, "never 
gonna quit." He shared how he realized it was his job to be "very consistent" with his son.

Similarly, Gabriel remarked how parenthood made him a man and how he had to "grow up" when he realized, "you're no longer number one. Your kids are number one, and you work, and worry, and strive to provide for your kids."

Fathers commented on sharing in their child's school experiences, specifically in their Individualized Education Program (IEP) planning meetings. William shared his involvement in his son's education stating, "I went to 36 IEP meetings." He continued, "there's laughter, and there's tears ... and his gratitude for teachers." Scott, however, had a different experience when attending his son's IEP meeting, "in the early years, I'll admit, sitting there with my ex-wife in an IEP meeting, they all talked to her." David shared two different occurrences with me: how his son's IEP meeting went once he was out of primary school, then how his son's IEP meetings went in elementary school. He used his knowledge as a school administrator during his son's IEP meetings, saying, "I would imagine for the teachers, it's kind of intimidating, but also it's also a comfort because I could walk into an IEP meeting and all the [usual school] preliminaries didn't have to be talked about." However, he had the opposite occur during his son's first IEP meeting, "it was kind of disheartening because" the teachers did not "even give me a chance. Instead, they would deal with my wife first, which I don't mind cause she needs to."

In Paul's IEP meeting with the school, "No men at the IEP meetings I went to." He attended all his son's (IEP) meetings but was ignored. Fathers want to be not only included in their child's (IEP) meetings, they want their voices to be heard and welcomed in those meetings.

Fathers of children with severe autism talked about how they had no one to talk to about their experiences and wanted to know what other fathers' experiences were like. As the fathers 
with a child with severe autism shared their experiences of isolation, they additionally shared with me their experiences in their communities as leaders and mentors.

\section{Community Leaders and Mentors}

William, David, and James discussed their roles as advocates and leaders in the disability community. William shared his role in the business community as a mentor to other fathers who had a child with a disability. He became a disability employment advocate in the business sector. David started a men's group at his church so men could mentor one another.

Once James started talking about his son's autism in the business community, he became a disability advocate. James commented, "others began to engage with him [my son], you're talking about it, then other parents opened up." One individual, his business partner, shared his story about his own family connection, "my daughter has that too." Just as James became a disability advocate, William became a leader in the area of disability leadership as a result of his son being on the autism spectrum.

William shared his experiences taking on a leadership role in the area of disability employment after his son received a diagnosis of PDD. William recalled how he started thinking about the impact of disability and how he could create opportunities for individuals not just with autism but other disabilities as well at the company where he was senior vice president. William remarked, "in helping one individual with a disability, all people benefited." He recalled how using universal design where the environment is designed so it can be accessed by all individuals regardless of their age, size, ability or disability really is, "it's universal. It's seems that the world forgets that part."

Fathers were also involved in faith-based organizations. David began a men's group where he attends worship called Men's Breakfast, held every third Sunday. The fathers get 
together, and David brings his son with him to their meetings. He expressed his feelings on the lack of places at his church for men to talk and address male issues. Fathers meet and talk about what is going on in their lives how they have "a need to voice some of their concerns." Although he is grateful, he stated, "at the same time, it's going to sound weird. I had to create it in order for it to exist."

William discussed what his involvement in his faith-based community brought to his life. Going to church reminded William of the things he knew, things that are often forgotten outside of his faith community

It's not nothing we hear anything new. We were reminded of some things we want to be reminded of, but we're with a group of people, [his faith community] who care about each other and try to bring out the best in each other cause the world can do [the world doesn't often bring out the best in us].

Just as William shared the impact of his participation in his faith-based community, Gabriel discussed his community involvement. In the disability community, Gabriel serves as a volunteer mentor in a youth sports league for young people with developmental disabilities. This is a place where he gets to spend time with his daughter on the AS and other kids with developmental disabilities. He shared his views on being a mentor,

I want the kids just to be out in a park, running around on the grass, under the sky, like kids are supposed to do. I put a lot of time into the social dynamics, so I always have circle.

Anthony described the community as family, "we're very involved with our families, both sides." Anthony viewed community engagement as time spent with his extended family. 
Just as the fathers discussed their roles and participation in the community, the community from faith-based organizations to youth sports to business organizations, they also shared about their role as provider.

\section{Father as Provider}

Participants in this study talked about their role as provider, although they defined the role of provider somewhat different. The fathers defined provider as disciplinarian and monetary provider. For example, William discussed part of his role of being a provider also meant that he provided the discipline in the family. William shared his thoughts on the impact of going to counseling/therapy with his son to learn about using timeouts. He learned how to be patient with his son, "that saved us. Thousands of dollars we spent in therapy just to learn that lesson." He explained how his son got so good at timeouts. His son would "pick up the egg timer and walk in the living room and sit there by himself. .. [having] awareness like, Oh, I screwed up. I've got two minutes on the timer down. I'm doing my timeout."

Mark mentioned his role as being the main financial provider for his wife and children. He remarked, "I bring home the bacon, and my wife makes sure that those children are not wanting for anything." Scott shared, "I've been able to, uh, make enough money. I mean intentionally to really focus on not spending. I mean, my job is, I see it is to make sure he's taken care of for the rest of his life."

The fathers discussed the financial strain of autism in their role as provider. When a child is diagnosed with autism, there is often an additional financial stress as a result. John commented how his son was diagnosed with severe autism when services and autism interventions were all out of pocket costs, as autism was not covered by insurance. He recalled, "I didn't make much money at the time and didn't know how we were going to make ends meet." During the early 
days of autism, back in 2000, interventions were not covered by insurance, and families had to pay out of pocket for services. William's family had to survive on only one income, as his wife had quit her job as soon as their son was diagnosed with severe autism. When asked about the financial burden of autism, William recalled after his son's PDD diagnosis asking experts what amount he should save for. He was told "Four million [dollars], that's what they said, so that's a pretty big number." Such an amount was supposed to be enough for the care of his son for his son's lifetime. Wilson was also told, "the target's like two and a half, three million bucks. I'm like, man, and I don't think I'm going to get the three million bucks."

Providing care for their children is another role fathers play in their children's lives. One father in this study who had a child with severe autism was his son's main care giver along with his ex-wife. Scott disclosed the care he gives his adult son, "I've just never gotten used to it [changing his adult son's diaper], I hate it. I hate it as much today as I did the first days, changing his diaper. I just hate that.”

Gabriel, another father to a son with severe autism, talked about how he creates an illusion when helping his grown son take a shower, that it is just he and his son with the son's three aides standing by in case they are needed. He wants a neurotypical life for his son, even though his son has three aides who live with his mother, the father's ex-wife. Gabriel talked about his physical interaction with his son while assisting him in showering. He stated that his son "is wet and slippery and naked and really hard to hold down." He continued talking about how he uses illusion to help normalize the situation, "that it's just me and Jack. We're doing a normal thing. We're talking maybe this could even be bonding." He followed up how he loves his son, but the amount of planning that needs to go into it, even a simple task as taking a shower --and the level of resources needed to get those things done, are different. 
Gabriel also shared how he worries for the safety of his daughter whenever his son is having severe behaviors. He shared one experience where his son and his son's three aides were all in the car, and his daughter was sitting in the front seat of the car. He stated how his son, started displaying severe behavior in the backseat, he was crying, screaming, rocking back and forth. He grabbed [sister's] hair, who sits up front with me, and then he grabbed my arm, and I'm driving. So, this is clear and present danger. We, we need to stop. Fathers who have a child with severe autism are challenged and pushed almost beyond their limits of caregiving, still with all the difficulties, these fathers are committed to being the best fathers they can be to their children. Their lives are not easy, and they continue day after day being present for their children even in very difficult circumstances. Just as fathers have the role of providers in their children's lives, they also guided their children in navigating through life skills.

\section{Father as Teacher}

Fathers in this study taught their children life skills which included personal grooming skills. David shared his thoughts on how his son is getting older and how he needed to teach him how to shave. He guided him through step-by-step how to shave using scaffolding. Due to his son's autism, he could not just hand him a razor and shaving cream and show him once how to shave. David spent weeks teaching his son the steps involved in shaving. David knew shaving would bring his son stress, “you can't just take your son to the bathroom and say well I'm going to show you how to shave." Instead, he showed his son with the guard on the razor. "We kind of went through those steps. Everything is a procedure." To be available for their children and to be able to teach necessary living skills, it takes time and the availability and presence of a father to teach his children needed life skills. This father had to think more carefully and creatively about 
engaging in an everyday grooming task. This is a vastly different situation from fathers of neurotypical sons who do not have to worry about teaching their sons to shave.

Anthony taught his son another essential life skill. He taught his son how to selfadvocate, and 'I'm educating him being a man, how to show respect, how to give respect, how to advocate for yourself, and I want him to learn that how to advocate for himself." Anthony additionally shared how he is teaching his son to like himself and not to "worry about anybody else."

Paul teaches his son how to text his mom, as he is not really "communicative." He teaches him to say through a text message, "this is a way to say I love you. I tell him, you know, if you really love your mom, you really want to make her feel good. This is how you can do it by yourself." In contrast, Gabriel teaches his son a different lesson. He shows his son a safety lesson in using counting to keep safe during a prone restraint his father uses when he is going through severe autism behaviors. Gabriel is "literally wrestling with him, trying to pull him out, trying to get him to count. 'Let's count to 10, Jake.' Because he can do that." Fathers play many roles in the lives of their child on the AS, from teaching basic life skills to texting as an expression of a son's love for his mother.

\section{Fathers' View of Disability}

The participants in this study discussed their views on disability in three different ways: the gifts of autism, familial similarities, and the fathers' beliefs regarding autism.

\section{Gifts of Autism}

James discussed his ability to have empathy for parents who have kids with severe autism, "and you see kids that are more severely impaired functioning, that are much bigger burdens for their parent, have it a lot, a lot more empathy for them." When asked to comment on 
the gift autism brought to their lives and how their life plan changed, Steve said how his son's AS diagnosis forced him to think about what was important in life, how his plan changed. He pointed out, "Were they really that important? And is my plan really a good idea to begin with? God had a different plan for me. And I had a choice whether to follow it." Wilson shared his feelings regarding his daughter's autism and how he was surprised at what his daughter could do. His daughter sends correctly punctuated texts to him even as her autism, 'is a moderate to severe. She talks and surprising what she's capable of doing." These three fathers who have a child on the AS spoke of the gifts of autism. Fathers experienced greater empathy, and the focus of their life shifted as a result, once the gifts of having a child on the AS were revealed.

\section{Familial Similarities}

Mark shared with me his realization regarding autism and his sharing AS characteristics with his child. He stated, "and that's when it dawned on me that hey, that 30 years ago, this would have been a behavioral problem." He continued, "the diagnosis is when you read it in black and white, autism spectrum disorder. But when you look at the reasoning why and listing why. I go, well they just described me. Twenty years ago. It's shocking.” Paul remarked, “I think many of us would have been diagnosed with some of these things, had they been around back when we were kids." While James, commented on how he recognized familial similarities with between his son and his uncle:

If you just turned like a couple of knobs of my brain to the right, I can end up with like my son. I think it was easy for me to make that, and I looked at my uncle and other people in my family.

Some fathers had autism knowledge, and some did not have autism knowledge. 
James discussed his expertise regarding the DSM-IV. James studied the DSM-IV while a former girlfriend was studying for her psychology exams. For him, reading the DSM-IV was for pure intellectual reasons. James talked about his interpretation of why the DSM-IV was relevant. He thought in the case of autism. Autism diagnosis rates were rising, combined with the controversy regarding vaccines now being over; individuals are now having to "actually figure it out yourself." The fathers additionally shared their specific autism beliefs.

\section{Fathers' Beliefs Regarding Autism}

The fathers also shared the beliefs they had regarding autism. William discussed the changing mind and described autism as "some people say this may be the next generation of evolution." While John commented on the social construct of autism, he stated, "And then there's a social construct to it there. And you know, parents with kids with autism and people in the autism world. It's funny because then you start pointing out the people [with autism] that are engineers." Scott, a father of a son with severe autism stated, "if you can't, you know, wipe your bottom, and you're in diapers. So, yeah. So, we used disabled; well, it doesn't make me feel better to call them something different."

David, in referring to fathers who had child that was more severely involved than his child stated, “I couldn't imagine having a low functioning autistic child. I don't know. I don't know what that's like. I don't know what that would be like." For David, having a child with low functioning autism would be too difficult for him to engage in interaction. Scott brought up two points regarding his beliefs on autism. He replied, "my life is forever changed" and continued with his feelings on autism prevalence rates. He is bothered that everybody has autism now. David shared how, as the prevalence rates of autism diagnosis increased, his son's severe autism 
was viewed as “less than" and not crucial as Asperger's gained more popularity. His son's severe autism was viewed not as valid as the other less severe forms of AS.

He remarked, "it sort of diminishes how you feel. Maybe he's teeny bit on the spectrum, and if you're looking for sympathy, you're not going to get it from me." He is a "little disappointed that it seems like its watered-down autism...There, there's huge degrees on the spectrum." As fathers shared their beliefs regarding autism, they expressed their perceptions of the labeling of children under the umbrella of autism. They additionally shared the impact and the role their faith had in their lives as fathers who have a child on the AS.

\section{Impact of Fathers' Faith}

Several fathers brought up the subject and the impact of faith in their journey in having a child on the AS. They spoke about how faith served as a lens for how they viewed their child, the effect of grace, and the hope that faith gave them in difficult times. John talked about how in his Christian faith helped him view his son's severe autism, "we are all flawed, we're all broken" that, in his view, "we are under the grace of God. We are all loved, regardless of our limitations." John further affirmed, "I think I would have a hard time, much harder time," without his faith. Wilson shared, "God knows where our lives are going to be.” Similarly, John shared, "Well, Bible says, you know, 'I have planned for each of you.' God knew what would happen with [his son], and He allowed that to happen for whatever reason. He allowed [his son] to be who he is."

In contrast, William shared about the impact and view of his faith, which differs from Wilson's and John's. "I don't try to understand, predict what God is all about." William continued sharing the impact of his faith. He trusts that, 
There is a living God whom I don't understand and that things happen and that that's a source of strength for me when I can't bear it. My God didn't put pain on the earth, illness, and all that kind of stuff as some sort of cosmic lesson.

He further explained that when the bad things that happen, "That's not God's doing, good things or the grace you got, all the bad things. Shit happens." He stated, "not that hell is a big a thing to me and in heaven as a hope. But faith is for this life."

David spoke about the role his faith played in his life and the life of his son, "We have a place where he can go to feel accepted. He is involved in some different things at church, like in the church choir, he doesn't sing, but he plays an instrument." David further stated on the impact of faith in his life, "my faith personally, I think plays a role because that means that I know that God is in control." He continued, "I know that there's things that are outside of my control, and it gives me comfort and knowing that there's someone bigger and stronger and more able than me to protect my son and to help."

Paul stated his faith gave him a place to pray for his son and the concerns he has and space to deal with his feelings of aloneness, "I prayed for him a lot. I think he is sad and lonely. I'm usually alone." Faith's role in the lives of these fathers provided: (a) community for themselves and their child, (b) the knowing that they were not alone, and (c) a space to turn inward for comfort and guidance. Once again, their journey, and its impact upon their growth as fathers, are interconnected. Just as their faith played a role in their experiences of having a child on the AS; fathers who have two children on the AS have different experiences.

\section{Distinctive Experiences of Fathers who have Two Children on the AS}

Fathers in this study who have more than one child on the AS had unique experiences not discussed by the other fathers. Those experiences include: (a) walking on eggshells, (b) constant 
vigilance and awareness of behavioral issues, (c) focusing on the child, (d) lacking a neurotypical frame of reference, (e) unpredictable behavioral concerns, and (f) parenting differences between the children. In the next section, the perspectives of Gabriel, Mark, and Wilson, are presented regarding the additional parenting challenges they experience as a result of having two children on the AS.

\section{Walking on Eggshells}

Gabriel discussed how he feels like he "walks on eggshells with his son." He never knows what will trigger his son's severe autism behavior. He lives in fear when he is with his son, when they are out in public, or at his ex-wife's house where his son lives. He also fears for his daughter's safety as she is also on the AS. She lives with her brother in a house that is on lockdown, in that every door and every window is locked. Having two children on the AS brings a state of constant vigilance to the life of this father who has two children on the AS.

\section{Constant Vigilance and Awareness of Behavioral Issues}

Mark, Gabriel and Wilson all discussed being very aware of the possibility that their child's behavior could change at any given moment. Hence these fathers walk through their days being constantly aware. Mark discussed how he needs to be aware of his son acting out his frustrations on his daughter, "you're punching your little sister." Gabriel added there is "the constant worry, and the constant anxiety" in having two kids on the AS. Gabriel, shared having two children on the AS, and with his son's extreme behavioral challenges, resulting in his son living with three aides in a home that is on 24/7 lockdown, produces a high level of anxiety for him. Gabriel also lives forty-five minutes away from his son, and this lack of proximity adds to his concerns. Wilson shared, how he and his wife spent years when they avoided taking their kids out to dinner because, "we had so many incidents where someone would act out and in the 
middle of the meal you're like having to leave or, you know, you're disrupting the whole restaurant. It's like, well, you do that once or twice and it's, you know, you avoided after that." Just as fathers had challenges with being constantly aware of their children's behavior, fathers who had two children on the AS expressed their concerns.

\section{Focus on One Child}

Mark articulated a parenting concern regarding his daughter. He mentioned that the primary focus has been on his son and dealing with his autism, not on his daughter and her autism. He asks himself, "We have put so much time and effort into [his son], have we been failing, our [daughter]?" He wonders if he has ignored his daughter?

\section{Lacking a Neurotypical Frame of Reference}

Fathers who had two children on the AS pondered what it would be like to have a neurotypical child because both their children were on the AS. Mark wondered, "I don't have a sense of what's typical. I'm trying to make them normal and [wondering] 'what's normal?'” He had no idea what or how his life would be different if his children were not on the AS or how the lives of his children would be different. Gabriel having two children on the AS where his son's autism brings extreme behavior challenges that his son lives with three aides residing in a home that is on lockdown produces a high level of anxiety for him. Gabriel also lives forty-five minutes away from his son, and this lack of proximity adds to his concerns. Fathers who have a

child on the AS and a neurotypical child have distinctive life experiences (i.e., their children can go off to college, their children can get married). Fathers who only had children on the AS had no idea what the experiences were of a father with one neurotypical child and one on the AS. They did not have experience comparing to or a means of knowing what it was like to raise a child without autism. 


\section{Unpredictable Behavioral Concerns}

Gabriel spoke about wondering what kind of a day he will have with his son and daughter, who are both on the AS, when he has them all day on a Saturday, as his ex-wife has primary custody of their children. He spends time on the weekends with his kids, and his children live at his ex-wife's home. He told me how these are the thoughts running through his head. He wonders "is it gonna be horrible? Are we going to the hospital? Are the police gonna be involved? Or are we just gonna have a cool day." Gabriel has those thoughts each and every time he is with his children.

\section{Parenting Differences Between the Children}

The fathers who have two children on the AS in this study indicated that they parent each child according to their needs. Mark shared, "They both struggle from being able to see somebody else's point of view. There's absolutely no flexibility and so she [my daughter] wants nothing more than to be in her brother's space." Mark's daughter wants to be close and connect with her brother however, her brother has difficulties with this.

Wilson also has two children on the AS, a boy and a girl, just like Mark. Wilson expressed a similar challenge between his two kids. Wilson's parenting trials are teaching his kids how to relate to one another regarding why they are treated differently by their father. His son, "can't put himself in her [his sister] shoes." His son thinks everything should be equal and complains how "I wouldn't be able to get away with that." Because Wilson has to parent his two children differently, as his daughter's autism is more severe than her brothers, his son would not be able to get away with the same acting out behavior that his sister does (e.g., throwing a remote at the tv). Wilson will say to his son: 
I'm sorry that you feel that way, but you're right. [Daughter's] goals are a little different than your goals or my goals, and you need to understand that that's part of her disability. And then he [my son] just cannot put himself in her place.

The fathers in this study who have two children on the AS often face unique parenting challenges. This is especially true when one of the siblings has more severe autism than their sibling. William revealed how trust impacted his journey with his son on the AS. He stated, "trust is not just that I have trust, the craziest part is to have the courage to trust." Parenting differences were often daily struggles for fathers that had two children on the AS. These fathers faced these struggles with trust, determination, and courage.

\section{Impact of the Study on the Fathers}

The fathers who participated in the study discussed the impact of the study on their lives. This was not a question asked by me; their sharing was voluntary. The fathers shared their appreciation for taking part in the study.

\section{Gratefulness}

Mark expressed his gratefulness for the opportunity to talk to someone about his experiences. He stated, "I'm just saying, it's very nice to have a conversation with somebody about it."

Anthony expressed his appreciation and gratitude for the time spent during his interviews, "I thank you. Thank you for, you know, letting me take the time and give you my information and my take on it. I have really appreciated our conversations." He continued with, "many of your questions have prodded me to think of things in a way that I hadn't quite done before and really become kind of introspective." Gabriel similarly echoed this sentiment saying 
It's been a nice process for me to kind of work through things that are very familiar, that I'm very familiar with and kind of verbalize them and explaining it to you is kind of a way of like explaining it to myself almost sometimes.

David also expressed his thankfulness for he and his son to be a part of the study.

Participating in the study for Scott was "cathartic." He did not feel that there were other fathers who were having the same experiences he was having in parenting a child with severe autism. David shared with me how having this space to talk about his experiences in being a father helped him. He replied, "it's almost therapeutic to be here to talk to somebody about it. Let me put it that way because I don't talk to very many people about it." For Scott and David their participation offered an opportunity to be open and reflective. David had another need, to discuss how autism could be corrected. He articulated how he had to talk to me about his experiences, how his wife always wants to talk about her emotional experiences. In contrast, he has other thoughts and feelings. He expressed, "I had to talk to you because she [his wife] just wants to talk about the emotional aspect and unload a little bit, and I'm always wanting to get to how do we correct it."

Gabriel shared, "I'd like to say that many of your questions have prodded me to think of things in a way that I hadn't quite done before and really become kind of introspective and think about it." William commented how talking with me gave him moments of self-reflection, and “it's an honor that somebody even wants to hear me talk. So that's, that's a good, that's a huge gift to give me. Thank you." Just as the fathers discussed the impact of their participation in the study, they also shared their moments of growth. John expressed how speaking with me during his three interviews offered him an opportunity to look back on his son's life and how much he and his son have grown. 


\section{Fathers' Personal Growth}

The concluding finding is how some fathers shared their personal development with me. Their progress in their continuing journey centered on: (a) growth realization, (b) need for a physical timeout, and (c) overcoming experiences of public stigma.

\section{Growth Realization}

As fathers continued along the journey of being a father to a child on the AS, William commented on his realization of personal evolution He stated, " he has continued to mature at age 69 , but I'm not the same person that I was. I was a better person because of it [his son's autism]." William also indicated that he was not the same man because he had a son on the AS; he was a better man because of his son and his son being on the AS. John stated:

I think I'm a better person. And you kind of think about what might have been. And back to the dream. You start to realize what you based that dream on, that dream on, and what you thought about how your life was going to go and all that, was based on a lot of stuff that didn't really matter.

Just as William realized his own progress in his journey, Mark realized his maturity as a father was the internal recognition of needing a physical timeout.

\section{Need for Physical Time Out}

Mark brought up his awareness in recognizing when he needed a time out from his two kids who are on the AS. He commented, "My room's a sanctuary for me. So that, that is a, that's a tool that we learned from one of the therapists early on." For Mark, having a place to retreat helped him regain his center and find a quiet inside himself. After Mark's physical time out, he

was then able to return to his son and resume being a father. While Mark expressed his need for a 
physical timeout from his son so he could regain a sense of calm, other fathers discussed how they experienced personal growth in overcoming public shame.

\section{Overcoming Experiences of Public Stigma}

One example of a father overcoming stigma is found in Wilson's example of taking his daughter grocery shopping. He and his daughter were in the market shopping. Wilson's older daughter is 29 years old; however, with her severe autism, she functions at a teenage emotional level. She brings with her to the market her 10 stuffed toy Disney characters. He shared with me how, at first, it hurt his soul when other people who were shopping would stare at his daughter and him. The public's funny looks of, "What's wrong with her?" when he sees adults staring at both of them, was hurtful and he wanted to say, "mind your own business." His growth took time to occur, and he subsequently realized how "they [the public] don't understand, whatever. That's their problem, not mine. But it takes a while to get there to that stage."

\section{Summary}

This chapter illustrated the findings of the main research question of the study, what are the experiences of fathers who have a child on the AS. The data was presented through the through the subquestions: (a) the fathers' before and after reactions in having a child on the AS, (b) the new reality of the fathers' lives, (c) the specific roles they played in their children's lives,

(d) their views regarding disability, (e) the impact of the fathers' belief system, (f) experiences of fathers who have two children on the AS, (g) the impact of the study on the fathers, and (h) the fathers' own growth.

Chapter 5 will include the following sections: (a) a discussion of the findings, (b) the linking of the theoretical frames to the findings, (b) implications for the field (c) areas of future research, (d) reflection on the study, (e) significance of the study, and (f) call to action. 


\section{CHAPTER 5-DISCUSSION AND CONCLUSION}

In this chapter, I discuss the findings related to the research questions in the context of the current literature and my overarching theoretical frames. First, the research questions will be delineated, and the findings connected to the literature base and the theoretical frames used in this study. If there is no literature base that connects to the findings, I will simply discuss the findings. Next, I will link the findings to the theoretical frames of constructivism, disability studies (including the social model of disability), and mindsets (i.e., fixed, stress, and growth). Mindset theory adds to each of the fathers' experiences in having a child on the AS. Mindset theory reflects the fathers' struggles and triumphs and the use of different mindsets explains how the each father was able to explore and overcome the issues and difficulties they faced each day with their child and within the self. In the next section, I suggest implications the study may have for the field. Then I outline the limitations of this study, followed by areas for future research, reflection, and the significance of this study. This chapter will conclude with a call to action. It is my hope that the findings will contribute new knowledge to the research base on the phenomenological experiences of fathers who have a child on the AS.

\section{Central Research Question and Eight Subquestions}

The central research question of this phenomenological study was: What are the lived experiences of fathers who have a child on the AS? The experiences of the fathers are similar in many ways but also quite different. Variations occurred primarily on two major dimensions: the

severity of the child's autism and whether or not fathers had more than one child with autism. In addition, the fathers' experiences tended to differ depending on their community supports and the support offered by family members. The experiences prior to and following their child's AS diagnosis affected the fathers' (a) hopes and dreams they had for their children, (b) views of 
fatherhood, and (c) their roles as fathers. The fathers' thoughts and feelings were affected prior to and following their child's AS diagnosis. All fathers played a variety of roles as a result of having a child on the AS. In addition, the fathers' views on disability were impacted by having a child on the AS. In analyzing the interview data, it was clear that the fathers' lived experiences (i.e., their journeys) impacted their growth mindset as a father of a child on the AS, and, conversely, their mindset impacted their journey (i.e., their lived experience). Consequently, the eight subquestions that guided the study, in their totality, better answer the primary research question and are delineated and discussed in the next section.

Subquestion 1: What Were the Reactions of the Fathers Before and After Their Child's AS Diagnosis? After the Diagnosis, Did the Fathers Experience Challenges in Having a Child on the AS? If so, What Were They?

Fathers had a variety of reactions before and after their child received an official AS diagnosis. These reactions centered around observed delays in development and communication, the process of trying to understand their new reality, and financial worries. The fathers in this study were aware of their child's developmental delays which is similar to the experiences expressed by fathers in previous studies (Donaldson et al., 2011; O’ Halloran et al., 2013). The fathers' experiences before and after their child's AS diagnosis were constructed through their lived experiences as they moved from a fixed mindset, to a stress mindset, and toward a growth mindset (Crotty, 1998; Crum et al., 2017; Dweck, 2012, 2016, 2019).

Fathers stated how their children had delays in muscle and motor coordination prior to their diagnosis. This is consistent with findings in which fathers reported their children had difficulties in daily living including motor coordination (i.e., toilet training and sitting up; O'Halloran et al., 2013). In addition to their child's delays in motor skills, communication delays 
also presented in the children in the current study. For example, when James's son was diagnosed, his son was not walking or talking. After James realized his son had a delay, he was able to do a reset. This reset is an example of James moving into a growth mindset after receiving the news from his son's doctor that his son's delays were real. He was able to reset the expectations he had of his son's development. His expectations as a father shifted as this new knowledge was processed and guided his thoughts. His shifting into a growth mindset influenced a new interpretation of his son's delays, and James was able to grow as a father as a result (Dweck, 1999, 2012, 2016).

The findings in this study also indicated fathers who had a child on the AS observed delays in their child's ability to speak and communicate. The findings from my study are aligned with findings from O'Halloran et al. (2013) who found that fathers were worried about their children's delayed communication and as result entered into a stress mindset due to their reaction regarding their child's speaking issues (Crum et al., 2017). Wilson watched his daughter lose her ability to speak as she regressed into her autism world, a similar experience reported in the literature (Donaldson et al., 2011). Specifically, Wilson became sensitive to his child's slow regression into noncommunication. This was similar the study by Donaldson et al. (2011) in which the fathers' ability to communicate with their child was a vital part in their ability to connect. When communication was changed or stopped, connecting became more difficult and the relationship with their child changed as a result. In their stress mindset, the fathers focused on the health and well-being of their children and on the nature of their stress (Crum et al., 2017; Crum et al., 2013).

In addition to the fathers' suspicions of autism prior to their child's AS diagnosis, they experienced post-AS reactions and feelings. Upon receiving the news that their child was, in fact, 
on the AS, the fathers in this study experienced a combination of feelings (e.g., anger, denial, and questioning), which are similar to the experiences expressed by fathers in previous studies (Burrell et al., 2017; Donaldson et al., 2011; O’Halloran et al., 2013; Russell \& Norwich, 2012). Some of the fathers in the current study reacted in anger after the doctor told them the news; their suspicions were now true which is consistent with what Burrell et al. (2017) found. Paul's reaction to hearing the news his child was on the AS is similar to what previous studies documented in the literature. Paul shared how he was still in denial ever since receiving the news from his son's doctor; thus his experiences and understanding were constructed with the interactions he had with his child's doctor (Crotty,1998). With Paul sharing that he is still in denial, this admission indicates he continues to live in both fixed and stress mindsets. Due to the strain in his life, Paul's stress impacts his ability to cope regarding his son's AS diagnosis, as Paul moves between a stress mindset and a fixed mindset. Due to this fluctuation in mindsets, his stress mindset and fixed mindset continue to remain fixed, resulting in his continual denial of his son's autism which continues to impact his life (Crum et al., 2017; Dweck, 2012, 2016, 2019; Kammrath \& Dweck, 2006).

Whereas one of the fathers experienced deep denial of his son's diagnosis, others went through a period of questioning their child's AS diagnosis. Along with their feelings of anger, denial, and questioning, the fathers also worried about the future with their children. It appeared the immediate experiences the fathers were dealing with following the diagnosis of their children set into motion concerns about their own futures and the futures of their children. That is, the fathers' fears of the future were constructed through their lived realities. This is consistent with the theory of constructivism (Crotty, 1998). 
One of these future related fears the fathers experienced was the fear of not being able to provide for the lifetime welfare of their child. Specifically, fathers discussed their long-term economic fear of having to provide a staggering amount of $\$ 2$ to $\$ 3$ million over the course of their child's lifetime to provide for their child, as suggested by experts in the field to whom they had spoken. Isaacson (2016), in his autobiographical book, discussed this same fear of how he could save such a large amount for the care of his child. This economic fear of failing to provide for their child is similar to previous studies which showed that there is often no roadmap to follow (Burrell et al., 2017; Hannon \& Hannon, 2017); thus fathers have to create their own roadmap, and, in that process, personal growth has the opportunity to emerge.

The experiences of the fathers in this study are also similar to those discussed by Donaldson et al. (2011). In Donaldson et al.'s study with fathers, one of fathers' overarching concern was how his child would be taken care of upon his death. Specifically, who would take care of his child? As the fathers in the present study discussed their fears and concerns, they also discussed feeling helpless. Their fear of not being able to provide a lifetime of care for their child's needs is an example of fixed and stress mindsets. Their worry revolved around their ability to provide for their children (Crum et al., 2017; Crum et al., 2013; Dweck, 1999, 2012, 2016, 2019; Kammrath \& Dweck, 2006). The fathers in the present study focused on how they would obtain such a large sum of money for their child's care. Their focus on providing financial security is an example of how their fixed and stress mindsets moved each of the fathers to provide the necessary economic stability needed throughout their child's lifetime (Dweck, 1999, 2012, 2016, 2019; Kammrath \& Dweck, 2006). Their stress mindset reflects the intensity of the two choices the fathers could make (Crum et al., 2017; Crum, 2013). They could either remain in a fixed/stress mindset or they could do something about what they were experiencing. As the 
fathers learned more about the additional expenses and care they would need to provide for their child, several of them chose to take action to try to resolve the situation they were facing. Consequently, they moved into a growth mindset as their thoughts were focused on earning income which motivated each father to make changes that impacted their futures (e.g., one father changed his job so he could be closer to his home; Dweck, 1999, 2008, 2012, 2016). While reflecting upon what life was going to be like prior to and following the diagnosis of having a child on the AS, the fathers evolved into a stress mindset. The fear of possibly not being able to provide for their child took hold. The fathers' reactions to this stress then created the opportunity for the fathers to escape from the stress by taking action (Crum et al., 2017; Crum et al., 2013). By taking action, the fathers were able create a new reality, demonstrating the growth mindset (Dweck, 1999, 2008, 2010, 2012, 2016). In their growth mindset, the fathers took action and had a deeper understanding of self and their journey in being the provider for their child (Dweck, 1999, 2008, 2010, 2012, 2016).

After the fathers received the news their child was on the AS, there was a period when some of them had a feeling of helplessness that they lacked the knowledge of how to help their children, which produced a great deal of stress for the fathers. This is consistent with Burrell et al.'s (2017) study in which fathers reported feeling upset, lost, and unsure about what to do next. This was followed by a sense of loss for the hopes and dreams they had for their children. Robinson et al. (2015) also found that fathers reported feeling helpless and wondering what kind of a parent they were, which initially became immobilizing for some fathers. In this study, Mark reported, after his child's AS diagnosis, he had never heard about autism and knew nothing about it. This finding coincides with research by Robinson et al. (2015), in which fathers discussed 
their own lack of autism knowledge. After the fathers received the news that their child was on the AS, there were some fathers who struggled and others who did not struggle.

In the present study, William, Anthony, Mark, Scott, and James reported not struggling with feelings of grief or depression and were in a growth mindset. The fathers' nonexperience of depression is in alignment with the autobiographical book by A Father (1945), in which the father chose not to struggle with his reaction to his daughter's brain issues. There were 3 out of the 24 books written by fathers that did not mention grief experiences, Freihow (2006), Haguel (2018), and Pakkala (2015). There were over nine articles in which fathers did not have the experience of grief to report (Boström \& Bromberg, 2014; Donaldson et al., 2013; Gray, 2002; Hannon \& Hannon, 2017; Hornby, 1992; Keller et al., 2014; Martins et al., 2013; Meadan et al., 2015). After a period of time had passed and the 10 fathers in my study had received the news of their child's AS diagnosis, some of the fathers entered into a new place in time, a movement into a growth mindset that served as a buffer to events occurring in their life (Burnette et al., 2020; Dweck, 1999, 2008, 2012; Schroder et al., 2017). For these fathers, it was not a time of depression, rather new thoughts entered their minds. All 10 fathers in my study asked themselves questions and went into problem-solution mode: (a) What can I do? (b) How can I help my child? (c) How can I earn the needed money for their lifetime care? and (d) How can I earn the needed money for their lifetime care? This problem-solving mode helped some of the fathers grow through their understanding of self and autism (Dweck, 1999, 2008). Their questions were constructed through their layered lived experiences (Crotty, 1998). The fathers experienced a growth mindset by confronting the obstacles they faced after receiving the news of their child's AS diagnosis (Dweck, 1999, 2008, 2010, 2011, 2012, 2016). Thus, lived experiences created this reality, which is consistent with constructivism theory (Crotty, 1998). 
The fathers in the study also mentioned how they experienced trust after their child's AS diagnosis, how trust impacted their new journey into autism, and how trust impacted their growth mindset. For example, William in his growth mindset trusted that God would be there for him. It was this act of trust that guided him through his experiences (Dweck, 1999, 2008, 2010, 2011, 2012, 2016). Similarly, John's faith and the living of his faith were his life experiences constructed through his faith in God. This finding regarding trust is not obvious in the current literature. With the trust that fathers had, not only in God but in themselves, they could face all the unknowns that autism would bring on their journey. Because of the trust in God and their faith, they entered into a growth mindset. They now were prepared to face new obstacles in the lives of their children (Dweck, 1999, 2008, 2010, 2011, 2012, 2016). This was a new world they had entered, one without roadmaps and with new challenges to face. These were challenges the fathers had not or could not conceive of until later in their journey. Having a growth mindset offered the fathers an opportunity to understand self and continue their evolution in being a parent to a child on the AS because their thoughts impacted how they saw their reality (Dweck, 1999, 2008, 2010, 2011, 2012, 2016).

\section{Subquestion 2: Did the Fathers Experience a "New Reality" as a Result of Their Child's Diagnosis? If so, What Did This New Reality Look Like?}

The fathers in this study experienced a new reality as a result of their child's AS diagnosis which included the loss of hopes and dreams they originally had for their child. One of the dreams fathers had was that of academic success for their child. For example, Anthony mentioned he had hoped his son would earn a diploma, not a certificate of completion which signifies that a student has completed high school but did not meet all the requirements required for graduation. James reported his dream for his son was to attend an Ivy League school like 
Harvard and become even more successful than himself. James put the dream of his son attending Harvard or another Ivy League school on hold, a liminal place of not knowing what will happen as his son gets older. Though these specific academic dreams are not reported in the literature, Donaldson et al. (2011) found that fathers had dreams that might no longer be attainable.

When fathers realized that their child may not experience the academic success they had hoped for their child, some fathers acknowledged the need to reset those dreams. For example, Anthony expressed his shift to a new reality regarding his son's educational goals, how he and his wife have, "hopes and dreams that he's going to get his diploma, but we're going to be okay if he just, you know, gets the certificate of completion." This shift to a new reality is a change from what Anthony and his wife thought would happen, and they have made peace with what may actually happen. This finding is consistent with the Donaldson et al. (2011) study which found that when a father hears the news his child has autism, the hopes the father had for his child are lost; however, after a father loses the dreams he had for his child, a resetting of his dreams can occur.

The fathers' educational dreams for their child (i.e., achievement of a diploma, an Ivy league education) initially were a fixed mindset. The fathers' thinking evolved into a growth mindset as new meanings were assigned and their thoughts shifted the educational outcomes they had for their children (Dweck, 1999, 2008, 2012, 2016). For James, his belief that his son would attend an Ivy League school is an example of a fixed mindset (Dweck, 1999, 2008, 2012, 2019). He later found out from his son's teacher this might not be a reality. When he accepted this new information and realized his dream may not occur he moved into a growth mindset (Dweck, 1999, 2008, , 2012, 2016), 2019. This flexibility in thinking allowed him to still maintain the 
hope his son would earn a college degree, though perhaps not at an Ivy League school. Anthony had hoped his son would earn a diploma and not a certificate of completion, which represented a fixed mindset. However, in time Anthony made peace with the possibility that his son's earning a diploma may not occur due to his experience as an educator. His thinking therefore evolved into a growth mindset as he reset the academic dream for his child (Burnette et al., 2020; Dweck, 1999, 2012, 2016).

In addition to academic dreams fathers had for their children, some fathers also had envisioned their child's future would include participating in organized sports. The fathers dreamed of passing along their love of sports to their child. The findings of the current study concur with prior studies (Cheuk \& Lashewicz, 2016; Keller et al., 2014) in that fathers of children on the AS had hopes their child would play in a team sport only to realize this was not a possibility. The fathers demonstrated strong feelings regarding their child's participation in sports. This is an example of a fixed mindset (Dweck, 1999, 2012, 2016). When the fathers learned that their child would not be playing sports, they had to reset their hopes and dreams regarding their child's participation in sports. Specifically, Gabriel moved from a fixed outcomebased mindset (i.e., his child would play sports) to a growth mindset (i.e., he became a coach for other children with developmental disabilities) as his initial dreams had to shift (Dweck, 1999, 2012, 2016, 2019). This shift in their reality occurred due to their life experiences and how they constructed and changed their truth (Crotty, 1998).

The findings suggest as time passes a new paradigm emerges. In the current study, during this period of time, the fathers reset the hopes and dreams they had for their children. Donaldson et al. (2011) found this resetting of new hopes and dreams did not occur immediately, rather it occurred over time. Consistent with findings from Shave and Lashewicz (2016), the current 
study found that after the fathers had lost their hope and dreams, time served as a placeholder in allowing the fathers to redetermine their wishes for their child in light of their newly constructed reality (Crotty, 1998). One father in the current study expressed that the resetting of his dream, he thought, was liberating for his son and for himself, allowing a new reality to occur. This finding was not readily evident in the literature, although one could argue it appears to be a reasonable possibility. As fathers went through a period of resetting their dreams, there were also expectations they felt society placed on them which also created a new reality in their lives.

Another example of a new reality fathers experienced as a result of having a child on the AS spectrum was, once having received the diagnosis, fathers felt like they had additional societal expectations and responsibilities placed upon them. The fathers expressed their thoughts regarding the societal expectations they were supposed to meet. These expectations included having a typical relationship with their child, effectively communicating with their child, and being present in all aspects of their child's life. While these expectations may be typical for all fathers, these dimensions of parenting can be very challenging with a child on the AS. For fathers who did not have the possibility of connecting with their child in a typical manner due to the child's limited communication skills, their feelings about what it meant to be a good father were impacted. Thus, they had to reshape in their own perceptions and expectations of how they would communicate with their child. Wilson reported he became quiet and less extroverted after his son's AS diagnosis because he perceived societal expectations that he may not meet. There is a paucity in the literature regarding fathers who have a child on the AS and their perceptions of being a father. However, Keller et al. (2104) found that fathers felt added pressure in their role based on expectations from society. I was unable to locate additional literature that specifically addressed this finding but in reflecting upon this, it does appear quite probable that society does 
place unique expectations, either spoken or unspoken, on men or fathers who have a child on the AS. It would be helpful to explore this concept further to determine if this a common experience that fathers of a child on the AS contend with more frequently than fathers of neurotypical children. Fathers who experienced a fixed mindset had specific thoughts about what parenting was going to be like, prior to knowing they were going to have a child on the AS. They struggled with a new reality upon their child's AS diagnosis, which produced a stress mindset (Crum et al., 2017; Crum et al., 2013; Dweck, 1999, 2012, 2016, 2019). However, as was the case in the current study, some of the fathers reshaped their expectations of what a good parent was, as they learned how to connect and communicate with their child. Thus, they participated to the fullest extent they could in their child's life. This demonstrates a growth mindset, as they learned new skills (e.g., communication, use of timeouts, patience; Crotty, 1998; Crum et al., 2017; Dweck, 2012, 2016, 2019; Schroder et al., 2017).

\section{Subquestion 3: What Roles Did the Fathers Play as a Result of having a Child on the AS?}

In this current study, each father took a journey after their child received an AS diagnosis. Fathers reflected on the various roles they played as parent, community leader and mentor, and provider for their children.

Role of parenting. The findings in this study showed fathers of more than one child on the AS experienced different parenting issues compared to fathers with a child on the AS and also a neurotypical child. Some fathers in the current study discussed how they were unaware of what neurotypical behavior would be like in children. They reported parenting experiences that were based only on their child on the AS, and they wondered what it would be like to have a neurotypical child. Fathers in this study also described their experiences in parenting two 
children who are both on the AS. Their experiences were somewhat different than fathers who had only one child on the AS (this will be further addressed in some of the other subquestions).

In this study, fathers played important parenting roles in the lives of their children. Some of these roles included caretaking, teaching, and advocating. For example, the fathers of children who have severe AS reported providing the most basic of care to their children. Their caregiving included the diapering of an adult son, one thing Scott shared he would never get used to doing. Gabriel, a father of a child with severe autism and severe ADHD, shared how he must bathe his son, even though his son is now an adolescent. David talked about teaching his son to shave. While these are things many fathers teach their children how to do, the time spent teaching their children took longer and was more involved than for fathers who did not have children on the AS. Thus, more time had to be devoted to teaching self-care issues.

The fathers in the current study also reported parenting challenges associated with trying to advocate for their child. Wilson shared his frustration in not being heard by the IEP team members. His son's IEP team would always turn towards his wife and ask her opinions or thoughts and not address him. He reported that there was an expectation during his son's IEP meeting for him to remain silent. He did not have anyone or anywhere to go to speak about his fears, concerns, and worries.

This finding of fathers serving in the roles of caretaker, teacher, and advocate aligns with similar findings in the literature base. Keller et al. (2014) described the numerous roles played by fathers who have children on the AS (e.g., caregiver, advocate, teacher). However, other literature (Flippin \& Crais, 2011) indicated mothers are the primary caregivers and frequently the only participants in early intervention services. Flippin and Crais (2011) reported that "there is evidence that responsive fathering is a strong predictor of better developmental outcomes for 
children including improved emotional regulation and cognitive and language development" (p. 25). The fathers in the present study were very involved with both the caretaking and teaching of their child, attempted to be involved with advocating for their child (some with more success than others), and gained insight as a result of their parenting. These findings also align with research conducted by Cheuk and Lashewicz (2016) whose study indicated fathers gained insights regarding their feelings of their child's AS diagnosis as a journey in becoming better men, husbands, and fathers to their children.

The fathers in this current study additionally shared the parenting challenges they experienced because, in not having neurotypical children, they did not understand how to parent from a neurotypical perspective; however, they persevered and did the best they could. The stories the fathers told provided evidence that the fathers continued to grow as fathers, even while wondering what neurotypical fatherhood was like. They continued to think about the outcome for their child. It was apparent in the interviews each of the fathers moved through fixed, stress, and growth mindsets while caretaking, teaching, and advocating for their child, each at their own pace. Their stress mindsets (e.g., having to change his adult's son's diapers, fears of children eloping, violent outbursts) motivated the fathers to take action which led to the fathers growth mindset (Crum et al., 2017; Crum et al., 2013). When fathers in the current study were in a growth mindset, they held and maintained a belief that they could learn new things about parenting resulting in the continuation of their parenting journey (Dweck, 2008, 2012, 2016, 2019; Kammrath \& Dweck, 2016). As the fathers kept growing, they moved into areas of individual growth and psychological adaptability.

Community leaders and mentors. Another role that some of the fathers took as a result of having a child on the AS was that of a community leader or mentor. William became very 
involved in his role as a CEO in advocating for people with disabilities in the business sector. In addition, as fathers began to open up to others about having a child on the AS, others began to talk with them about their own children on the AS, as was the case with James and David. Gabriel also served as a mentor in a sports league for youth with disabilities as a result of having a child on the AS.

This finding is consistent with the literature that the impact of community played a role in the lives of the fathers (Boström \& Bromberg, 2014; Fyre 2016; Hannon \& Hannon, 2017; Shave \& Lashewicz, 2016). Community became a place where fathers mentored other fathers whose child was newly diagnosed on the AS (Hoogsteen \& Woodgate 2013; Shave \& Lashewicz, 2016; Paynter et al., 2018). In the larger community the fathers realized they were not alone in having a child on the AS (Paynter et al., 2018). Their communities additionally served as places for fathers to come together and connect.

Clearly, some of the fathers in this study displayed a growth mindset through the development of their ability as fathers to learn new talents and skills (Dweck, 1999, 2012, 2016, 2019). They moved into the roles of advocating for others who are on the AS, whether it be in the corporate sector or through their communities of faith. They also served as mentors to other fathers and volunteered their services to the community. Consequently, their lived experiences were also richer as a result of the realities they constructed by giving of themselves (Braunstein et al., 2013; Cheuk, \& Lashewicz, 2016; Crotty, 1998; Fyre, 2016; O’Halloran et al., 2013).

Fathers as providers. Fathers who have a child on the AS serve as providers for their children. In the current study, all the fathers spoke about the importance of their role as a financial provider for their family. This became increasingly evident when their wives had to quit their full-time jobs to take care of their child, which resulted in a loss of income to the 
families. Thus, these fathers took on the role of sole provider for their child with greater seriousness. Frequently, there were additional expenses not covered by insurance which fathers both wanted to provide for their children and felt an obligation to provide to improve the quality of their child's life. For example, John reported during the early days of autism, interventions were not covered by insurance and were paid "out-of-pocket" by parents.

This finding is consistent with the research conducted by Frye (2016) who stated fathers felt they needed to provide for their children, which was part of the role of being a good father. Cidav, Marcus and Mandnell (2012) discussed the high cost of caring for children with disabilities; however, they did not mention specific out-of-pocket expenses. Ganz (2007) estimated that the lifetime cost of having a child on the AS was $\$ 3.2$ million. Montes and Halterman (2008) found the parental loss of income per year in raising a child on the AS was $\$ 6,000$, meaning that a parent who has a child on the AS loses $\$ 6,000$ a year by paying for medical expenses and interventions for their child on the AS.

Being the financial provider for their child/ren on the AS was a source of high stress for fathers in the current study, whether they were the sole providers for their child or not. The fathers took actions that would allow them to be better providers for their families and developed a deeper understanding of the needs of their child. Thus, the fathers in this study shifted into growth mindsets that paved a path for additional possibilities for growth and personal change (Burnette et al., 2020; Crotty, 1998; Dweck, 2012, 2016, 2019; Schroder et al., 2017).

\section{Subquestion 4: What Are the Fathers' Views on Disability?}

The findings of this study indicated that fathers held differing views regarding autism. Three areas that surfaced from this study related to the fathers' views on autism included: (a) autism is a gift, (b) there were familial similarities between fathers and their children on the AS, 
and (c) whether autism is the next evolution of the brain or a disability. Each of these findings will be briefly discussed and connected to the literature.

Reframing of autism as a gift. Fathers in the current study reported their children's autism diagnoses brought gifts to their lives as fathers. James shared that he has more empathy for parents of kids with severe autism now than he did before his child's AS diagnosis. All the fathers recognized a newfound belief about what was important in their lives. John's realization took a slightly different path. One of his gifts was the recognition that a change in his career would provide more stability for his son and family.

In addition to the gifts a father may personally receive in parenting a child on the AS, they may also recognize the gifts their children can bring to their families. For example, Wilson reported how his daughter's autism gifts brought surprises to his life and the journey as a father because of having a child on the AS. These types of gifts a child on the AS brings may go unnoticed or not be fully appreciated as fathers struggle with the day to day challenges of parenting a child on the AS (Hoogsteen \& Woodgate, 2013; Kirby, 2019). Fathers in the current study were aware of some of these gifts which is consistent with the somewhat limited literature base on this topic. The literature indicated some of the gifts fathers have appreciated about their children on the AS include (a) the intense and complete focus of their child to learn or complete a task (e.g., learning how to tie shoes; McCafferty, 2014), (b) the realization that their child is persistent and does not give up (McCafferty, 2014), and (c) their child's willingness to develop coping skills to work with individuals who are neurotypical (McCafferty, 2014).

The gifts of children on the AS are not always appreciated by the larger society. However, the fathers in this study recognized and appreciated the gifts their children brought to their families. Thus, these fathers were able to move beyond society's fixed views of disability 
(Davis, 2013; Ware, 2011, 2012) to a growth mindset (Dweck, 2012, 2016, 2019; Kammrath \& Dweck, 2006). In addition, this constructed reality allowed them to view their children through disability studies and the social model of disability lens (Crotty, 1998; Davis, 2013; Ware, 2011, 2012), which honor people with disabilities (Davis, 2013; Ware, 2011, 2012). By truly seeing the gifts of their children, they were honoring their child.

Familial similarities between fathers and their children on the autism spectrum. One finding in the current study that was of particular interest was several of the fathers noting that they had some characteristics similar to their child on the AS. Mark shared that 30 years ago the behavior he had as a child would now be described as autism. James reported how he and his uncle are like his son, and his understanding of the DSM-IV provided him with this realization. This is consistent with the work of Dryden (2014) who found, in diagnosing children on the AS, one or both of their parents also showed characteristics of autism. It is unclear how this realization may have impacted the mindsets of these fathers, or if it did impact these fathers. However, remaining open to the possibility that they too may share some similar AS traits may represent a growth mindset, allowing the fathers to form a deeper understanding of self which may have a positive influence on the decisions they make regarding their child (Dweck, 1999, 2012, 2016).

Evolution of the brain or a disability. Fathers indicated how their beliefs about autism impacted their journeys and contributed to the formation of their identities and growth as men. The fathers' autism beliefs assisted in their growth as individuals and, as a result, provided a path for understanding their child and their child's autism. These understandings however, varied considerably among the fathers. 
William reported he believes autism is the next generation in the evolution of the brain, and his son is part of that evolution. While there is little evidence of this in the literature, one cannot dispute that many children on the AS bring a unique perspective to looking at problems and solutions to those problems. William's perspective also reflects an "out of the box" type of thinking. He is not willing to let his son be pigeon-holed into more traditional ways of thinking about disability. He comes from a progressive disability studies perspective, focusing on what his son can do rather than what his son cannot do, and believes differences in individuals are typical and should be celebrated (Crotty, 1998; Davis, 2013; Shakespeare, 2014; Ware, 2011, 2012).

In sharp contrast, Scott, a father of a son with severe autism, had a belief that differed greatly than that of William. He shared he firmly believes his son with severe autism has a disability because his son cannot take care of himself. Scott also indicated he believes autism prevalence rates are too high. That is, now everyone has a little autism and that angers him beause it diminishes his son's severity. Scott stated that he has no sympathy for individuals who have what he described as "watered-down autism." Thus, Scott displayed a fixed mindset regarding his thinking about the outcome of an individual having autism. This belief impacted his views of autism and how he regarded his child and other children on the AS (Dweck, 2012, 2016, 2019). As evidenced by the very different perspectives of William and Scott, and the other examples provided, beliefs about autism impacted the journeys of the fathers in this study. These varying perspectives are consistent with how society views autism; hence, there are individuals who are supporters of the social model and individuals who are supporters of the medical model of disability (P. Ferguson, 2002; Linton, 1998; Miller et al., 2013). The fathers' mindsets about whether or not autism is a disability, impacted how they constructed their realities and also may 
have influenced the realities of their children (Crotty, 1998; Davis, 2013; Dweck, 2012, 2019;

McCafferty, 2014; Ware, 2011, 2012).

\section{Subquestion 5: Did the Fathers have a Belief System that Impacted Their Journey in Raising a Child on the AS? If so, How?}

The fathers' belief systems did impact their journeys and the construction and formation of their mindsets (Crotty, 1998; Dweck, 2012, 2019). Although these belief systems varied among fathers, the belief system that surfaced most frequently for William, John, and Wilson was their deeply held beliefs in God. For some of the fathers it was the support they received from their faith and their community of faith that got them through the challenges in having a child on the AS. Several of the fathers reported having a child on the AS resulted in a reciprocal interaction regarding their faith. That is, having a child on the AS had an impact on their faith and their faith had an impact on their views of parenting, disability, their future hopes, and their coping skills.

John, William, Wilson, David, and Paul's faith helped them during their times of stress and brought their families strength. William and John indicated their faith brought them strength after their sons were diagnosed with autism (Crotty, 1998). This finding is consistent with Tarakeshwar and Pargament (2001) who described how faith helped with families' coping skills.

In addition, John indicated that faith helps him know God has a plan for his son. He shared that his faith also shaped how he viewed his son with severe autism. That is, he sees his son through God's eyes as perfect, even though his son has severe autism. This finding is consistent with Jegatheesan, Miller, and Fowler's (2010) study of Muslim immigrant families which found that parents indicated their child was a gift from Allah. Consequently, the fathers in 
the Jegatheesan et al. (2010) study did not view their child through the medical model (i.e., where disability is viewed as a physical or mental condition that needs to be fixed).

William's beliefs about God and the birth of his son differed from that of John. William indicated his faith impacts his life and how he views the challenges autism has brought. He stated he arrived at his life's journey when his son was diagnosed. However, he does not view his son's autism as a cosmic lesson from God; it was not part of God's plan for his son to have autism, and the bad things that happen in life are not God's doing. This constructivist belief supports the disability studies theoretical frame and the social model of disability (Crotty, 1998; Davis, 2013; Shakespeare, 2014; Ware, 2011, 2012).

Wilson's beliefs took him in yet another direction than the other fathers. Wilson's faith impacted his constructed hope for a conversation with his nonverbal son someday in heaven. He holds this thought close to his heart; his faith helps him know someday this conversation can happen. Although there were varying views of the role that faith, God, and religion had in these fathers' lives, it was evident that it had a positive impact on their journeys. The fathers' beliefs were constructed and strengthened by the experiences they had, along with their original fixed beliefs held about God. The stress of having a child born on the AS also influenced the fathers' beliefs, and their faith helped the fathers cope and provided a source of strength for the fathers. This then allowed a growth mindset to occur, while also continuing to hold onto fixed beliefs about God. Subquestion 5 is an example of the complexity of the fathers' lived experiences constructed through mindset theories (Burnette et al., 2020; Crotty, 1998; Dweck, 1999, 2012, 2016, 2019; Schroder et al., 2017). This is an example of how the three mindsets are connected. First, a fixed mindset because of their belief that God and their faith are a constant force in their lives. Second, their trust and confidence in God sustained them while they were in a stress 
mindset. Finally, the growth mindset offered an emotional and physical place (e.g., by attending church and participating in community) for their faith to provide a buffer against the pain and stress of their lives (Dweck, 2012, 2016, 2019; Kammrath \& Dweck, 2006).

\section{Subquestion 6: Do Fathers Who Have More than One Child on the Autism Spectrum have a Significantly Different Lived Experience Compared to Fathers Who have Only a Single Child on the Autism Spectrum?}

In the current study, fathers with two children on the AS identified several factors that were not brought up by fathers with only one child on the AS. These factors included: (a) feeling like they were walking on eggshells, (b) being constantly vigilant, (c) feeling like they had to focus on only one of their children at a time, and (d) needing different parenting styles when the father had two children on the AS. Although it would make sense that fathers who have two children on the AS would possibly have a different experience than fathers with only one child on the AS, I was unable to document this finding in the research literature. However, Hoogsteen and Woodgate (2013) found that autism became the focus in the family with parents putting the needs of their child ahead of their own.

Walking on eggshells. Two fathers, Scott and Gabriel, both having two children on the AS, reported they live their lives like they are walking on eggshells. Gabriel shared how he never knows what his son's behavior will be or how he will react to any given situation; thus, he lives in continual anticipation that his son will exhibit a severe behavior (e.g., self-injurious behavior). He reported that he and his son could be having a day that was behavior free, and, in a moment, it could all change. This is consistent with the findings from Hoogsteen and Woodgate (2013) that plans need to always be flexible to accommodate any change involving a child who is on the AS. As a result, both fathers' life experiences were constructed through their interactions in the 
world of uncertainty. This uncertainty influenced and impacted the formation of the Scott's and Gabriel's fixed and stress mindsets regarding their children's behavior (e.g., something was going to happen whenever they went out, if something happens how will it go, can we get through it; Crum et al., 2017; Dweck, 2012, 2016, 2019; Kammrath \& Dweck, 2006). However, a growth mindset provided a potential buffer for Gabriel and Scott against the adverse and stressful events in life. This was developed through the fathers' understanding of self. Scott and Gabriel expected these types of occurrences and each faced and confronted these challenges although they continued to walk on eggshells (Dweck, 2012, 2016).

Constant vigilance. Gabriel, a father with two children on the AS, reported he lives in a state of constant vigilance or, actually, hypervigilance. Frequently, the fathers had few opportunities for their stress to be released. Though it is not unusual for families to feel stressed when they have a child on the AS (Sanders \& Morgan, 1997), little has been reported in the literature about the challenges that two children on the AS may bring into the family dynamic. This is an area where additional research would be beneficial for families and respite care workers. Because of this constant vigilance, Gabriel lives in a continual stress mindset while he responds to his two children on the AS (Crum et al., 2017; Crum et al., 2013). In addition, due to the intensity of the stress he experiences, it also facilitates a state of perpetual awareness for him which resulted in a growth mindset. This offered Gabriel an opportunity for greater understanding of the stresses he experiences by having to be in a state of constant awareness (Crotty, 1998; Dweck, 2012, 2016, 2019).

Being able to only focus on one child at a time. Mark, one father in the present study, shared his realization that he had primarily been focusing on only one of his children on the AS. He reported his deep concerns and fears that his focus on his son could be impacting his daughter 
who is also on the AS. Likewise, he wondered what kind of a parent he was and shared how difficult it was at times to parent both of his two children on the AS (Crotty, 1998). This is another area where there is little information in the literature base, and it would be helpful to conduct additional research to support fathers who find themselves in this situation. Mark's wondering about his parenting skills facilitated his movement into a mindset of growth as he became aware and understood how his primary focus on his son could be impacting his daughter

(Dweck, 2012, 2016). This new reality allowed him to pay additional attention to the needs of his daughter.

\section{Parenting style differences when the father had two children on the autism}

spectrum. Wilson reported his style of parenting differed greatly between his son on the AS and his daughter on the AS. Wilson had to take into account the differences between his two children, his son's rigidness and his daughter's behavior and inability to understand due to her emotional immaturity. Wilson expressed that he needed to explain to his son, with less severe autism, why his sister, whose autism was more severe, had to be treated differently. The son had difficulty understanding why this was the case, as the son saw the world through a rigid black and white lens (i.e., a fixed mindset; Dweck, 2012, 2016, 2019). He was angry that he and his sister were treated differently. Wilson continues to take action by exploring ways to communicate with his son while exercising different parenting styles with his children. These actions constructed a new reality for Wilson and his family, resulting in a growth mindset (Crotty, 1998; Dweck, 2012, 2016).

There is little research on the challenges of parenting two children on the AS who exhibit very different ways of being in the world. This is an area where future research could be extremely helpful to parents with more than one child in the family on the AS. 


\section{Subquestion 7: Did the Fathers Experience Personal Growth as a Result of Having a Child on the Autism Spectrum? If so, What Growth Did They Experience?}

There is a paucity of literature regarding personal growth of fathers as a result of parenting a child on the AS. However, in one study involving parents, Scorgie and Sobsey (2000) found positive and significant changes that resulted in the lives of parents who had a child on the AS. Those changes included: their marriage became stronger, they now could see life from a different perspective, they became stronger as parents, and their lives became better as a result of finding the good in their experiences. These findings are similar to the experiences of several fathers in the current study who reported they had learned a great deal about themselves as a result of having a child on the AS. For example, William shared the wisdom that resulted from having a child on the AS. He stated his personal philosophy "in a pile of horse crap, there had to be a pony somewhere." One of his ponies was the growth he continued to experience as he navigated being a parent of a child on the AS. He learned things about himself he could learn no other way than going through the experiences he had gone through. Specifically, he reported he was more patient with his son and also with his family. He shared autism taught him about who he is as a man; a man with faults who strives to make the world a better place for others with autism and individuals with other disabilities too. This inner growth resulted in his disability activism in the corporate world where he became a spokesperson for individuals with disabilities and created jobs in the company for which he had been the CEO. These were lessons the fathers could learn no other way as they were constructed by the living of unique experiences of raising a child on the AS (Crotty, 1998).

An unexpected finding was fathers indicated that by participating in this current study they also experienced personal growth. For several of the fathers, they had kept their inner 
experiences to themselves, that is, in the silence of their minds until they were asked the interview questions in this study. While not always pleasant, in reflecting upon the questions asked, several of the fathers remarked how helpful the experience was in shedding new light on some of the issues raised. For example, Gabriel expressed he felt like he was being "dragged through a pile of crap" responding to the interview questions. However, after the interviews were over, he realized he had developed a new understanding of himself. That is, he was a better man because he has a son on the AS. He also noted by participating in the study he knew he was not alone on his journey; there were others who also walked this path of fatherhood.

No literature was found regarding fathers who had a child on the AS finding benefit from participation in a research study such as the current study. These are areas where future research could glean information about the fathers' experiences regarding personal growth.

The lessons fathers learned about themselves could be learned no other way; they were constructed by their living through the unique experiences of raising a child on the AS (Crotty, 1998). The theory of constructivism is rooted in individuals connecting the meaning of life through experience (Crotty, 1998). Thus, from these unique experiences fathers had in parenting a child on the AS, fathers recognized they had grown as individuals and parents. In addition, participation in this study also provided fathers with a unique experience which facilitated personal growth. In the sharing of Gabriel's personal experience of participating in this study, it was evident he moved from the intensity of a stress mindset into a greater understanding and perspective of self, that is, a growth mindset (Dweck, 2012, 2016, 2019). 


\section{Subquestion 8: Does the Severity of Autism Create a Different Lived Experience Among}

\section{Fathers?}

Based upon the findings of this study, it appears that fathers with children on the AS who exhibit behavioral issues may have a somewhat different experience than fathers whose children do not exhibit behavioral issues. This would make sense because adding a behavioral dimension to parenthood can be challenging whether a child is on the AS or not. There is a paucity of literature on fathers' experiences with children on the AS who have severe behavioral issues. Price-Bonham and Addison (1978) briefly addressed the issue but in refence to children with "mental retardation $[$ sic]" (p. 228). In the current study, the fathers shared explicit details of the interconnectedness of their journey and their inability to control their child's behavior. Gabriel felt helpless and, thus, inadequate when his son demonstrated self-injurious behavior, lashed out, eloped, or harmed others. Scott and Gabriel both shared that because of their son's often unpredictable behavior they felt they lived their lives in 20-minute increments; consequently, the behaviors of their children caused these fathers to be in a stress mindset (Crum et al., 2017).

The fathers also reported that they felt stigmatized because they could not handle their child's behavior. This is consistent with findings from Gray's (2002) study; however, Gray's study involved mothers who reported they felt stigmatized and stared at while grocery shopping with their child on the AS. Gabriel reported the potential for public stigma exists every time he takes his children out the house as he never knows what will trigger his son's severe behavior. This is consistent with Broady et al.'s (2015) study which found stigmatization for families with children on the AS generally occurred in four locations (i.e., school, public places, with family, and with friends). As Broady et al.'s (2015) study involved families and Gray's (2002) study involved mothers, there is a paucity of research on this topic with fathers and is an area where 
future research would be beneficial and contribute to the knowledge base. Because fathers knew the potential for stigmatization could occur any time they took their children out of the house, there was little escape from the stress mindset this produced (Crum et al., 2013).

All 10 fathers continue their journey in the world of autism, combined with the continuing construction of their growth, fixed, and stress mindsets and their beliefs regarding their child's disability. Each father moved in and out of each of the three mindsets. Their choices contributed to their lives, their journey of fatherhood, and to the lives of their children.

\section{Implications}

The findings of this study have implications both in academia and beyond the walls of academia. The life experiences the fathers shared in this study were profound, and the information they shared about their journeys can teach us how fathers with children on the AS can be better supported. The results of this study have implications for (a) teachers, school psychologists, school counselors, administrators, and education faculty at universities; (b) medical personnel; (c) extended family members, friends, I neighbors who do not have children on the AS; (d) the clergy; (e) autism support organizations; (f) fathers of children with severe disabilities on the AS; and (g) fathers of children without autism. Each of these areas will be further addressed in the following sections.

\section{Implications for Teachers, School Psychologists, School Counselors, Administrators, and Education Faculty at Universities}

This study has implications for teachers, school psychologists, school counselors, and administrators. Some of the fathers in this study indicated they did not feel welcomed at their child's school. This could be a result of school personnel interacting more often with mothers than fathers. At times, fathers attend meetings only after there has been a disagreement that 
mothers have been unsuccessful in resolving. This can set the stage for potentially contentious interactions. School personnel may wish to consider ways in which they could be most welcoming and inclusive to fathers. This may include things like having special events for fathers and their children. Another possibility would be scheduling IEP meetings at times when working fathers could attend meetings. The IDEA (2004) mandates that IEPs are held at mutually agreed upon times and places, but frequently meetings are scheduled at times that are convenient for school personnel rather than for fathers. In addition, schools could employ electronic strategies such as Skype, Facetime, or Zoom to include fathers in IEP meetings. Making schools more welcoming to fathers of children on the AS could enhance fathers' involvement in the academic part of their child's life.

School personnel may not have an in-depth understanding of fathers who are raising a child on the AS. Therefore, there may be an opportunity for university professors to evaluate what information is being provided to students during their preservice teacher training courses regarding fathers of children on the AS. In addition, professional development opportunities could be created in which practicing professionals are exposed to information about how best to support and be inclusive of fathers of children on the AS.

\section{Implications for the Medical Profession}

Because doctors and nurses are frequently the professionals that interact with fathers before and after an AS diagnosis, it is essential that they are sensitive to these fathers needs. Because fathers are individuals and family structures vary greatly, medical professionals can have an enormous, either positive or negative, impact upon fathers. Consequently, medical professionals need to be well-trained in how to deliver a diagnosis that may be difficult to understand (e.g., unfamiliar, professional terms) or accept. It would be helpful if doctors could 
provide written materials and resources that are explicitly designed to address questions and concerns that fathers may have, as they may differ from questions that mothers or other family members may have at the time of diagnosis or shortly thereafter. Although mothers are generally considered to be the primary caregivers of children on the AS (Preece, 2014), as indicated in this study, fathers also serve in this role and at times feel they are not acknowledged as caregivers. Therefore, it would be helpful if medical personnel had a greater awareness about the variety of roles fathers play so they can better support fathers in making medically related decisions.

\section{Implications for Extended Family Members, Friends, and Neighbors}

The fathers in this study indicated that family events and activities with friends and neighbors were challenging because these social occasions did not feel inclusive, safe, or welcoming to their children on the AS. Because autism is still misunderstood in society (Broady et al., 2015), extended family members, friends, and neighbors may not be aware of nuances (e.g., noises, lighting, food, smells) that may set off a child's undesirable behavior at a social gathering. Therefore, it may be helpful if family members who are knowledgeable about these types of nuances help educate others who are planning and attending these events so that they run smoothly. This may include things such as designating a quiet place for the child to retreat if the environment becomes overwhelming, holding an event at a time of day when the child is at their best, providing food and beverages at the event that will not trigger a behavioral issue, and ensuring there are activities planned that the child enjoys. Through purposeful planning that attends to the needs of the child on the AS, a welcoming environment can be created and greater acceptance of the child and the father may be facilitated. 


\section{Implications for Clergy}

It may be helpful and useful for fathers of children on the AS if members of clergy (e.g., pastors, priests, rabbis, and imams) have a heightened sense of autism and how it may affect and impact a family. Also, if clergy members and congregations were aware of the issues facing fathers of a child on the AS, they may be better prepared and equipped to support fathers. Clergy, along with lay members, may want to consider establishing support groups for families of children on the AS (e.g., these could be family support groups or support groups specifically targeted for fathers). Also, places of worship may want to provide inclusive and accessible environments designed for families who have a child on the AS (e.g., sensory reduced rooms where families can participate and be a part of the community and their child can feel safe).

\section{Implications for Autism Support Organizations}

This study has possible implications for autism support organizations, as these organizations can serve as essential sources for information, resources, and support for fathers. Fathers who have a child on the AS often experience challenges while simultaneously experiencing little support (Shave \& Lashewicz, 2016). The psychological well-being for a father who has a child on the AS is a vital aspect of a father's role in the life of their child. Autism support organizations can provide father-based resources. Those resources could include: (a) opportunities for fathers to connect with other fathers (e.g., social events, sports-based activities designed for children on the AS); (b) support groups designed around the needs of the fathers (e.g., days and times conducive to their schedules such as evenings or weekends); (c) meeting times and days have free childcare included; (d) father focused support literature, (e) self-care based workshops; and (f) representation in social media (e.g., pictures depicting fathers with their children, YouTube video links focusing on fathers, links for Facebook support groups). 


\section{Implications for Fathers of Children with Severe Disabilities on the AS}

The fathers in this study indicated a want and a need to connect with other fathers who also have a child with severe autism. These fathers revealed their desire to know what other fathers were experiencing and if their experiences were similar. Connecting with other fathers of children on the AS would create a sense of community among fathers and help them not feel alone. This can be achieved through specific support groups designed for fathers of a child with severe autism such as: (a) autism groups; (b) faith-based organizations with autism support groups, specifically for fathers of children with severe autism; and (c) online-based meetings, making it easier for divorced fathers who do not have respite care.

\section{Implications for Fathers with Children who do Not have Autism}

This study has implications for fathers whose children do not have autism. Having a child on the AS is often a challenging experience for a father (Shave \& Lashewicz, 2016). Fathers who have a child on the AS may possibly want other fathers to know: (a) autism is a spectrum, and not every child with autism is the same; (b) autism is not always easy to see in every child; (c) children who are nonverbal and still communicate; (d) a child's autism does not define the child; (e) keeping a schedule may be a vital part of their lives as a father; (f) unsolicited advice may not be wanted; $(\mathrm{g})$ if the child is experiencing a meltdown, staying calm is helpful for both parent and child; and (h) fathers appreciate being invited to events even after they have repeatedly said no or have to leave early.

\section{Limitations of the Study}

The study has some limitations that need to be mentioned. There are inherent limitations in any qualitative research. Although I attempted to adhere to best practices of conducting 
qualitative research, there still were limitations. Those limitations include: (a) small sample size, (b) limited diversity, (c) limited geographical areas, and (d) author's subjectivity.

\section{Small Sample Size and Limited Population}

My sample size was limited to 10 fathers of children on the AS. Given the time frame to begin and finish my dissertation along with the initial difficulties in participant requirement, the sample size was limited to 10 fathers.

\section{Limited Diversity}

It was my intention to have a study with diverse fathers. However, I encountered recruiting difficulties. The local autism center I contacted had made a commitment to help me identify 10 diverse fathers for the study. However, when it came time to contact participants, they were unable to do so. As a result, I moved forward with recruitment and, despite my efforts to diversify the study, I was only able to identify eight Caucasian, one African American, and one Latino father. Originally when the study began, I had one additional father who was African American, but unfortunately, he dropped out after his first interview, due to time constraints.

\section{Participants Limited to Three Geographical Areas}

The study's participants were recruited locally in CA and in two additional states. A broader representation may have resulted in different outcomes.

\section{Author's Subjectivity}

In transparency, I revealed my subjectivity statement in Chapter 3. In that statement, I indicated, that I too was a member of the AS. My dissertation chair and I made the decision not reveal this information to the 10 fathers who participated in the study. Although I did my best in keeping my subjectivity in check, it is possible the results were influenced by my personal experiences. Other steps I took to try to ensure bias did not influence my study included: (a) 
speaking with members of my committee throughout the process, and (b) spending time writing in my researcher's journal and reflecting upon what was written, that is, searching for bias. These practices are in keeping with the tenets of heuristic phenomenology.

\section{Areas for Future Research}

These findings also highlighted the need for future research. I recommend future research in the following areas:

1. Conduct a longitudinal study examining the father's journey from the moment their child is diagnosed on the AS until the child turns 18 or 21 . This will aid researchers in understanding the father's journey in real time.

2. Conduct a study with fathers who have multiple children on the AS. This would also include fathers who have identical or fraternal sets of twins. How might the fathers' journeys be different without neurotypical siblings in the family?

3. Explore the differences of fathers' experiences based on the decade of diagnosis. Is there a difference in the fathers' journeys depending on when the child was diagnosed? If so, what are these differences?

4. Examine the experiences of fathers who have two children on the AS. Are their lives different from fathers who only have one child on the AS? If so, how?

5. Explore how single fathers experience having a child on the AS. What is the impact upon a father who has full custody? What are the challenges experienced, if any, and how do those challenges impact their journey and identity formation?

6. How might the experiences of mothers and fathers who have a child the AS be similar or different? 
7. What are the experiences of fathers who have a child with severe autism? Are their experiences different than fathers with a child who has less severe autism? If so how?

\section{Reflection}

I had the humble privilege of spending time with 10 fathers, connecting over the course of 3 and a half months. We spent 45 to 90 minutes together during each of their three separate interviews. It was my honor to spend time with each father. Their voices shaped my research along with my desire to know their experiences. Their responses to my interview questions, revealed the essence of their experiences. To be with these men as their thoughts took them back through the passages of time revealed the inherent power of listening to hear and the ability to sit in the, often uncomfortable, moments of silence. They shared narratives of pain and triumph, late-night fears, and uncertainty.

For some, it was their belief and faith in God that shaped and impacted their views of autism, their child, and their life paradigm. Their faith and belief in the grace offered brought solace during difficult times. For some, it was the strength provided in their marriages, combined with their belief in self. For the fathers whose marriages ended in divorce or separation, their strength was a force found in their solo travels with autism.

Each of the 10 fathers entered the journey into the labyrinth of autism. Their mindset and growth were constructed and formed through the path autism offered. Through their separate passages, each father made a conscious decision to stay the course and become a parent to a child on the AS. There were moments along their passage when the path seemed to be far away from their center. Their journeys and the steps walked are reminiscent of the walking of a labyrinth. Just as the labyrinth is walked, there is a moment when the center appears to be close to attaining. In reality, the closer one is, the further away from the path one has travelled. This is the 
created illusion of the labyrinth. The 10 fathers in the study began a journey from the moment their child was born. The labyrinth describes the fathers' journeys into autism and the formation of their identities as individuals and as fathers. Their journeyed heuristic experiences are as the labyrinth, not a maze to be solved; they are a continuing inner journey to be walked.

\section{Significance of the Study}

With the increase in prevalence rates of children on the AS, the roles and definitions of parenthood and, relevant to this study, fatherhood continue to change; old definitions are expanding to be more inclusive. The findings from this study not included in the present literature base represent an opportunity for future research and add to the significance of this area of study. The voices of fathers who are often silent are a vital group to continue soliciting contributions in research on autism. It is time for the experiences of fathers to be recognized as unique, with a perspective that represents their role and place in the family which is separate from the literature and voices of mothers of children on the AS.

\section{Call to Action}

It is now imperative to break the walls of silence that have long held the voices of fathers. As this study has revealed, old notions of a father's nonparticipation in the raising of their child are continuing to change. With the prevalence of autism rates at their highest, it is time for fathers' voices and their participation in their child's lives to be recognized. The fathers in this study made a conscious choice to become, and continue to become, the best fathers they could be as they continue their walk along the wide spectrum called autism. Their views, feelings, and experiences are valid and a valuable part of both their child's life and their own lives. This study demonstrated the paucity in the literature regarding the experiences of fathers who have a child on the AS. Their journeys and the interconnectedness of their growth mind set play vital and 
critical roles in the raising of their children. Their phenomenological experiences need to be heard beyond this study, as fathers indicated their participation in the study was beneficial to them personally. Therefore, it is urgent and essential to continue research with fathers who have a child on the AS. 


\section{REFERENCES}

A Father. (1945). We committed our child. The Rotarian, 63(2), 1-4. Retrieved from http://www.disabilitymuseum.org/dhm/lib/detail.html?id=896\&page=all\&print=1

Achkova, M., \& Manolova, H. (2014). Diagnosis “Autism”: From Kanner and Asperger's to DSM-5. Journal of Intellectual Disability, 2(2), 112-118. doi:10.6000/22922598.2014.02.02.4

Al Ghazi, L. (2018). History of autism. The beginnings. Collusions or serendipity. Journal of Educational Sciences, 38(2), 5-17. doi:10.35923/JES.2018.2.01

Allan, A. (2015). The four pillars of meditation. Positive Health, 225(1), 1-7. Retrieved from http://www.positivehealth.com/article/meditation/the-four-pillars-of-meditation

Ambersley, K. (2013). Autism: Turning on the light: A father's shares his son's inspirational life's journey through autism. Bloomington, IN: Authorhouse.

American Psychiatric Association. (1987). Diagnostic and statistical manual of mental disorders (3rd ed., revised). Washington DC: American Psychiatric Publishing.

American Psychiatric Association. (1994). Diagnostic and statistical manual of mental disorders (4th ed.). Washington, DC: American Psychiatric Publishing.

American Psychiatric Association. (2013). Diagnostic and statistical manual of mental disorders (5th ed.). Washington, DC: American Psychiatric Publishing.

Anderson, M. (2015). Connor, brave \& kind: A love letter from devoted father. New York, NY: Foundation Press.

Autistic Self Advocacy Network. (2020). About. Retrieved from https://autisticadvocacy.org/about-asan/ 
Baio, J., Wiggins, L., Christensen, D. L., Maenner, M. J., Daniels, J., Warrne, Z., . . Dowling, N. F. (2018). Prevalence of autism spectrum disorder among children aged 8 years: Autism and developmental disabilities monitoring network, 11 sites, United States, 2014. Morbidity and Mortality Weekly Report: Surveillance Summaries, 67(6), 1-23. doi:10.15585/mmwr.ss6706a1

Bayardo, L. M. (2014). Autism: A dad's journey. Silver City, NM: Mercury Heartlink.

Barnes, C., Mercer, G., \& Shakespeare, T. (1999). Exploring disability: A sociological introduction. Cambridge, UK: Polity Press.

Barahona-Correa, J. B., \& Filipe, C. N. (2016). A concise history of Asperger syndrome: The short reign of a troublesome diagnosis. Frontiers in Psychology, 6(1), 1-7. doi:10.3389/fpsyg.2015.02024

Beech, I. (1999). Bracketing in phenomenological research. Nurse Researcher, 6(3), 35-50. Retrieved from https://coventry.rl.talis.com/items/E1F00D1E-F1FA-C8B4-FEB7B4436F72A41C.html

Benson, J., \& Dvesdow, S. (2003). Discovery mindset: a decision-making model for discovery and collaboration. Management Decision, 41(10), 997-1005. doi:10.1108/002517840310509526.

Bent, C., Barbaro, J., \& Dissanayake, C. (2017). Change in autism diagnoses prior to and following the introduction of DSM-5. Journal of Autism \& Developmental Disorders, 47(1), 163-171. doi:10.1007/s10803-016-2942-y

Bissinger, B. (2012). Father's day: A journey into the mind \& heart of my extraordinary son. Boston, MA: Houghton Mifflin Harcourt.

Blacher, J., \& Christensen, L. (2011). Sowing the seeds of the autism field: Leo Kanner (1943). 
Intellectual and Developmental Disabilities, 49(3), 172-191. doi:10.1352/1934-955649.3.172

Boström, P. K., \& Broberg, M. (2014). Openness and avoidance: A longitudinal study of fathers of children with intellectual disability. Journal of Intellectual Disability Research, 58(9), 810-821. doi:10.1111/jir.12093

Boushey, A. (2001). The grief cycle: One parent's trip around. Focus on Autism and Other Developmental Disabilities, 16(1), 27-30. doi:10.11771/108835760101600107

Broady, T. R., Stoyles, G. J., \& Morse, C. (2015). Understanding carers' lived experience of stigma: The voice of families with a child on the autism spectrum. Health \& Social Care in the Community, 25(1), 224-233. doi:10.1111/hsc.12297

Braunstein, V. L., Peniston, N., Perelman, A., \& Cassano, M. C. (2013). The inclusion of fathers in investigations of autistic spectrum disorders. Research in Autism Spectrum Disorders, 7(7), 858-865. doi:10.1016/j.r.as.d.2013.03.005

Burnette, J. L., Knouse, L. E., Vavra, D. T., O’Boyle, E., \& Brooks, M. A. (2020). Growth mindsets and psychological distress: A meta-analysis. Clinical Psychology Review, 77(1), 101816. doi:10.1016/j.cpr.2020.101816

Burns, D. E. (2009). Saving Be: A father's story of autism. Denton, TX: University of North Texas Press.

Burrell, A., Ives, J., \& Unwin, G. (2017). The experiences of fathers who have offspring with autism spectrum disorder. Journal of Autism \& Developmental Disorders, 47(4), 11351147. doi:10.1007/s10803-017-3035-2

California Department of Education. (2016). Epidemiology report of autism in California. Retrieved from https://www.dds.ca.gov/autism/docs/6conclusion.pdf 
Casey, M. (1996). Sacred reading: The ancient art of lectio divina. Liguori, Mo: Triumph Books.

Centers for Disease Control and Prevention. (2014). Autism spectrum disorder: Key findings. Retrieved from http://www.cdc.gov/ncbddd/autism/data/html

Cheuk, S., \& Lashewicz, B. (2016). How are they doing? Listening as fathers of children with autism spectrum disorder compare themselves to fathers of children who are typically developing. Autism: The International Journal of Research and Practice, 20(3), 343-352. doi:10.1177/13623613115584464

Cidav, Z., Marcus, S. C., \& Mandell, D. S. (2012). Implications of childhood autism for parental employment and earnings. Pediatrics, 129(4), 617-623. doi:10.1542/peds.2011-2700

Cummings, S. T. (1976). The impact of the child's deficiency on the father: A study of fathers of mentally retarded and of chronically ill children. American Journal of Orthopsychiatry, 46(2), 246-255. doi:10.1111/j.1939-0025.1976.tb00925.x

Creswell, J. W. (2013). Qualitative inquiry \& research design: Choosing among five approaches. Los Angeles, CA: Sage.

Creswell, J. W., \& Poth, N.C. (2018). Qualitative inquiry and design, choosing among five approaches (4th ed.). Los Angeles, CA: Sage.

Crotty, M. (1998). The foundations of social research: Meaning and perspective in the research process. Los Angeles, CA: Sage.

Crum, A. J., Akinola, M., Martin, A., \& Fath, S. (2017). The role of stress mindset in shaping cognitive, emotional, and physiological responses to challenging and threatening stress. Anxiety, Stress \& Coping, 30(4), 379-395. doi:10.1080/10615806.2016.1275585 
Crum, A. J., Salovey, P., \& Acho, S. (2013). Rethinking stress: The role of mindsets in determining the stress response. Journal of Personality and Social Psychology, 104(4),716-733. doi:10.1037/a0031201

Dalton, J. E. (2018). Lectio divina and meditation: Exploring identity through contemplative practices. Visual Inquiry: Learning \& Teaching Art, 7(3), 251-255. doi:10.1386/vi.7.3.2.2517

Davis, L. J. (Ed.). (2013). Disability studies reader. New York, NY: Routledge.

Democracy Disability and Society Group. (2003). The social model of disability. Retrieved from http://ddsg.org.uk/taxi/social-model.html difference

Donaldson, S. O., Elder, J. H., Self, E. H., \& Christie, M. B. (2011). Fathers' perceptions of their roles during in-home training for children with autism. Journal of Child and Adolescent Psychiatric Nursing, 24(4), 200-207. doi:10.1111/j1744-617.2011.00300x

Donvan, J., \& Zucker, C. (2016). In a different key: The story of autism. New York, NY: Crown.

Douglass, B. G., \& Moustakas, C. (1985). Heuristic inquiry: The internal search to know. Journal of Humanistic Psychology, 25(3), 39-54. doi:10.1177/0022167885253004

Dryden, C. (2014). Being Married, Doing Gender: A critical analysis of gender relationships in marriage. London: Routledge.

Dweck, C. S. (1999). Self-Theories: Their role in motivation, personality, and development. Philadelphia, PA: Psychology Press.

Dweck, C. S. (2008). Can personality be changed? The role of beliefs in personality and change. Current Directions in Psychological Science, 17(1), 391-394. doi:10.1111/j.14678721.2008.00612.x 
Dweck, C. S. (2012). Mindsets and human nature: Promoting change in the Middle East, the schoolyard, the racial divide, and willpower. American Psychologist, 67(8), 614-622. doi:10.1037/a0029783

Dweck, C. S. (2016). Mindset: The new psychology of success. New York: Random House.

Dweck, C. S. (2019). The choice to make a difference. Perspectives on Psychological Science, 14(1), 21-25. doi:10.1177/1745691618804180

Dweck, C. S., \& Leggett, E. L. (1988). A social-cognitive approach to motivation and personality. Psychological Review, 95(2), 256-273. doi:10.1037/0033-295X.95.2.256

Dweck, C. S., \&Yeager, D. S. (2019). Mindsets: A view from two eras. Perspectives on Psychological Science, 14(3), 481-496. doi:10.11777/1745691618804166

Eisenberg, L. (1957). The fathers of autistic children. American Journal of Orthopsychiatry, 27, 715-724. doi:10.1111/j.1939-0025.1957.tb05539.x

Errea, R. (2011). Adventures in raising an autistic son. North Jersey: Giant dog Books.

Ferguson, P. M. (2002). A place in the family: An historical interpretation of research on parental reactions to having a child with a disability. Journal of Special Education, 36, 124-131. doi:10.1177/00224669020360030201

Ferguson, D. L., \& Ferguson, P. M. (2000). Qualitative research in special education: Notes toward an open inquiry instead of a new orthodoxy? Journal of the Association for Persons with Severe Handicaps, 25, 180-185. doi:10.2511/rpsd.25.3.180

Fields-Myer, T. M. (2011). Following Ezra: What one father learned about gumby, otters, autism, and love from his extraordinary son. New York, NY: New American Library

Finlay, L. (2009). Debating phenomenological research methods. Phenomenology \& Practice, 3, 6-25. doi:10.29173/pandpr19818 
Fitzgerald, M. (2014). Overlap between autism and schizophrenia: History and current status. Advances in Mental Health and Intellectual Disabilities, 8, 15-23. doi:10.1108/AMHID09-2013-0058

Flanagan, B. (2014). Quaestio divina: research as spiritual practice. The Way, 53(4), 126-136. Retrieved from https://www.theway.org.uk/back/534Flanagan.pdf

Fleischmann, A., \& Fleischmann, C. (2012). Carly's voice: Breaking through autism. New York, NY: Simon \& Schuster.

Flippin, M., \& Crais, E. R. (2011). The need for more effective father involvement in early autism intervention: A systematic review and recommendations. Journal of Early Intervention, 33, 24-50. doi:10.1177/1053815111400415

Fombonne E. (2009). Epidemiology of pervasive developmental disorders. Pediatric Research, 65(6), 591-598. doi:10.1203/PDR.0b013e31819e7203

Fournier, R. (2016). Love that boy: What two presidents, eight road trips, and my son taught me about a parent's expectations. New York, NY: Penguin Random House.

Freihow, H. W. (2006). Somewhere over the sea: A father's letter to his autistic son. Toronto, Ontario: Publishers Group West.

French II, R. P. (2016). The fuzziness of mindsets: Divergent conceptualizations and characterizations of mindset theory and praxis. International Journal of Organizational Analysis, 24(4), 673-691. doi:10.110808/IJOA-092014-079

Frye, F. (2016). Fathers experience with autism spectrum disorder: Nursing implications. Journal of Pediatric Health Care, 30, 453-463. doi:10.1016/j.pedhc.2015.10.012

Gallardo, M., \& Gallardo, M. (2018). Maria and me: A father, a daughter (and autism). London, UK: Jessica Kingsley. 
Ganz, J. B. (2007). Using visual script interventions to address communication skills. Teaching Exceptional Children, 40(1), 54-58. doi:10.1177/00400599070400020

Geertz, C. (1973). The interpretation of cultures. New York, NY: Basic Books.

Giorgi, A. (2005). The phenomenological movement and research in the human sciences. Nursing Science Quarterly, 18(1), 75-82. doi:10.1177/0894318404272112

Goffman, E. (1963). Stigma: Notes on the management of spoiled identity. Englewood Cliffs, NJ: Prentice Hall.

Goodley, D. (2010). Disability studies: An interdisciplinary introduction. Thousand Oaks, CA: SAGE.

Gorlin, J. B., McAlpine, C. P., Garwick, A., \& Wieling, E. (2016). Severe childhood autism: The family lived experience. Journal of Pediatric Nursing, 31, 580-597. doi:10.1016/j.pedn.2016.09.002

Gray, E. D. (2002). 'Everybody just freezes. Everybody is just embarrassed': Felt and enacted stigma among parents of children with high functioning autism. Sociology of Health \& Illness, 24(6), 734-749. doi:10.1111/1467-9566.00316

Greydanus, D. E., \& Toledo-Pereyra, L. H. (2012). Historical perspectives on autism: Its past record of discovery and its present state of solipsism, skepticism, and sorrowful suspicion. The Pediatric Clinics of North America, 59(1), 1-11.

doi:10.1016/j.pcl.2011.10.004

Grinker, R. R. (2007). Unstrange minds. A father, a daughter, and a search for new answers. Remaking the world of autism. New York, NY: Basic Books. 
Hamill, C., \& Sinclair, H. A. H. (2010). Bracketing: Practical considerations in Husserlian phenomenological research. Nurse Researcher, 17(2), 16-24. doi:10.7748/nr2010.01.17.2.16.c7458

Hannon, M. D., \& Hannon, L. V. (2017). Fathers' orientation to their children's autism diagnosis: A grounded theory study. Journal of Autism and Developmental Disorders, 47(7), 2265-2275. doi:10.1007/s10803-017-3149-6

Hague, J. (2018). Aching joy. Following god through the land of answered prayer. Eugene, OR: NavPress.

Heelan, P. A. (1987). Husserl's later philosophy of natural sciences. Philosophy of Sciences, 54, 368-390. doi:10.1086/289389

Hernández-Saca, D. I., \& Cannon, M. A. (2016). Disability as psycho-emotional disablism: A theoretical and philosophical review of education theory and practice. In M. Peter (Ed.), Encyclopedia of educational philosophy and theory (pp. 1-7). New York, NY: Springer Publishing.

Hiles, D. R. (2001, October). Heuristic inquiry and transpersonal research. Paper presented at the Centre for Counselling and Psychotherapy Education, London. Retrieved from http://www.psy.dmu.ac.uk/drhiles/HIpaper.htm

Hock, R. M., Timm, T. M., \& Ramisch, J. L. (2012). Parenting children with autism spectrum disorders: A crucible for couple relationships. Child and Family and Social Work, 17, 406-415. doi:10.1111/j.1365-2206.2011.00794.x

Hoogsteen, L, \& Woodgate, R. L. (2013). Centering autism within the family: A qualitative approach to autism and the family. Journal of Pediatric Nursing, 28(2), 135-140. doi:10.1016/j.pedn.2012.06.002 
Hornby, G. (1992). A review of fathers' accounts of their experiences of parenting children with disabilities. Disability, Handicap \& Society, 7, 363-374.

doi:10.1080/02674649266780431

Individuals with Disabilities Education Act of 2004, 20 U.S.C. $§ 1400$ et seq. (2004).

Isaacson, R. (2009). The horse boy: A father's quest to heal his son. New York, NY: Little, Brown and Company.

Isaacson, R. (2016). The long ride home: The extraordinary journey of healing that changed a child's life. Elgin, TX: Hors ${ }^{\mathrm{e}}$ Boy Press.

Jegatheesan, B., Miller, P. J., \& Fowler, S. A. (2010). Autism from a religious perspective: A study of parental beliefs in South Asian Muslim immigrant families. Focus on Autism and Other Developmental Disabilities, 25(2), 98-109. doi:10.1177/1088357610361344

Johnstone, D. (2001). An introduction to disability studies (2nd ed.). London, UK: David Fulton.

Kabat-Zinn, J. (1982). An outpatient program in behavioral medicine for chronic pain patients based on the practice of mindfulness meditation: Theoretical considerations and preliminary results. General Hospital Psychiatry, 4(1), 33-47. doi:10.1016/16383439(82)90026-3

Kammrath, L. K., \& Dweck, C. (2006). Voicing conflict: Preferred conflict strategies among incremental and entity theorists. Personality and Social Psychology Bullerton, 11(1), 1497-1508. doi:10.1177/0146167206291476

Kaufman. B. N. (1994). Son rise: The miracle continues. Novato, CA: New World Library.

Keller, T., Ramisch, J., \& Carolan, M. (2014). Relationships of children with autism spectrum disorders and their fathers. The Qualitative Report, 19(33), 1-15. Retrieved from https://nsuworks.nova.edu/tqr/vol19/iss33/2 
Kelly, J. P. (2019, March 22). An avid reader? Consider the spiritual practice of lectio divina: Through this meditation, texts both secular and sacred become part of a reader's heart and soul. U.S. Catholic. Retrieved from https://www.uscatholic.org/articles/201903/avidreader-consider-spiritual-practice-lectio-divina-31680

Kenny, G. (2012). An introduction to Moustakas's heuristic method. Nurse Researcher, 19(3), 6-11. Retrieved from https://pdfs.semanticscholar.org/55ee/9b73744b38977d3cf33767ec877f3df81c65.pdf

Kirby, P. (2019). Gift from the gods? Dyslexia, popular culture and the ethics of representation. Disability \& Society, 34(9/10), 1573-1594. doi:10.1080/09867599.2019.1584091

Kogan, D. M., Vladutiu, J. C., Schieve, L. A., Ghandour, R. M, Blumberg, S. J, Zablotsky, B., \& Lu, M. R. (2018). The prevalence of parent-reported autism spectrum disorder among U.S. children. Pediatrics, 142, 2017-3701 doi:10.1542/peds.2017-4161

Krishnamurti, K. (1956). First series commentaries on living. Wheaton, IL: The Theosophical Publishing House.

Krishnan, R., Russell, P. S., \& Russell, S. (2017). A focus group study to explore grief experiences among parents of children with autism spectrum disorder. Journal of the Indian Academy of Applied Psychology, 43(2), 267-275. Retrieved from https://www.questia.com/library/journal/1P4-1964553501/a-focus-group-study-toexplore-grief-experiences-among parents of children with autism spectrum disorder Kübler-Ross, E. (1969). On death and dying. New York, NY: Scribner.

Kübler-Ross, E., \& Kessler, D. (2005). On grief and grieving: Finding the meaning of grief through the five stages of loss. New York, NY: Scribner. 
Lambert, L., Walker, D., Zimmerman, D. P., Cooper, J. E., Lambert, M. D., Gardner, M.E., \& Ford Slack, P. J. (1995). The constructivist leader. New York, NY: Teachers College Press.

Lashewicz, B. M., Shipton, L., \& Lien, K. (2019). Meta-synthesis of fathers’ experiences raising children on the autism spectrum. Journal of Intellectual Disabilities, 23(1), 117-131. doi:10.1177/1744629517719347

LeVasseur, J. J. (2003) The problem of bracketing in phenomenology. Qualitative Health Research, 3(3), 408-420. doi:10.1177/1049732302250337

Lincoln, Y. S., \& Guba, E. G. (1985). Naturalistic inquiry. Beverly Hills, CA: Sage.

Lincoln, Y. S., \& Guba, E. G. (2013). The constructivist credo. Walnut Creek, CA: Left Coast Press.

Linton, S. (1998). Claiming disability: Knowledge and identity. New York, NY: University Press.

Lurigio, A. J. (2015). DSM-5. In P. Moglia (Ed.), Salem health: Psychology \& behavioral health (4th ed., pp. 4-5). Ipswich, MA: Salem Press. Retrieved from https://searchworks.stanford.edu/articles/ers115297534

Lutz, A., Jha, A. P., Dunne, J. D., \& Saron, C. D. (2015). Investigating the phenomenological matrix of mindfulness-related practices from a neurocognitive perspective. American Psychologist, 70(7), 632-658. doi:10.1037/a0039585

Lyons, V., \& Fitzgerald, M. (2007). Did Hans Asperger (1906-1980) have Asperger syndrome? Journal of Autism and Developmental Disorders, 37, 2020-2021. doi:10.1007/s10803007-0382-4 
Mackey, E. A. (2016). An interpretative phenomenological analysis of the experiences of fathers of adults diagnosed with Asperger's syndrome or high functioning autism (Doctoral dissertation, University of Hertfordshire). Retrieved from https://uhra.herts.ac.uk/bitstream/handle/2299/17188/12239475\%20Mackey\%20Ellen\%2 0final\%20DClinPsy\%20submission.pdf?sequence $=1$

Manouilenko, I., \& Bejerot, S. (2015). Sukhareva-prior to Asperger and Kanner. Nordic Journal of Psychiatry, 6, 478-483. doi:10.3109/08039488.2015.1005022.

Margalit, M., Leyser, Y., \& Avraham, Y. (1989). Classification and validation of family climate subtypes in kibbutz fathers of disabled and nondisabled children. Journal of Abnormal Child Psychology, 17, 91-107. doi:10.1007/BF00910772

Martins, C. D., Walker, S. P., \& Fouché, P. (2013). Fathering a child with autism spectrum disorder: An interpretative phenomenological analysis. Indo-Pacific Journal of Phenomenology, 13(1), 1-19. doi:10.2989/IPJP.2013.13.1.5.1171

Meadan, H., Stoner, B. J., \& Angell, M. E. (2015). Fathers of children with autism: Perceived roles, responsibilities and support needs. Early Child Care Development and Care, 185, 1678-1694, doi:10.1080/03004430.2015.1019876

McCafferty, K. R. (2014). Over under trough: We've found a way to make both the restrictions and gifts of autism work for us, forged a life filled more with beauty than with pain. The Exceptional Parent, 44(5), 58-58. Retrieved from http://www.ep-magazine.com

McConnell-Henry, T., Chapman, Y., \& Francis, K. (2009). Husserl and Heidegger: Exploring the disparity. International Journal of Nursing Practice, 15, 7-15. doi:10.1111/j.1440172X.2008.01724.X 
Miller, J., Bilder, D., Farley, M., Coon, H., Pinborough-Zimmerman, J., Jenson, W., . . . McMahon, W. (2013). Autism spectrum disorder reclassified: A second look at the 1980s Utah/UCLA autism epidemiologic study. Journal of Autism \& Developmental Disorders, 43(1), 200-210. doi:10.1007/s10803-012-1566-0

Mitchell, J., \& Lashewicz, B. (2018). Quirky kids: Fathers' stories of embracing diversity and dismantling expectations for normative play with their children with autism spectrum disorder. Disability \& Society, 33, 1120-1137. doi:10.1080/09687599.2018.1474087

Mont, D. (2002). A different kind of boy. London, UK: Jessica Kingsley.

Montes, G., \& Halterman, J. S. (2007). Bullying among children with autism and the influence of comorbidity with ADHD: A population-based study. Ambulatory Pediatrics, 7(3), 253257. doi:10.1016/j.ambp.2007.02.003

Moran, D. (2000). Introduction to phenomenology. London, UK: Routledge.

Moss, G. (2004). Provisions of trustworthiness in critical narrative research: Bridging intersubjectivity and fidelity. The Qualitative Report, 9(2), 359-374. Retrieved from https://nsuworks.nova.edu/tqr/vol9/iss2/10

Moustakas, C. E. (1972). Loneliness and love. Englewood Cliffs, NJ: Prentice-Hall.

Moustakas, C. E. (1975). The touch of loneliness. Englewood Cliffs, NJ: Prentice-Hall.

Moustakas, C. E. (1990). Heuristic research, design, methodology, and applications. Newbury, Park, CA: Sage.

Moustakas, C. E. (1994). Phenomenological research methods. Thousand Oaks, CA: Sage.

Moustakas, C. E. (1995). Being-in, being-for, being-with. Northvale, NJ: Jason Anders. 
Murray, M. A. (1959). Needs of parents of mentally retarded children. American Journal of Mental Deficiency, 63,1078-1082. Retrieved from https://www.ncbi.nlm.nih.gov/pubmed/13649747

Nadesan, M. H. (2005). Constructing autism: Unravelling the 'truth' and understanding the social. New York, NY: Routledge.

O’Halloran, M., Sweeney, J., \& Doody, O. (2013). Exploring fathers' perceptions of parenting a child with Asperger syndrome. Journal of Intellectual Disabilities, 17, 198-213. doi:10.1177/1744629513494928

Olmsted, D., \& Blaxill, M. (2016). Leo Kanner's mention of 1938 in his report on autism refers to his first patient. Journal of Autism and Developmental Disorders, 46, 340-341. doi:10.1007/s10803-015-2541-3

Pakkala, B. (2015). Broken by autism: A father and son story. Kenmore, WA: Conicker Publishing.

Paynter, J., Davies, M., \& Beamish, W. (2018). Recognising the "forgotten man": Fathers' experiences in caring for a young child with autism spectrum disorder. Journal of Intellectual \& Developmental Disability, 43, 112-124. doi:10.3109/13668250.2017.1293235

Paul, J., Kleinhammer-Tramill, J. K., \& Fowler, K. (2009). Qualitative research methods in special education. Denver, CO: Love Publishing.

Pennington, M. L., Cullinan, D., \& Southern, L. B. (2014). Defining autism: Variability in state education agency definitions of and evaluations for autism spectrum disorders. Autism Research and Treatment, 1(50), 1-8, 50. doi:10.1155/2014/327271 
Phillips-Pula, L., Strunk, J., \& Pickler, R. H. (2011). Understanding phenomenological approaches to data analysis. Journal of Pediatric Health Care, 25, 67-71. doi:10.1016/j.pedhc.2010.09.004

Polkinghorne, D. (1982). What makes research humanistic. Journal of Humanistic Psychology, 2(3), ss47-54. doi:10.1177/0022167882223007

Polkinghorne, D. E. (1989). Phenomenological research methods. In R. S. Valle, \& S. Halling (Eds.), Existential-phenomenological perspectives in psychology (pp. 41-60). Boston, MA: Springer.

Polkinghorne, D. E. (2005). Language and meaning: Data collection in qualitative research. Journal of Counseling Psychology, 52, 137-145. doi:10.1037/0022-0167.52.2.137

Preece, D. (2014). A matter of perspective: The experience of daily life and support of mothers, fathers and siblings living with children on the autism spectrum with high support needs. Good Autism Practice, 15(1), 81-90. Retrieved from https://www.ingentaconnect.com/content/bild/gap

Price-Bonham, S., \& Addison, S. (1978). Families and mentally retarded children: Emphasis on the father. Family Coordinator, 27, 246-255. doi:10.2307/582583

Robison, J. E. (2013). Raising cubby. A father and son's adventures with Asperger's trains, tractors and high explosives. New York, NY: Crown.

Robison, J. E. (2017). Kanner, Asperger, and Frankl: A third man at the genesis of the autism diagnosis. The International Journal of Research and Practice, 21, 862-871. doi: $10.1177 / 1362361316654283$ 
Robinson, C. A., York, K., Rothenberg, A., \& Bissell, L. (2015). Parenting a child with Asperger's syndrome: A balancing act. Journal of Child \& Family Studies, 24, 23102321. doi:10.1007/s10826-014-0034-1

Reiners, M. G. (2012). Understanding the differences between Husserl's (descriptive) and Heidegger's (interpretive) phenomenological research. Nursing and Care, 1(5), 1-3. doi:10.4172/2167-1168.1000119

Roche, M. (1973). Phenomenology, language and the social sciences. London, UK: Routledge \& Kegan Paul.

Rockmore, T. (2005). On constructivist epistemology. Lanham, MD: Rowman \& Little Field. Rose, P., Beeby, J., \& Parker, D. (1995). Academic rigour in the lived experience of researchers using phenomenological methods in nursing. Journal of Advanced Nursing, 21, 11231129. doi:10.1046/j.1365-2648.1995.21061123.x

Sanders, J. L., \& Morgan, S. B. (1997). Family stress and adjustment as perceived by parents of children with autism or Down syndrome: Implications for intervention. Child \& Family Behavior Therapy, 19(4), 15-32. doi:10.1300/J019v19n04_02

Savarese, R. J. (2007). On the meaning of family and the politics of neurological difference: Reasonable people, a memoir of autism \& adoptions. New York, NY: Other Press.

Schroder, H. S., Yalch, M. M., Dawood, S., Callahan, C. P., Brent Donnellan, M., \& Moser, J. S. (2017). Growth mindset of anxiety buffers the link between stressful life events and psychological distress and coping strategies. Personality and Individual Differences, 11(1), 23-26. doi:10.1016/j.paid.2017.01.2016 
Scorgie, K., \& Sobsey, D. (2000). Transformational outcomes associated with parenting children who have disabilities. Mental Retardation, 38(1), 195-206. doi:10.1352/00476765(2000)038<0195:TOAWPC >2.0.CO;2

Seidman, I. (1988). Interviewing as qualitative research: A guide for researchers in education \& the social sciences (3rd ed.). New York, NY: Teachers College Press.

Seidman, I. (2013). Interviewing as qualitative research: A guide for researchers in education \& the social sciences (4th ed.). New York, NY: Teachers College Press.

Seligman, K., \& Darling, R. B. (2007). Ordinary families, special children: A systems approach to childhood disability. New York, NY: The Gillford Press.

Shakespeare, T. (2014). Disability rights and wrongs revisited. London, UK: Routledge.

Shave, K., \& Lashewicz, B. (2016). Support needs of fathers of children with ASD: Individual, family, community and ideological influences. Journal of Applied Research in Intellectual Disabilities, 29, 495-507. doi:10.1111/jar.12204

Sheean, S. (2014). A conceptual framework for understanding transcendental phenomenology through the lived experiences of biblical leaders. Emerging Leadership Journeys, 7(1), 10-20. Retrieved from https://www.regent.edu/acad/global/publications/elj/vol7iss1/2ELJ-Sheehan.pdf

Shinn, K. (2014). We win: A father's journey through autism. Maitland, FL: Xulon Press.

Shyman, E. (2016). The reinforcement of ableism: Normality, the medical model of disability, and humanism in applied behavior analysis and ASD. Intellectual and Developmental Disabilities, 54(5), 366-376. doi:10.1352/1934-9956-54.5.366

Siebers, T. (2011). Disability theory. Ann Arbor: The University of Michigan Press. 
Silverman, S. (2015). NeuroTribes: The legacy of autism and the future of neurodiversity. New York, NY: Random House.

Simmonds, C., \& Sukhareva, G. E. (2019). The first account of the syndrome Asperger described? Part 2: The girls. European Child \& Adolescent Psychiatry. doi:10.1007/s00787-019-01371-z

Smith, H. (2015). Sticks and stones. A father's journey into autism. Kelseyville, CA: Author.

Straus, J. N. (2013) Autism as culture. In L. J. Davis (Ed.), The disability studies reader (4th ed., pp. 460-484). New York, NY: Routledge.

Sultan, N. (2017). Embodiment and the therapeutic relationship: Findings from a heuristic Inquiry. Journal of Humanistic Counseling, 56(3), 180-196. doi:10.1002/johc.12052

Sultan, N. (2019). Heuristic inquiry, researching human experience holistically. Los Angeles, CA: Sage.

Tarakeshwar, N., \& Pargament, K. I. (2001). Religious coping in families of children with autism. Focus on Autism and Other Developmental Disabilities, 16(4), 247-260. doi: $10.1177 / 108835760101600408$

Wang, P., \& Michaels, C. A. (2009). Chinese families of children with severe disabilities: Family needs and available support Chinese families of children with severe disabilities: Family needs and available support. Research \& Practice for Persons with Severe Disabilities, 34, 21-32. doi:10.2511/rpsd.34.2.21

Wakefield, J. (2013). DSM-5: An overview of changes and controversies. Clinical Social Work Journal, 41, 139-154. doi:10.1007/s10615-013-0445-2 
Ware, L. (2011). Disability studies in education. In S. Tozer, B. P. Gallegos, A. Henry, M. B. Greiner, \& P. G. Price (Eds.), Handbook of research in the social foundations of education (pp. 244-259). New York, NY: Routledge.

Ware, L. (2012). Disability studies. In J. A. Banks (Ed.), Encyclopedia of diversity in education (Vol. 2, pp. 657-661). New York, NY: Routledge.

West, W. (2001). Beyond grounded theory: The use of a heuristic approach to qualitative research. Counselling \& Psychotherapy Research, 1, 126-131. doi:10.1080/14733140112331385168

Wilson, C. J. (2008). Weather reports from the autism front: A father's memoir of his autistic son. Jefferson, NC: McFarland \& Company.

Vacca, J. J. (2013). The parenting process from the father's perspective: Analysis of perceptions of fathers about raising their child with autism spectrum disorder. Best Practices in Mental Health, 9(2), 79-93. Retrieved from https://www.fatherhood.gov/sites/default/files/Resource\%20Files/e000002948.pdf

Vagle, M. (2014). Crafting phenomenological research. London, UK: Routledge.

Van Manen, M. (2014). Phenomenology of practice. London, UK: Routledge.

Vatanoglu-Lutz, E. E., Ataman, A. D., \& Bicer, S. (2014). Vignette: Medicine in stamps: History of autism spectrum disorder (ASD) through philately. The Online Journal of Neurological Sciences (Turkish), 31(2), 426-434. Retrieved from https://pdfs.semanticscholar.org/f020/6b78a7c5410effcaee3b1e07fa630ce15610.pdf?_ga $=2.127153485 .1739613646 .1583958038-94090415.1583867188$

Verhoeff, B. (2013). Autism in flux: A history of the concept from Leo Kanner to DSM-5. History of Psychiatry, 24, 442-458. doi:10.1177/0957154X13500584 
Volk, D., \& Volk, D. (2015). Chasing the rabbit: A dad's life raising a son on the spectrum. Biddeford, ME: Greatlife Press.

Yanofsky, J. (2012). Bad animals: A father's accidental education in autism. New York, NY: Arcade Publishing.

Yaylaci, F., \& Miral, S. (2017). A comparison of DSM-IV-TR and DSM-5 diagnostic classifications in the clinical diagnosis of autistic spectrum disorder. Journal of Autism \& Developmental Disorders, 47, 101-109. doi:10.1007/s10803-016-2937-8 


\section{Appendix A}

\section{Bracketing Example of Self-Dialogue From My Research Journal}

[ ] my feelings/thoughts Date: 10:16 PM, October 3, 2019

Transposed Always in the Words

I stand transposed before the hourglass of time. This ever changing and evolving construct envelopes me, envelopes each of us.

It is and continues to be in the words, heard or spoken that grab at my soul. This is followed with the emotion behind the words. While going through William's s third and final transcript, his words grab at me. [Last week I had pondered why do his words resonate and enter my mind like they do?] [My narrative writing is born out of a need to understand my feelings, and thoughts, as I continue to interview fathers. Quiet are the moments of the mind's transcendence, deep from the fathoms of thoughts and unconscious feelings. It is the power of voice and the ability to hold one's own in divergent paradigms of thought and belief that will stand the test of time.]

William said,

Aristotle said it right be kind to everyone you meet for each is fighting a hard battle. I mean, that's a, that's a, that's a pushup for the soul and a lot of this stuff, I guess. I know it's a field of shit I'm being dragged through on this plow, but on the other side of it, when you look back, you go, wow, huh. I'm not the person I was and I'm a better person for it. Not that it was, I would have ever signed up for that elk club.

William talked further,

Lisa but what has made it less tough? 
William What's made it less tough?

Lisa Uh, your, is it your faith? Is it your why?

William it's, I think it's faith. think it's, it's, it's lots of things and realizing I'm not alone and I'm not special in this happens. I was not singled out for this. Uh, nobody's trying to make my life harder that people deal with things that are much tougher than this is.

[I find myself at times placing a wall upon the pages my heart reads and the emotions I hold back from internal or written expression.]

[Back to William's words and how my mind connects, something is here... something I am drawn to keep writing about, even as his transcript sits open, I'm only on page 6 and have 22 more pages to read and listen to his voice talking to mine. It's his words of, 'it's, it's lots of things and realizing I'm not alone and I'm not special in this happens. I was not singled out for this.] 
Appendix B

Three Poems Written During Interviewing From Research Journal

\section{0:18 PM December 5, 2019}

\section{Coding}

Sometimes when the house grows dark,

And the thoughts of the day,

Are laid to rest.

The earth and I breathe a quiet sigh.

With thoughts swirling about my mind,

And fears I say, "please subside"

I code.

The night brings a silence,

The day cannot offer.

This slice of the clock's hour,

Its own impermanence.

For the process of a dissertation,

Opens the soul and offers the mind,

Its own states of liminal passages,

This time is scared.

A time for honor.

And sometimes a time for tears,

Coding brings the fathers words,

Alive in a different way, 
Separated out,

from long transcribed pages,

They are so much more alive.

I feel their falling presence,

Set upon my face,

And the responsibility of honoring,

Theses 10 fathers' words.

For it is their stories,

Who make the work possible.

What a process this is.

One so unique,

It's further narrative description,

Waits,

till the appointed hour,

When the praxis of reflection,

Will greet me with arms open wide.

Till then:

I'll Code.

I'll then write Chapters.

7:53 PM, October 1, 2019 \& 7:54 pm October 2, 2019

The Doors

For every door that opens

Another, changes shape.

Humility 
Out from the pages of answered questions

Lies the silence

the fathers hold close to their hearts.

I sit in this held silence,

Not asking a question at times.

This is the quiet space between I and thou.

This space cannot be rushed,

Pushed and or manipulated.

It's occurring generated,

by the formation of:

Mutual trust and the opening of both hearts.

Fathers continue to place,

Their thoughts and feelings upon the table,

Where all are welcome.

In the welcoming.

Quiet reverence is placed upon my:

Mind,

Soul, and

Heart.

To sit with each father,

Through each of their three interviews,

Has been and continues to be, a state of humility.

The formation of trust is a multilevel triad.

\section{The Formation of Trust}


The formation of trust,

Is not given automatically;

Like the flowing of a river before and after a storm.

It comes through the arrival of layered contemplation, and a sincere desire to be $110 \%$ present

to the best of my ability

in each and every interview.

The ascendance of trust

Requires a leap into the unknown,

On both sides of the table. 


\section{Appendix C \\ Example of Tacit Knowing Journal Entires}

\section{9:01 PM, October 3, 2019}

I am a woman somewhere on the wide and complex spectrum called autism. While interviewing the 10 fathers in my study a total of three separate interviews. I and my dissertation committee made the decision for me not to disclose this to the fathers during the course of their interviews. I wanted the fathers to answer my interview questions freely without the shadow of my presence on a wide spectrum. To write is to ask the mind to bare its truth to page, it is often contemplated in early hours when sunrise seems like a whisper upon the soul. Writing is a choice of written communication, a trusting of self that truth and its journey is a path filled with many turns.

\section{6:11 AM, September 8, $2019 \quad$ Juxtaposed}

Below the heart beating anxiety lies my feelings, sometimes they are concealed from view, my feelings of being on the AS. They feel like a scorched piece of land whose entranceway stands waiting for waters extinguishing. It's the thoughts in my mind who's often swirling positionally strike like a swift moving storm across a dry sea. They advance like ghosts in the midnight hours. Unspoken fears often greet feelings soon to be acquisition, laid bare by quietly falling tears. I awake in the morning sometimes emotionally tired, a result not of the day prior; but from a few days ago. The after shot of interviewing strikes not in the immediate moment it's after as my feelings find their way. They find their way from my mind to my heart. When the entranceway between thought and feeling submerges the transformation begins its own journey. Often it is the day before another scheduled interview. This often pile of feelings is then placed upon another shelf. 


\section{Sometimes}

Sometimes, I just don't want to do this anymore, the feelings of being overwhelmed. I feel overwhelmed as my own experiences of being on the AS stand at the doorway. I place them to the side, for when the fathers have talked about the isolation their children experience. I quietly nod my head inside, knowing this feeling all too well when I was a child. This complies with another interview tomorrow; one in fact I want to do. My tears roll down as I sit here in the bike, as a meltdown of sorts is occurring. At times, I feel as though my dissertation has a life all of its own. It demands much, it asks much, and simultaneously gives much. 


\section{Appendix D}

\section{Example of Intuition}

Intuition

\section{7:53 PM, October 1, 2019}

For every door that opens another changes shape. It's a continuing choice to be in the moment, to choose to be aware, so moments of illumination and intuition can shine through dark clouds.

\section{Words}

To write is to ask the mind to bare its truth to page, it is often contemplated in early hours when sunrise seems like a whisper upon the soul. Writing is a choice of written communication, a trusting of self that truth and its journey is a path filled with many turns. To place words upon the page of self and others, in part requires a stripping away of known realities and a heartfelt dose of humility. My intuition reminds me in the quiet moments that staying in the silence with a father opens doors, whose passages require a key to not just the mind but to the soul. Trust is the bridge between the unseen world of intuition and the minds contemplation. My intuition walks me into the quiet and opens my soul to spaces where humility is the bridge to connection and deeper trust.

\section{Humility}

Out from the pages of answered questions lies the silence the fathers hold close to their hearts. I sit in this held silence not asking a question at times. This is the quiet space between I and thou, this is not a single journey of researcher removed completely from the process. To sit with a father whose child had a severe autism diagnosis required so much. To sit in the opening doors of silence was mutual gift. 


\section{Appendix E}

Indwelling Example From Research Journal

During indwelling, I turned within and sought greater understanding of the experiences my fathers had. In adapting the sixth century Benedictine practice of contemplative meditation known as lectio divina, helped center my mind as I: (a) I reread each of the 30 participant interviews and chose three of the 2,155 significant statements from each of the participants' interviews, and (b) I reflected on each of the significant statements.

Father: John

Interview: Third

Significant Statement: "there's no point in doing anything going crazy to make us try and make his life better or whatever. So, so that was what was infuriating. It's like you've just sentenced our child to a child to a particular future. And I just thought that was the most awful thing you could say. And okay. Yeah, he'll probably be with us for the rest of list. We've accepted that, but it goes again in places and back into the second-class citizen." Indwelling Reflection:

As I reflected upon this long significant statement by John, I heard again the pain and anger in his voice. The Doctor handed a lifelong sentence to John and his wife. They didn't have any issues with their son and how he would be living with them for the rest of their son's life. It was the careless attitude of the Doctor as he rendered this information. I could hear pain still after all the years since this Doctor gave John and his wife their child's diagnosis, over 15 years had passed and still John's pain came through.

Father: Gabriel

Interview: Second interview 
Significant Statement: "But, you know, it's, it's, it's Saturdays for me. if- if that was my life on the daily it- it would be a, it would be a, just a vital struggle to be able to continue to exist." Indwelling Reflection:

Gabriel only has his two children on Saturdays, he cannot fathom how he could survive if he had full custody of his two children on the AS every day. It reminds me of how he spoke in an earlier interview of how autism broke up and destroyed his marriage. I thought how much this must of hurt him, the impact of his children's autism on his marriage and in his life. He lives 45 minutes away from his children. I thought about how he told me his goal was to move closer to his children, so he could be closer and spend more time with his kids. Then I wondered would he be able to handle his kids more than one day? He was so honest in his admission of only being able to cope with having his kids for 1 full day. 


\section{Appendix F}

Example of Bracketing Research Journal

\section{November 29, 2019 no time stamp [ ] Represents Bracketing}

\section{Carry}

[I carry the words from these fathers, like raindrops upon my soul. Inherent in the power proclaimed in the spoken word, are rivers of truth.] His reality of and view of self. Marks' words, "I just had, I have such a, I feel that I had such a low [inaudible] self-esteem, self -worth that it's hard for me to really think about it... it's not going to change soon. It's in like the sunrise. You're not going to wake up tomorrow morning your kids are no different.” [this reality of AS reality regarding his children.]

\section{Spoken Word}

[Inside words a lifetime of feelings and stores are held by the fathers I have interviewed. I hold their words like scared vessels as water has been turned into wine. Their lives are filled with spoken and remembered moment I, who draw their and my breath in. This dance of words asked questions by $i$ the researcher. Their responses fill pages of lines transposed like the rhythms of a dance, a held space between us, this space of the I and thou.] Father's autism reality and experiences as fathers.

[There is a fluidity to words, some spoken like hissed water escaping from a hot valve. Still others, who silent pauses show emotional process brought down from unconscious frames of images still forming. They speak rapidly at times, words whose meanings strike at the very core of fatherhood and identity. Others, their pauses reveal perhaps only to self; answers sought and fought for in-between their pasts and present sorrows, losses and hard for triumphs. Truth 
spoken in quiet sentences, deep pauses and always ever we walked onward.] This feeling I experienced as the fathers talked about the reality of having a child with severe autism. 


\section{Appendix G}

Self-Dialogue

\section{[ ] Represents Bracketing December 1, 2020 no time stamp}

\section{The Mind's Transcendence}

[Quiet are the moments of the mind's transcendence, deep from the fathoms of thoughts and unconscious feelings.] I realized when the fathers expressed pain, their moments of silence after speaking from their souls]. Their words formed impressions upon my mind taking me into ah moments, Scott expressed this in his third interview. [His pain ran through my consciousness, real in the moment- I too understood his sorrow and loss]

You've seen Harry Potter of course, with the dementors. Well, it sucked the life out of you sometimes. Yeah. That's what happened. An autistic kid. It's, it's that same, that's what I imagined it. That dementor is when you're sitting there laying on top of your kid because he wants to kill you or hurt himself or break company and you're trying to keep him from doing any of that stuff. And you sit in a picture like those, the mentorship, that's what it's like autism as a Dementor. 


\section{Appendix H}

Calendar of Lectio Divina

\section{November 2019}

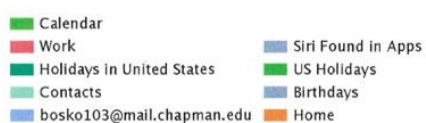

Wednesday

Thursday

October $2019 \quad$ November $2019 \quad$ December 2019

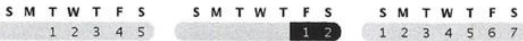
6789101112

1314151617181

20212223242526

2728293031

\begin{tabular}{l}
3456789 \\
\hline
\end{tabular} $10111213141516 \quad 15161718192021$ $17181920212223 \quad 22232425262728$

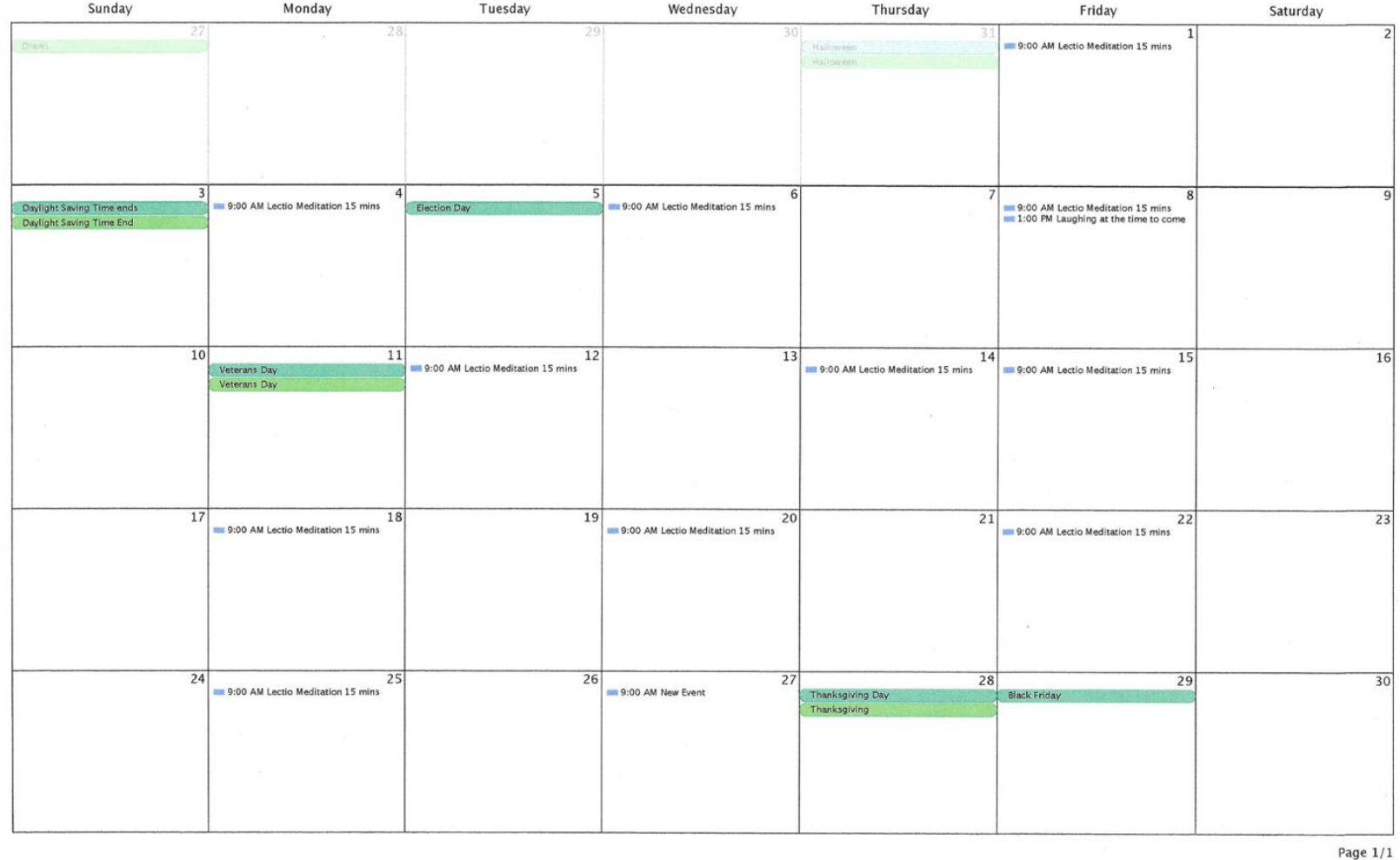




\section{Appendix I \\ Dissertation Coding Example From Excel}

Father: Mark

Interview: 1, p. 18

Significant Statement: "Not, the fact that I had, probably alienated so many people for suggesting that he was autistic."

Abbreviated Statement: Alienated for ASD Denial

Detailed Abbreviated Statement: Fathers Experience of: own Denial and Alienation

Categories: Father's Journey of Child's AS: Denial and Alienation

Father: William

Interview: 2, p. 4

Significant Statement: “every challenge is in the context. What's going to happen after I'm gone? Time when I can't wait, when I can't be there to protect them and we can't be there."

Abbreviated Statement: "for everything challenge there is a context"

Detailed Abbreviated Statement: "What will happen to his son when he is gone? The time when he won't be there to protect him?"

Categories: Father's Worries

Father: Gabriel

Interview: $1, \mathrm{p} .11$

Significant Statement: "Yeah, and he will also hit attack and bite and scratch other people, regularly when we intervene to stop the sib (symptom) then he'll go and take it out after us. "

Detailed Abbreviated Statement: "son will hit, attack, bite and scratch other people, will go father or the aides"

Categories: Child's ASD Behavior 
Appendix $\mathbf{J}$

Consent Form

\section{$\triangle \mathrm{CHAPMAN}$ \\ $\triangle$ UNIVERSITY \\ CHAPMAN UNIVERSITY}

\section{CONSENT TO ACT AS A HUMAN RESEARCH SUBJECT}

Fathers of Children on the Autism Spectrum

You are being asked to take part in a research study. Research studies include only people who choose to take part. A member of the research team will explain the study to you and will answer any questions you might have. You should take your time in deciding whether or not you want to participate.

\section{RESEARCH TEAM}

\section{Lead Researcher}

Lisa Boskovich Doctoral Candidate

Attallah College of Educational Studies

Graduate Disability Studies Program

bosko103@mail.chapman.edu

\section{Faculty Sponsor}

Dawn Hunter, Ph.D.

Professor 
Director, Ph.D. in Education Program

Attallah College of Educational Studies

dhunter@chapman.edu

STUDY LOCATION(S): Chapman University

STUDY SPONSOR(S): Chapman University

No one on the study team has a disclosable financial interest related to this research project.

\section{WHY IS THIS RESEARCH STUDY BEING DONE?}

The purpose of this research study is to explore the role and relationship fathers have with their child on the Autism Spectrum.

\section{HOW MANY PEOPLE WILL TAKE PART IN THIS STUDY?}

We expect 10 fathers will be in this research study.

\section{WHAT PROCEDURES ARE INVOLVED WITH THIS STUDY AND HOW LONG WILL THEY}

\section{TAKE?}

1. If you agree to participate, you will be asked to participate in 3 interviews in either an individual in-person or phone each interview lasting approximately 60 minutes which will be audio recorded.

2. The semistructured interview will gather an understanding of being a farther to a child along the Autism Spectrum. The interview protocol will be flexible (to allow for the questions to evolve throughout the study and will not be provided in advance.

3 . There are 3 number of visits

4. These visits will take 3 total hours

\section{AM I ELIGIBLE TO PARTICIPATE IN THIS STUDY?}

\section{Inclusion Requirements}

Fathers with a child with a Autism Spectrum diagnosis. 


\section{Exclusion Requirements}

Fathers without a child on the Autism Spectrum

\section{WHAT ARE THE POSSIBLE DISCOMFORTS OR RISKS RELATED TO THE STUDY?}

There are no known harms or discomforts associated with this study beyond those encountered in normal daily life. The possible risks/discomforts associated with the procedures described in this study may include emotional discomfort. However, you may choose to skip any question at any time, and you may withdraw from this study at any time.

\section{ARE THERE BENEFITS TO TAKING PART IN THE STUDY?}

\section{Participant Benefits}

No benefit to the subject.

\section{Benefits to Others or Society}

The participant may benefit from participating in the study by sharing their thoughts on being a father of a child along the Autism Spectrum knowing they may help other fathers. Furthermore, this study will hopefully inform researchers in the field of autism.

\section{WILL I BE PAID FOR TAKING PART IN THIS STUDY?}

Compensation You will not be compensated for your participation in this research study.

Reimbursement You will not be reimbursed for any out of pocket expenses, such as parking or transportation fees.

\section{HOW WILL MY PERSONAL INFORMATION BE KEPT?}

\section{Subject Identifiable Data}

Identifiable information collected about you will be removed at the end of data collection.

\section{Data Storage}

Research data will be stored electronically on a secure [computer in an encrypted file with password protection.

The audio recordings will also be stored in a secure location; then transcribed and erased at the end of the study. 


\section{Data Retention}

The researchers intend to keep the research data indefinitely.

\section{WHO WILL HAVE ACCESS TO MY STUDY DATA?}

The research team, authorized Chapman University personnel, and regulatory entities such as the Office of Human Research Protections (OHRP), may have access to your study records to protect your safety and welfare.

Any information derived from this research project that personally identifies you will not be voluntarily released or disclosed by these entities without your separate consent, except as specifically required by law. Study records provided to authorized, non-Chapman University entities will not contain identifiable information about you; nor will any publications and/or presentations without your separate consent.

While the research team will make every effort to keep your personal information confidential, it is possible that an unauthorized person might see it. We cannot guarantee total privacy

\section{WHO CAN ANSWER MY QUESTIONS ABOUT THE STUDY?}

If you have questions, concerns, or complaints, or think the research has hurt you, talk to the research team at bosko103@mail.chapman.edu or d hunter@chapman.edu

This research has been reviewed and approved by an Institutional Review Board (“IRB”). You may talk to them at 714-628-2833 or irb@chapman.edu if:

- Your questions, concerns, or complaints are not being answered by the research team.

- You cannot reach the research team.

- You want to talk to someone besides the research team.

- You have questions about your rights as a research participant.

- You want to get information or provide input about this research.

\section{HOW DO I AGREE TO PARTICIPATE IN THIS STUDY?}

You should not sign and date this consent form or participate in this study until all of your questions about this study have been answered by a member of the research team listed at the top of this form. You will be given a copy of this signed and dated consent form or you may save 
a copy of this information to keep for your records. Participation in this study is voluntary. You may refuse to answer any question or discontinue your involvement at any time without penalty or loss of benefits to which you might otherwise be entitled. Your decision will not affect your future relationship with Chapman University.

\section{AUDIO RECORDING:}

I have received an adequate description of the purpose and procedures for audio recording sessions during the course of the proposed research. I give my consent to allow myself to be audio recorded during participation in this study, and for those records to be reviewed by persons involved in the study, as well as for other professional purposes as described to me.

Yes, I agree to allow the research team to audio record my interview(s).

No, I do not wish to have my interview(s) audio recorded.

Your signature below and study participation indicates you have read the information in this consent form and have had a chance to ask any questions you have about this study.

\section{I agree to participate in the study.}


Printed Name of Subject

Researcher Signature

Date

Printed Name of Researcher

CHAPMAN UNIVERSITY

Experimental Subject's Bill of Rights

The rights listed below are the right of every individual asked to participate in a research study. You have the right:

1. To be told about the nature and purpose of the study.

2. To be told about the procedures to be followed in the research study, and whether any of the drugs, devices, or procedures is different from what would be used in standard practice. 
3. To receive a description of any side effects, discomforts, or risks that you can reasonably expect to occur during the study.

4. To be told of any benefits that you may reasonably expect from the participation in the study, if applicable.

5. To receive a description of any alternative procedures, drugs, or devices that might be helpful, and their risks and benefits compared to the proposed procedures, drugs or devices.

6. To be told of what sort of medical treatment, if any, will be available if any complications should arise.

7. To be given a chance to ask any questions concerning the research study both before agreeing to participate and at any time during the course of the study.

8. To refuse to participate in the research study. Participation is voluntary. You may refuse to answer any question or discontinue your involvement at any time without penalty or loss of benefits to which you might otherwise be entitled. Your decision will not affect your right to receive the care you would receive if you were not in the experiment.

9. To receive a copy of the signed and dated written consent form and a copy of this form.

10. To be given the opportunity to freely decide whether or not to consent to the research study without any force, coercion, or undue influence.

If you have any concerns or questions regarding the research study you should contact the research team listed at the top of the consent form. 
If you are unable to reach a member of the research team and have general questions, or you have concerns or complaints about the research study, research team, or questions about your rights as a research subject, please contact the Chapman University IRB staff at 714-628-2833 or irb@chapman.edu.

\section{CHAPMAN UNIVERSITY}

\section{Experimental Subject's Bill of Rights}

The rights listed below are the right of every individual asked to participate in a research study. You have the right:

11. To be told about the nature and purpose of the study.

12. To be told about the procedures to be followed in the research study, and whether any of the drugs, devices, or procedures is different from what would be used in standard practice.

13. To receive a description of any side effects, discomforts, or risks that you can reasonably expect to occur during the study.

14. To be told of any benefits that you may reasonably expect from the participation in the study, if applicable.

15. To receive a description of any alternative procedures, drugs, or devices that might be helpful, and their risks and benefits compared to the proposed procedures, drugs or devices.

16. To be told of what sort of medical treatment, if any, will be available if any complications should arise.

17. To be given a chance to ask any questions concerning the research study both before agreeing to participate and at any time during the course of the study. 
18. To refuse to participate in the research study. Participation is voluntary. You may refuse to answer any question or discontinue your involvement at any time without penalty or loss of benefits to which you might otherwise be entitled. Your decision will not affect your right to receive the care you would receive if you were not in the experiment.

19. To receive a copy of the signed and dated written consent form and a copy of this form.

20. To be given the opportunity to freely decide whether or not to consent to the research study without any force, coercion, or undue influence.

If you have any concerns or questions regarding the research study you should contact the research team listed at the top of the consent form.

If you are unable to reach a member of the research team and have general questions, or you have concerns or complaints about the research study, research team, or questions about your rights as a research subject, please contact the Chapman University IRB staff at 714-628-2833 or irb@chapman.edu 
Appendix K

IRB

IRB \#: 19-119

The IRB will add this number when your application is approved.

Title of Study: Fathers of Children on the Autism Spectrum

\section{Members of the Research Team}

Student Researcher: Lisa Boskovich, MA Office: (714) 290-2307

Lead Researcher: Dr. Dawn Hunter Ph.D. Office: (714) 997-6815

Other Researcher: Whitney McIntyre Miller, Ph.D. Office: (714) 744-2134

Other Researcher: Margie Curwen, Ph.D. Office: (714) 744-2134

\section{Invitation}

You are being asked to take part in a research study. Research studies include only people who choose to take part. A member of the research team will explain the study to you and will answer any questions you might have. You should take your time in deciding whether or not you want to participate.

\section{Why are you being asked to be in this research study?}

You are being asked to participate in this study because you are the biological father to a child who has an official Autism Spectrum diagnosis.

\section{What is the reason for doing this research study?}

The purpose of this Heuristic Inquiry research study is to examine the impact of being a parent who has a child/young adult on the Autism Spectrum.

\section{What will be done during this research study?}

1. Lisa Boskovich will be the primary researcher. If you agree to participate, you will be asked to participate in 3 interviews in either an individual in-person or phone each interview lasting approximately 60 minutes.

2. Interviews will be audio recorded. The semistructured interview will gather an understanding of being a farther to a child along the Autism Spectrum. The interview protocol will be flexible (approximately 48 opened-ended questions) to allow for the questions to evolve throughout the study and will not be provided in advance. 


\section{What are the possible risks of being in this research study?}

There are no known harms or discomforts associated with this study beyond those encountered in normal daily life. The possible risks/discomforts associated with the procedures described in this study may include emotional discomfort. However, you may choose to skip any question at any time, and you may withdraw from this study at any time.

As with any study involving collection of data, there is the possibility of breach of confidentiality of data.

There are no known risks to you for being in this research study.

\section{What are the possible benefits to you?}

You may be benefit from participating in this study by sharing your thoughts on the experiences of having a child along the Autism Spectrum.

\section{What are the possible benefits to other people?}

This study will hopefully provide greater understanding of the relationship fathers have with their child/young adult who is on the Autism Spectrum.

\section{What will participating in this research study cost you?}

There is no cost to you to be in this research study.

\section{Will you be compensated for being in this research study?}

You will not be compensated for your participation in this research study.

\section{What should you do if you have a problem during this research study?}

Your welfare is the major concern of every member of the research team. If you have a problem as a direct result of being in this study, you should immediately contact one of the people listed at the beginning of this consent form.

You are free to withdraw from this study at any time. If you decide to withdraw from this study, you should notify the research team immediately. The research team may also end your participation in this study if you do not follow instructions, miss scheduled visits, or if your safety and welfare are at risk.

If you have a problem or experience harm as a direct result of being in this study, you should immediately contact one of the people listed at the beginning of this consent form. If needed, seek immediate emergency care for this problem. It is important for you to understand that Chapman University will not pay for the cost of any care or treatment that might be necessary because you get hurt or sick while taking part in this study. That cost will be your responsibility. Agreeing to this does not mean you have given up any of your legal rights. 
If you experience any side effects, if your health worsens, or if you are injured during the research, you may need to be withdrawn from the study, even if you would like to continue. The research team will make this decision and let you know if it is not possible for you to continue. The decision may be made to protect your safety and welfare, or because the research plan does not allow people who develop certain conditions to continue to participate.

If you withdraw or are removed from the study, the researcher may ask you to complete an exit telephone interview. If you elect to withdraw or are withdrawn from this research study, the researchers will discuss with you what they intend to do with your study data. Researchers may choose to analyze the study data already collected or they may choose to exclude your data from the analysis of study data and destroy it, as per your request.

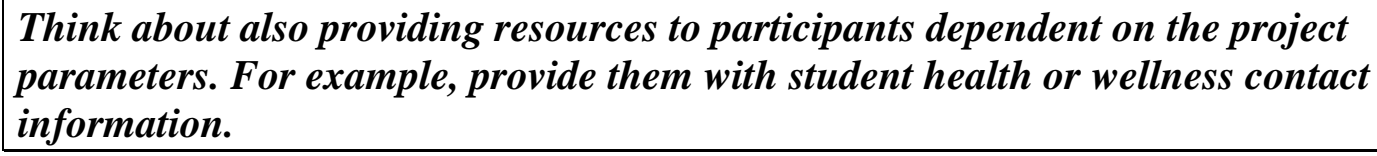

\section{How will information about you be protected?}

Reasonable steps will be taken to protect your privacy and the confidentiality of your study data. All identifiable information collected about you will be removed at the end of data collection.

All identifiable information collected about you will be removed and replaced with a code. A list linking the code and your identifiable information will be kept separate from the research data.

Identifiable information collected about you will be kept separate from the research data, so the answers are not linked to their person.

\section{Data Storage}

Research data will be maintained in a secure location and only authorized individuals will have access to it.

Research data will be stored electronically on a laptop computer in an encrypted file [and is password protected).

The audio recordings that can identify you will also be stored in a secure location; then transcribed and erased as soon as possible.

The data will be stored in a locked cabinet in the investigator's office and will only be seen by the research team during the study and for [2] years after the study is complete.

The data will be stored electronically through a secure server and will only be seen by the research team during the study and for [7] years after the study is complete.

\section{Data Retention}

Data discarded no later than 7 years after publication of this study. 
The researchers intend to keep the research data for approximately _ $7 \_$years

\section{For all protocols, include the following standard clause and edit as needed.}

The only people who will have access to your research records are the members of the research team, the Institutional Review Board (IRB), and any other person, agency, or sponsor as required by law. Information from this study may be published in scientific journals or presented at scientific meetings but the data will be reported as group or summarized data and your identity will be kept strictly confidential.

\section{What are your rights as a research subject?}

You may ask any questions about this research and have those questions answered before agreeing to participate in the study or during the study.

For study related questions, please contact the investigator(s) listed at the beginning of this form.

For questions concerning your rights or complaints about the research, contact the Institutional Review Board (IRB) at (714) 628-2833 or irb@ chapman.edu.

\section{What will happen if you decide not to be in this research study or decide to stop participating once you start?}

You can decide not to be in this research study, or you can stop being in this research study (i.e., "withdraw") at any time before, during, or after the research begins for any reason. Deciding not to be in this research study or deciding to withdraw will not affect your relationship with the investigator or with Chapman University [list others as applicable]. You will not lose any benefits to which you are entitled.

\section{Documentation of informed consent}

You are voluntarily deciding whether or not to be in this research study. Signing this form means that (1) you have read and understood this consent form, (2) you have had the consent form explained to you, (3) you have had your questions answered, and (4) you have decided to be in the research study. You will be given a copy of this consent form to keep.

Printed Name of Participant or Legal Guardian

Signature of Participant or Legal Guardian

Date

If using audio or video recording, include the boxes below. Otherwise, delete.

AUDIO RECORDING: 
I have received an adequate description of the purpose and procedures for audio recording sessions during the course of the proposed research. I give my consent to allow myself to be audio recorded during participation in this study, and for those records to be reviewed by persons involved in the study, as well as for other professional purposes as described to me.

Yes, I agree to allow the research team to audio record my interview(s).

No, I do not wish to have my interview(s) audio recorded.

Signature of Participant or Legal Guardian

Date

\section{Investigator certification:}

If applicable, include the following investigator certification clause. (Generally used for greater than minimal risk studies).

My signature certifies that all elements of informed consent described on this consent form have been explained fully to the subject. In my judgment, the participant possesses the capacity to give informed consent to participate in this research and is voluntarily and knowingly giving informed consent to participate.

Signature of Person Obtaining Consent

Date 


\section{Appendix L}

High Level Interview Synopsis Example

High Level Synopsis William First Interview July 25, 2019

\section{Feelings and Observations}

Phone Interview: He lives in a suburb outside of Chicago

William: is 69-year-old white male and is married.

Has 3 children, has two older daughters, Middle Child, Diagnosed at 3 with PDD

William is a caring and easy to talk with father. He's a an soft-spoken man with a Texas accent that shines through. He has a voice one could listen to for a long time, it's a radio voice of warmth. His warmth of self-came through over the phone and with that, his love for his son combined with the helping of others through the program he set up during his years at a national chain in the area of distribution along with his continuing work in the area of disability advocacy. He is a man who believes in serendipity.

His mind walked back through the halls of time since his son is now 32 and was diagnosed over 29 years ago. His son was a late talker and didn't speak till 10.

His focus from the time his son was diagnosed was on his son's future, from day one and with that how could he provide for his son when he was gone.

It was so easy to speak with him- from the beginning. I'd ask a question - and he would answer with a story, a narrative detailing his son's or his experience. He looked for what motivated his son.

He spoke of pride in his son in a voice full of love. He truly liked talking about his son's special interests. "he loves talking about movies specially movies he's seen ever every animated movie he loves Simpson's. He loves American Airlines, you let's talk about those things. He loves talking about those things. He loves um, anything about police departments. He's very curious he likes those kinds of things, but he also lacks when it comes to work getting done.

(I heard pride in William's Voice)

His son has never had a, "Well he's never had a violent movement. I've never seen him angry.

He is curious. Ah, he's straight forward. He will ask questions. He will ask questions, "Why do people not like black people? Why do people steal? Why do people lie? He asks those kinds of questions.

William- still has challenges with his son, "he won't take a glib answer. When the child ask, why does this happen? I remember my mom, or my dad told me, because."

Didn't Experience Denial 
His son was slow to talk and he thought it was, "I thought boys are just delayed"

NOT Denial. "We actually went through the testing. I was not so much in denial. I just thought well hey, boys are different. It's ok."

Reaction to son's AS diagnosis, "Yeah, I said is he going to get better? and doctor said he might get worse... I got quiet...

\section{Attitude Toward Son's Diagnosis}

my attitude at the time was probably self-protective of myself or whatever but I remember telling Kay, well we have. I have a good job; I have good insurance. We are a stable family if this is gonna happen to somebody, it probably couldn't happen to a better place than us to deal with this.

No Pity. No anger. Acceptance "it probably couldn't happen to a better place than us to deal with this.

Social Economics Having Money and Insurance Difference That Makes, "Because well because I have a steady job that paid well and I had insurance and we had a strong marriage. That's what the key thing was and then we would get through this"

Key Thing: "We had a strong marriage." "Shit happens"

He didn't ask why us, he said, “so, why wouldn't it be us. Why us? It was why not us?

His wife had a harder time, "well she said the bottom fell out. She got, she says it's she looked at the son and said why can the sun still be shot? He pauses... This is her heart. And she probably knows that she's got two other girls to raise, and most of this is going to fall on her and I'm gonna get to go to work every day and deal with my son's world right and she's dealing with the child that doesn't talk, doesn't react and what's she gonna do about him but what she can do that those 2 girls."

\section{Wife's Role and His Role}

I mean mom's bear the brunt of all this and so I can certainly appreciate her reaction and even though I was Pollyannaish, and I was not.

\section{Community Church Community (He Brought up Community)}

"I went back to the office the first day we were pretty much involved in the church. When We moved up to Chicago. We decided we want our friends to be in from church vs work

\section{Finds Out Who True Friends Were}

"Because, I had this is a long-time placing work in Dallas we moved up there and when I started to leave, I found out that it all my best friends we no longer my best friends there anymore well. 
And this wasn't natural, so we come up to Chicago instead of building our relationships around work we're going to build then in the community and we're going to find the church that we're comfortable in.

We are Episcopalians; we had joined when we came up. So let's see Austin was born here, Sara was 1 . So, we ended up in the church for a year let's see we've been church 4 years when Austin was diagnosed."

\section{Lisa- Follow UP Question:}

Were they welcoming? Was your Episcopalian community welcoming of your son?

"Oh Sure!"

\section{He has a sense of humor-}

"My attitude about my church. Ah, you know Austin we would take him to church. He would be different because we always sit up front too"

(Stating he sits up front says something really important- its like the analogy of the student who sits in the first row in a classroom- it's a very deliberate choice- it's a visual statement as a faith person and as a father.) in the third row, and you know he would be not like the typical child. But you know my attitude was, if anybody had anything to say about us and they need to tell me about it. (Attitude toward his son-come talk to me)

But nobody ever did, as he got older. He would leave church and walk across the street and we have a graveyard across here in Austin would walk through the graveyards and then all of a sudden he would show up for communion. (We both laugh- shared knowing of communion, church)

Here comes Autism up and walk by himself up received communion, (Pride in his son- sense of normality in his son going to receive communion- a rite and ritual in the church) he'd became like the hunchback of St Michael's Episcopal Church. (He was received), "with open arms" (pride) in the acceptance of his son)

"Yeah, he was, he was my son and I remember when we had first got that diagnosis I was good friends with our priest who is close to my age. I remember telling him one night one night, I don't know if I have the strength to deal with this.

Role of His Faith/ Role of Father/Identity and His Priest in his son getting an PDD/Autism Diagnosis in a time of doubt if he had the strength.

Yeah, he was he was my son and I remember when we had first got that diagnosis I was good friends with our priest who is close to my age.

I remember telling him one night one night, I don't know if I have the strength to deal with this. 


\section{Priest /Williams friends responded with,}

He said, 'that's what we're here for', this is where you lean on us, that's what we're here for. You lean on us.'

Lisa Follow Up Question- do you think your life I and Austin life would have been different without your faith community?

Oh. Yeah

Lisa- Comment/So you church your Episcopalian community.

Did your faith play a role?

"Oh, Hell, yea!

Lisa- Follow up, "Can you tell me about that?"

Role of Faith in His Life in: What Faith Brings to Him

Well, ah, it allows you not to put yourself in the center of the universe. (Pauses) To realize it these things, happen and it's not for a reason,

Lisa- Ok.

Faith and Trust

His voice paused for a moment. These things happen. My faith is not one which God's hand is going to manipulate in this and that and making the sun rise, (pauses) I don't understand. Well, ah, it allows you not to put yourself in the center of the universe. To realize it these things, happen and it's not for a reason,

I don't try to understand predict what God is all about. I do know I trust, (Trust) that there is a living god whom I don't understand and that uh, and that (pauses) things happen and that that's a source of strength for me when I can't bear it (His Source of Strength as a man) . I know I'm not alone, and I was fortunate to have the human relationships to go along with that, a loving wife who never doubted me, and a community of faith.

\section{William Never Felt Stigma about his Son or his Autism}

I never felt the stigma. You know he's my son and I love him completely, fully. Why would I be ashamed if anything about it. You know there was no stigma, that would mean the world weren't gonna understand him, and that's going to be a hard thing.

Silver Lining (Has a sense of humor) 
One thing I always remember telling my wife, now look if we go to Disneyland maybe if we go to we can get in the fast line now (William chuckles). There is a silver lining in here.

"In a room full of horse shit, that has got to be a pony somewhere." (Best Quote Ever!)

\section{View on Autism and How He Helped His Son}

We got a Martian but born into an earthling world. He's our Martian.

Lisa, and you are the earthlings.

We were given this Martian and we were going to raise him in this earthling world. We can't make him an earthling, (didn't want to change his son) but hopefully we can, the world isn't going to adjust to him, but we're going to help him navigate our little Martian.

\section{Lisa, and you did and you continued to do so.}

Oh, yea, but he also teaches us too.

\section{How the World Won't Understand His Son: How He Dealt and Approached Autism}

You know there was no stigma, that would mean the world weren't gonna understand him, and that's going to be a hard thing. We know what we're in for and we were in for. When he did things, people are saying we could the thought balloons you know we're not being responsive parents. We could appreciate it. They don't know. let their child run free and all that kind of stuff and you just learn to deal with it. They don't know how to do that? We could appreciate it. They don't know. We had to kinda think of them, they don't know. You see some kid like that and our first reaction your not responsible parents and we could appreciate it, it didn't stop it from hurting sometimes, if you only knew.

\section{His Son Was Always in His Mind}

I was laying in bed, it was probably let's see, I would think about Austin every 5 seconds. Probably you know the first couple of months and then you get down to every half, half minute maybe every minute well. The click click click on like you know it over time 5 minutes sometimes be 10 minutes. This is a long time before it was 10 minutes. It was years before it was ever not ever 10 minutes, and I would lay in bed at night the first thing you think about you think about a job, I do remember that.

\section{First Thought After Son's Diagnosis}

When he got that diagnosis, holy smokes. What are they gonna do after I'm gone?

Can I make enough money (pause) to protect him? So he be homeless pushing a golf cart as a crazy person

\section{Fear of: What Will Happen to My Son}


"and even diagnose that's a truism, when he got that diagnosis, holy smokes. What are they gonna do after I'm gone? Can I make enough money (pause) to protect him?

\section{Greatest Fear?}

So, he be homeless pushing a golf cart as a crazy person

\section{Lisa: follow up question: Is that your greatest fear? Follow Up}

Sure, that's every parent's but more so that's one thing we talk about. We want to live one day longer than our child. Because we're so scared after we are gone, because you realize immediately you realize your time is short, gee this is autism this is not like something that has a short lifespan. He's going to live to be 85 too and I'm not. What's going to happen after I am gone?

\section{Cure}

\section{Parents Take 1 of 2 Paths He told Me}

Talking about Curing Autism when Autism was that age (first diagnosed)

Music therapy, allergies, ABA, all things, everything coming out of the blue. They were talking about curing autism, you knew when Austin was that age, curing autism. Ad uh, parents would tend to take one of two paths. One is to look for the silver bullet, waste no steps, waste spare nothing, but to make sure their child tries to get the best care possible that's one that's one reaction.

\section{Path 1 Cure Path Parents Take 1 of 2 Routes}

Pretty much what everybody wants to do but there's a huge cost. So one of the things that we had to talk about what are we going to do? Because we have two other children to raise and it wouldn't help us to raise to drop their upbringing and spend everything on Austin and create resentment from our daughters about Austin.

Path 2 Be Diligent World Didn't Stop Around Austin: Family First So we can say we're going to be diligent but we're not going to the world doesn't stop around Austin you know we're not going to go live in Canada. He had great therapies. We're not going to travel across the US and ignore the needs of the rest of the family.

Strong Marriage Wife and I had a strong relationship. We were committed to each other and we're gonna get through this together even though she was going to bare most of the load.

\section{Disability Advocate}

I mean if a big company like ours can't do something about it which company can? and if I can't do something about it, who will? 
I asked him if he could use a descriptor would it be Courage? (in being a living wage advocate for individuals with Disabilities.

William, Amen! Strong amen

\section{Construct of Trust}

Lisa-about yourself about your relationship with Autism, Austin, your wife, your daughters, it would be courage?

William- I think it would be trust... To have the courage to trust.

Lisa, Trust, and does that go back to your faith?

William, ah. Well I think you know it's, it's maybe it's an outlook. Maybe I was blessed with that early on. I mean from my parents, is that things are a lot can be a lot worse than they are. Nothing is as bad as its going to be, nothing is an imagined as its going to be, defiantly

I found out the things we worried about didn't happen, we never thought about. And when I say trust, it isn't, well it isn't to just say. I have trust, that's the courageous part of it. Is to have the courage to trust.

Impact of Community Lisa, So, with autism you had your faith, your courage, your wife, and your community.

William, Yeah. We'd say if you throw your troubles into the pile and everybody else throw their troubles. I don't know If I'd be willing to do that, it could be worse.

Impact of Community After the interview ended, I spoke of the sacredness of interviewing and how it was a sheer pleasure and place of humbleness to sit with him.

I thanked him for being willing to talk with me. He replied, "well I enjoyed it. You made it easy

William, "Well thank you. I've enjoyed telling you the story I haven't thought about in a while.

Lisa- to me interviewing is a sacred place even though you and I aren't sitting in front of one another. I have felt like that I did we've shared a couple coffee together.

We’ve broken bread.

William- Exactly 


\section{Appendix M}

\section{Dissertation Interview Questions}

The first set of interview questions contained demographic questions that were sent via email to each participant prior to conducting the first interview. The first set of interview questions I used are below.

Thank you so much for being willing to participate in my research. To facilitate our first interview, I would greatly appreciate it if you would answer the brief demographic questions I've attached and email me your responses prior to our first interview.

Sincerely, Lisa Boskovich

NOTE: AS is Autism Spectrum

\section{Demographic Info: Sent Via Email}

1. What is your age?

2. How do you identify your race/ethnicity?

3. What is the sex of your child?

4. What is the age of your child who is on the autism spectrum?

5. How many children are in your family?

6. How old were the other children in the family when your child was diagnosed with AS?

Thank you for answering my demographic questions. I look forward to meeting you and doing the first interview.

Sincerely, Lisa Boskovich

\section{First Set of Interview Questions}

\section{NOTE: AS is Autism Spectrum}

The life history is used to establish the content of the participants experience (Seidman, 1998, 2013). This first interview will focus on your life history between you and your child who is on the AS. Thank you again, for being a part of my study and taking time to talk with me.

1. Tell me about your child. 
2. When did you first notice or become concerned in the development of your child?

3. What was your child's age when you became concerned?

4. How old was your child when they were diagnosed along the Autism Spectrum?

5. Tell me about your initial reaction to your child's diagnosis?

6. What was your family's reaction to your child's diagnosis? (e. g., spouse, siblings, grandparents, aunts, uncles, and cousins).

7. Who was the first person you told outside of your family that your child was on the AS?

8. When did you tell them?

9. What was your reaction to your child's autism diagnosis?

10. Has a diagnosis of AS for your child affected your life? If so, how?

11. After learning of your child's diagnosis, what happened next?

12. Have your feelings toward you child's diagnosis changed since that day? If so, how?

Is there anything else you would like to add or share today?

Thank you for answering this first set of questions and meeting with me. I look forward to our second interview.

Sincerely, Lisa Boskovich

\section{Second Set of Interview Questions}

The second set of interview questions is on the focused and detailed experience of the fathers (Seidman, 1998, 2013). The second set of interview questions is designed to have the fathers talk more on the details of their experience as a father of a child on the AS. In this second interview, the questions will focus on your experiences as a father, Thank you again, for being a part of my study and taking time to talk with me.

\section{Demographic Questions}

1. What is your education level?

2. What is your current zip code?

3. What is your employment status? 
4. What is your current marital status?

\section{Second Set of Interview Questions}

1. Who is the primary caregiver in your family?

2. What are the challenges you face as a parent of a child on the AS?

3. What are your strengths as a parent of a child on the AS?

4. Tell me about your interactions with your child on a daily basis. What types of things do you do together and how much time do those account for?

5. How does your child's behavior impact how you parent as a father?

6. Does your child have a special interest? If so, what is it?

7. How do you and your child connect? Can you provide me with a few examples?

8. What are the joys/happiest moments with your child?

9. Has having a child on the AS changed you as a person? if so, how? (this also allows the option for the revelation of negative changes as well - not just positive changes)

10. Tell me about the strengths you have discovered within yourself.

11. Tell me about the challenges also discovered.

Is there anything else you would like to share or add today?

Thank you for answering this second set of questions and meeting with me. I look forward to our third and final interview.

\section{Third Set of Questions}

The third and final set of interview questions has the fathers reflect on the meanings of their experience of having a child with an official AS diagnosis (Seidman, 1998, 2013). This set of questions asks the fathers to consider the contextual factors in their experience (Seidman, 1998, 2013).

\section{Third Interview}

This is our third and final interview and will be about the meaning of your experiences with your child. Thank you for spending time with me during the past two interviews and participating in my study.

1. Has your day to day life changed as a father? If so, how? 
2. As your child has grown have you encountered a new set of coping mechanisms? If so, what are they?

3. Do you draw strength and resilience from your experience as a father of a child on the AS? If so and in what ways?

\section{Father's Views on Disability}

4. Do you view your child's Autism as a disability? If so, how?

\section{Questions Regarding Stress}

5. Does having a child on the AS impact your stress level? If so, how?

6. Do you struggle balancing your responsibilities in your working life with the responsibilities of caring giving with your child? If so, how?

7. Does stress impact the relationship you have with your child? If so, how?

8. Does having a child on the AS add to the stress in your relationship with your wife, family or friends? If so, how?

\section{Parenting}

9. What lesson do you need to teach/ model or have you taught your child on the AS that you haven't had to teach your NT child?

\section{Autism's Impact on Siblings (for the fathers who have more than 1 child)}

10. Has your child's Autism impacted the other children in the family? If so, how?

\section{What Influences a Father's Acceptance of the child on the AS}

11. Have you accepted your child's AS Diagnosis?

12. What factors have influenced your acceptance?

13. Have you been on a journey in accepting your child's Autism? If so, tell me about the journey.

\section{Child's Diagnosis Predictions Fact or Fiction}

14. After your child received their AS diagnosis, did the diagnosis impact the view of your child? If so, how? If the view changed, how did it change? 
15. Have any of the predictions you were given regarding your child's protentional changed since their initial diagnosis? If so, what was the original prognosis? Did it change? If so, how?

16. How has your child or has your child changed? If so how?

\section{Father's Involvement in their Child's Education \& Schooling}

17. Are you involved or have you been involved in the education and schooling of your child? If so, how?

18. Have you been left out or felt left of your child's schooling experiences? If so how?

19. Have you experienced challenges as a result of being involved in your child's schooling experience/experiences? If so, what have been your experiences?

20. Have you had to fight to receive services for your child? If so, what were the services and how did you obtain services? And how did you obtain services?

\section{Father's Identity Question}

21. Has your identity as a father changed or shifted through the years? If so, how?

\section{Role of Father in Child's Life}

22. What is the role of fatherhood/ being a father in your child's life?

23. Has your child's AS impacted your role as father? If so, how?

24. Has your child's AS impacted your ability to be a parent? If so how?

\section{Concluding Statement}

I appreciated the commitment of your time, energy, and effort. I have truly valued your participation and the time we have spent together as you talked about your child and yourself. Thank you for sitting with me and opening up about your child over the course of three interviews and over three hours. Thank you. Soon, after this interview is transcribed, I will be sending you all the interviews typed for you to read and review. My sincerest appreciation. 


$$
\begin{gathered}
\text { Appendix N } \\
\text { Interview Schedule Month of July } 2019
\end{gathered}
$$

July 2019

July 10, 2019 William First Interview (Phone)

July 16, 2019 Gabriel First Interview (Phone)

July 17, 2019 Mark First Interview (In-person)

July 24, 2019 John First Interview (In-person)

July 25, 2019 William Second Interview (Phone)

July 30, 2019 Mark Second Interview (In-person) 


\section{Appendix $\mathrm{O}$}

\section{High-Level Synopsis Example}

\section{Gabriel First Interview July 16, 2019 Phone Interview}

It's the kind of autism, the head banging hole leaving in his son's room kind of autism, the high hand flapping that disturbs strangers and passerby. Where all this father wants is a place to go, a place to be with his 17-year-old son who disturbs his peace and keeps his father up at night wondering what will happen next kind of autism. The kind of failed pharmaceutical failures and lined up drugs given by a Doctor with false promises and hoped for dreams that failed to materialize. The one that landed his son a 51/50 call to the police, the kind where his home is like a group home not a place as in his words," a place to raise my daughter." This father two children on the AS. He didn't talk from pity, more like a father who was doing the very best he could each and every day. His transparency, I didn't ask for it- he gave it, words that flowed out of his mouth, like water whose journey was ever continuing- one that would last till his last day and breath. His words were rapid, as if they had been stored for a very long time yet simultaneously been spoken before, before me, words I will now hold, spoken from a sacred river still looking for a home. His words rushed forward, I wondered if he would even stop to take a breath?

This father cares deeply about his son, wants what all fathers want the best inside of deep challenges of communication and fought for moments of connection. This is the autism not often talked about, it's whispered in the night shadows, far away dreams that haven't and didn't come to pass. It's held like a thief in an ever present battle to connect- to want to be in public without stares from those whose grief is openly displayed as yet another "teaching moment" is in progress -another moment when getting out of a car becomes an act of active restraint of his son and the onlookers who photo snapping pictures break the wall of privacy only offered to those 
whose children are typical. For this dad is stared at in mock display for all to see, all. To hear his reality in plain sight.

This father has few places to take his 17 -year-old son, places where his sons loud grunts and deaf sounding speech are not moments of disruption, for the disruption is not just seen as his sons- it is the world whose broken through glass is interrupted by a Father who only wants a day out with his son, a slice of normalcy not offered. So, he now resorts to car rides and plotted out destinations, with his sons 3 one-on-ones- not just for the safety of his son, for the safety of them all. My words are not neatly perfectly placed, they fall out connected at times between my feelings and thoughts whose expression still waits, waits only for me. His daughter for this father has 2 children on the Spectrum- she's older 14 but looks much younger he tells me, more like 8 . He has hopes and dreams for her, he wants her to have a job- bagging groceries, friends, 2 friends. Yet, I wonder in the rapid words transcending our of his mouth, are these only dreams he wonders if fruition will help come to pass.

John First Interview, July 24, 2019 First Interview John- High Level Synopsis

\section{Narrative - A Father and Faith}

\section{A Father Faith and Autism}

It was his faith that made his journey into autism and his sons' autism a road whose journey still continues. It was faith and the belief that god made his son just as he was / this father's faith was strong - played a role not only in his personal acceptance of his son but his acceptance of autism. John opened up. I wonder since John's son is now older will his experiences be than the fathers whose children have been diagnosed in the last 5 years. What could those differences be as a father? And as the father's identity? 
What community or was if he a part of? Did being in community make a difference? If

so, how?

\section{Father's Opening UP}

Some fathers are easier to talk to than others. I carry this feeling inside of me ever

watchful - for spillage into their interview. Each of the father's journeys are unique still there are commonalities: love, the deep desire to do and provide the very best for their child. Still, autism adds another layer, a deeper layer of commitment to their child, and self. 


\section{Appendix P}

\section{Code Book Example Significant Statement Examples From Excel}

Father: Mark First Interview P.18

\section{Significant Statement:}

"I feel bad, I don't, I don't want him to be on it. He, uh, when he... after the first couple of days of him coming off of this medication, it's... it's not fun. It's not fun in the house to be around him, but after a while, everything kind of normalizes."

Father: Antony First Interview P. 6

Significant Statement:

"To be honest with you. It was a combination of him being on the spectrum and getting to the point where everything, you know, in the middle and elements of school, everything was so rigid and so and so. It's always black and white, you know? “"

Scott: Second Interview P.10

Significant Statement:

"When I'm on top of him and he's bucking so hard. Yeah. He literally flipped me over his, so I'm on top of him. He's spread eagle on the ground, on his back and I'm on top and trying to pick his arms and his wage because he's, he's, he's so in rage if he will scratch and [inaudible]."

\section{David First Interview P.5}

Significant Statement:

"Whereas my faith personally I think plays a role because that means that I know that God is in control."

\section{Paul First InterviewP. 4}

\section{Significant Statement:}

"I want him to have a buddy and I want him maybe someday fall in love. And then you have kid. Cause I would love for that kid who will be normal to take care of them when I'm done." 


\section{Appendix Q}

\section{Excel Page Example Significant Statements}

\begin{tabular}{|c|c|c|c|}
\hline Father & Interview & Page & Significant Statement \\
\hline Scott & 2 & 2 & "Yes. My son, I've never hit him. Wanted to." \\
\hline Scott & 2 & 2 & $\begin{array}{l}\text { "Well, I just can't do it. I mean, I guess what stops me is right. I have } \\
\text { more control than he does. Uh, at the end of the day." }\end{array}$ \\
\hline Scott & 2 & 2 & $\begin{array}{l}\text { "I mean, you know, it doesn't happen very often anymore, but it's not } \\
\text { happening. I just can sense it coming on better than I used to and I just, I } \\
\text { just tried to go over." }\end{array}$ \\
\hline Scott & 2 & 3 & $\begin{array}{l}\text { "I don't know if I mentioned this or not before, but it's interesting as it's } \\
\text { routine in my house, he has his routine at his mom's house. He likes to } \\
\text { watch, and he can run the TV. He likes to watch YouTube videos." }\end{array}$ \\
\hline Scott & 2 & 3 & $\begin{array}{l}\text { "I guess the worst in order of, from worst to not so bad. The worst would } \\
\text { be the aggression, the, um, have to be walk on eggshells to make sure } \\
\text { that he doesn't go off and hurt you or hurt himself." }\end{array}$ \\
\hline Scott & 2 & 4 & $\begin{array}{l}\text { "So every couple of weeks he will. So, a little nuts and bashes his until } \\
\text { it's, you know, if he creates bleeds on his forehead and stuff and he, you } \\
\text { know, he'll bite his hand." }\end{array}$ \\
\hline Scott & 2 & 4 & $\begin{array}{l}\text { "What parent likes to see their kid? Well, she said in a bit slower. No, I } \\
\text { would hope none. Yeah. So that's really a struggle that that which just } \\
\text { makes you, you, you're helpless. You can't, you can't really do anything } \\
\text { about it." }\end{array}$ \\
\hline Scott & 2 & 4 & $\begin{array}{l}\text { "another thing I've just never gotten used to is I hate it. I hate it as much } \\
\text { today as they did the first, first days, changing his diaper. I just hate that. } \\
\text { "“ }\end{array}$ \\
\hline Scott & 2 & 5 & $\begin{array}{l}\text { "I'm not, I mean I'm used to it, but it is, I mean, not like AA and he } \\
\text { fights me. Uh, it's not it's not normal poop. he's a, he has, he's } \\
\text { hypertonic so we have to give them their lots and that system, it's a } \\
\text { disaster. It's like } 30 \text { wipes every time." }\end{array}$ \\
\hline Scott & 2 & 5 & $\begin{array}{l}\text { "But it's still difficult to get babysitters because we just, yeah, only a } \\
\text { certain kind of person can watch him and we all will only trust certain } \\
\text { people are, then they grow up and move on and get married and } \\
\text { whatever." }\end{array}$ \\
\hline Scott & 2 & 5 & $\begin{array}{l}\text { "That's been really hard. That can really tough. So that means that we } \\
\text { don't, he never got a break. We can't get a break." }\end{array}$ \\
\hline Scott & 2 & 5 & $\begin{array}{l}\text { "No, I'm a real conservative and I'd have a hard time taking. Yes, that } \\
\text { kind of help. Personally, that's my bad." }\end{array}$ \\
\hline Scott & 2 & 5 & $\begin{array}{l}\text { "So she does respite care. She gets somebody every, every once one } \\
\text { night, every week. I just never done that. So the question is that because } \\
\text { you're a man and you think you can handle it all or are you just don't, I } \\
\text { just don't want, I consider it welfare and I don't need welfare." }\end{array}$ \\
\hline
\end{tabular}




\section{Appendix R}

\section{Coding Process Examples Four levels}

\begin{tabular}{|c|c|c|c|c|c|c|}
\hline Father & Interview & Page & Significant Statement & $\begin{array}{l}\text { Abbreviated } \\
\text { Statement }\end{array}$ & $\begin{array}{l}\text { Third Level } \\
\text { Coding }\end{array}$ & Categories \\
\hline Mark & 1 & 19 & $\begin{array}{l}\text { "he struggles to make friends in } \\
\text { his own age groups. He really } \\
\text { doesn't have it. He really } \\
\text { doesn't have any friends at all. I } \\
\text { struggled. I struggled a lot." }\end{array}$ & $\begin{array}{l}\text { Son struggles to } \\
\text { make friends, } \\
\text { father also } \\
\text { struggled }\end{array}$ & $\begin{array}{l}\text { Father and } \\
\text { Son Similar } \\
\text { Shared } \\
\text { Struggles }\end{array}$ & $\begin{array}{l}\text { Father and } \\
\text { Son's } \\
\text { Shared } \\
\text { Struggles: } \\
\text { Making } \\
\text { Friends }\end{array}$ \\
\hline
\end{tabular}




\section{Appendix S}

\section{Full Codes 40 Complex Codes to 19 Themes and the Corresponding 8 Subquestions}

\begin{tabular}{|c|c|c|}
\hline 40 Complex Themes & 19 Themes & 8 Subquestions \\
\hline $\begin{array}{l}\text { Father's Description } \\
\text { Of Child }\end{array}$ & $\begin{array}{l}\text { Father's Parenting } \\
\text { Experiences }\end{array}$ & $\begin{array}{l}\text { Subquestion 1: What were the reactions of the fathers before and } \\
\text { after their child's AS diagnosis? Did the father's experience } \\
\text { challenges in having a child on the AS? If so, what were they? }\end{array}$ \\
\hline Labeling of a Child & $\begin{array}{l}\text { Reactions to } \\
\text { Child's Diagnosis }\end{array}$ & $\begin{array}{l}\text { Subquestion 1: What were the reactions of the fathers before and } \\
\text { after their child's AS diagnosis? Did the father's experience } \\
\text { challenges in having a child on the AS? If so, what were they? }\end{array}$ \\
\hline Labeling of a Child & $\begin{array}{l}\text { Reactions to } \\
\text { Child's Diagnosis }\end{array}$ & $\begin{array}{l}\text { Subquestion 1: What were the reactions of the fathers before and } \\
\text { after their child's AS diagnosis? Did the father's experience } \\
\text { challenges in having a child on the AS? If so, what were they? }\end{array}$ \\
\hline Father's Struggles & $\begin{array}{l}\text { Fathers' Reaction } \\
\text { to Child's } \\
\text { Diagnosis }\end{array}$ & $\begin{array}{l}\text { Subquestion 1: What were the reactions of the fathers before and } \\
\text { after their child's AS diagnosis? Did the father's experience } \\
\text { challenges in having a child on the AS? If so, what were they? }\end{array}$ \\
\hline Impact of Faith & $\begin{array}{l}\text { Father's Life } \\
\text { Paradigm }\end{array}$ & $\begin{array}{l}\text { Subquestion 1: What were the reactions of the fathers before and } \\
\text { after their child's AS diagnosis? Did the father's experience } \\
\text { challenges in having a child on the AS? If so, what were they? }\end{array}$ \\
\hline $\begin{array}{l}\text { Father's } \\
\text { Perception/View of } \\
\text { Child }\end{array}$ & $\begin{array}{l}\text { Fathers' Parenting } \\
\text { Experiences }\end{array}$ & $\begin{array}{l}\text { Subquestion 2: Did the fathers experience a "new reality" as a } \\
\text { result of their child's diagnosis? If so, what did this new reality } \\
\text { look like? }\end{array}$ \\
\hline Father's Struggles & $\begin{array}{l}\text { Father's Loss of } \\
\text { Hopes and Dreams }\end{array}$ & $\begin{array}{l}\text { Subquestion 2: Did the fathers experience a "new reality" as a } \\
\text { result of their child's diagnosis? If so, what did this new reality } \\
\text { look like? }\end{array}$ \\
\hline $\begin{array}{l}\text { Father's } \\
\text { Perception/View of } \\
\text { Child }\end{array}$ & $\begin{array}{l}\text { Father's Insight's } \\
\text { and Realizations }\end{array}$ & $\begin{array}{l}\text { Subquestion 2: Did the fathers experience a "new reality" as a } \\
\text { result of their child's diagnosis? If so, what did this new reality } \\
\text { look like? }\end{array}$ \\
\hline Family Legacy & $\begin{array}{l}\text { Father's Insight's } \\
\text { and Realizations }\end{array}$ & $\begin{array}{l}\text { Subquestion 2: Did the fathers experience a "new reality" as a } \\
\text { result of their child's diagnosis? If so, what did this new reality } \\
\text { look like? }\end{array}$ \\
\hline $\begin{array}{l}\text { Father's Life } \\
\text { Paradigm }\end{array}$ & Father's Struggles & $\begin{array}{l}\text { Subquestion 3: What roles did the fathers play as a result of having } \\
\text { a child on the AS? }\end{array}$ \\
\hline Role of Father & Role of Father & $\begin{array}{l}\text { Subquestion 3: What roles did the fathers play as a result of having } \\
\text { a child on the AS? }\end{array}$ \\
\hline Community & Fathers Identity & $\begin{array}{l}\text { Subquestion 3: What roles did the fathers play as a result of having } \\
\text { a child on the AS? }\end{array}$ \\
\hline Father's Parenting & $\begin{array}{l}\text { Fathers' Parenting } \\
\text { Experiences }\end{array}$ & $\begin{array}{l}\text { Subquestion 3: What roles did the fathers play as a result of having } \\
\text { a child on the AS? }\end{array}$ \\
\hline Father's as Mentor & Role of Father & $\begin{array}{l}\text { Subquestion 3: What roles did the fathers play as a result of having } \\
\text { a child on the AS? }\end{array}$ \\
\hline
\end{tabular}




\begin{tabular}{|c|c|c|}
\hline $\begin{array}{l}\text { Fathers and Child's } \\
\text { Interaction }\end{array}$ & $\begin{array}{l}\text { Fathers' Parenting } \\
\text { Experiences }\end{array}$ & $\begin{array}{l}\text { Subquestion 3: What roles did the fathers play as a result of having } \\
\text { a child on the AS? }\end{array}$ \\
\hline $\begin{array}{l}\text { Child and Father } \\
\text { Share Similar } \\
\text { Autism } \\
\text { Characteristics }\end{array}$ & $\begin{array}{l}\text { Child and Father } \\
\text { Share Similar } \\
\text { Autism } \\
\text { Characteristics }\end{array}$ & Subquestion 4: What are the fathers' views on disability? \\
\hline $\begin{array}{l}\text { Father's ASD } \\
\text { Knowledge }\end{array}$ & $\begin{array}{l}\text { Father's AS } \\
\text { Journey/Inner } \\
\text { Journey }\end{array}$ & Subquestion 4: What are the fathers' views on disability? \\
\hline $\begin{array}{l}\text { Father's View of } \\
\text { Disability/Belief of } \\
\text { Disability }\end{array}$ & $\begin{array}{l}\text { Father's AS } \\
\text { Journey/Inner } \\
\text { Journey }\end{array}$ & Subquestion 4: What are the fathers' views on disability? \\
\hline $\begin{array}{l}\text { Father's View of } \\
\text { Disability/Belief of } \\
\text { Disability }\end{array}$ & Autism's Lessons & Subquestion 4: What are the fathers' views on disability? \\
\hline $\begin{array}{l}\text { Father's Life } \\
\text { Paradigm: View of } \\
\text { God }\end{array}$ & $\begin{array}{l}\text { Father's AS } \\
\text { Journey/Inner } \\
\text { Journey }\end{array}$ & $\begin{array}{l}\text { Subquestion 5: Did the fathers have a belief system that impacted } \\
\text { their journey in raising a child on the AS? If so, How? }\end{array}$ \\
\hline $\begin{array}{l}\text { Father's Life } \\
\text { Paradigm: View of } \\
\text { God }\end{array}$ & $\begin{array}{l}\text { Father's AS } \\
\text { Journey/Inner } \\
\text { Journey }\end{array}$ & $\begin{array}{l}\text { Subquestion 5: Did the fathers have a belief system that impacted } \\
\text { their journey in raising a child on the AS? If so, How? }\end{array}$ \\
\hline Autism's Lessons & $\begin{array}{l}\text { Father's AS } \\
\text { Journey/Inner } \\
\text { Journey }\end{array}$ & $\begin{array}{l}\text { Subquestion 6: Do fathers who have more than one child on the AS } \\
\text { have a significantly different lived experience compared to fathers } \\
\text { Who have only a single child on the AS? }\end{array}$ \\
\hline $\begin{array}{l}\text { Father's Experience } \\
\text { of Child's AS } \\
\text { Behaviors }\end{array}$ & $\begin{array}{l}\text { Father's } \\
\text { Experience of } \\
\text { Child's AS } \\
\text { Behaviors }\end{array}$ & $\begin{array}{l}\text { Subquestion 6: Do fathers who have more than one child on the AS } \\
\text { have a significantly different lived experience compared to fathers } \\
\text { Who have only a single child on the AS? }\end{array}$ \\
\hline $\begin{array}{l}\text { Father's ASD } \\
\text { Reality }\end{array}$ & Autism's Lessons & $\begin{array}{l}\text { Subquestion 6: Do fathers who have more than one child on the AS } \\
\text { have a significantly different lived experience compared to fathers } \\
\text { who have only a single child on the AS? }\end{array}$ \\
\hline $\begin{array}{l}\text { Father's ASD } \\
\text { Reality }\end{array}$ & Autism's Lessons & $\begin{array}{l}\text { Subquestion 6: Do fathers who have more than one child on the AS } \\
\text { have a significantly different lived experience compared to fathers } \\
\text { who have only a single child on the AS? }\end{array}$ \\
\hline $\begin{array}{l}\text { Father's ASD } \\
\text { Journey/ Father's } \\
\text { Inner Journey }\end{array}$ & $\begin{array}{l}\text { Father's Insight's } \\
\text { and Realizations }\end{array}$ & $\begin{array}{l}\text { Subquestion 7: Did the fathers experience personal growth as a } \\
\text { result of having a child on the AS? If so, What growth did they } \\
\text { experience? }\end{array}$ \\
\hline Father's Identity & Father's Identity & $\begin{array}{l}\text { Subquestion 7: Did the fathers experience personal growth as a } \\
\text { result of having a child on the AS? If so, What growth did they } \\
\text { experience? }\end{array}$ \\
\hline $\begin{array}{l}\text { Father's Reaction to } \\
\text { Child's ASD } \\
\text { Diagnosis }\end{array}$ & $\begin{array}{l}\text { Father's Fears, } \\
\text { Doubts, and } \\
\text { Concerns }\end{array}$ & $\begin{array}{l}\text { Subquestion 7: Did the fathers experience personal growth as a } \\
\text { result of having a child on the AS? If so, What growth did they } \\
\text { experience? }\end{array}$ \\
\hline
\end{tabular}




\begin{tabular}{|c|c|c|}
\hline Father's Struggles & $\begin{array}{l}\text { Father's Loss of } \\
\text { Hopes and Dreams }\end{array}$ & $\begin{array}{l}\text { Subquestion 7: Did the fathers experience personal growth as a } \\
\text { result of having a child on the AS? If so, what growth did they } \\
\text { experience? }\end{array}$ \\
\hline $\begin{array}{l}\text { Father's Hopes and } \\
\text { Dreams Father's } \\
\text { Insight }\end{array}$ & $\begin{array}{l}\text { Father's Insight's } \\
\text { and Realizations }\end{array}$ & $\begin{array}{l}\text { Subquestion 7: Did the fathers experience personal growth as a } \\
\text { result of having a child on the AS? If so, what growth did they } \\
\text { experience? }\end{array}$ \\
\hline $\begin{array}{l}\text { Father's Life } \\
\text { Paradigm }\end{array}$ & $\begin{array}{l}\text { Father's AS } \\
\text { Journey/Inner } \\
\text { Journey }\end{array}$ & $\begin{array}{l}\text { Subquestion 7: Did the fathers experience personal growth as a } \\
\text { result of having a child on the AS? If so, what growth did they } \\
\text { experience? }\end{array}$ \\
\hline $\begin{array}{l}\text { Father's Feelings } \\
\text { Regarding Research } \\
\text { Study }\end{array}$ & $\begin{array}{l}\text { Father's Feelings } \\
\text { Regarding } \\
\text { Research Study }\end{array}$ & $\begin{array}{l}\text { Subquestion 7: Did the fathers experience personal growth as a } \\
\text { result of having a child on the AS? If so, what growth did they } \\
\text { experience? }\end{array}$ \\
\hline $\begin{array}{l}\text { Child's } \\
\text { Autism/Impact on } \\
\text { Family }\end{array}$ & $\begin{array}{l}\text { Father's AS } \\
\text { Journey/Inner } \\
\text { Journey }\end{array}$ & $\begin{array}{l}\text { Subquestion 8: Does the severity of autism create a different lived } \\
\text { experience among fathers? }\end{array}$ \\
\hline $\begin{array}{l}\text { Child's Behavior } \\
\text { Descriptions }\end{array}$ & $\begin{array}{l}\text { Father's } \\
\text { Experience of } \\
\text { Child's AS } \\
\text { Behaviors }\end{array}$ & $\begin{array}{l}\text { Subquestion } 8 \text { : Does the severity of autism create a different lived } \\
\text { experience among fathers? }\end{array}$ \\
\hline $\begin{array}{l}\text { Child's Severe AS } \\
\text { Behavior }\end{array}$ & $\begin{array}{l}\text { Father's } \\
\text { Experience of } \\
\text { Child's AS } \\
\text { Behaviors }\end{array}$ & $\begin{array}{l}\text { Subquestion 8: Does the severity of autism create a different lived } \\
\text { experience among fathers? }\end{array}$ \\
\hline $\begin{array}{l}\text { Family's Reaction } \\
\text { to Child's ASD } \\
\text { Diagnosis }\end{array}$ & $\begin{array}{l}\text { Fathers' Parenting } \\
\text { Experiences }\end{array}$ & $\begin{array}{l}\text { Subquestion } 8 \text { : Does the severity of autism create a different lived } \\
\text { experience among fathers? }\end{array}$ \\
\hline
\end{tabular}

